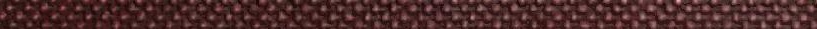

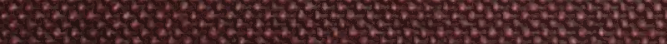

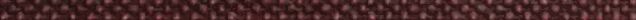

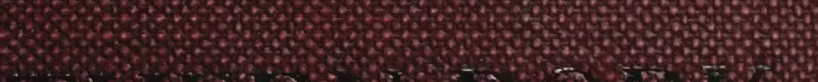

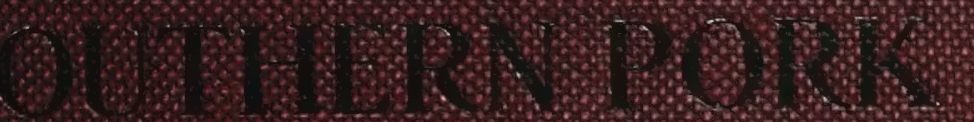
$\therefore 3$ 20.

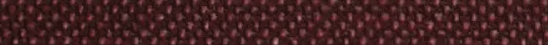
$\therefore \because 3 \therefore 20$

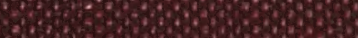

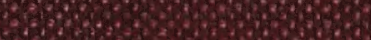




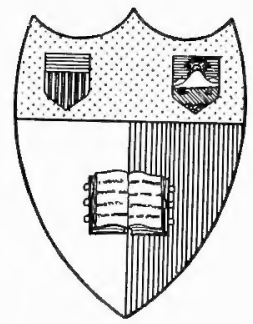

ANeur Hark

\section{State Uallege of Agrirulture}

At Garmell Antuersity

IIthara, A. 1.

\section{Withraxy}


SF 395.E8 ${ }^{\text {Cornell University Library }}$

Southern pork production,

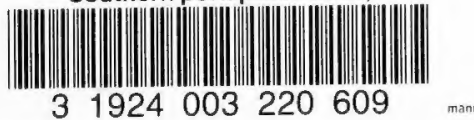




\section{SOUTHERN PORK PRODUCTION}




\section{Cornell University Library}

The original of this book is in the Cornell University Library.

There are no known copyright restrictions in the United States on the use of the text. 


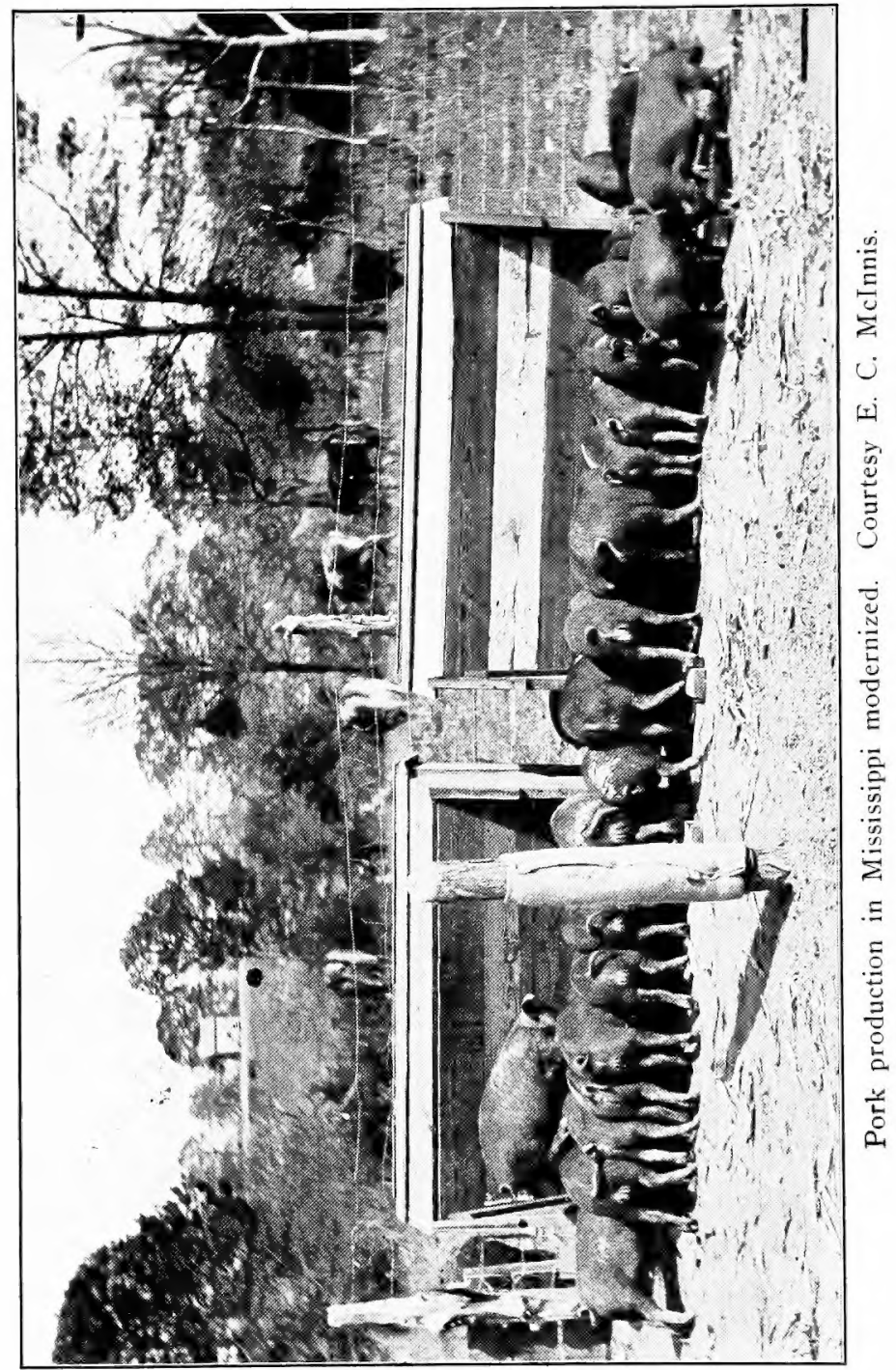




\section{SOUTHERN PORK PRODUCTION}

BY

P. V. EWING, M. S.

Animal Husbandman in Charge of Swine Investigations, Texas Agricultural Experiment Station. Formerly with Ohio State

University, Kansas State Agricultural College, and Georgia Agricultural Experiment Station.

\section{ILLUSTRATED}

NEW YORK

\section{ORANGE JUDD COMPANY}

1918 


\section{COPYRIGHT, I9I8, BY ORANGE JUDD COMPANY All Rights Reserved}

[Printed in U. S. A.] 


\section{PREFACE}

A leading thought in the preparation of this volume has been that swine husbandry offers the easiest and safest kind of live stock endeavor to which the South, as a whole, is generally adapted. Special emphasis and stress has been placed on the practical side of pork production, but as much of the scientific and theoretical as may have an important bearing on the practice has been included. Successful southern hog growers have been freely consulted, and the farm press of the South has assisted materially in the preparation of the manuscript.

The author here wishes to express his appreciation of the generous assistance which has been accorded him by many, and especially for the aid given him by his father, R. B. Ewing, by Prof. C. L. Willoughby of the College of Agriculture of the University of Florida, and by the many agricultural workers and swine breeders who assisted in supplying the photographs.

P. V. EWING. 



\section{CONTENTS}

CHAPTER I

PAGE

Economic Aspects of the Swine Industry........ 1 CHAPTER II

Principles of Swine Breeding............. 17

CHAPTER III

Breeds of Swine...................... 48

CHAPTER IV

Judging Swine $\ldots \ldots \ldots \ldots \ldots \ldots \ldots \ldots \ldots \ldots . . .60$

CHAPTER V

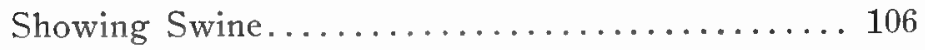

CHAPTER VI

Feeding Swine....................... 121

CHAPTER VII

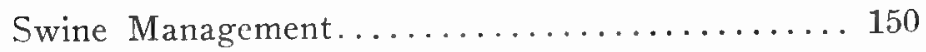

CHAPTER VIII

Swine Diseases and Their Control............. 174

CHAPTER IX

Marketing ............................. 209

\section{CHAPTER $\mathrm{X}$}

Pork 



\section{List of Illustrations}

Pork production in Mississippi modernized--Frontispiece

Some farmers combine beef and pork production . . . 2

Typical unprofitable Coastal Plain pine-woods rooters . . 8

Moultrie Packing Plant, Moultrie, Ga. . . . . . 11

Distribution of boys' pigs club pigs . . . . . . 13

Distribution of swine in southern states. . . . . 1 r

Proper feeding must accompany breeding . . . 21

Swine breeding is dependent on the reproductive process . $\quad 24$

This type is on the increase in many sections of the South . 29

Utility should be made the basis of all breeding operations . 37

Litter mates; fed by a pig club boy and his father . . . 40

Blood lines of the Poland-China . . . . . . 54

Poland-China gilt, Jennie Girl (581414) . . . . . 55

Blood lines of the Chester White and O. I. C. . . $\quad 56$

Blood lines of the Small Yorkshire . . . . . . 58

Blood lines of the Duroc-Jersey . . . . . . 60

Duroc-Jersey boar, Defender's Ohio Chief (45899) . . 61

Blood lines of the Essex . . . . . . . . 63

Blood lines of the Cheshire . . . . . . . 64

Berkshire gilt, Premier's Queen 25 (179325) . . . . 65

Blood lines of the Berkshire . . . . . . . 66

Hampshire gilt . . . . . . . . . 67

Louisiana bred Tamworth sow . . . . . . 71

Big Guinea swine on Willow Dale Farm, Mayfield, Ga. . 74

Points of the hog. . . . . . . . . . 79

The butcher helps establish the ideal pork type . . . 85

From the rear the fat hog presents a compact appearance . $\quad 86$

Wholesale cuts marked on Champion Barrow 1913 Inter-

national . . . . . . . . 87

The body of the fat hog is judged largely from the side view 90

Large type breeding swine are popular in the show ring . 96

Mississippi State Fair Grand Champion Sows of 1915 . 10 \%

Proper shelter is essential in show fitting . . . 113

Personal attention is essential in show fitting . . 118 
Most grazing crops should be supplemented . . . . 123

Feed wastes can be prevented by properly constructed troughs 133

Feeding city garbage near New Orleans, La. . . . . 144

Self-feeders are becoming more popular in the South. . 148

Monitor type winter farrowing house . . . . . 150

Half monitor type winter farrowing house . . . . 152

The common A-shaped portable hog house . . . . 155

Cheap type small farrowing house and pen . . . . 156

A-type individual farrowing houses . . . . . 157

Grazing lots make fall litters profitable. . . . . 162

Winter farrowing houses in North Carolina . . $\quad 169$

Lots to which sows and pigs are taken from farrowing houses 171

Sunlight and dips are used to prevent disease . . . 174

Administering serum to prevent hog cholera . . . . 185

Cement wallowing hole used to control lice . . . . 200

Typical drove of fat hogs coming to the Atlanta market . $21 \%$

Co-operative hog shipping day at Yazoo City, Mississippi . 22,

Too large for suitable pork production in the South . $\quad 230$

Home packing products resulting from high specialization . 233

Making pure-bred Tamworth pork on Westview Stock Farm 236

In the cooler at Moultrie Packing Plant, Moultrie, Ga. . 241

Hung up to cool overnight on farm of O. F. Troutman . . 247

Showing the usual method of cutting a side of pork . . 248

Smoke room of modern southern packing plant - . 256 


\section{CHAPTER I \\ ECONOMIC ASPECTS OF THE SWINE INDUSTRY}

Live stock farming necessary.-It is imperative that southern farmers grow more live stock if we are to have a permanent system of agriculture. We can raise more cotton by adopting a system of farming that will guarantee an increase in soil fertility instead of a continual decrease, as at present. The tenant cotton farmer has no attachment for his land. Even the cotton farmer who owns his land is in reality a tenant, for he hopes that his children may not need to live on his farm, but that they will have something better. On the contrary, the man on the live stock farm looks far into the future, and he is more firmly attached to his land and has its future at heart, and he is a true landowner and improver.

Importance of soil conservation.-Over 40 per cent of all products used in the factories of our country have their origin in the soil. This makes agriculture the most fundamental of all our national resources. We should, therefore, take steps to conserve and add to our resources of soil fertility rather than to continue depleting them, as in the past. This is much more applicable to the South than elsewhere, for here, not merely 40 , but over 90 per cent, of the raw products used in our factories come from the soil. Without a fertile soil the South cannot long retain the position she now holds as the world's greatest producer of cotton. We must also have foods, 
are fortunate in having a few good swine breeders scattered widely over the South. It is largely due to their efforts and courage that the southern swine industry has developed so rapidly in the past 10 years. They have demonstrated what can be done. They have not only produced pork at a profit, but they have enriched their soils, greatly increased their acre yields, and now have a competence. It is high time that others follow their example. The higher prices of meats in general, the continued depletion of our soils under the one-crop system, the tenancy evil, and the boll weevil menace, are all sufficient reasons in themselves to cause every farmer to enter the field of live stock production. The four combined reasons make either pork production or the beginning of some other form of live stock work an economic necessity, to which we must acquiesce sooner or later.

\section{Adaptability of the South for swine production.-The} South is pre-eminently adapted to pork production for several reasons. In the first place, we can supply feeds for swine cheaper than any other section. We have grass a greater number of days in the year than elsewhere. This is a blessing in disguise, for grass is the basis of any system of live stock farming. The South can have cheap grass in the greatest abundance. The mild climate permits a long growing season for cultivated feed crops. Also, the expense of housing and sheds for protection from the elements is not so great as in the more severe climates. Cheap lands are abundant, and most of these are admirably adapted to pork production. The amount of tillable land is ample to produce the forage and other crops. We can grow the greatest variety of forage crops, especially the legumes, which not only supply an abun- 
dance of nutritious feeds, but which assist in enriching our depleted soils.

Natural conditions favorable for pork production.-On account of climatic and economic advantages, and in every other way, the South is destined to become a great pork-producing section. Corn is increasing in use as a human food without the agency of the hog, and the crops which will be used for pork production in the South are not such as can be used for human food so easily as corn. In the South, grazing crops can be used all the year to a greater or lesser extent. Not only do legumes and the small grains do well, but fattening crops, such as corn, chufas, peanuts, cowpeas, beans, sweet potatoes and cassava, all make good growth. In an economic way the production of live stock in the cotton regions has become a necessity, and in adapting ourselves to some type of animal husbandry, we shall naturally take to that type which has proven most profitable. The seasons are adapted to swine production because the winters are mild and the summers not excessively hot, as they are tempered by cool breezes and an abundant rainfall. Diseases are no more prevalent than in other sections, and the indications are that diseases are rarer in the South than in the North (probably due to more sunshine), and that the losses are due more to poor management than to disease.

Pork production a pasturing proposition.-One of the principal advantages of the South as a swine-growing section is the ease with which so many valuable swinegrazing crops can be grown. Grasses do well and cultivated crops can be produced practically every month in the year. Summer grasses, such as Bermuda, nut grass, crab grass and wire grass, do well; while the clovers, 
such as crimson, burr, red, white and Japan, and the vetches, both the wild and the tame, provide legumes for grazing the cntire year. In addition, crops such as rape, oats, rye, sweet potatoes, alfalfa, cowpeas, velvet beans, chufas, cassava, artichokes, corn, peanuts, sorghum and other valuable crops, make it possible to arrange for hog pastures at all times. With no cheap carbohydrate concentrate, it is out of the question for the South to compete with the Corn Belt in fattening hogs in feed lots. The Corn Belt is rapidly coming to realize the advantages of grazing crops, but the South can grow a greater variety and have more grazing in winter than is possible in the North and West. It has for a long time been recognized that hogs cannot be successfully produced on an extensive scale without pastures, and any large swine industry in the South must of necessity be to a considerable extent a pasture proposition, as this has proven to be the most practical and profitable.

Market values of beef and pork.-In making a study of market prices of hogs and cattle in the South with corresponding market prices in the North and West, we must of necessity be impressed with the fact that at all seasons of the year the prices paid for hogs compare well, with occasional better prices in the South. In the case of cattle, the prevailing prices are seldom equal to the northern and western prices, and in most cases they are only about three-fourths of the prices prevailing in the North and West. It is true, of course, that southern hogs compare better in class with the hogs produced in the North and West than the classes of cattle compare. Nevertheless, there is a difference which is sufficient to have a considerable effect on pork production. 
Credits and swine production.-One important reason why more southern farmers have not entered into an extensive system of pork production has been the lack of adequate capital, for some capital is required, and bankers and merchants have not been willing to credit farmers on many crops except cotton. With some farmers it is therefore compulsory that they raise cotton exclusively. Conditions in this respect are rapidly improving, however, and banks and bankers are encouraging in every way possible a greater production of live stock, especially swine. The merchants will be influenced by the action of the bankers, and this great drawback will gradually be overcome, and the farmers will reduce their cotton acreage and devote more attention to a permanent system of live stock farming that will guarantee a more permanent agriculture for the cotton belt. The time is near at hand when live stock will be considered as much or more of an asset than so much cotton.

Labor a limiting factor.-One of the important limiting factors upon a greater swine industry in the South is that of labor. It is not so much a question of quantity of labor as of quality. The average cotton negro has no interest in live stock and has little natural ability in the care, feeding and management of animals. This is due to congenital conditions and environment. A few negroes that have been brought up with live stock about them in early life may by proper training become excellent caretakers and manifest some interest and love for the work. While the labor question requires careful consideration, yet it is a difficulty that will decrease readily with effort toward education. The average cotton negro has not been trained to properly take care of swine. 
Classes of hogs grown in the South.-There is no reason why the pork produced in the South cannot be equal in every respect to that produced in the North and West. To be sure, the hogs that are marketed in the South at present vary some from those marketed from the Corn Belt. The hogs that are produced in the South do not as a rule have the breeding, uniformity of size and

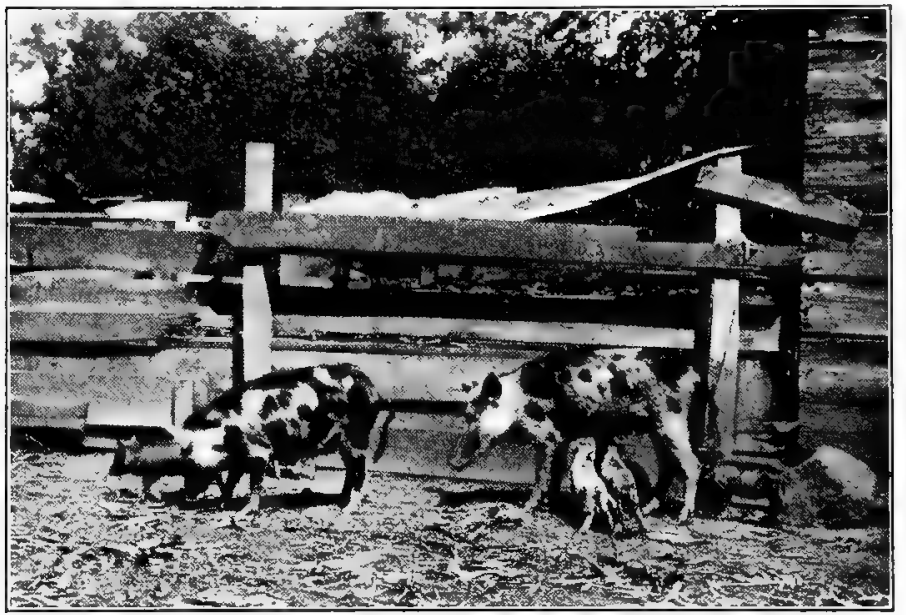

Typical unprofitable Coastal Plain pine-woods rooters. Courtesy S. M. Byars of South Carolina.

condition of the northern and western hogs. Also, a great many swine from the Coastal Plain region of the southern states are fattened on peanuts or ground peas, with the result that the pork has an oily constituency, and is termed soft pork, which is greatly discriminated against by most packers. When swine are fattened on peanuts, it is usually the custom to top them off with corn or other feeds to harden the fat. 
When we consider breeding, the South is far behind other sections of America, and the proverbial "razorback" is altogether too frequent. Improvement is rapidly taking place and this drawback will soon be removed. The number of hogs that are produced on each farm is, as a rule, more or less limited, which means than uniformity will be somewhat difficult to attain. The improvement made in recent years in arriving at the most profitable class of hogs from both the standpoint of the producer and packer has been rapid, and it will not be many years until the South in general will be marketing swine that on the whole will compare quite favorably with swine from the Corn Belt and West.

Increase in soil fertility due to swine grazing.-Not only is it possible for the farmer to make a profit from grazing off a crop and turning it into pork, but by so doing he thereby greatly increases the future capacity of the land for growing staple crops. This has been clearly pointed out by $\mathrm{Gray}^{2}$, in reports on some work done by Bennett ${ }^{2}$ at the Arkansas Station, with results as shown in the following table:

INCREASE IN COTTON YIELD DUE TO GROWING AND GRAZING OFF OF CROPS Av. $\%$ Val. of inc. in inc. per seed acre each cotton year

Lbs. seed Lbs. seed Av, yield growing 11c. cotton cotton seed cotton and graz- Seed

Cotton following peanuts $\begin{array}{llll}1899 & 1900 & 1899-1900 & \text { ing crop } 60 \mathrm{c} .\end{array}$

grazed by hogs--.-.--

Cotton following soy

beans grazed by hogs_-

Cotton following chufas grazed by hogs

Cotton following corn

not grazed by hogs ---

$\begin{array}{lllll}1,771 & 1,134 & 1,452.5 & 61.1 & \$ 22.81\end{array}$

$\begin{array}{lllll}1,588 & 1,020 & 1,304.0 & 44.6 & 16.35\end{array}$

$\begin{array}{lllll}1,200 & 981 & 1,090.0 & 20.9 & 7.68\end{array}$

$1,005 \quad 798 \quad 911.5$

3 Arkansas Agricultural Experiment Station Bulletin 68. 
From this is scen the great increase in yield in future crops by growing and srazing certain crops. Thus, when we compute the value of an acre in grazing crops for swine, we must not only figure on the amount of pork it will produce, but also on the increase in the futurc producing capacity of the land in cotton, corn and other crops. From the above figures we can see, in the case of growing and grazing a crop of peanuts followed by cotton, that more cotton was produced 11 the two following years than would have been produced had cotton been in the land all three years. In addition, this cotton was produced at two-thirds the cost required with land in cotton three years straight. Thus in three years' time, by growing a crop of peanuts and pasturing them off, the farmer not only can make money on each crop of cotton and on the pork produced on the peanuts, but in the two years following, the increase in yield is more than enough to make an extra crop of cotton without additional cost. This increase in yield holds over for several years. Thus we can see that the growing of crops and grazing them off not only offers a direct means of profit, but provides for a much greater indirect proint through increased soil fertility. It virtually means that every man can have a fertilizer factory on his farm that will not only supply him with nearly all of the fertilizers he needs free of cost, but will itself be a source of revenue.

Hogs on diversified farms.- At some time in the furure most of the farms of the South will be diversified farrns, farms from which some grain, some cotton, truck crops, fruit, dairy products, and some meat animals will be sold. A diversificd farm is not complete without some hogs. They can make pork out of what would be otherwise wasted. They can save the grain left in the field after 
harvest; they will eat the left-over cottonseed and waste of culls from all sorts of trucking operations, fallen fruits containing the larvæ of injurious insects will be utilized, the skim milk and buttermilk can be made into pork, and the droppings of other live stock will be gleaned for undigested food materials. As converiers of otherwise waste products into something with a market value hogs are supreme.

Southern tendency of pork production.-The southward tendency of pork production is not better illustrated than by reference to the report of the Thirteenth Census. In this we find that during the decade of 1900 to 1910 the West Central states, comprising the grcater portion of the Corn Belt, lost 12.9 per cent in number of hogs, while the south Atlantic divisions gained 7.2 per cent in the

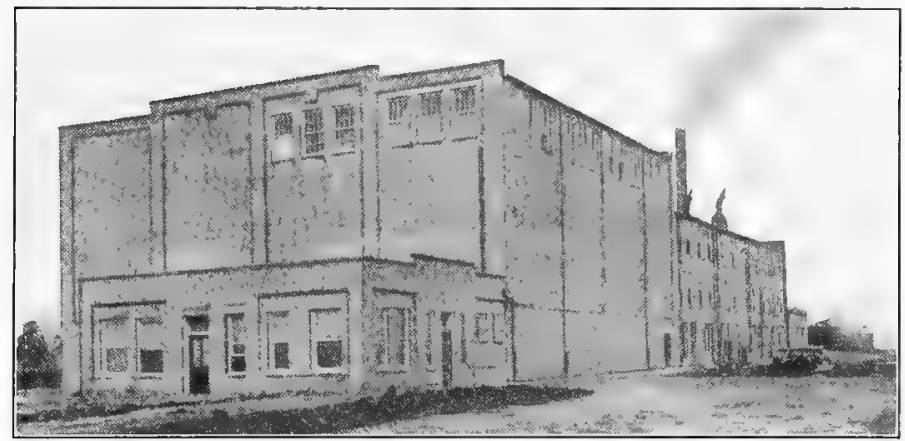

Moultrie Packing Plant, Moultrie, Ga.

same period. The southern tendency of pork production is shown in several ways. A study of the several censuses shows that there has been a continual rise in value per head of swine for the several southern states, which rise has been greater than in the other sections. Also, 
the development of a pork industry is attested by the establishment in recent years of several packing houses throughout the South.

Boys' pig clubs.-Of all the organized efforts at improvement in the swine industry in the southern states none is accomplishing more than the boys' pig club work. This work is fostered by federal, state and local officials and organizations, with the most active part, however, being taken by the Bureau of Animal Industry in cooperation with the Farmers' Co-operative Demonstration Vork of the Bureau of Plant Industry. In each state is placed a state pig club agent, a specialist in swine husbandry, who looks after and supervises the work in his state. In this work the county is made the unit, but frequently smaller units in the county are made. County demonstration agents usually have the immediate responsibility of organizing the work in the county. This pig club work has been in existence a comparatively short time, but already it has accomplished wonders in the way of introduction of improved blood, the teaching of improved methods of production, and of showing what can be done with swine in a small way.

The objects of the pig club work are briefly set forth in Farmers' Bulletin 566, United States Department of Agriculture, as follows:

1. To stimulate an interest in swine production and to teach the boys how to raise better and cheaper hogs by the use of improved blood and the growing of forage crops.

2. To increase the number of hogs raised on the farms in order that the meat for the home and that required to feed the extra farm labor may be produced instead of being bought. 
3. To complement the work of the boys' corn clubs by showing the boys how they can profitably sell their corn through hogs.

4. To encourage the home curing of meats on the farm.

5. To teach the boys how to judge hogs and to select them for breeding or market purposes.

6 . To encourage the growing of forage crops and discourage the use of high-priced feeds.

7. To instruct the boys in a practical way in the management, feeding, sanitation and prevention of diseases

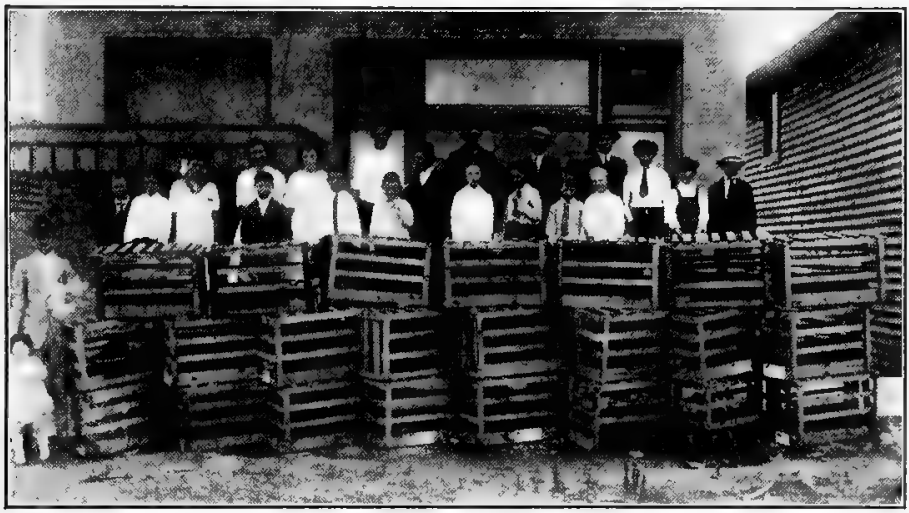

Distribution of boys' pig club pigs. Courtesy R. S. Mitcheil of Mississippi.

of swine, all of which information proves valuable with respect to other forms of live stock work.

8. To give the boys a means of earning some money for themselves while at home.

9. To instill in the boys while young a love of animals which will result in their taking more interest in farm life. and to furnish them at the same time some work which will in a practical way give an insight into the business side of farm life and incite in them a desire to struggle for and attain success. 
The pig clubs are usually organized in a business manner with officers. A simple constitution and by-laws are adopted. For a president of the club a leader of such work in the community is generally chosen. Other officers are likewise elected, and the duties are prescribed in the constitution and by-laws. Each club adopts a set of rules, which are given also in the above-mentioned Farmers' Bulletin, as follows:

1. Any boy between the ages of 10 and 18 years may become a member.

2. Each boy must secure at least one pig if he becomes a member.

3. Each member must care for his stock in person, and keep a record of the feed given and the pasture grazed. He must record the weight of each pig when it came into his possession, and at stated intervals, so as to determine the gains. The date of farrowing should also be recorded.

4. Record blanks, which will be furnished, should be filled out and certified by two disinterested persons.

5. Each member must have owned and kept a record of his pig for at least four months in order to compete for a prize.

6. The members must, whenever possible, show at least one pig at the county exhibit, and the winner of the county exhibit must show his pig at the state fair.

Geographical distribution of swine in the South.-As a result of the last census we find the distribution of hogs in the several southern states as follows:

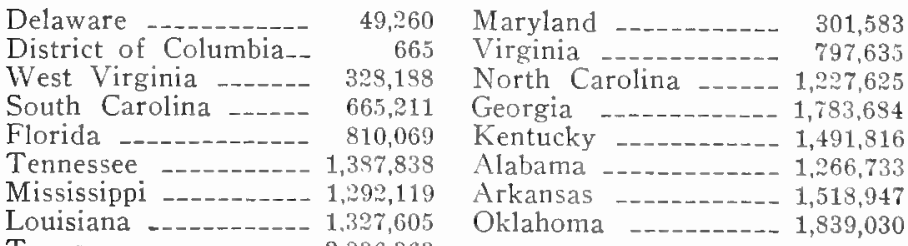


From the above figures and from the accompanying map it is seen that as a general proposition swine are rather evenly distributed over the entire South. The larger states lead in total numbers and the smaller states have the least numbers. In numbers the states rank as follows: Texas, Oklahoma, Georgia, Arkansas, Kentucky, Tennessee, Louisiana, Mississippi, Alabama, North Carolina, Florida, Virginia, South Carolina, West Virginia and Maryland. A study shows that the more

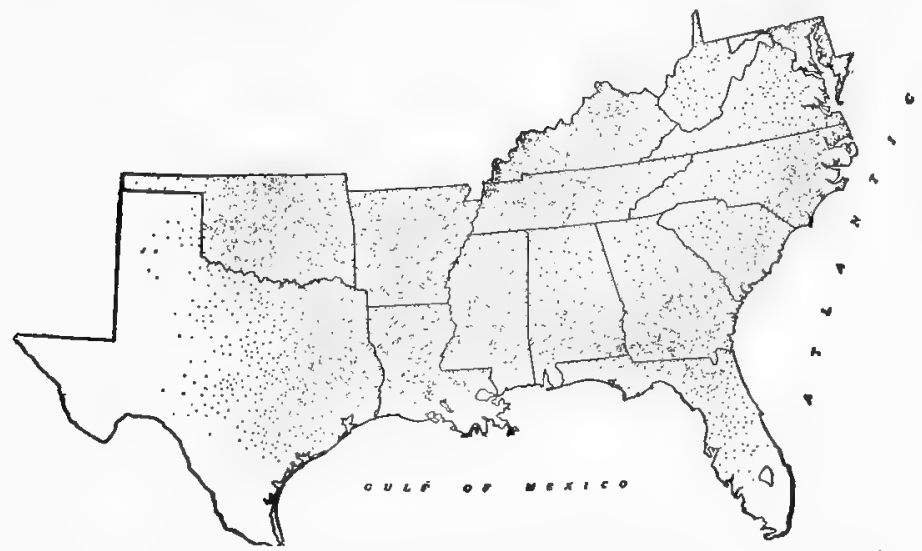

Distribution of swine in southern states according to Thirteenth Census. (One dot equals 2,500 hogs.)

level sections sustain more hogs than do the rougher and more mountainous sections. The tendency seems to be for the industry to develop more rapidly in those sections that are more easily cultivated. There are great differences in the hogs of the different sections of the country, which differences are largely due to the extent of the infusion of improved blood. As a general proposition, the farther south towards the Gulf Coast one goes the less improved the individual. 
Average value of swine per head.-The difference in value of the hogs in the different states is well brought out by the following figures, showing the value of hogs per head for several states on January 1, 1916, according to figures issued by the United States Department of Agriculture :

Texas

$\$ 7.70 \quad$ Kentucky

$\$ 6.50$

Oklahoma

7.20

Louisiana

West Virginia

900

Mississipp

Alabama

7.30

Virginia

South Carolina

Tennessee

North Carolina

8.50

Georgia

Maryland _._._._- $\quad 8.50$

Florida

\subsection{0}

6.80

7.70

New Jersey

12.80

These figures show how the value of swine in a general way declines as we move southward. This is largely due to inferior breeding and feeding, both of which can be remedied. One of the first efforts to be made in the development of a swine industry for the South should be to use pure-bred boars and to improve the feeding by greater production of feeds suitable for hogs, and by the application of modern methods of feeding. There is no good reason why just as valuable hogs cannot be raised in Florida as in New Jersey. 


\section{CHAPTER II \\ PRINCIPLES OF SWINE BREEDING}

Swine breeding.-While swine breeding is a science in so far as it concerns biological functions and processes and evolution, it is an art in practice. The practice of swine breeding consists in the development of those characteristics which are of value to man. In order to accomplish this, the characteristics must be possessed by the animal to start with. Our improved breeds of swine 'would never have attained their present degree of perfection had not the high capacity for feed utilization been inherent. This capacity has been cultivated and developed.

Selection.-Progress in swine breeding has been made by artificial and methodical selection based on utility. In this selection both individuality and pedigree have been considered. This selection has enabled the breeder to favor and propagate desirable variations and to avoid the more undesirable ones. Natural selection has also played an important part in the development of breeds of swine. The application of the law of "the survival of the fittest" proceeds in the domesticated as well as in the wild state, but in the domestic state it comes nearer being "the survival of the best," since our efforts at artificial selection are toward the favoring and fixing of those tendencies of special value to man. Thus the progress in breeding swine is dependent on the making of those selections of value to man, depending upon heredity to fix the selected qualities or characteristics. 
Laws of breeding.-From time to time we read or hear of the laws of breeding. The farmer or swine breeder desires to know if he can make use of these to further his interests. It is certainly well for the breeder to know what progress has been made in the science of breeding. but if it is something very practical desired the breeder had best study the influence of environment, the origin, history and pedigree of his animals, and make special effort toward breeding more prolific strains than to trouble about infection, saturation, maternal impressions and the transmission of acquired characters.

Heredity.-Heredity embodies those characteristics which an individual acquires from its parents through its germ plasm. The laws of heredity are none too well understood, but it is so universal in its application and has been the basis of our breeding operations until we have accepted it as a fundamental. Like begets like has been the basis of all of our improvement in breeding. Unfortunately, good and bad characteristics are equally transmitted, when taken as a whole. Difficulty is experienced in placing a quantitative value on heredity.

In the case of some characters we can measure the character accurately, but the animal does not necessarily transmit those characters of its body, or somatic character, by means of its germ plasm, which we must recognize as the sole carrier of hereditary substance. Weismann, a famous investigator, has shown that the reproductive cells are entirely distinct and separate from the body or somatic cells. The germinal cells alone are the carriers of the hereditary substances, and since these are formed long before the birth of the animal, the impossibility of inheritance of acquired characters is evident. 
This germ plasm is highly stable and independent of the other cells of the body, which merely act as a carrier for the germ plasm.

Variations.-One of the fundamental principles underlying our progress in breeding is that no two animals are alike. All are different. These differences are referred to as variations. They constitute to a large extent our basis of selection, and without selection we would have had no improved breeds of swine. All variations are of two types, the inherent or congenital ones, and those produced by environment. Only the inherited or congenital variations that arise spontaneously from the germ plasm are inheritable. Unfortunately, the breeder cannot always distinguish between the inherited and acquired variations. Environment both magnifies and obscures inherited variations, and thereby assists in the making of selections. Variations arise spontaneously from the germ plasm, or else they are produced environmentally. As brecders, we are interested in both kinds of variations, but primarily, of course, only in the congenital variations.

Inheritance of acquired characters.-If a pig is stunted and as a result develops a long snout and small stature, we would call these acquired characters. If a pig has its tail cut off, that would be an acquired character. For a long time it was considered that all characters possessed by an animal were inheritable and transmissible to the next generation. In the light of more recent science we must conclude that only those characters that are congenital and have their origin in the germ plasm are inheritable.

Mendelism.-This is something about which we have heard much in the field of scientific breeding, yet as a 
matter of fact it has never proven to have any important commercial value. In the past we have always considered that the crossing of two distinct characteristics results in an intermediate character. This may occur in the first generation, but if the characters are what have been referred to as unit characters and Mendelize, something very strange happens, for instead of being an intermediate type it will resemble more or less one of the two original characters, and that character or type which it resembles most is referred to as the dominant character. These first crosses are called hybrids, so far as the particular character being studied is concerned. If two hybrids are crossed the characters may Mendelize, or break up, and all of the offspring do not have the same characters, for while about half will resemble their parents, the other half will resemble their grandparents, giving a numerical proportion of $1: 2: 1$ so far as the characters are concerned. This ratio is the Mendelian proportion stated in its simplest form.

Unit characters.-The number of different characters that are susceptible to Mendel's Law is unknown. New ones are continually being worked out and added to the 1ist. It is assumed that most characters that do not Mendelize are composed in reality of several separate characters, which makes it impossible to study the segregation of the several unit characteristics of the offspring. Since each character that Mendelizes is a unit, and since no further division of the character is possible, the character is referred to as a unit character. A great many characteristics have been proven to be unit characters, inherited according to the laws discovered by Mendel.

Breeding the best to the best.-Since swine improvement first began, the principle which has led to the 
greatest success has been the breeder's maxim, "Breed the best to the best." While as a general rule this is a good one to follow, and in most instances is the best, there are instances where it will result in failure. If the breed is pure as to origin the results may prove satisfactory, but if the origin of the breed has been complex, and especially if the brced is of recent origin, the practice of breeding the best to the best may yield a high per cent

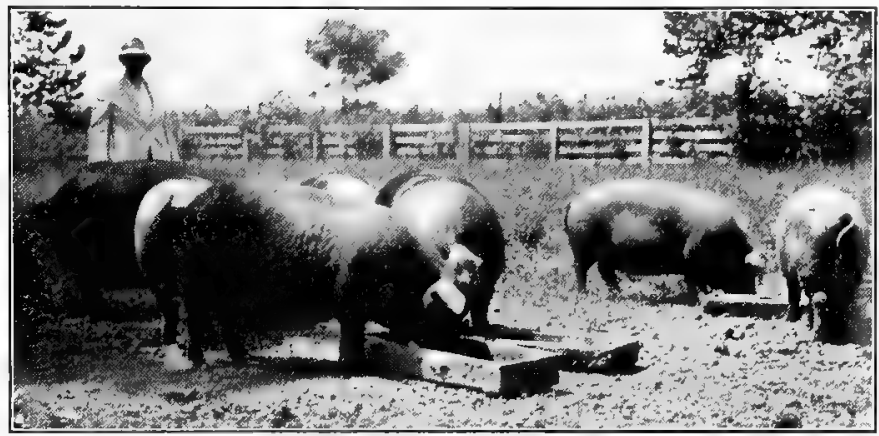

Proper feeding must accompany breeding. Courtesy of E. J. McCall of Louisiana.

of failures. This is easily understood when we consider that if a breed is pure there is a variation around one mean only, while when the breed is complex as to origin and is made up of several types, the variations tend to cluster around several means, and marked reversions too often accompany crossing of members of the breed that appear similar. Therefore, while it is fraught with danger in some instances, about the best we can do is to breed the best to the best, unless we have good reasons for doing otherwise.

Pedigree.-Our progress in swine breeding must be to a large extent based upon proper utilization of pedigree 
or records of ancestry. Especially are pedigrees important in determining the prepotency of breeding swine. The boar or sow possessing for several generations back high-class individualities in their ancestry gives greater assurance of itself being prepotent over another boar or sow with equally as good an individuality, but lacking in high-class individualities in their pedigree. Our pedigrees are dependent on the record associations, and frequently it is impossible to trace the pedigree of swine back for more than twenty generations.

Environment.-Environment is the external factor of food, climate, shelter, etc., with which an animal is surrounded. It is impossible to state just the exact influence that environment has on animals, but, as a rule, it is much greater than one might suppose. The quality of early maturity, a much sought for character in our improved swine, is greatly influenced by environment. This factor of environment is very largely under the control of the breeder. With it he can accomplish a great deal. Environment may be as valuable as inheritance, and either alone is valueless. Since environment is simply the development of inherited traits, heredity is probably the most important. The one great value of environment to the breeder is that it so magnifies and modifies the inherited traits as to make minute variations between individuals discernible, so that selections can be made with a considerable degree of reliability.

Inbreeding.--Inbreeding consists in the mating of rather closely related individuals that possess desirable characteristics, with the object of fixing or stamping the type into the offspring. When carried too far, or when the crossing is too radical, a loss of size, vigor and fertility occurs, accompanied by a strong tendency for the 
occurrence of malformations of various sorts. The results of inbreeding are different with different strains and breeds. That inbreeding has a place in our breeding practice is indicated by the fact that it has been freely made use of in the formation of practically all of our improved breeds of swine. In the hands of the right man it can be used to good advantage.

Line breeding.--This is a term that is applied to one of the methods often employed by breeders to fix a certain type or character on their animals. Most breeders of pure-bred hogs are line breeders, for they endeavor to breed along a certain line. Line breeding resembles inbreeding, but it is not so drastic. It has virtually the same effects as inbreeding in fixing characters and establishing types, but it acts slower. As in inbreeding, it may result in loss of vigor, size and fertility when carried out without using sufficient judgment. Line breeding has the opposite effect from cross-breeding. In practice it consists of the continued use of the blood of some Farticular individual or strain of individuals in trying to stamp or fix a certain character into the herd. This method of improvement also has its drawbacks, for while we are establishing some good characteristics we may also be fixing and magnifying undesirable qualities. Good examples of this are seen in those extremely wellbred animals that in reality do not have the individuality to merit registration. Nevertheless, in spite of its drawbacks, our most successful breeders have made free use of it. At present it is about the quickest way we have to magnify and fix a character. The main thing is in knowing the character and in realizing its value, and to have the courage and conviction to stick to the character once it is known. 
Cross-breeding.-Strictly speaking, by cross-breeding we refer to the crossing of two different breeds, yet from the standpoint of breeding it may refer to the crossing of different types or strains. This crossing is often made use of in our breeding operations where increased size,

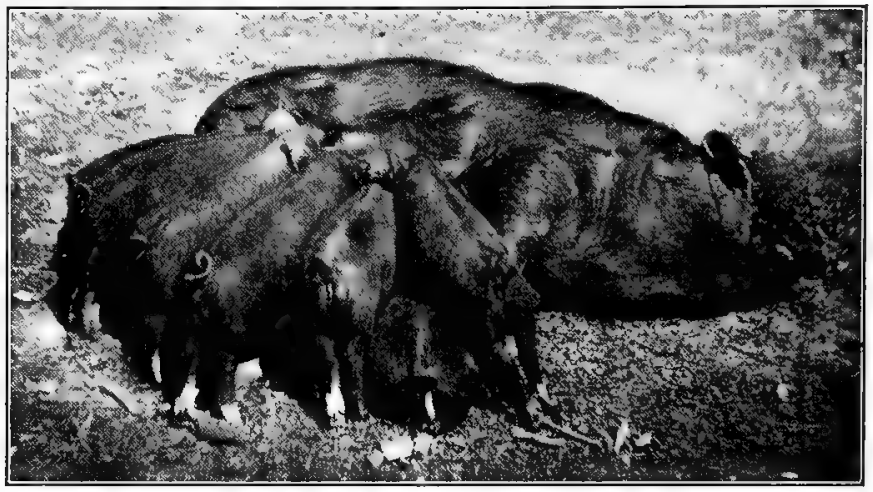

Successful swine breeding is dependent on the reproductive process. Courtesy Joe R. Martin of Georgia.

vigor, thrift and fertility are sought. Many highly bred females will not conceive to their kind, and a different strain must be used. While, of course, there are advantages to be gained by cross-breeding, it is not without disadvantages. It always results in more or less instability, and one cannot foretell with what success the cross is being made. For this reason it is better to always make moderate crosses only, for radical crosses more often result unsatisfactorily, the instability of type probably running several generations before being re-established.

The reproductive process.-In order that a breeder may carry on his work with intelligence, he should become 
first well informed on the general principles of biology that underlie reproduction. He cannot appreciate the importance of heredity, the necessity of selection and the value of variation until he does this. To understand these principles he must first appreciate the cell and the part it plays in the animal kingdom. He must look upon the cell as the biological unit. He must know what cells are, how they act, and why they are so important. He must know something of cell structure, functions and processes.

The cell.-The entire body of any animal is made up of cells. These cells may partake of a variety of shapes and functions. In the simplest form it consists of a mass of protoplasm with a nucleus, with the whole inclosed in a cell wall. Within this cell absorption, assimilation, growth and reproduction take place. The reproductive function is of greatest importance, since the process of growth and production of the animal is dependent on cell division. The process of cell division is quite complicated. The somatic cells, or body cells, are being built up and destroyed continuously, but the reproductive or germinal cells live from the time the animal is conceived until they are expelled, or until the animal dies. Therefore, the breeder should look upon the animal as made up of millions of units, and before the entire animal can be understood the functions and process of the individual units must be understood and appreciated.

The male germ cell (spermatozoon).-This cell originates in the germinal cells in the testicle. After several divisions, they are fully developed spermatozoa, and pass from the testicle as mobile cells, consisting of a head, which contains the nucleus, a neck, and mobile tail. This 
cell passes to the female organs and is attracted to the female germ cells, with fertilization as the result.

Female germ cell (ovum).-These cells originate in the ovary in a manner somewhat similar to the way in which the spermatozoa originate. The cell is very large. Each of these cells, as a rule, unites with one spermatozoon to develop into the embryo from which a pig comes. In some instances a fertilized ovum may split and two pigs may result from the same cell, but more often each pig comes from a separate ovum after it has united with a spermatozoon. This cell is not mobile, but it gravitates from the ovary to the uterus by the oviduct or the Fallopian tube.

Fertilization of ovum.-The female cells travel toward the uterus, and the sperm cell travels about in the uterus and may go up the Fallopian tube to meet the female cell to which it is attracted. When the two cells meet, the male cell enters the female cell, leaving his tail behind, with the result that the two nuclei of the germ cell coalesce to start the process of cell division which results in the embryo from which the pig comes. Since the hereditary material of an animal is carried in its germ plasm, the offspring partakes of the characters of both parents.

Pregnancy.-When the male germ cell unites with the female cell the result is a pregnancy. The pregnancy extends until parturition. When a sow becomes pregnant it is indicated by (1) cessation of periods of heat, (2) change in disposition, (3) tendency to fatten, (4) enlargement of the abdomen, (5) and in the later stages by sinking of loins, congestion of udder and external genitals. 
Reversion, or atavism.-Breeders frequently have animals appear in their herds that are unlike their parents or any near ancestor, but they seem to resemble some of the older types of animals from which the breed originated. These variations are referred to as reversions, and the tendency to revert is spoken of as atavism. The tendency to revert is constant, and it seems that the higher bred and more specialized our types become, the more subject they are to reversion. It seems that even through most extensive breeding we cannot escape the influences of atavism. Especially does atavism manifest itself when two different strains are crossed, or when the animals are placed under different or adverse conditions. Usually these reversions are undesirable in breeding, but those reversions resulting from changed environmental conditions can be controlled to some extent. Those atavisms that are congenital are beyond our control and use. Therefore, the further we advance in our swine breeding the greater will be the efforts required to maintain what we have produced up to the attained standard.

Superfœtation and superfecundation.-This is an abnormal condition resulting from a pregnant sow conceiving during a pregnancy. They sometimes will come in heat while pregnant, and if served may conceive. This condition is rare, however. It also may happen that during a period of heat a sow may be served by more than one boar, with the result that she may have pigs in the same litter by both. Such a condition is referred to as superfecundation. It will occur often where the opportunity is presented.

Fecundity.-Fecundity of swine refers to their prolificacy, or their ability to produce young in abundance. 
Fecundity is determined to a very large extent by environmental conditions, such as exercise, confinement, climate, food supply, and season; in addition, it is influenced by such factors as age, size, condition, disease and health, constitution and conformation. The most common causes of a low fecundity are lack of exercise and too high a condition. As to age, usually the number of pigs in the first litter is less than the number in the next few litters; then, after five or six years of rather heavy production, there is a more or less gradual, sometimes rapid, decline, until the breeding powers cease, at about ten years, a few remaining active breeders beyond this age. Of course, the higher producing sows are more desirable. Even though under the most favorable conditions natural selection will assist materially in weeding out the poorer breeders, care should always be taken in the making of selections of breeding animals to choose only those animals coming from large litters.

Determination of sex.-Rules for the control of sex seem to have always existed, and they still flourish. Thousands of theories have been propounded, and all have failed to survive the tests of time.

The hog breeder.-To be a successful hog breeder one must have a high-class breeding herd and yet be able to produce each year individuals that are an improvement over their parents. This requires a man of more than ordinary ability and skill. He must of necessity give his work great thought. He should know the demands of the market and breed accordingly. The known laws of breeding should be utilized. Men capable of becoming successful hog breeders are few, especially as compared with those who would make successful producers of 
market hogs. Above all, the true swine breeder must appreciate the principles of breeding, and he should study and apply the established laws of breeding to his operations.

Breeding conditions in the South.-The breeding of pure-bred swine has never become an established prac-

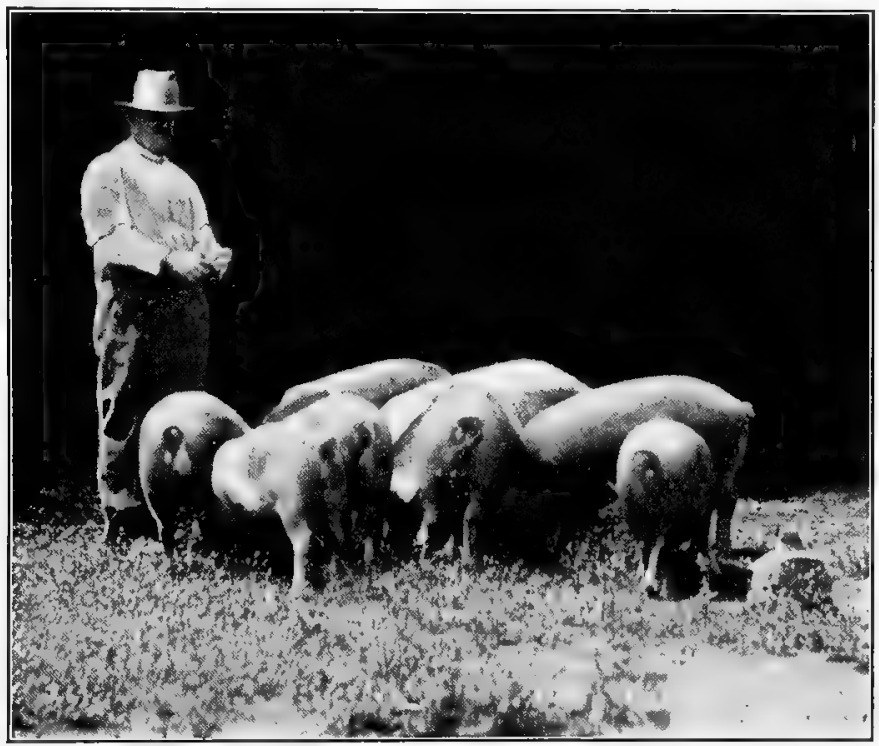

This type is on the increase in many sections of the South. Courtesy Dr. R. Thor Weaver of Florida.

tice in the greater part of the South as it has in the Corn Belt. But comparatively few pure-bred herds are maintained in the South below the southern Tennessee line, yet within recent years there has been a decided tendency for the more progressive breeders to grow registered animals. The result has been a rather rapid im- 
provement in numbers and quality of swine. For many years past, of course, the cotton industry has predominated, but it is rapidly becoming recognized that a system of live stock farming is essential to a permanent system of cotton production, and that the total cotton production can be greatly increased by the proper introduction of a system of swine husbandry.

Proportion of pure-bred swine.-In the southern states there are approximately $20,000,000$ head of hogs. Of these there are much less than 20,000 pure bred and registered that are used in improving and increasing the quality and quantity of hogs. In other words, there is less than one pure-bred and registered hog in the South to exert its influence in the improvement of every 1,000 head of grade and scrubs. These figures readily show the present status of the pure-bred swine breeding industry in the South, and they bring out sharply the great possibilities for improvement. Especially do these figures show that the possibilities of pure-bred swine business in the South are based on sound principles, and that it is merely in its infancy in many respects.

The lack of improved breeding.-While the present condition of our swine-breeding industry in the South is far from what it should be, it is nevertheless hopeful. In order to correct and perfect conditions we must fully appreciate the present status of the industry. In the first place, there has been a general lack of infusion of good blood. In the second place, what pure blood has been used has been indiscriminatingly mixed with other blood and has not been conserved. Thirdly, grade and scrub boars have been indiscriminately and promiscuously used. And, fourth, inferior pedigreed boars have been 
used as sires where they should have been sent to the pork barrel. One of the most regrettable sights is to see a scrub boar masquerading under a pedigree heading the herd of a would-be breeder, who knows no better than to assume that, because his boar is registered, he is fit to head a herd.

Better blood always needed.-In all of our swinebreeding operations there is one thing that must be constantly borne in mind, and that is that there is always need for improved blood. The aim of the breeder should always be to produce something better. With all of the effort that will ever be directed toward improvement, there will always be room for more. That stage in swine breeding will never be attained at which no further effort will be needed to maintain the perfection of the breeds. This is in a measure due to the fact that there is a constant tendency for an improved strain or breed to revert to an original type, and the higher the specialization and the nearer perfection we approach the greater will be the effort required to maintain, much less improve, the breeds of swine.

Co-operative swine breeding.-Of late we have heard considerable of co-operative dairy and beef cattle breeding associations. There is no reason why the same principle would not apply to swine breeding. In general, the plan would be for a community of farmers interested in a particular breed of swine to form an association, binding themselves by an agreement to advance the interests of the chosen breed. They would agree to use nothing but pure-bred and registered boars and sows, as each member might choose. The plan would be for the boars to be purchased by the association from the best 
breeders after they had been passed on by a capable judge. These boars would then be distributed among the different breeders, to be used until such a time as inbreeding might result, when an exchange of boars would be made. This exchange is then made without additional expense to the breeders, and an entirely new boar is received. By this method the most valuable boar would soon be recognized by his pigs, and these pigs could be used for general improvement. Another great advantage of such an association would come through the attraction of buyers of swine for pork and breeding purposes. Such an association, if of sufficient size, could afford a sales agent to do nothing else but make sales.

County swine breeders' associations.-In forming cooperative brecding associations the county can frequently be most conveniently made the unit, especially where the counties have farm demonstration agents or similar officers. Under such conditions the formation of an association is very desirable and should be encouraged, especially in every county where the swine interests are sufficiently large to justify its existence. The chief aims of such an association should be the promotion of better breeding, better methods of selling and better and more profitable swine husbandry in general. Several county swine breeders' associations are already in existence, and the county as a unit has generally proven more effective than larger and more scattered units.

Pure-bred swine breeding as a business.-But very few swine breeders have attained wealth through their swinebreeding operations. The requirements for success in this business are as exacting as in any other business, and the infinite amount of painstaking work and attention 
required is such that success is possible with but remarkably few men. Less than ten per cent of those who enter the business remain in it longer than ten years and make what would ordinarily be called a success.

Future of pure-bred swine business.-The pure-bred swine business is at the very foundation of our entire pork-producing industry. Naturally, as in the past, the pure-bred herds will be called on in the future more and more to improve our pork-producing herds and maintain the perfection which has already been attained. The necessity of a liberal use of pure blood is recognized by pork producers, and the outlook for pure-bred swine is good, to say the least. A careful review of the pork industry in southern states in general will show that there is a very profitable future near at hand for producers of pure-bred swine of the right sort.

Pure-bred swine business looks tempting.-Far too many men enter the pure-bred swine business with inadequate capital and experience, and they are unwilling to give the business the time and care it demands, which, of course, means ultimate failure. True, all breeders who have accomplished anything to be proud of have only done so after failures and disappointments, but these disappointments would be fewer if we took greater precautions in starting.

Number of hogs to grow.-The number of hogs which one can conveniently and profitably produce will depend to a great extent on the factor of food supply. Therefore, in the contemplation of swine production, one of the first considerations should be that of available food supply. This will, of course, depend on the feeds and the quantities which one expects to feed. A probably easier method 
of calculating is to place the number of hogs on the acre basis, since any system of swine production in the South will largely depend on the growing and grazing of pasture crops. While single acres have been known to produce with one crop upwards of 1,400 pounds of pork, a fair average would be somewhere between 250 and 500 pounds, depending on the fertility. If the land is fertile, one could therefore produce annually an average of four head per acre that would average from 100 to 150 pounds per head. If the land is very fertile, it may provide fecd for more than this, but the most of the land, especially in the start, will provide feed for a smaller number.

The boar breeder.-There are a great many breeders of pure-bred swine who make it a business to breed purebred boars to supply the needs of farmers and other breeders. Such a breeder is forced to breed animals to meet the demands of the pork market, although he may never send animals to the market. It therefore behooves him to thoroughly inform himself on what the market demands, for the boars he sells must be capable of siring the type the market desires. While fashionable pedigrees are desirable, market type and superior individuality are more desirable, and those breeders who breed on pedigree alone and who ignore the demands of the market and show ring will sooner or later lack buyers for their boars. The necessity of basing all of our swine-brecding operations on the utility basis becomes continually more and more apparent.

Breeding for pork.-The aim should be to produce only the type most sought after, for, as a general rule, those hogs that bring the higher prices have been most profitable to their owners. Not only must the selections be 
based upon the demands of the market, but the owner must figure profits closely on each animal. Above all, the individuals should be the quick-growing kind, with a good constitution and a natural heavy fleshing. They should show their breeding and give evidences of their superiority. The blocky, compact, low-set animal most nearly conforming to the ideal pork type should be sought.

Always use a pure-bred sire.-There is one rule that is applicable to all forms of swine-breeding industry that should never be disregarded. This is to use always a pure-bred sire, regardless of the objects sought, whether the aims be to produce animals for breeding purposes or for market. We frequently find grade individuals of marked excellence that are considered good enough to head a herd, but in most cases the resultant offspring in the first generation will show marked traces of the inferior breeding.

Continually grade up.-One thing that will have to be borne constantly in mind by all breeders is that there is always a necessity to select and breed up continually, even though no improvement may be sought. This is necessary if we are to maintain the excellence of our animals. The condition is just as true, or more so, with a pure-bred herd than with a market herd. This results from the fact that the higher bred and specialized our swine are, the greater the cffort to maintain that breeding and specialization. This tendency to reversion to an inferior type is constant, and calls for a constant effort at improvement which cannot be ignored.

Breeding for type.-In all breeding operations the ideal must be kept constantly in mind, and all efforts must 
have one aim-to secure that type. If one is selecting an ideal grazing type of hog, he must know what constitutes an ideal grazer. In breeding for a special type, ancestry must be given due consideration. Individuals possessing the desired type, but with different ancestry, may give the desired results. On the other hand, the selection of individuals with ancestry conforming to the desired type, and as nearly similar in characteristics as possible, might accomplish results quicker. Less variation in type is apt to result when ancestry of similar characteristics are used, and the desired type may be fixed in the offspring much quicker than where the types involved in the offspring varied greatly.

Type--Type is a generic term applied to those groups of swine of similar size, conformation and utility. These various types have been evolved to meet certain demands for swine, with certain qualifications. The result is that each breed has its own special peculiarities which are not fornd in the individuals of other breeds in the same proportions. These characters grouped together are referred to as "breed type." In a general way the several breeds of swine, therefore, are naturally classed or grouped into certain classes, dependent upon their characteristics. Thus we have the lard type of swine, in which there are several breeds. These swine have strong propensities for fattening, and their carcasses yield a large amount of fat or lard. In the same way we have the bacon types of swine, which are inclined to make lean meat rather than fat.

Breed for utility.-All breeding for improvement must be based upon utilitarian lines in order to be justifiable. This is the prime requisite for a successful breeder, and 
all successful breeders have made utility the basis of their operations and the goal of their efforts. The real value of any meat animal depends upon its ability to convert the products of the farm that are unfit for human food into something that is edible. Its ability to do this most economically determines its relative earning capacity to its owner. Of course, fashionable pedigree, color mark-

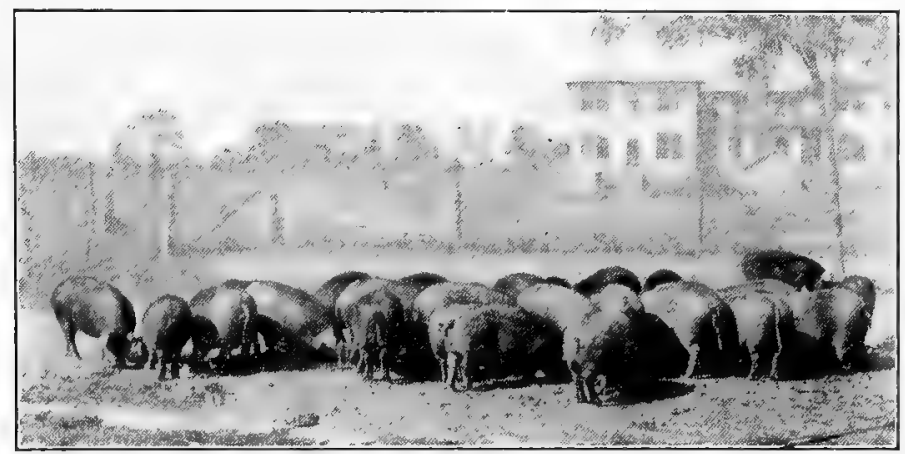

Utility should be the basis of all breeding operations. Courtesy E. C. McInniss of Mississippi.

ings and fads may be given some consideration, but utility should never be sacrificed for any of these to the least extent. While formerly some of the show ring judges failed to recognize these cardinal principles, they are now fully appreciated, and the animal that indicates having brought the greatest profit to its owner is generally given first consideration.

Breeding for utility involves pedigree and individuality. - Some breeders are inclined to place too much emphasis on the fancy side and forget the practical, while others place too much emphasis on the practical side and totally 
ignore pedigree and blood lines. What we should aim for is a middle ground, which alone can be the basis of real utility. The middle ground takes note of not only breeding and blood lines, but of individual merit and suitability for breeding purposes. For the beginner, this is a hard ground to take. He knows that the pedigrees are the tabulated record of the ancestry of the individual, and only guarantee ancestry, whether they be good or bad. A good pedigree would, of course, contain a large number of individuals possessing high merit.

Pure-bred hogs for farmers.-Many farmers are of the opinion that purc-bred swine are for the rich and gentlcmen farmers only, and that they are not suited for average farm use, as they lack constitution and cannot maintain themselves under average farm conditions. In the latter assumption they are partly correct, but it is due to no fault of the swine. What the farmer wants is an animal that will make pork and make it cheaply, and that is what pure-bred or high-grade animals will do. In the selection of breeding animals the farmer can do no better than to select a pure-bred boar and either pure-bred or high-gradc sows, in spite of the fact that they may seem to cost a little more to start with, for the advantages of type, early maturity and cconomy of production soon outweigh any extra original cost. Scrubs and unimproved animals are, of course, adapted to some farming methods, but if a farmer is equipped for pork production at all, and desires steady profits, he should consider no other breeding animals than pure breds or high grades.

Cross-breds.-The term "cross-bred" is used somewhat more loosely than the term "pure bred." Some authorities state it is used to designate that an individual is the 
offspring of parents from different breeds, and that it is not necessary that the parents be pure bred, but they must be very high grade. Others state that an animal is a cross-bred when the sire and dam were both pure bred, but belong to different breeds.

Under certain circumstances it may be well to cross two breeds, but the cross should never be carried farther than one generation. In the second generation the tendency is for various characteristics to Mendelize and split off, and the resultant great variation is decidedly detrimental. Therefore, if we do any crossing at all, we should not carry it farther than the first generation. It is true that swine breeders and pork growers in general attach great value to crossing brceds, claiming greater vigor, quicker maturity and larger and stronger bone. These advantages are to a large extent only apparent, and experimental evidence shows the advantages to be so slight as not to justify the crossing as a regular practice. Breeds should only be crossed, therefore, when hogs are to be grown for the market. Most any breed will cross up well with other breeds, but crossing is usually not advisable, and should only be carried out under exceptional circumstances.

Prepotency of pure-bred boars.-Pure-bred boars secm to possess a certain prepotency and ability to stamp their type that is not possessed by scrub or grade boars. This is very much in evidence where a pure-bred boar is used on a few native sows, in which the pigs of the first generation are apparently almost full blooded. This ability to stamp type on the offspring is not possessed by the scrub. This characteristic of pure-bred swine is undoubtedly due to long and continued line inheritance as a result of selection. The type of the pure bred we might say is 
dominant,- while that of the scrub is recessive. This means that the type of the pure-bred animal is inherited and can be implanted on those swine not now possessing pure-bred type. In this connection the fact must not be lost sight of that the superiority of the pure bred over the scrub is not alone in breeding, for a pure-bred animal when starved soon takes on a great many characteristics of the scrub animal, and the well fed up scrub can be

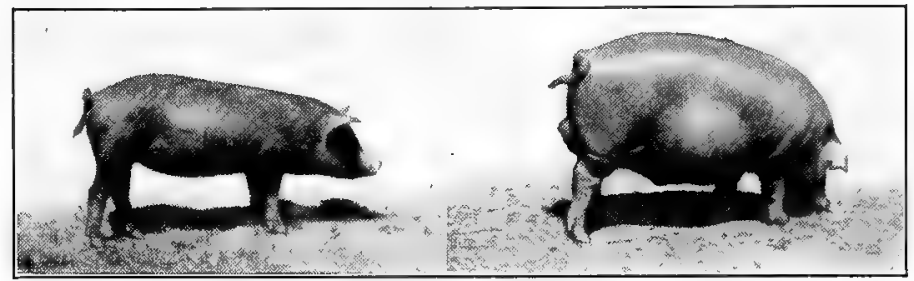

Litter mates; one fed by a pig club boy and the other by his father. Courtesy W. W. Browder of Kentucky.

made to partake of some of the characteristics of the purebred type. This shows that breeding and feeding must go hand in hand, and further indicates the better and more economical use to which a pure-bred animal puts his food than does the scrub.

Why pure-bred swine seem expensive.-When fullgrown hogs are selling at from $\$ 25$ to $\$ 50$ per head, it seems to the inexperienced that $\$ 25$ for a registered boar pig is a very liberal price. While this may seem an $\mathrm{cx}$ cessive figure to pay for a pure-bred boar pig, it is not. Pure-bred swine of the right kind cannot be grown as cheaply as scrubs, for they must be better fed and cared for in order to be in salable condition, and the trouble and costs of keeping up registrations is no small item of 
expense. The trouble is that too many look at the first cost alone. Twenty-five dollars is not an unreasonable price to pay for a registered pig to make a herd header of, and a sire selected at $\$ 75$ to $\$ 100$ would probably be far more profitable in the long run than a cheaper one. The additional value placed upon each pig in the first crop generally much more than pays the difference between a cheap or scrub sire and a good, pure-bred one.

Swine-breeding terms.-Before one can intelligently understand the underlying principles of swine breeding, it is necessary that he familiarize himself with certain terms that are met with more or less frequently in discussing the subject. Among these terms we frequently find "pure bred," "full blooded," "thoroughbred," "crossbred," "high grade," "grade," "unimproved," “scrub," "native."

Pure bred.-Used synonymously, but erroneously, with the term "pure bred," are the terms "full blooded" and "thoroughbred." In speaking of any phase of swine breeding it is never necessary to make use of the latter two terms, and their use should be avoided as they are more or less confusing. In discussions on swine brecding the term "pure bred" is probably met with more frequently than any other of the terms used. This term is applied to those hogs whose ancestors came from the native homes of the breeds in question and conformed to the requirements of the breed. The blood must be pure and the breeding and ancestry must be known for several generations back. An animal cannot be considered as a pure bred unless it is capable of being registered in the standard herd book for the breed to which it lays claim. The advantage of a pure-bred animal lies in the fact that 
its ancestors were especially selected animals, all possessing certain desirable characteristics insisted upon by the men who founded and developed the breed.

Grades.-The term "grade" is generally used in conjunction with one of the breeds, as "grade Duroc-Jerseys," or "grade Berkshires." It indicates that the animal has one-half or more of the blood of the breed mentioned. In its use the term "high grade" is closely related to that of "grade." "High grades" are those hogs containing as much as seven-eighths of the blood of one of the improved breeds. When an animal becomes a high grade it is almost impossible to tell it from a pure bred by a casual observation.

Scrub swine.-Used synonymously with the term "scrub swine" are "native" and "unimproved." All of these terms are applicable to those animals that do not carry more than at least a small amount of the blood of any of the improved breeds. They bear no evidence of superior breeding. None of their ancestors were pure bred, or at least if they were it is so distant that none of their influence is manifested in the offspring. The term "scrub" may be, and often is, applied to inferior swine of any breeding. In general, the term "native" has a little broader application than the other two terms, and is often used to designate the swine of all kinds gathered up in a certain locality.

Breeding management of a pork-producing herd.- 'To start with, a uniform lot of sows should be secured. The breeding and degree of excellence of these will be determined by several factors. If pork production alone is desired, and high grades are secured, these should have indications of the blood of one breed only. From the 
same breed a pure-bred boar should be selected to mate with these sows in order to secure a uniform lot of pigs. While uniformity of itself may possess no real value, it is one of the best paying investments to be made, for it generally costs little or nothing and the market pays well for it. The selection of the boar should be most carefully made, regardless of the ultimate object of the breeding. If grade sows are used and pork is to be produced, the aim should be to continue the grading up from year to year and from boar to boar. Such breeding practice continued through but a few years will give one a herd of grade animals comparing quite favorably with pure breds so far as uniformity of product and resultant offspring are concerned. Breeding for pork production alone has several distinct advantages over breeding for brceding purposes, and not the least among these advantages is the fact that in the pork-producing herd it is necessary to keep the breeding animals in as high condition as in the case of the pure-bred herd.

Breeding condition.-While we must not forget the necessity of keeping our breeding animal in high condition, we must recognize the incompatibility of too high a condition with the best of breeding qualities. The best results are obtained when the animals are neither too fat nor too lean, but when they are in what might be considered the most healthy condition.

The results of too high condition.-This danger of too high a condition in breeding animals is already well known. As to the causes, there may be several, but in the cases of the females it is safe to assume that the large quantities of fat deposited around the internal reproductive organs do not make for the best breeding quali- 
ties. The excess of fat seems to crowd the embryos, possibly pressing against certain blood vessels and nerves, thereby cutting off a part of the nutrition and limiting the reproductive functions. In addition to this, very fat animals do not, as a rule, take sufficient exercise to guarantee the most healthy condition. This applics to the overfed boar as well as to the sow. In the boar the factors of proper nutrition and blood supply to the reproductive organs may also play an important role.

Sterility, or barrenness.-Many of our high-bred swine are barren, or sterile. This is a matter of vital importance to the brecder. It is not a trouble confined solely to one sex. In the female it may be due to failure of development of the ova, to diseased organs, fatty degeneration, contraction of the cervix of the uterus, to acid discharge in vagina, weakness of the germ cells after conception, lack of exercise, and to other physiological abnormalities. In the male, many of these same or paralleled conditions prevail to cause sterility. Where the trouble is due to faulty management, it is the best plan to see that the affected animals are allowed ample exercise, that they are kept healthy and in good breeding condition, but not too fat, and that the sexual functions are not overworked.

Number of pigs to litter.-The question of the possible number of pigs to the litter, the most desirable number to have, and the ways of influencing the numbers of pigs in litters have attracted some attention from breeders. In numbers, it is possible for sows to have all the way from 1 to 24 . The latter figure is the number of pigs farrowed at one time by one of the early sows in the history of the Poland-China breed. This litter was farrowed in the herd of Chas. Hankinson, in Warren County, 
Ohio, the place of origin of the breed mentioned. The average number of pigs farrowed is much less than this, of course, and for no breed does it exceed ten head. Most breeds will average between six and ten head to the litter, the fat or lard type of hogs generally farrowing the smaller numbers. As to the most desirable number to have, it is never desirable for a sow to have more pigs than she has mamma. Most sows have 13 possible functional mammæ. This number is, however, too large, and as a rule ten is as many pigs as one can expect to handle and care for in one litter.

The number of pigs per litter and their sex is to a large extent beyond our control. The boar has but little influence on the number, and in most cases it is determined by the sow. In attempting to correct troubles with deficient litters, we should first look to the sow for the possible trouble. A great many swine breeders seem to have the impression that there are direct means whereby the number of pigs to the litter can be increased. Such, however, is not the case, and the only thing that can be done is to keep the sows and boars in the best breeding condition. Above all, the sow must not be too fat, she should be properly fed, her reproductive functions must not be overtaxed, and she should have sufficient exercise to give her the best breeding condition. Practically the same management should be applied to the boar, for at times the small litters may be due to lack of sexual vigor and prepotency in the boar. With care being taken to see that the boar and sow are both kept in the best of breeding conditions, one should be able to secure the largest litters possible with the individuals at hand. 
Work done by Carlyle at the Wisconsin Station has shown that there is a direct relation between the size of the litter and the size of the sow, the larger sows having the larger litters. The same holds true for the age, although to a lesser extent, and the greater the age the larger the litter, up to certain limits, of course. These are important facts and should be kept in mind by the breeder desiring large litters.

Color of swine.-The color of swine usually is of secondary importance. Our pure-bred swine are more or less constant in color, because this was one of the easiest characters to establish in the formation of the breeds. In the case of the wild types of swine, the coloration, while fairly constant, is, as a rule, variegated for protective purposes. The necessity of color protection in the case of domestic swine is not present. Color in swine has some value in protection from adverse climatic condition. Most wild swine inhabit temperate and subtropical climates, where sunshine tends to produce a scalding on white swine. None of the wild breeds of swine are light in color.

Period of heat.-When the sow gives off germ cells there are certain symptoms manifested which, taken collectively, indicate the period of heat. The external genitals may become swollen and congested, and there may be a slight discharge. The mammary glands may also become slightly congested. Restlessness and change of voice are also manifestations. These periods occur with some degree of regularity. They first appear in the gilt in subdued or premature form at about three months of age. After that, they occur every twenty-one days or

${ }^{1}$ Bulletin 104 Wisconsin Agr. Exp. Station. 
thereabout until pregnancy intervenes, when they cease. This cessation prevents superfotation, or double pregnancy, which sometimes occurs in cattle or horses, but rarely or never in swine.

\begin{tabular}{|c|c|c|c|c|c|c|c|c|c|c|c|c|}
\hline \multicolumn{13}{|c|}{$\begin{array}{l}\text { Day of } \\
\text { month } \\
\text { bred }\end{array}$} \\
\hline in & $\begin{array}{l}\text { Jan. } \\
\text { Apr. }\end{array}$ & Feb. & - Mar. & $\begin{array}{l}\text { Apr. } \\
\text { July }\end{array}$ & $\begin{array}{l}\text { May } \\
\text { Aug. }\end{array}$ & $\begin{array}{l}\text { June } \\
\text { Sept. }\end{array}$ & $\begin{array}{l}\text { July } \\
\text { Oet. }\end{array}$ & $\begin{array}{l}\text { Aug. } \\
\text { Nov. }\end{array}$ & $\begin{array}{l}\text { Sept } \\
\text { Dec. }\end{array}$ & $\begin{array}{l}\text { Oct. } \\
\text { Jan. }\end{array}$ & $\begin{array}{l}\text { Nov } \\
\text { Feb. }\end{array}$ & $\begin{array}{l}\text { Dec. } \\
\text { Mar. }\end{array}$ \\
\hline 1 & 22 & 23 & 21 & 22 & 21 & 21 & 21 & 21 & 22 & 21 & 21 & 23 \\
\hline 2 & 23 & 24 & 22 & 23 & 22 & 22 & 22 & 22 & 23 & 22 & 22 & 24 \\
\hline$\overline{3}$ & 24 & 25 & $2 \overline{3}$ & 24 & 23 & 23 & 23 & 23 & 21 & 23 & 23 & 25 \\
\hline 4 & 25 & 26 & 24 & 25 & 24 & 24 & 24 & 24 & 25 & 24 & 24 & $2 \hat{o}$ \\
\hline 5 & 26 & 27 & 25 & 26 & 25 & 25 & 25 & 25 & 26 & 25 & 25 & 27 \\
\hline 6 & 27 & 28 & 26 & 27 & 26 & 26 & 26 & 26 & 27 & 26 & 26 & 28 \\
\hline 7 & 28 & 29 & 27 & 28 & 27 & 27 & 27 & 27 & 28 & 27 & 27 & 29 \\
\hline 8 & 29 & 30 & 28 & 29 & 28 & 28 & 28 & 28 & 29 & 28 & 28 & 30 \\
\hline 9 & 30 & 31 & 29 & 30 & 29 & 29 & 29 & 29 & 30 & $29 \mathrm{~N}$ & $\operatorname{Tar} 1$ & 31 \\
\hline 10 & May 1. & June 1 & 30 & 31 & 30 & 30 & 30 & 30 & 31 & 30 & 2 & Apr.1 \\
\hline 11 & 2 & 2. & July $1 \mathrm{~A}$ & Aug. 1 & 310 & Det. 1 & 311 & Dec. $1 \mathrm{~J}$ & Tan. I & 31 & 3 & 2 \\
\hline 12 & $\mathbf{3}$ & 3 & 2 & $2 \mathrm{Se}$ & ept. 1 & 2 I & Jov.1 & 2 & $2 F$ & eb. 1 & 4 & 3 \\
\hline 13 & 4 & 4 & 3 & 3 & 2 & 3 & 2 & 3 & 3 & 2 & 5 & 4 \\
\hline 14 & 5 & 5 & 4 & 4 & 3 & 4 & 3 & 4 & 4 & 3 & 6 & 5 \\
\hline & 6 & 6 & 5 & 5 & 4 & 5 & 4 & 5 & 5 & 4 & 7 & 6 \\
\hline 16 & 7 & 7 & 6 & 6 & 5 & 6 & 5 & 6 & 6 & 5 & 8 & 7 \\
\hline & 8 & 8 & 7 & 7 & 6 & 7 & 6 & 7 & 7 & 6 & 9 & 8 \\
\hline 18 & 9 & 9 & 8 & 8 & 7 & 8 & 7 & 8 & 8 & 7 & 10 & 9 \\
\hline 19 & 10 & 10 & 9 & 9 & 8 & 9 & 8 & 9 & 9 & 8 & 11 & 10 \\
\hline 20 & 11 & 11 & 10 & 10 & 9 & 10 & 9 & 10 & 10 & 9 & 12 & 11 \\
\hline 21 & 12 & 12 & 11 & 11 & 10 & 11 & 10 & 11 & 11 & 10 & 13 & 12 \\
\hline 22 & 13 & 13 & 12 & 12 & 11 & 12 & 11 & 12 & 12 & 11 & 14 & 13 \\
\hline 23 & 14 & 14 & 13 & 13 & 12 & 13 & 12 & 13 & 13 & 12 & 15 & 14 \\
\hline 24 & 15 & 15 & 14 & 14 & 13 & 14 & 13 & 14 & 14 & 13 & 16 & 15 \\
\hline 25 & 16 & 16 & 15 & 15 & 14 & 15 & 14 & 15 & 15 & 14 & 17 & 16 \\
\hline 26 & 17 & 17 & 16 & 16 & 15 & 16 & 15 & 16 & 16 & 15 & 18 & 17 \\
\hline & 18 & 18 & 17 & 17 & 16 & 17 & 16 & $17^{\circ}$ & 17 & 16 & 19 & 18 \\
\hline 28 & 19 & 19 & 18 & 18 & 17 & 18 & 17 & 18 & 18 & 17 & 20 & 19 \\
\hline & 20 & & 19 & 19 & 18 & 19 & 18 & 19 & 19 & 18 & 21 & 20 \\
\hline 3 & 21 & & 20 & 20 & 19 & 20 & 1.9 & 20 & 20 & 19 & 22 & 21 \\
\hline 31 & 22 & & 21 & & 20 & & 20 & 21 & & 20 & & 22 \\
\hline
\end{tabular}




\section{CHAPTER III \\ BREEDS OF SWINE}

Swine are plastic.-The life history of every species of animal forms a more or less distinct arc, which may cover a period of a hundred thousand or even a million years. Species of animals are stable or plastic, depending on their relative position on the arc of the life history of the species. The nearer the species is to the starting point of the arc, or, in other words, the younger the species, the more plastic it is. At first a species is quite plastic and variations abound, and progress in breeding, whether it be natural or artificial, is very rapid and easy. Later, the inherent tendencies of the species carry it along in certain directions, and after a certain time the characteristics may become so fixcd that the species may not be able to become harmonized with its surroundings, and the result is the extinction of the race or species. The swine species is, comparatively speaking, near the beginning of its arc of development. It is quite plastic and variations are numerous. Breeding progress is comparatively easy in the hands of man. Wild swine are much more constant in characteristics than are domestic swine, for in the wild state mutations not in accord with nature are at once eliminated. Under domestication, all sorts of variations and mutations have been preserved and modified, and the result is that we have many types of domesticated swine that are not in harmony with their surroundings, which, of course, means ultimate loss. Therefore, we might conclude, that, for instance, as compared with horses, the formation and molding of breeds 
of swine is comparatively easy, and such is the case, although we may not at all times be able to see it.

Original swine.-The original types of swine from which our present day breeds have descended have been the Sus Scrofa and the Sus Cristatus or S. Indicus, both belonging to the species Suidc. Nearly every part of the world has native members of the Suida, but so far as we know, only the two above have played an important role in the formation of our present day breeds of swine, which may be considered as having arisen by the crossing of these two strains. The Sus Scrofa was the native swine of the British Isles and Europe, while the $S$. Indicus was a native of Asia and southeastern Europe. These are related to the wart hog of Africa, to the babiroussa of the East Indies and the peccary of Central and South America. The Sus Scrofa was a very large, coarse animal, measuring often over three feet in height, of a dark gray color with the young more or less striped. The Sus Indicus, on the other hand, was nearer like our present day swine, being short and thick, with a strong tendency to fatten easily and mature early. They were of several colors. The Asiatics were the first to domesticate and make progress at breeding, with the result that at a very early time there were three strains or breeds of the $S$. Indicus, known as the Chinese, Siamese and Neapolitan, which breeds or strains played a very important part in the formation of the present day breeds, which for the most part trace to England or to English origin.

Influence of domestication on swine--Knowing as we do the principal characteristics of the original types of swine and of the present breeds, we are able to state what 
changes have been brought about by the process of domestication. In the first place, it has brought about a marked increase in their efficiency for converting feed into pork. It is true that through domestication they have lost to a marked degree their capacity to survive adverse conditions, but this is not detrimental to their usefulness and value, for they should not be forced to withstand adverse conditions under present methods of production. Economically, therefore, their value has been increased through the loss of their capacity to withstand the vicissitudes of climate and insufficient food supply. A bit of reflection tells us that this is not only true of swine, but that it is likewise true of other domestic animals and plants, and we find it a general rule that those plants or animals which are the most persistent are the least valuable.

Origin of breeds and strains of swine.-While we may be continually making new breeds and strains of swine, we do not make the material from which new breeds and strains arise. We are able to make our new strains only by utilizing the inherent variations already present in our animals. We control, develop and magnify these variations as much as we are able by controlling the environment. Any marked variations are referred to as sports or mutations, which mutations cannot be isolated and experimented with, but which have been studied enough that we know that they are inherited as units, hence the term unit characters, which is sometimes applied to them. It is by the assembling of the right sorts of these variations that we are able to form new breeds and strains. We simply collect into one animal, or into a few animals, those characters and groups of 
characters which are most desirable. These characters are then established and stabilized by continued selection.

It is a noteworthy fact that all of our breeds of swine of today have had extremely local origins. For example, the Poland-China, a lard type of swine that originated largely in Warren County, Ohio, now has a world-wide distribution. Among the other breeds, the Berkshire and Yorkshire were extremely local during their early development, but now their distribution is very wide. Thus we have many breeds of hogs, some very generally distributed and of great importance, and others very much localized and of less importance. In the British Isles alone, there have been numerous breeds described. On the Continent breeds and sub-breeds are present in abundance, and we find almost every agricultural section with its own native breeds. It was not until about the middle of the eighteenth century, or a little later, that an active and systematic effort was made to improve the breeds. At that time the efforts were centered upon the production of new breeds, while all of our efforts at present should be centered on perfection of what these breeders have accomplished.

Breeds of swine.-Breeds and races of swine are identical. By these terms we refer to the several small groups of swine that closely resemble each other. The breeds usually derive their names from the locality in which they originate. Our present day breeds are the results of generations of effort, and we are very fortunate to have them in their present state of perfection.

In making a study of the breeds of swine, one is at once impressed by their numbers, which far exceed 
average expectations. Any statement as to the number would be purely an estimate, but the number is no less than fifty. This large number results from the fact that frequently a community will develop a breed that is of purely local distribution. Very frequently these breeds have considerable merit, but owing to geographical isolation their distribution may remain limited for years, or until the breed is finally absorbed. It is these kinds of breeds that are so numerous, and in most instances the division line between local breeds and native swine would be obscure. The number of well-known breeds that have a wide distribution is not more than a dozen. Among these the Poland-China, Duroc-Jersey, Berkshire, Hampshire, Large Yorkshire, Small Yorkshire, Essex, O. I. C., Chester White and Tamworth are important.

The breeds and their principal characteristics. - In the old-established breeds, color, conformation, habits and the like nced to be considered when determining their adaptability to one's requirements. Sometimes active rustlers are needed; again, quiet, home-staying, dependcnt hogs are best. In some instances quick-maturing hogs are needed, and in other instances a slower-maturing kind may more nearly meet one's needs. Some breeds will not fatten well until they are nearly grown. Others will fatten at any time enough feed is given. All breeds have their good and bad qualities. There are various breeds well adapted to our southern conditions. There is not so much difference in breeds, however, as there is generally thought to be, so that usually the preference of the owner may be followed without injury, except in those cases where the environment demands a particular type. 
Breed types.-In a general way, the different breeds of hogs may be divided into two classes, dependent to a large extent upon the relative proportion of fat and lean they carry when finished. The two classes, or types, are referred to as the lard and bacon types. The lard, or fat type, predominates, and is best adapted to the corn-raising sections, where it conomically converts all surplus corn into pork. The several lard breeds differ but little from one another in essentials, so that as a rule personal preferences may be indulged in without disadvantage. The bacon breeds do not have the tendency to fatten so marked as do the lard types, however, and some breeds are either lard or bacon type, depending on the environment in which they are placed. Nevertheless there seems to be a tendency for the bacon type of hogs to gain in popularity, and especially are they adapted to the conversion of grazing crops into pork. This is one thing that prospective producers of pork will have to watch, and that is to see that the breed or animals they select are adapted to grazing. In addition, color plays a part in our southern climate. The strictly lard type of hog will probably never be so popular in the South as it has been in the Corn Belt. In the selection of breeds to mect our particular conditions we cannot ignore types; therefore, in discussing the characteristics of the several breeds, they are taken up in the order of their tendencies from the lard to bacon type.

The Poland-China.-This is strictly an American breed that originated about the middle of the last century in Butler and Warren Counties of Southwestern Ohio. It resulted from the crossing of the Russian, Byfield, Big China, Irish Grazier, and Berkshire on the native Warren 
County Pig. The name is the result of the use of a strain of hogs that were bred by a Polander and which went

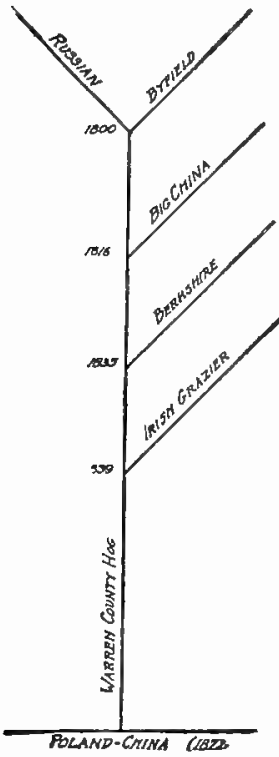

Blood lines of the

Poland-China. under the name of Polands and, of course, the China came from the Big China stock that was used. The early animals of the breed were large and quick-maturing, with a spotted color.

This is a breed that comes as near as is possible to conforming to the ideal fat hog type. The head is of medium size, with nose straight and with the ears pendent. The body is compact, with a broad back and deep sides. The hams are perfect. It is the ideal lard type. In color it very much resembles the Berkshire, being black with white markings. The breed is of medium size, mature boars weighing around 450 and the sows around 350 to 375 pounds.

It is not as adaptable a breed as some of the others. It was made primarily for use in the Corn Belt, where for many years it has outclassed all other breeds. It is strictly a lard type and is well suited for corn feeding. It is an extremely early maturing type, but is of that disposition that wants all of its feed placed right before it. Some class it as a lazy breed. They are of second rate as grazers and rustlers, largely for the reason that they do not stand up well on their feet and pasterns. As a fecder and fattener, this breed has no superior. The quality of pork is quite fat and is not classed as the best 
by some on this account. It is good for crossing with other types when pork-producing qualities of the extreme type are sought. The boars, however, are not as prepotent as the boars of some breeds in stamping their type on the offspring. In fecundity qualities this breed is lacking, and has been severely criticized on this ground. Dr. A. W. Bitting found 1,086 litters to avsrage 7.45 , while Dr. G. M. Rommel ${ }^{2}$ found the average to be 7.04 with 50,000 litters. As a breeder, therefore, it is second rate.

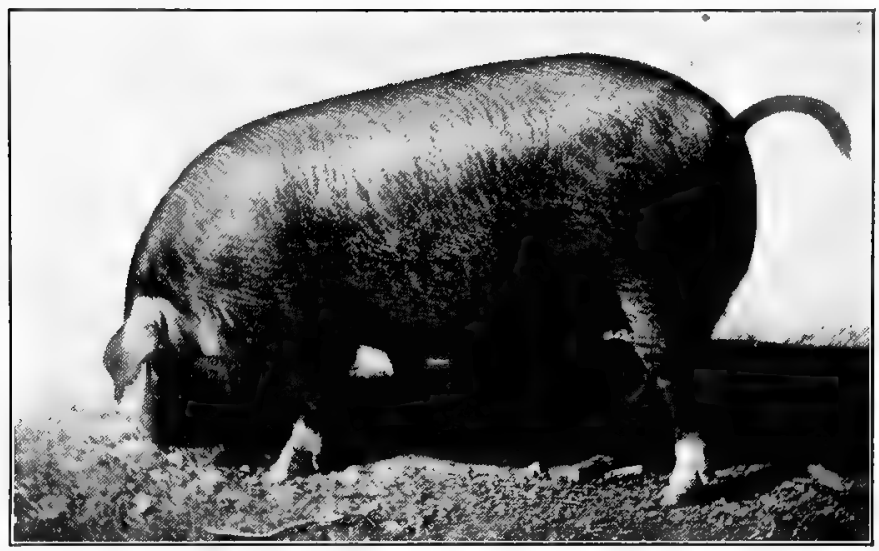

Poland China gilt, Jennie Girl (581414) owned by Joe R. Martin of Georgia.

The breed is pretty generally distributed over the South, but in the extreme South it has not met with the popularity that has been awarded some other breeds. The prices paid for individuals of this breed were ab-

\footnotetext{
${ }^{1}$ 10th Ann. Rept. Ind. Agr. Exp. Sta. (1897).

${ }^{2}$ U. S. Dept. Agr. B. S. I. Circular 95.
} 
normally high several years ago, but they are now normal and not above the average. The interests of the breed have been looked after by several associations. The American Poland-China Record Company

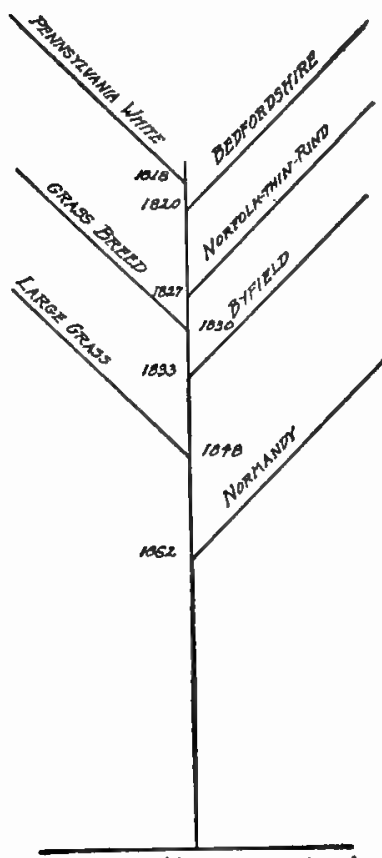

Crzesten-WHite \& alc (106)

Blood lines of the Chester White and O. I. C. (1878), W. M. McFadden, Secretary, Union Stock Yard, Chicago, Ill.; the National Poland-China Record Co. (1905), A. M. Brown, Secretary, Winchester, Ind.; and the Standard Poland-China Record Association (1887), Geo. F. Woodworth, Secretary, Marysville, Mo., all register and look after the interests of the breed.

The Chester White.-This is a distinctly American breed that originated largely in Chester County, Pennsylvania. The foundation stock for the breed came from England, principally from Bedfordshire and Cumberland. Chinese, Irish Grazier, and Normandy swine were also used in making the breed, according to Plumb. The farmers, principally from Chester County, developed the breed, and being a white breed, the name Chester White was appropriate.

This breed is distinctly of the lard type and conformation. The face is medium in length and straight. The ears break over for the outer third or half their length. 
The back and hams show the extreme of development. As a rule, the bone is small and weak, and it is in the pasterns that this breed is noticeably deficient. The color is pure white, and the animals average large in wcight on account of the extreme fattening tendencies. Mature boars will weigh around 500 and the sows around 400 pounds. Some individuals will, of course, greatly exceed these figures.

The breed is suited primarily for Corn Belt conditions, and is not casily adapted to other conditions. There are a few small herds of the breed in the South, but they will probably never attain any great prominence. They are extremcly carly maturing, but they rank low as grazers. They cannot stand up in the pasterns. As feeders and fatteners they rank high, but they are not adapted to intensive methods of feeding on grazing crops. Their color is against them in the extreme South. The pork is usually too fat, very similar in many respects to the meat of the Poland-China. For crossing they do fairly well where early maturity and fattening propensities are desired in the offspring. The boars are only fairly prepotent in stamping their type. As breeders they rank rather high and are considered as the most prolific of the heavy types. Dr. A. W. Bitting found 600 litters to average 8.96 per litter, which is high for the lard type of hog.

There are a few herds scattered over the South, but their distribution cannot be said to be widespread. They are probably on the decline in popularity rather than on the increase. In prices, they have never brought the fancy figures obtained by the individuals of some breeds,

'10th Ann. Rept. Ind. Agr Expt. Sta. (1897). 
but they have been average in price. The Chester White Record Association, F. F. Moore, Secretary, Rochester, Ind., attends to the registrations and looks after the interests of the breed.

Ohio Improved Chester.-This is a distinct breed that

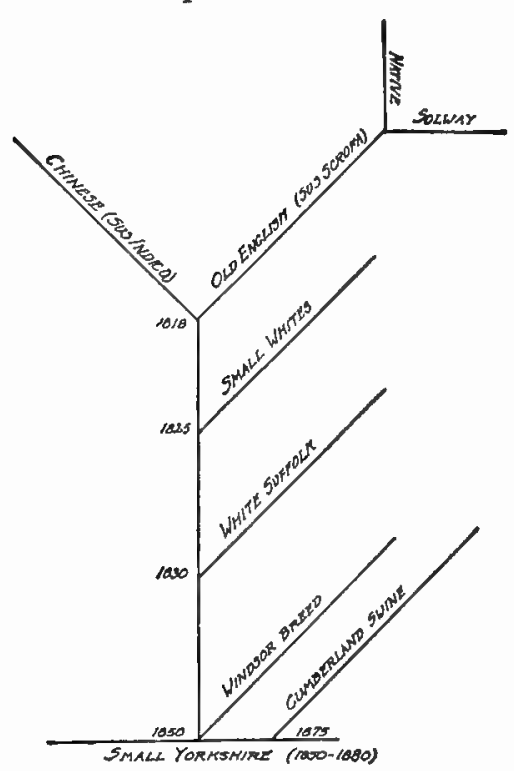

Blood lines of the Small Yorkshire. resulted as an offshoot from the Chester Whites. It was originated by Mr. L. B. Silvers, who developed his herd by crossing and selection until he considered it superior to the original Chester White. He referred to them as the International Ohio Improved Chesters, and in 1891 an association was formed to look after the registration of the animals. This association is now known as the O. I. C. Swine Brceders' Association, J. C. Hiles, Secretary, Cleveland, Ohio.

As a breed, it must be considered along with the Chester Whites in so far as it concerns a southern swine industry. It will probably never enjoy the popularity that has been accorded the Duroc-Jersey and Berkshire breeds.

The Small Yorkshire.-This English breed originated in Yorkshire County, England, over a century ago as a 
result of the use of Chinese, Solway, Small White, Suffolk, Windsor, and Cumberland stock on the native pigs of the country. According to Curtis, they were introduced to this country about 1869 . This is a distinctly lard breed. The ears are erect and the face short, with an extreme dish. The breed is white, except for occasional black spots on the skin, which are objectionable. They are small of size, and mature boars average around 250, while the sows will average about fifty pounds less. They are in all probability not a breed that would be well adapted to our southern requirements. They are registered as Class A by the American Yorkshire Club, H. G. Krum, Secretary (1893), with headquarters at White Bear Lake, Minn.

Duroc-Jersey.-This is distinctly an American breed, that originated in New York and New Jersey during the half century from 1822 to 1872 . According to Plumb, it resulted from the amalgamation of blood of Guinea, Portuguese, Spanish Red, and possibly Berkshire blood, upon the native stock, and finally by the amalgamation of the local Duroc swine and the Jersey Reds in 1883. The latter incident suggests the origin of the name. The name Duroc, however, happened to be of local origin, and was the name of a stallion owned by one of the early breeders of these swine. The Jersey part of the name comes from the place of origin, New Jersey. The early types of Duroc-Jersey swine were long and rangy, with tendencies to coarseness and size.

Among the noticeable characteristics of the breed are the small head, with a straight or slightly dished face of medium length and with the outer one-third of the ear broken over or pendent. The general form of the body 
of the hog is approximately that of the ideal fat hog, with a short, wide, deep body, with a maximum of development in the hams and the valuable part of the back. In many ways it resembles the Poland-China hog in form, although it is not quite the extreme lard type that this latter named breed is. In color it is some shade of red,

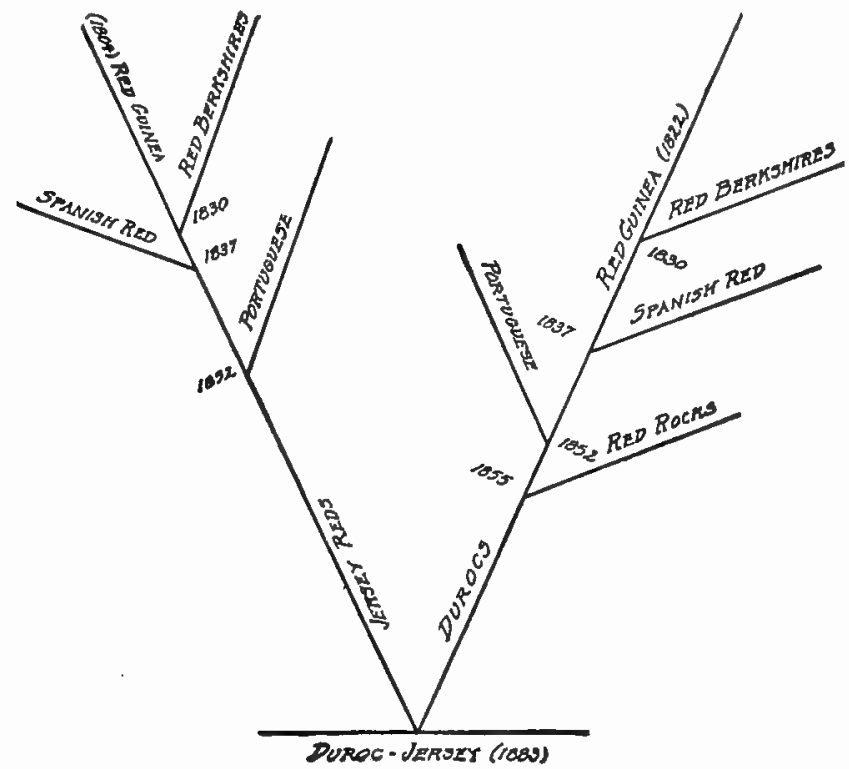

Blood lines of the Duroc-Jersey.

which may vary from a very light to a very dark red. In some instances they have black spots on the skin, but this is not objected to. In size they are classed as medium to large. Some individuals attain weights close to 1,000 pounds, but mature boars will average around 500 pounds and mature sows around 400. This is one of the 
most adaptable breeds of swine we have, and on account of its color and general qualities it is remarkably well suited to southern conditions. It is an early maturing breed that will fatten readily at almost any age.

Its grazing qualities are fair and, as a rule, it is to be looked upon as a good rustler. When the feed is put

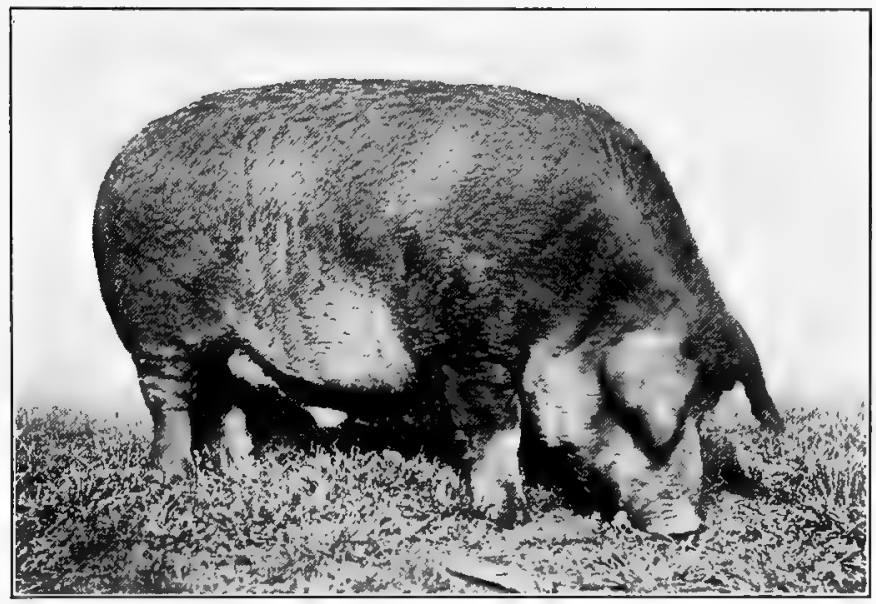

Duroc-Jersey boar, Defender's Ohio Chief (45899), owned by A. Ramey \& Bro. of Tennessee.

within its reach it will consume large quantities and make gains as economically and as rapidly as any breed. The quality of the pork produced is classed by some as lacking in quality, but there seems no justifiable evidence for these conclusions. It is, of course, inclined to be a little too fat. For crossing on other types of swine, it is admirably adapted, and early-maturing, easy-feeding and fattening qualities are added to the offspring. A cross that is commonly and successfully made is that of a 
Berkshire boar with sows of this breed. The fecundity of the breed is high, and the sows have comparatively large litters. In a study of the prolificacy of breeds of swine, Dr. Rommel of the L'nited States Department of Agriculture found that 21,652 litters of this breed averaged 9.26 to the litter, which must be considered as quite high and above the average for pure-bred swine. The breed, having been bred along definite lines for many years, is quite prepotent, and the boars seem to stamp their type and color well on all their offspring, the result of the first generation when they are crossed onto grade or common stock being of the red color and possessing to a considerable degree the desirable characteristics of the breed.

The breed is one of the most widely distributed and probably enjoys the widest distribution of any of the breeds in the South. In prices they range all along from rather high to lower and average prices. It is especially to be recommended for southern use for several reasons, as mentioned above. Its quietness of disposition is a most admirable quality, which makes it easily confined. The registration and the interests of the breed are fostered by two associations, the American Duroc-Jersey Swine Breeders' Association (1883), R. J. Evans, Secretary, with offices at Chicago, I11, and the National DurocJersey Record Association (1891), J. R. Pfander, Secretary, with offices located at Peoria, I11.

The Essex.-This is an old English breed that originated in the County of Essex in England, from whence the breed gets its name. The stock used in its foundation were principally Neapolitan, Black Suffolk and Berkshire.

${ }^{2}$ U. S. Dept. Agr. B. A. I. Circ. 95. 
The early types were both black and white and were very refined, showing plainly the results of the Neapolitan blood. Early types of Essex were introduced to America about 1820 , but the breed never met with any great success here. In many ways the breed resembles the Berkshire, the blood of which breed it shows plainly. The face is broad and the nose short and upturned. It is inclined to be on the order of bacon hogs in form, but decidedly of easy-fattening tenddencies. It is small of stature and bone, and possesses extreme quality. In color it is black all over, and white is objectionable. The size of the individuals is as a rule small, and mature boars average around 300 pounds, and the sows about 250 .

Their distribution is not

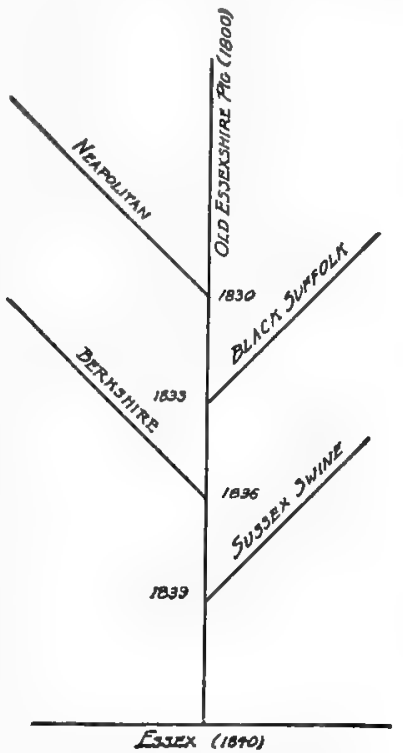

Blood lines of the Essex. widespread, but a few are found in the southern states. As a rule they seem to be increasing just a little in popularity. The American Essex Association (1887), F. M. Strout, Secretary, McLean, Ill., attends to the registrations and looks after the interests of the breed in general.

Cheshire.-This is a distinctly American breed that was originated largely in Jefferson County, New York. It resulted from the use of Large Yorkshire and White Suffolk blood on the native stock of the county. The origin of the name is obscure, but in all probability it 
traces back to Cheshire, England, in some way. The older types very much resemble the Yorkshire breed.

Owing to the free use of the Large Yorkshire breed, it very much resembles that breed in characteristics. It is

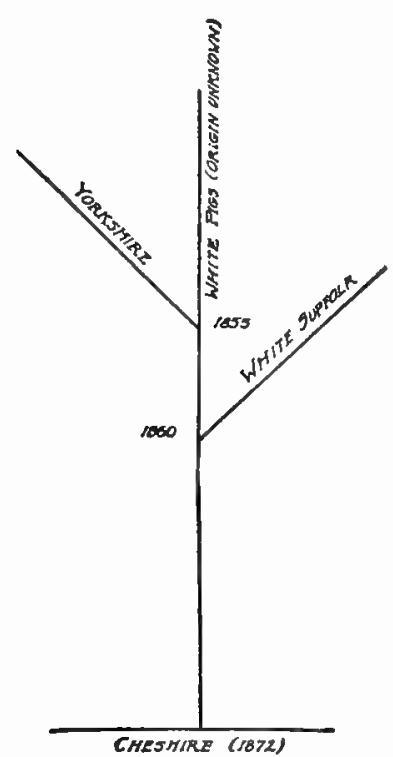

Blood lines of the Clieshire. smaller, however, and more nearly resembles the Middle Yorkshire breed. It has a dished face, straight ears, and a form between the lard and bacon type. It is solid white in color. They are only medium in size, mature boars weighing around 450 and mature sows around 350 to 400 pounds.

As a breed it is not widely distributed in the South. There are a few herds in the Southeast, where they have been bred for many years: The Cheshire Swine Breeders' Association (1884), Ed. S. Hill, Secretary, with offices at Freeville, N.Y., looks after the registrations and the general interests of the breed.

The Berkshire.--This is one of the older English breeds that originated in the counties of Berkshire and Wiltshire, England. It resulted from the crossing of Chnese, Siamese and Neapolitan swine on the native English swine. The name, of course, comes from the county in England where the breed largely originated. The early types of the breed had large pendent ears, with 
colors varying from a reddish brown to a spotted color. In quality and physical form they plainly showed the refining effects of the Chinese, Neapolitan and Siamese blood. They were first imported into the United States in 1823 by John Bretwell of New Jersey.

The breed is a type peculiar to its own. In England it is a bacon breed, but in America it inclines strongly to the lard type. The face is of somewhat medium length and is generally dished, with the ears standing erect and forward. It has excellent bone and stands up

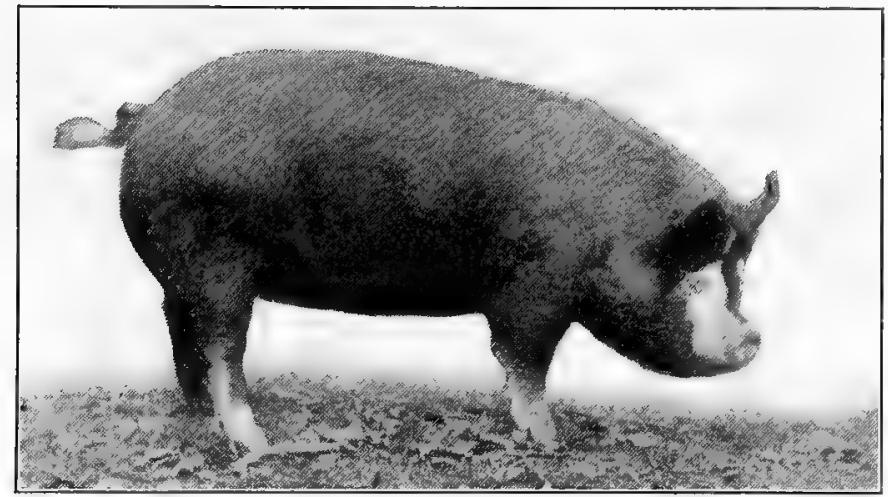

Berkshire gilt, Premier's Queen 25th (1793:5), owned by J. W. Strickland of Georgia.

well on its pasterns. The color is generally black, with white markings on the face, end of tail and on the four fcet. It is only a medium-sized hog and the mature boars will on the average weigh around 450 , while the sows will run about 100 pounds less. Some individuals readily attain twice this size.

Like the Duroc-Jersey, it also is a very adaptable breed and is well suited to average southern conditions. Its 
color is suited to our climate, and, being an early maturer and a good grazer, it meets our requirements well. It is one of the best feeders and fatteners we have, making gains rapidly and economically. It is not of the quiet

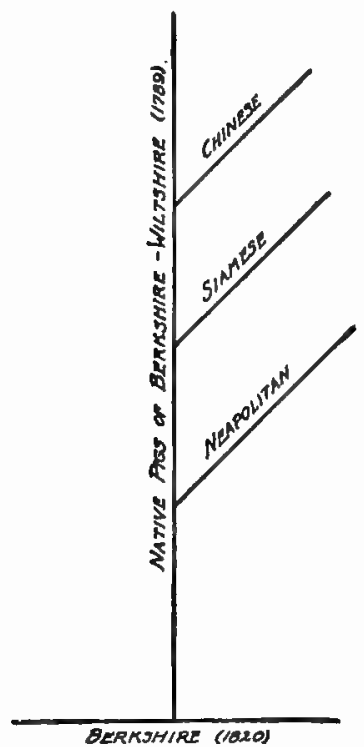

Blood lines of the Berkshire. disposition of some breeds, and is therefore not easily confined. It is a good rustler, however, and if there is anything to be found to eat, it will take care of itself. It is almost as prolific as the Duroc-Jersey, and the sows show themselves to be excellent mothers and less apt to lie upon their pigs than the Durocs. The quality of the pork is unsurpassed, having a very high percentage of lean. This breed had been used extensively in crossing, both in grading up and in crossing with other breeds, Crossed with the Duroc-Jersey, an ideal pork animal is produced. Their fecundity and breeding capacity is high. Dr. A. W. Bitting found 400 litters to average 8.22 pigs each, which must be considered high. The boars are quite prepotent on account of the age of the breed, and they stamp their type strongly on unimproved and grade animals.

As a breed they are widely distributed over the South, but they are not so numerous as the Duroc-Jersey. They have sold in the past at rather fancy prices, but they do

\footnotetext{
${ }^{2}$ Tenth Ann. Rept. Ind. Agr. Exp. Sta. (1897).
} 
not now range above the average. The interests of the breed are largely looked after by the American Berkshire Swine Breeders' Association (1875), F. S. Springer, Secretary, with headquarters at Springfield, Ohic. This association looks after registering the pure-bred animals.

Hampshire or Thin Rind.-This is distinctly an American breed that originated in Massachusetts and

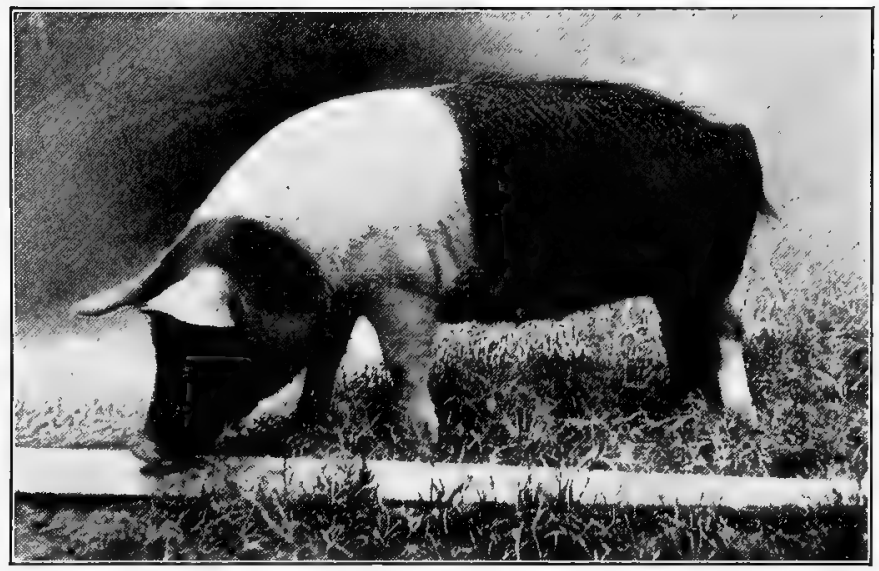

Hampshire gilt owned by J. P. Tilley, Jr., of Alabama.

Kentucky, principally in the latter state. It is possible that some swine from Hampshire, England, figured in the formation of the breed, but no authentic evidence is at hand to prove it. There is evidence, however, that some Chinese blood was used. In characteristics of body the animal possesses many things similar to the Berkshire. The nose is rather long and the ears point straight ahead. The conformation tends toward the bacon type, but the development of the hams is excellent. 
The color is black, with a white belting from 4 to 12 inches wide that starts at the neck or fore shoulder and extends back to the heart-girth, generally taking in the forelegs. It is not a large breed; mature boars will average around 400 pounds, and the sows from 300 to 350 pounds. As a breed, it seems fairly well adapted to southern conditions, and will probably meet with considerable favor, as it has already done in several sections of the South. The breed has not bcen used to any great extent in crossing, but the individuals are prepotent and could be used in the improvement of many herds. The breeding qualities are excellent and above the average. The breed is rather widcly distributed in the South, but not densely. The prices that have been obtained for the breed have been only average. The registrations and interests of the breed are looked after by The American Swine Record Association, E. C. Stone, Secretary, Armstrong, I11.

Mule Foot.-This is a rather recent American breed of uncertain origin. The foundation stock used was probably Berkshire, Poland-China and native blood. The first members of the breed were mutations in which the cloven foot gave way to the onc-toed condition, such as prevails in the horse and mule, hence the name. S. H. Dunlap of Ohio has been prominent in developing and putting the breed before the public. It resembles the Berkshire in body characteristics, but the ears are pendent, and the color is solid black, with white permissible. The individuals are small to medium in weight, mature boars averaging around 450 to 500 , and the mature sows averaging about 100 pounds less. The breed has been boosted a great deal upon the ground 
that it was cholcra immune, but they have proven to be just as susceptible to the discase as other breeds. They do not mature very early, and in breeding capacity they average pretty well up, resembling the Berkshire in this respect. The quality of the pork produced is excellent. They are not very desirable for crossing purposes, for the breed is too young and the individuals lack in prepotency. They have not enjoyed a wide distribution and popularity. The interests of the breed and the registrations are looked after by the National Mule Foot Hog Record Association, W. H. Morris, Secretary, with headquarters at Indianapolis, Ind.

The Large Yorkshire.-This English breed originated in Yorkshire County, England, over a century ago. It resulted from the use of Berkshire, White I-eicester, Small Yorkshire and Solway blood on the Old Yorkshire pig--hence the name. The early types were very large and coarse, with but little or no refinement, with large, coarse, heavy ears and strong tendencies toward extreme bacon type. The breed was introduced to America prior to 1840. Most of the importations of the brecd to America went to Canada, where the breed attained some prominence, but it has never met with great popularity in the States.

The breed is quite large and is of the extreme bacon type. The face is short and dished and the ears stand erect. There is a slack development of the back and hams, but with great depth and length of side. The breed is characterized by a heavy bone. The color is white. This is one of the largest breeds we have, and the boars when matured will weigh around 600 and the sows around 500 pounds. Individuals frequently weigh close 
to 1,000 pounds. The breed as a whole is not one that is readily adaptable to changed conditions. In the United States it has not met with much favor, and probably will not meet with any appreciable success in the South. It is a slow-maturing type. One very commendable feature about the breed is the very high breeding capacity, which is excelled by no other breed. The litters average nearly twelve pigs. The breed is valuable for crossing where bacon type is desired. The boars are usually quite prepotent, due to the age of the breed.

The distribution of the breed in the United States is very limited, and the numbers in the southern states are few. It is not popular in the South, and probably never will be. The registrations and interests of the breed are attended to by the American Yorkshire Club (1893), H. G. Krum, Secretary, with headquarters at White Bear Lake, Minn.

Tamworth.-The origin of this breed is more or less obscure. It probably originated in the counties of Stafford, Leicester, Northampton and Warwick, in England, and possibly the Irish Grazier in Ireland may have played some part in its development. The foundaticn stock used is likewise unknown, but it was probably principally Old English stock on which some Berkshire, Irish Grazier, and some White and Neapolitan stock were used. The name comes from Tamworth, a borough on the borders of Stafford and Warwickshire, in England. The early type did not differ materially from the present day type, having long legs and snout, narrow body, a slow-maturing capacity, with great constitution and activity, which combined to make it an excellent grazer. It was a farmer's hog and was improved largely by 
farmers. The first importation of the breed was made in 1882 by Thomas Bennett of Illinois.

The Tamworth has a striking appearance, with a long head, body and legs. The snout is, as a rule, noticeably long and narrow. The ears are large and crect. The back is narrow and the hams deficient. Some individuals

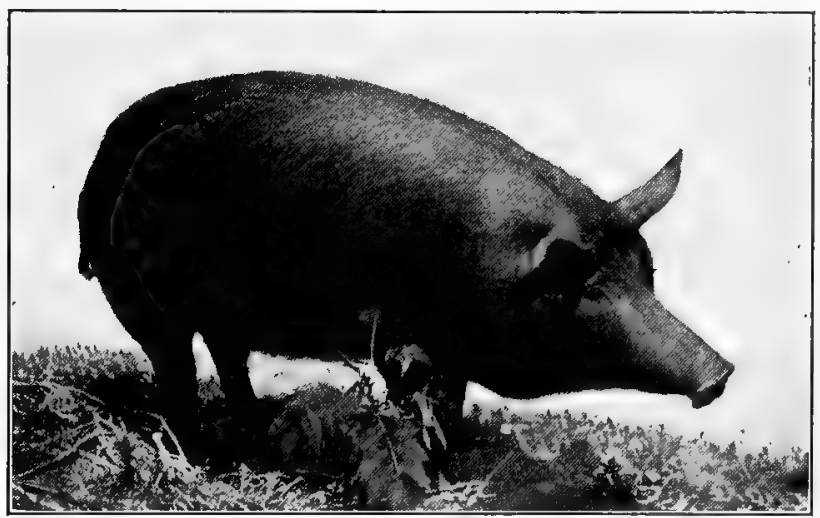

Louisiana bred Tamworth sow. Courtesy B. M. Jackson.

represent the extreme bacon type. The color is red, generally a sandy red, and usually is not as bright as the Duroc color. Some individuals attain great weight, and the breed is a large one. The mature boars will average around 500 pounds and the sows around 400 to 450 .

The breed is not so well adapted to southern conditions where modern methods are used. It is a breed that will stand much abuse and is, therefore, suited to conditions where the hogs must range over a wide territory for their food supply. It is a slow-maturing animal, but as a grazer it ranks high. As a feeder and fattener it is only medium, for it has never been developed to the extremes 
along these lines, as have some of the other breeds. The quality of the meat produced is excellent. As an animal for crossing with other stock it is excellent where certain rustling qualities are desired, and the boars will usually be found quite prepotent in stamping their type.

The breed is pretty widely distributed orer the South, but the numbers are comparatively few. It seldom meets with much popularity on account of its unattractive appearance. It yet remains to be seen how nearly it meets our requirements. The American Tamworth Swine Record Association (1897), E. N. Ball, Secretary, Ann Arbor, Mich., looks after the registrations and general interests of the breed.

The Victoria.-Two strains of this breed were produced, one by Col. F. D. Curtis in Saratoga County, N.Y., and the other by Geo. F. Davis of Dyer, Ind. The sow, Queen Victoria, was one of the early notables of the breed. In many respects they resemble the Middle Yorkshire, the face having a medium dish, with the ears small and erect, and of medium lard type. They are white in color, in size they are medium, and mature boars will average about 500 pounds, and the sows about 100 pounds less. They are, as a rule, not well adapted to southern conditions on account of their color, and there are but very few in the South. The registrations are handled and the interests of the breed looked after by the Victoria Swine Breeders' Association, which was organized in 1886.

The Large Black hog.-A breed of swine that has come into prominence in recent years that may play a role in southern swine husbandry is the Large Black pig from 
England. The popularity of this brecd is increasing. The origin is obscure, but it has been developed in the east and the south of England. The breed is large, as the name implies; the bodies are long and of bacon tendencies, with a general coarseness of all parts, especially of the head, which has a long, pendent ear. The individuals of this breed are good feeders and do well under conditions of adverse food supply, especially where the food is obtained by considerable effort. The breed is quite prolific, and litters usually average between 10 and 12 . The interests of the breed in this country are looked after by the American Large Black Pig Society, Lexington, Ky., of which Mr. J. F. Cook is Secretary.

Big Guinea hogs.-This is the only breed of hogs that can be classed as strictly southern. It originated in the South. Forty or 50 years ago it was quite popular. While this was a distinct breed, no attempt has been made to record them and keep them pure. They have been kept pure only in a few places. The origin of the breed is more or less obscure, but the Essex is reputed to have had a part in their improvement. They also show evidences of Berkshire blood. In color they are either solid black or else black and white spotted, like the spotted Poland-China. The ears are short and thin and stand erect; they have a nose of medium length, which is straight; the body is only average in dimensions; the hair is thin and sometimes wavy; they are characteristically short of leg and at first glance they appear dumpy; they rank intermediate in type, and are reputed to have a high dressing percentage, yielding a pork of high quality. 
The individuals of the breed seem to do well on rather limited feed supply, and having been bred along grazing lines they are to be classed as excellent grazers. They

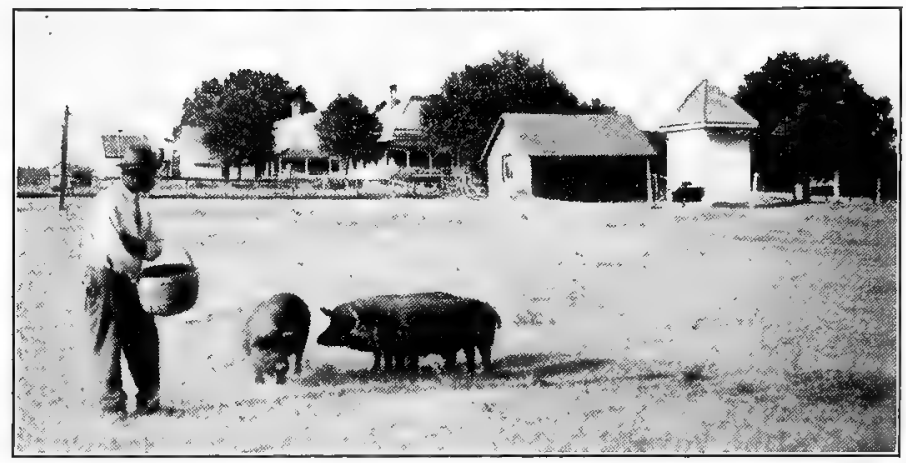

Big Guinea swine on Willow Dale Farm, Mayfield, Ga.

have an advantage in the shortness of leg in that a comparatively low fence will retain them. While the pigs grow off at a fairly rapid rate, the mature individuals of the breed do not attain a large size. The mature sows weigh from 200 to 250 pounds, and the boars from 250 to 300 pounds. They are only fairly prolific, averaging from six to ten pigs a litter. Their distribution has been confined chiefly to the southern states east of the Mississippi River, although a few have been taken into Arkansas and other southwestern states. As to just what part these hogs will play in the future swine industry of the South it is difficult to state. They have certainly declined in numbers and popularity for several years, but just at the present time considerably more interest is being manifested in them. 
The best breed.-There are 20 or 30 different breeds of swine. Each of these is claimed to be the best by its supporters. Strictly speaking, from a market standpoint, this matter of breed is of but little consequence. Swine are intended for the production of pork, and on the market we find that they are bought and sold strictly upon the basis of their pork-producing capacitics. The prices do not vary according to the breed, but according to condition and quality. What one wants, therefore, are breeding animals that will produce individuals which will economically grow into pork. The principal considerations are, therefore, the selection of those animals regardless of particular characteristics of some particular breed, but emphasizing those points that make the animal a more economical producer of pork.

The question is frequently asked as to which is the best breed of hogs. There is no best breed for all conditions of soil, climate and food supply. The breeds have their adaptabilities, and one might succced admirably where others would fail utterly. For the most part, however, the selection of breed will be a matter of taste. The special advantage and qualifications of each breed should be carefully weighed before a final decision is made.

The selection of a breed.-In selecting a brecd to use, the preferences of the breeder should have considerable weight. The personal interest and belief in a breed has a great deal to do with success. As a matter of fact, numerous experiments at various experiment stations have shown that no one breed is always superior to the other breeds. The only exception to this is that in Canada the Berkshires excelled the other breeds in a noticeable number of instances. Generally it is better to select the 
breed most raised in the neighborhood, as it gives an opportunity for co-operation with neighbors, and is apt to result in better prices and greater interest. It is important to select a breed adapted to the particular farm or neighborhood, with special reference to pasture and feed supply. In the selection of a breed for average southern conditions there are several considerations that can be generally observed. First, white breeds should be avoided to a limited extent at least. Then those breeds that are of the extreme lard or extreme bacon type should be avoided. This means that a black or red breed of a rather intermediate type would be best suited to average southern conditions, and as it happens such is the case.

The type of hog best suited to southern conditions is a semi-grazer type, such as the type approached by the English Berkshire and some other breeds. All of our present breeds have been developed, for the most part, to consume large quantities of concentrated grains. What is needed is a type adapted to the consumption of large quantities of green forage and crops such as we can easily raise and such as can be harvested by the hogs themselves. It is a fact that something a little more specialized than what we now have is needed, but we should adapt one of our present breeds to meet the new conditions. We want a hog with a larger stomach than the present types have, a more active hog, and one that is strong in bone and that stands up well on its pasterns, and one that is able to search out a living, even though it may be difficult to find. Some of our native swine possess this latter characteristic to a marked degree, but there are other improvements that our native swine do not possess that we desire. 
Registration of swine.-Every breeder of pure-bred swine that expects to sell registered stock for breeding purposes will find it necessary to keep his animals registered up. It is a simple matter, but one that is often neglected because of the fear of inability to make out the application papers correctly. The registering of pigs is often neglected, and later one finds it impossible to trace animals and have them recorded. The result is that many animals have been sold as pure bred, eligible to registry, for which it has been impossible to trace the pedigree. One, in purchasing, is therefore forced to assume that all animals, especially the older animals, are not pure bred unless the breeding certificates accompany them. The breeder should keep all breeding animals recorded up to date, and when pigs are sold the papers should be secured at once and forwarded, or if they have already been secured, they should be transferred at once to the new owner. When one has pigs to register he should write to the secretary of the association in which the sire and dam are recorded, and he will send the blanks and instructions required to be filled out before pigs can be registered. These application blanks are filled out, and a fee per head is generally charged, which is to cover the costs of registering the animals and maintaining the association.

Practically every breed has an association that looks after the registrations, and some breeds have several. The matter of keeping up the registrations is one that the breeder of pure-bred swine cannot afford to neglect.

Purpose of record associations.-The work of the swine record associations is classified under two heads. The first of these is the record work, and the second is the exploitation work. The first of these is of the greatest 
importance, since it has to do with the improvement and preservation of the purity of the breed. The success of all swine breeders, whether breeders of purc-bred swine or producers of pork, is dependent to a greater or lesser degree on the swine record associations. Were it not for our record associations our present perfection would soon be lost and largely absorbed by the abundance of unimproved swine. The recording work of the associations becomes all the more important as the number of individuals in the breed increases. These swine breeders' associations are generally officered by men who have attained more or less distinction in some way in connection with the breed they serve. Stability and perfection in organization are two important essentials for complete success of the swine record associations.

Exploitation work of record associations.-Aside from the work and good the swine record associations do in keeping the records of breeding, they should advance the interests of the breed they record in every way possible. Above all, they should encourage perfection and improvement in the individuals of their breed.

Swine shows create a desire for better stock, but they fail to show wherein one can profit by the adoption of the pure breds or improved types instead of the unimproved scrubs. The farmer must be able to see the economic value of making any change before he makes it. One way in which this can be encouraged is for a method to be devised whereby the reasons for making awards in the show ring can be explained. The judges, and others, sometimes try to supply this much nceded information, but the record associations should also strive to show the advantages of the pure bred over the scrub. The breed- 
ers must be encouraged and reccive appreciation of their accomplishments.

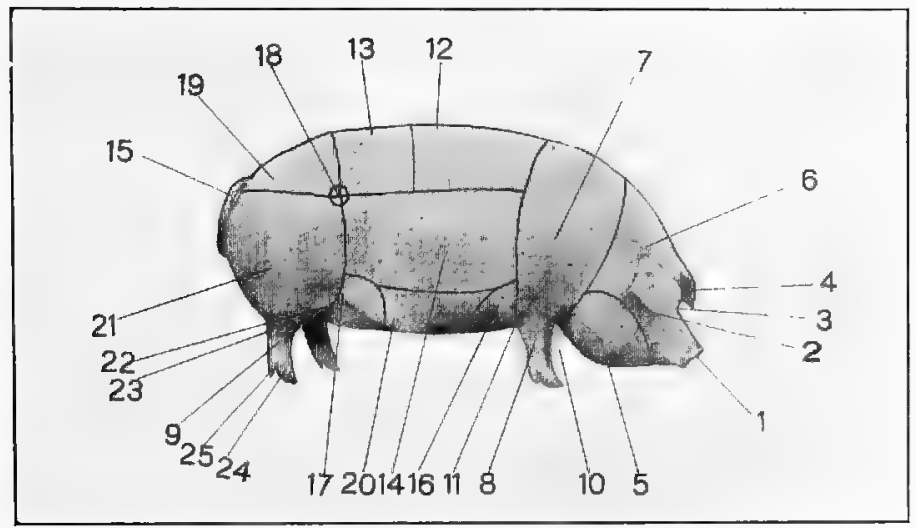

Points of the hog.

$\begin{array}{lll}\text { 1-Snout } & \text { 10-Chest } & \text { 18-Point of hip } \\ \text { 2-Eye } & \text { 11-Heart girth } & \text { 19-Rump } \\ \text { 3-Face } & \text { 12-Back } & \text { 20-Belly } \\ \text { 4-Ear } & \text { 13-Loin } & \text { 21-Ham } \\ \text { 5-Jowl } & \text { 14-Side } & \text { 22-Stifle joint } \\ \text { 6-Neck } & \text { 15-Tail } & \text { 23-Hock } \\ \text { 7-Shoulder } & \text { 16-Front flank } & \text { 24-Foot } \\ \text { 8-Front leg } & \text { 17-Rear flank } & \text { 25-Dew-claws } \\ \text { 9-Hind leg } & & \end{array}$




\section{CHAPTER IV \\ JUDGING SWINE}

Judging swine.-The judging of swine is the exercising of the ability to distinguish between the respective merits of swine intended for special purposes. The standards for comparison are ideals. A good judge of swine must possess a clear conception of what constitutes an ideal. When a pen of swine is placed before him to be judged he nuust be able to recognize values. Especially must a judge stick to his ideal type and have the conviction of his judgment to enable him to stand by his decision. As a rule, the judging of swine is best learned by association with a good judge. The judge should be encouraged to discuss the various points of the hogs being judged in order to illustrate the standards of perfection he employs. If, in addition to this, one can become familiar with a good herd, the standard types may be more readily fixed in mind. It is not often that the same person can become a good judge of several breeds, but almost anyone may become a fair judge of swine in a general way after a short time of practice and application.

In the main, we judge hogs on three bases. The first of these is the market hog basis, in which pork is the direct object sought. In the second place, we judge for breeding purposes, in which the production of swine for slaughter is the ultimate object; we sometimes judge on the feeding or stock hog basis. Since at the bases of all swine judging is ultimate slaughter, we may well say that the second and third bases of judging are merely exten- 
sions of the first, and that the all-important point to bear in mind is the ideal market type hog.

Producer's ideal.-In order to more intelligently and profitably carry out the business of pork production, one should know the demands of the market. He should have firmly fixed in his mind the ideal market hog. The producer or feeder must see the finished product in his mind before the animal is finished, or he will never be able to attain the ideal. To appreciate and understand what constitutes the ideal market hog, one should go to the market and study the several market types in detail and learn which types are in greatest demand. The best swine shows should be attended and special study should be made of the prize winners. Of course, the demands on different markets differ, but in general the ideal market type is similar, and one should learn this ideal and attempt to produce it in order that the swine he produces may bring the highest market price.

Classification.-As a general rule, hogs fall into one of two classes. Most of the swine in the South are what are known as the lard or fat hog type. Contrasted with this is the bacon type, that is used primarily in the production of bacon. The two types are of different conformation. The lard type is the type that has been largely developed in the Corn Belt. On the market hogs of the lard type go for the production of lard, cheap side meat, some bacon, hams and shoulders. The bacon types of hogs furnish bacon as their principal cuts, although they also furnish hams and shoulders. The type of hog best suited for the South is not the extreme lard type, but is an intermediate between the lard and bacon types, a type that is a good 
grazer and that can gather its own living, and yet one that makes good use of the feed allowed it. Fundamentally, the requirements in judging the two types of hogs are the same, and we shall therefore largely discuss the subject of judging from the standpoint of the ideal market type. To facilitate this study and the judging of swine a score card has been developed to cover the ideal market type.

Method in judging.-One cannot become an expert judge of swine without considerable training. It is true that to some the matter of judging is casier than to others. However, in order to make accurate observations and become expert in the placing of swine, it is necessary that one use some method or system in ascertaining the relative merits of the animals being judged. Above all, the judge must know what constitutes the ideal type. Probably the best way to fix this in mind is by means of the score card. The score card should be used freely, especially by the beginner. Later on, as one becomes more expert, he can go through the process of scoring in his mind, and then later make the placings according to the mental scores. A good plan to follow is to take up first the matter of general appearance, under which weight, form, condition and quality should each be given consideration. Then the several parts of the head and neck should be looked over, followed by an examination of the forequarters, body, and last by the hindquarters. The ease, facility and accuracy with which the animals can be correctly placed will depend on the skill and expertness of the judge.

Pork type.-In conformation the ideal market hog and the ideal pork animal are identical. The general expres- 


\section{SCORE CARD}

\section{MARKET HOGS}

GENERAT APPEARANCE-30 per cent

Standard Actual

Weight-According to age_-_...- 4

Form-Medium depth, breadth and length; smooth, compact and symmetrical; standing squarely on short legs......................

Quality-Hair smooth and fine, with strong, clean bone; general refinement.

Condition-Finished, deep, even covering of firm flesh. Free from wrinkles.

Temperament_Quiet and placid

Constitution--Showing indications of having been a profitable feeder and now in a healthy condition

HEAD AND NECK-6 per cent

Snout_Medium length and breadth

Eyes-Clear and not sunken

Face_Short, with full cheeks.

Ears-Merlium sized and neatly attached

Jowl-Full but neat_.

Neck-Thick and short, smoothly blended to shoulder

FOREQUARTERS-12 per cen

Shoulders-Smooth and compact on top, with medium breadth and depth.

Breast - Full breadth but neat

Legs-Straight, short, strong, standing up well on short pasterns

\section{BODY-34 per cent}

Chest-Deep, wide, large heart girth

Sides-Deep, full, smooth, medium length

Back-Broad, strong, evenly covered-_._-

Loin-Wide, thick and strong

Belly-Straight, smooth, trim

\section{HINDQUARTERS-18 per cent}

Hips_Broad and smooth.

Rump-Long, level. wide, smooth

Ham-Heavily fleshed, wide, deep and full

Legs-Straight, short, strong, standing up on short pasterns. Bone clean and hard

Bone clean and hard................

Total score 
sion of the animal should be neither active and masculine, nor should it be passive and effeminate, but rather inexpressive and negative, with a tendency toward the passive and lymphatic, characteristic of an unsexed animal. A description of an ideal market or fat hog is given later. Proper conformation is especially important.

Early pork types.-The attainment of great weights seems to have been the chief aim of our earlier producers of pork. This idea was especially fostered in the show ring. Today the market discriminates against the large and excessively fat hog, yet the demand on the part of the average fair visitor is still to see the largest hog. The attainment of these great weights was a little more excusable in the former days of cheap feeds than now, but with the market demands as they are, and with the demand for meats on the farm from small hogs, size is no longer to be given such consideration in the show ring, and the standards will be placed more along utilitarian lines.

The ideal market hog.-The ideal porker fulfills in every detail the requirements of the purpose for which it is to be used in so far as such is possible. In a study of the ideal fat hog we look at his value as an animal designed for use as food, and do not take into account the value of the animal as a breeder, or whether or not the meat he carries was produced at a profit or loss. It is therefore the butcher and consumer of pork that set the standards of the ideal fat hog, but these standards must not be contrary to economical feeding and breeding. What the butcher demands is what should concern us. He demands conformation, quality and finish, a high 
dressing percentage and a high percentage of high-priced cuts. These are vital points with the butcher. If, in addition to the above, the animal possesses quality, the value of the carcass is still more enhanced because

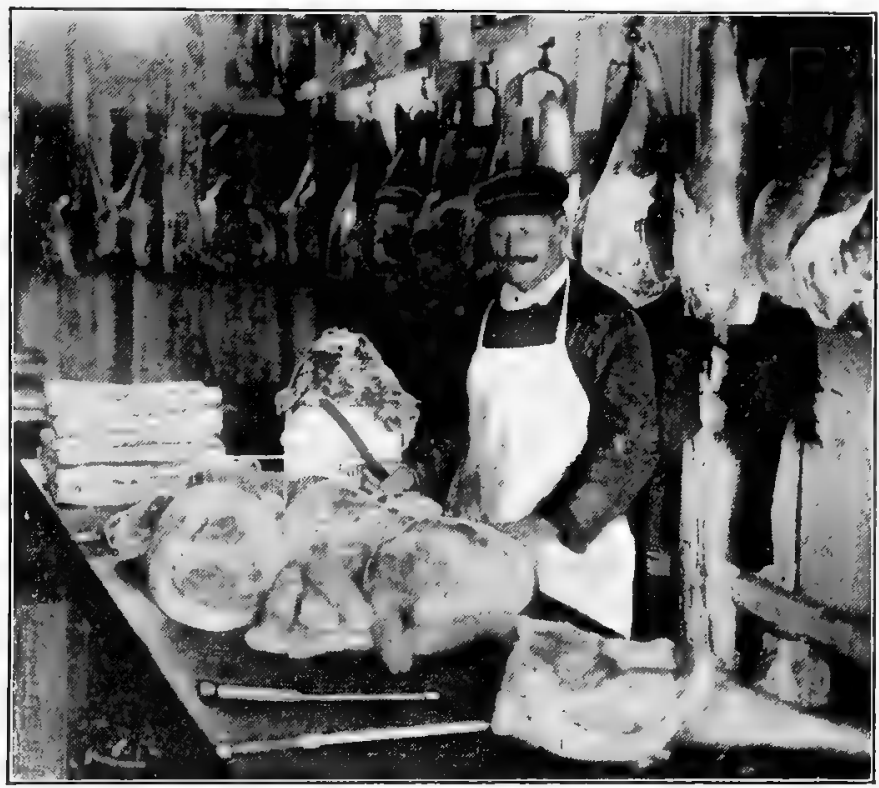

The butcher helps establish the ideal pork type. Courtesy O. F. Troutman of Kentucky.

quality is associated with high dressing per cent and high percentage of high-priced cuts. The butcher demands finish or fat because it also adds to the dressing percentage and increases the percentage of high-priced cuts, for it is mostly in the higher-priced cuts that an excess of fat is deposited. In short, the ideal fat hog is synonymous with the ideal pork type. 
General appearance.-A blocky appearance from every angle should be the first impression gained in the judging of an ideal market animal. From the side view the body is rectangular, with lots of depth and not too much length.

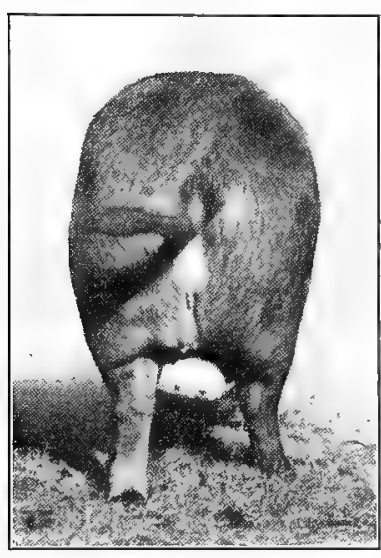

From the rear the fat hog presents a compact appearance. Courtesy B. P. Folk of North Carolina.

The body is wide and set squarely on short, strong legs. There is a general smoothness of outline, with all parts so blending and balanced as to create a symmetrical appearance. The top line, side line and underline are all straight or nearly so, and especially should a straight edge placed along the side of the finished market hog touch at all points between the shoulder and ham, with an absence of wrinkles. In short, the appearance should be such that a maximum of valuable meat is seen with as small amount of waste as is possible.

Weight.-This was formerly a much more important consideration than now. Now the demands of the market and the show standards have so changed that weight in fat hogs is of secondary importance. Naturally, with the required condition, weight will largely take care of itself. For pork type weights between 175 and 200 pounds would be ideal. Weight should always be considered in connection with age, for of two animals weighing the same, and other things being equal, the one 
that is the younger should be given the preference. Fat hogs should never weigh less than a pound for each day of age.

What constitutes form.-A judge of swine must appreciate what constitutes form in swine. When he sees

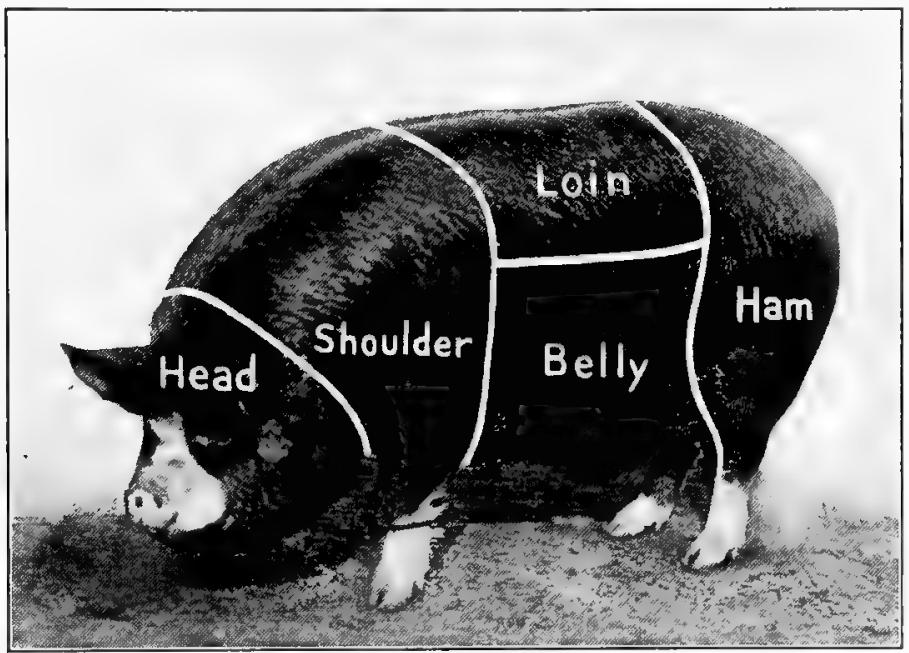

Wholesale cuts marked on Champion Barrow 1913 Internat ${ }_{2}$ or ... Owned by Iowana Farms, Davenport, Iowa.

excessive development in certain parts, he should be able to tell what the development consists of. He must apprcciate to what extent form is due to fat deposition. Individuals and breeds of swine vary greatly in the distribution of fat and lean over the body. In this respect there is a great difference between our improved and unimproved individuals. The unimproved swine are inclined to store fat in those parts where it will be of least value, such as in the body cavity surrounding the several 
organs, while the improved swine are inclined to store it more in those parts where fat has value, such as on the back and hams, and between the muscles. Thus the rotund and smooth form which a market hog takes on when finished is due to a large extent to skeletal and muscular development, but to a greater extent to the deposition of fat over and in the muscles and under the skin. The expert judge can tell by the touch the degree to which excessive development consists of fat and lean development. To do this it is necessary that he understand thoroughly the anatomy of the hog.

The Head of the ideal market hog should be short and broad, with large, bright, clear eyes set wide apart, and with indications of a gentle, passive, lymphatic temperament. The nostrils should be large and open, general features clean cut, indicative of breeding. The wide forehead and heavy jowl, with medium fine ears, are other points to be looked for in the head.

The Neck should be very short, thick and meaty, with a neat blending at the head and shoulders. Long necks are especially undesirable. The arch of the body should continue with the neck in such a manner that the attachment of body and neck is hardly discernible. The jowl should extend from the jaw beneath the entire neck to the shoulder.

The Shoulders should be smooth and rounding on top and evenly covered, blending perfectly with the rest of the body. The tops of the shoulder blades should not be prominent and stand out, but should be nicely rounded over and snug and neat. Rough shoulders constitute one of the most common defects in market hogs, as they tend 
to make the development back of the shoulders appear deficient, and they indicate an excess of bone.

Chest-On the fat hog the development of the chest is of minor consideration from the standpoint of the demands of the butcher. From the standpoint of the producer, this point is of considerable importance. The chest is that part lying between the shoulders and immediately behind them, and it should be very wide and deep. High development of chest is associated with constitution and vigor. A narrow, shallow chest with a small heart girth denotes a lack of constitution, vigor and vitality.

The Back should be wide and smooth, with a slight arch. The back is that part extending from the tops of the shoulder blades to the last rib. It furnishes some high-priced meats and should receive critical consideration. Too much width, due to natural spring of rib and fleshing, is impossible. Deep fleshing is most to be desired. In addition, it is desirable that the back be short, as the tendency with too long a back is to break down in the top-line.

The Ribs should be deep and well covered, with deep, long sides that will cut out a good strip of bacon or fat bellies. With a well-sprung rib, more space is offered for the deposition of high-priced meats.

The Loin is that portion lying between the rear edge of the back and the hams. It has no ribs below it other than the short, floating ribs of the lumbar vertebræ, and it consists largely of heavy muscles, which makes it cut some of the highest-priced meats. Especially should the muscling and fleshing of this part be the heaviest. The 
muscles of this part are used but little, which makes it tender.

The Hams, above all else, should have the maximum of development. They should possess great length, depth and width. The general width of the body should continue into the hams. The depth should continue to

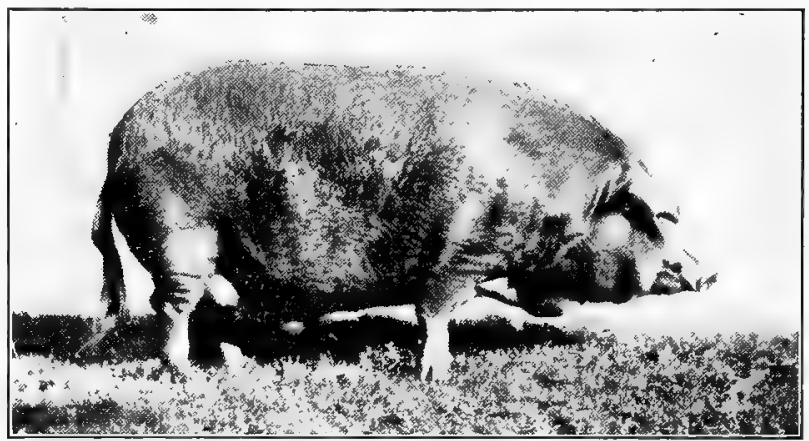

The body of the fat hog is judged largely from the side view. Courtesy B. P. Folk of North Carolina.

the hocks, giving a square appearance there instead of the usual cat-ham effect. By length we refer to the dimensions of the ham lengthwise of the hog's body. Especially is this likely to be deficient in the region of the flank.

The Fect and Legs should be strong enough to maintain the weight of the body; they should be placed squarely on the four corners of the hog's body, and should be straight and short. Fineness of bone and smoothness of joints are indicative of quality, while rough, heavy-boned legs and joints indicate a lack of quality. With hogs that have to graze and make their own living 
there is a strong tendency for them to break down in the pastern joints under market weight. Strong, short, straight pasterns are, therefore, to be sought after.

The Body should be compact, low-set and broad, as this is indicative of a high dressing per cent. Especially is breadth desirable in the upper part of the body, for here the width is due to the development of muscles and to the deposit of fat on the ribs. The top line of the body should be slightly arched. The underline should be nearly straight, and certainly not excessively curred down. The side lines should be such that all points fill out smooth and plump to maintain straight lines all along the sides. The flanks should be well filled out. Paunchiness in particular should be guarded against.

Quality in the fat hog.-Quality and refinement are synonymous. The ideal fat hog will show quality, both externally and internally. It is quality of pork that is sought after, and this cannot be obtained without external quality. In the first place, fineness of bone and indications of a high dressing per cent accompany an animal possessing quality. The quality of the meat the hog carries is indicated by the quality of his bone, by a soft, pliable hide or skin, by the fineness of his bristles, and, above all, by his touch, or the correct feeling of flesh from an external examination. The correct touch is difficult of description, but it should indicate an cren, firm fleshing, with an ample admixture of fat and lean.

Extreme quality undesirable.-Extreme quality and refinement are had only with the sacrifice of constitution and vigor. This condition is frequently met with in our highly bred hogs. The delicacy of make-up in such 
animals greatly reduces their breeding capacities. Especially is size reduced. This condition has been produced by the demand for early-maturing types. The tendency for such animals is to produce fat in abnormal quantities before they have matured their bodies. Quality is, of course, desirable in breeding animals, but we must be careful not to carry it to extremes. We want the maximum of quality so long as it is not obtained at the expense of constitutional vigor and size.

Condition.-One of the most distinguishing characteristics of our present types and breeds of swine is the even and properly mixing of the fat with the lean. A certain amount of fat is most desirable, but an excess production of fat over lean is to be guarded against. Hogs in low condition have a firm, hard feeling along the back and lack in width. As fattening takes place they widen out and become more yielding to the touch. The degree or extent to which the market pork should be fattened will depend to some extent upon the market and to some extent upon the available foodstuff. In the fat hog condition and finish are synonymous. The same degree of condition is not sought in breeding hogs as in fat or market hogs.

Fleshing.-We must make a distinction between condition and fleshing. By condition we refer to the amount of fat the animal carries. By fleshing we refer to the amount of lean meat. The fleshing should be present in abundance and should be placed on smoothly. An evenly fleshed thin hog will fatten smoothly, while an unevenly fleshed thin animal seldom fattens so smoothly. The fleshing is generally indicated by a firm touch along the back, on the sides and on the hams. Heavy, smooth 
fleshing is most desirable, for it indicates a profitable production and is desired by the consumer.

Temperament of market hogs.-Temperament is indicated for the most part by the features of the head. In general, the nose should be short, with width between the ears and eyes, with a full, high forehead, indicative of a well-developed nervous system and strong vitality. The temperament of the younger and unfinished animals had best be of the more active sort, while of the finished and fattened animal it had best be of the passive and lymphatic order. A wide-open, clear, full eye is indicative of the desirable temperament, and a few glances at the head and eye will generally convey to one a fairly accurate measurement of the temperament. The temperament is also indicated by the carriage of the hog in walking or moving about. Excitable and nervous hogs are not desirable, for the quality of meat is apt to be affected.

Style.-Style on a finished hog has a market value, but as a rule it is only in the show ring that it is taken into account. A stylish hog stands squarely on his feet, with a slight arch to his back, with his head in normal position, but with his eyes and ears ready to catch all that goes on. His style is also manifested in the manner in which he handles himself. Such a hog will attract buyers, for he forces his good points to the attention of the buyer.

Constitution.-The hog, whether it be a breeding animal or pork maker, must have constitution and vitality to properly support the digestive and other bodily functionings. The internal organs must have ample room and full development, for they play an important part in 
the transfer and assimilation of nutrients and in the elimination of waste, and the proper exercise of their functions demands a vigorous and strong constitution. Constitution is of no consequence to the butcher, but it is the breeder and feeder that must take it into account. Especially in breeding swine is it of importance, for they must not only provide the needs of their own bodies, but also of their offspring. Constitution is indicated to a large extent by a deep, broad, full body and large heart girth. This allows of ample room for the functioning of the vital organs. The eyes should be full, bright and clear. The bones must not be too fine.

Early maturity.-Early maturity refers to the ability of the animal to fatten sufficiently for marketing at an early age. It is the result of selection over many decades, and most of our improved breeds of swine possess the capacity to a marked degree. The tendency in breeding has been continually toward an earlier maturing type. Formerly hogs were not marketed until one year of age or over. Now they are sent to market at from six to nine months. Indications of early maturity are to be found largely in form and type. General refinement and compactness and ideal pork form are compatible with early maturity. Especially should the heart girth and chest development be ample. Extreme early maturity has a tendency to weaken the constitution.

Character in unsexed swine.-Barrows and spayed sows should attain a certain development of character that is inexpressive of either sex. They should be neither masculine nor feminine. When unsexed the secondary sexual development of either males or females tends 
to approach the same condition. The castrated males become more effeminate and the spayed females more masculine. The ideal pork animal should have an inexpressive character and resigned attitude suggestive that the only purpose for which it existed was the conversion of feed into pork.

Stock hogs.-The selection of stock hogs demands greater skill than the judging of fat swine. The judge of stock hogs must possess a conception of the animal after it has passed through a fattening process. He must not only pick the animals that will finish into the ideal market type, but due consideration must be given to the economy of production. In other words, he must be able to judge the fattening and gaining capacity of the animal. If one has a definite knowledge of the ideal market hog, the selection of stock hogs and the production of the ideal market type is a less complicated matter. In the selection of swine for feeding purposes we should therefore look for indications of thrift and gaining capacity, a strong constitution, quality, breeding, and a disposition consistent with the finishing of the animal into an ideal market animal.

Judging breeding swine.-Basically, the judging of breeding swine and market swine is identical in so far as conformation is concerned. With breeding swine, however, some allowances must be made for condition, but with a lack of condition there must be indications of early maturity and ample feeding capacity. In breeding swine there are, in addition to the above, certain things directly related to breeding capacity which must be doubly emphasized. Constitutional vigor and sexuality are of 
greatest importance. In the judging of breeding swine the fact should ever be borne in mind that it is desired that the offspring of the swine being judged are to be made into perfect ideal fat hogs, and all the character-

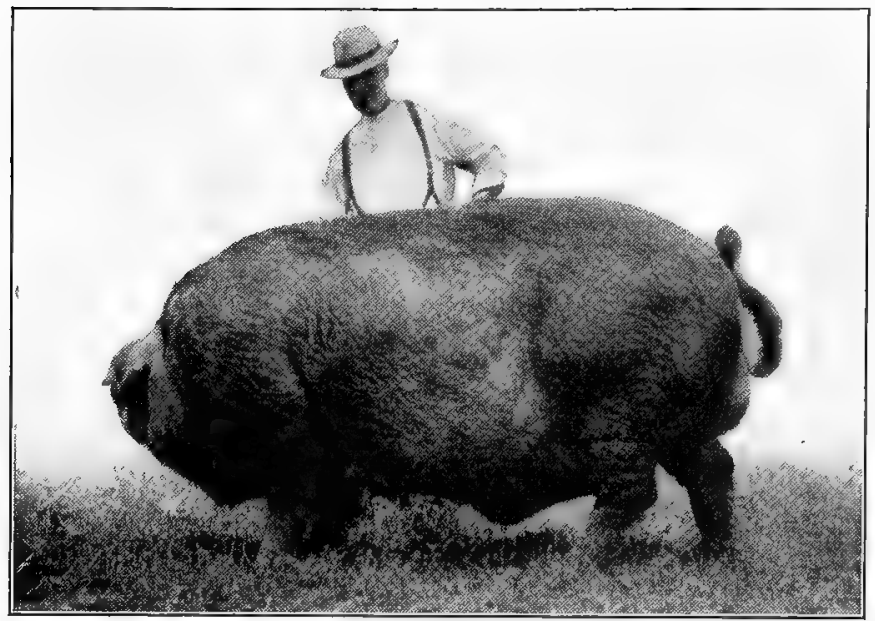

Large type breeding swine are popular in the show ring. Courtesy Chas. J. Tanner of Kentuckyr.

istics of the parents should contribute to this end. Consequently, special emphasis must be placed on size, conformation, feet and legs, quality, sexuality and disposition.

The foundation herd.-It is quite necessary that we have good individuals with which to start our breeding operations because of the inherent tendency of highly bred animals to revert to a poorer type. It is to be assumed that under all conditions only purc-bred toars will be used, and that pure-bred sows may or may not be used, depending on the ultimate objects sought. In either 
case the same precautions must be taken in the selection of the breeding animals. One must not accept an anima! for foundation stock simply because it bears a pedigree. In order not to select a scrub masquerading as a highly bred animal, he must know the true pork type, the ideal market animal. Even then his selections may go amiss, for the animals he selects may not breed true to type. Therefore, when possible, the beginner should use only young, tried animals, even though they may cost a trifle more. A little extra money is always well spent in the purchasing of better foundation stock.

Cost of breeding swine.-The cost of breeding swine scems almost prohibitive, and most of us are tempted to use scrub and unimproved animals with the hopes of improving them. This is not only true of the sows, but it is also frequently true of the boars. Most of us do not consider the increased value which a better boar puts on each of his pigs, which will very soon more than cover the small additional price. As a rule, a few extra dollars spent in better blood is well spent; but, of course, when one is spending the few extra dollars for better blood he wants to know that he is getting what is being paid for. One can only know this by becoming a good judge of breeding swine, which means that one must not only be able to recognize type, character and pork qualities in a breeding animal, but must be able to tell within a fair degree of accuracy the kind of offspring that will come from such an animal.

Selecting breeding swine.-Since the ultimate use of breeding swine is the production of ideal porkers, their selections should be made with this in view. Quick 
maturity and evidences of profitableness should be given consideration. In order to be profitable they must of necessity be in possession of a vigorous constitution. They must possess breed characteristics and breediness, or sex character. In addition to a deep, natural flesh and compact form, they must be possessed of reproductive ability and be capable of producing their like.

Purchasing breeders.-After the selection of the breeding herd from which it seems desirable to make some purchases, one should, if possible, visit the herd and carefully inspect the animals offered for sale, and find out what he can of their type and ancestry. He should then make his selections, being guided by the purposes for which the animals are desired, by individual preferences and by the information furnished by the breeder. An honest breeder will not misrepresent his stock in order to make a sale. Under no circumstances should a slight difference in price influence the purchaser to buy inferior animals, for it has been demonstrated time and again that it pays to use only the best in starting a breeding herd of pure-bred swine.

How to make selections.-While we can select for conformation, type and early maturity, we must also base our selections on performance, or the ability to make good use of feed and rapid gains up to the limit of the capacity of the animal. In the case of swine greater skill is required to select for performance than in the case of some other animals. In race horses, for instance, where all is sacrificed for speed, the matter of selection on the performance basis is a simple matter. With swine in the feed lot, the closest observation and the exercise of the 
greatest skill are required. The show yards and sale rings assist some in the making of these sclections, but for the most part the breeder will have to depend on his own observation and judgment.

Age of breeding swine.-In the selecting and purchasing of swine for breeding purposes there are in the main two methods that can be employed so far as age is concerned. The first is to purchase young animals and grow them to maturity, and the other is to purchase older animals that have been used for breeding purposes. The first of these methods is frequently the most economical method of purchasing, but one's expectations are not always fulfilled, and the animals may not develop as they should. The second method has the advantage of being a little surcr, which in the long run may be the best policy. In selecting older animals one must be careful to get breeding animals that have been merely tried out and have not been worn out through several seasons of breeding. The most profitable ages are between two and seven years for either sex.

Mature breeding swine.-The reproductive functions of swine are not fully developed until about the time the individual begins to mature. The sexual organs and instinct develop rapidly as maturity approaches, and we say the breeding age has arrived. Gilts generally arrive at this age a month earlier than males. The age at which the breeding powers become manifested depends on breed, method of handling, feeding and sex. With the gilt the first period is co-existent with the bursting of the Graffian follicle and liberation of the first ova. With the male the arrival at breeding age is a more gradual 
process. By no means should swine be permitted to cxercise their breeding powers as soon as they are manifested. Gilts should not be bred before they are eight months of age, for before that time they have not reached the age of sufficicnt sexual maturity, and the age of somatic maturity is not reached for some months after this age. Boars should likewise not be used to any extent before this age, and they should then be used only very lightly until after they are one year of age.

Early maturity in breeding swine.-In the selection of our boars and sows the early-maturing qualities must be sought so that they can be transmitted to the offspring, for it is of the greatest importance from the standpoint of the grower and butcher that the hogs mature and fatten at the earliest possible age. Especially should boars be selected largely on the basis of their early fattening propensities.

Conformation.-The conformation of breeding swine must therefore be similar to that of the ideal pork animal, and must give the indications of being able to produce the ideal market animal, either through feeding or through a process of reproduction and feeding. To be sure, the condition of breeding swine and the ideal markct animal are different. In the conformation of the breeding swine, as compared with the ideal porker, there are other considerations. In the breeding animals $\mathrm{sex}$ character will cause variations in boars and sows that will not be found in the ideal market animal. The body of the sow will be longer, with a greater development in the hindquarters, and the boar will have a seemingly surplus development of the forequarters, head and neck. 
Weights.-The tendency at present is towards market hogs of medium size. This preference is probably due to the facts that the meat is better and the cost of producing is less than in the large hogs. The production of the second hundred pounds in weight costs much more than the first hundred, and the cost increases with the size. The weights of swine are dependent on so many factors that an approximation of average weights is difficult. The age, feeding, sex, breeding, condition and quality influence the weight. The following table may be considered as average weights under different conditions of feeding and care.

\begin{tabular}{|c|c|c|c|}
\hline & 6 months & 12 months & 18 months \\
\hline 1. Roughed & -100 & 200 & 275 \\
\hline fed & $-\quad 200$ & 350 & 450 \\
\hline 3. Full fed & -250 & 450 & 550 \\
\hline 4. Show fed & -300 & 500 & 600 \\
\hline
\end{tabular}

A good standard for mature boars in breeding condition is from 450 to 500 pounds, and for sows from 75 to 100 pounds less than the boars.

Variation in weight.-While we have certain standards of weight according to age, there are other factors, such as breed and sex, that play a part. The more common breeds will rank in size in about the following order, from the heavier to the lighter breeds: Large Yorkshire, Chester White, Duroc-Jersey, Tamworth, Poland-China, Berkshire, Hampshire, Middle Yorkshire, Essex, and Small Yorkshire. The boars generally weigh from onesixth to one-quarter more than the sows. Swine are usually nearly mature at two years of age, although they will continue to grow some after that age. If slowly fed, they may take as much as four years in which to mature. 
Condition of breeding swine.-High condition is incompatible with the best results in breeding. In general, the breeding animals should possess an abundance of natural fleshing rather than high condition. Under no circumstances should they be excessively fat, nor should they be excessively lean. Show animals in show condition are nearly always below par in breeding capacity. Especially is high condition to be guarded against in the sow, as an excess of internal fat is apt to result in crowding these organs and shutting off the normal blood supply, preventing normal functioning. Also, high condition causes a lymphatic disposition, which is not conducive to the most desirable breeding qualities. Especially is this true of boars, and they should never be fattened to the point where they become sluggish and inactive.

Size and vigor.-In the selection of swine for breeding purposes size and vigor are vital points to be considered, as they largely control heavy and economical gains. Vigor is especially to be desired to conform to our grazing methods. Vigorous hogs are also less subject to parasites and diseases in general. As to size, what is wanted is not a large animal, but we do want a large one for its age, for this indicates early maturity and economical production. We can only have earlymaturing animals when they have proper vigor and vitality. Thus, size and vigor are of importance from the standpoint of economical production, and these qualities must be taken into account in the selection of our breeding animals in the future if we are to secure hogs best suited to our conditions. 
Importance of strong bone.-In our judging and selcction of breeding swine greater attention will have to be given to strength and quality of bone than has been given in the past. This comes from a changed method of production, in which we will no longer do extensive lot feeding, but will produce our pork by means of grazing crops. It is not so much a great size of bone that is desired as moderate size with quality. Too much size without quality would not be desirable from the standpoint of the butcher. A strong bone is wanted to support the weight of the animal in the larger amount of walking that will have to be done in the gathering of its food supply.

Vitality and prolificacy.-In a herd of breeding swine vitality and prolificacy are of considerable importance, and on them to a large extent depends the outcome. Care and attention are continually required to maintain the required vitality and prolificacy, and under the conditions with which we surround most of our pure-bred herds there is a strong tendency toward over-refinement. This lack of vitality and prolificacy is not so noticeable in the body form as in the weakened breeding powers manifested. In the sows, with a lack of these qualities we have irregular and abortive breeders, lessened fecundity, and low milk secretion. These weaknesses seem to accentuate themselves as they go from one generation to the next, but fortunately they are ultimately automatically eliminated.

Breed type.-All our breeding swine should possess some breed type, whether the object is pork production or the production of breeding animals. By breed type we 
refer to the indications that the individual belongs to a specific breed, or, that the blood of a specific breed predominates. The possession of this breed type is a good indication of prepotency. Any pork animal should possess these indications for at least one of the improved breeds; otherwise, it may safely be assumed that a poor pork type exists, for a good pork type seldom exists without breed type. Especially should breeding swine be typical and characteristic as to breed type.

Prepotency.--Prepotency refers to the ability of breeding animals to impress their own likeness upon their offspring. While it is not definitely recognizable from the appearance, it should be one of the distinctive characteristics of good breeding animals. An animal with proper sexual development, breed type and breeding is very apt to be prepotent. When two animals are crossed, the one that impresses its kind more strongly on the offspring is said to be more prepotent. Prepotency is one of the bases of our progress in improvement in swine breeding. Breeding animals that are not prepotent are said to be impotent, or, in other words, they are not able to stamp their type.

Quality in breeding swine.-Good quality is especially evidenced by ability to make good use of feed. Other indications of quality are to be found in the bone, bristle and hide. Usually the hog of good quality makes a good appearance, and by his smooth skin, bright eye and general disposition makes a good impression. In addition to being masculine, our breeding boars should possess a certain degree of quality. His features should be clear cut and symmetrical, showing strength and character 
without coarseness. The breed characteristics should be pronounced. The sow likewise should be more than effeminate. She should be in possession of the quality that is necessary in the make-up of a perfect brood sow. She should show general refinement and symmetrical and clear-cut features, combined with proper breed characteristics. Quality and breed character go hand in hand. 


\section{CHAPTER V \\ SHOWING SWINE}

The show ring.-There is probably no other single institution connected with the swine industry that has made for more real progress than the show ring. Without it our present day swine would have presented nothing like the uniformity of type and general perfection which they now possess. The show ring has been the guiding star for the breeders of pure-bred swine and to the producers of market swine to a less degree. The producer of market hogs can get much from the market as to the demands and standards of the times, but the breeder of pure-bred swine must rely on the show ring. It has been the show rings that have made the standards of perfection toward which we have been striving. They tended to standardize and systematize the goal of perfection toward which all breeders have been striving, which has been largely responsible for the progress that has been attained. The show ring has given the individual breeders an insight into what the best swine judges have considered the ideal types. In addition, the friendly rivalry of the show ring has been a great stimulus in bringing about the production of continually better individuals. The sporting instinct of man has been aroused by the competition in the show ring. All in all, the show ring has been a wonderful stimulus for the good of swine breeding, and it is to be hoped that more and more of the small breeders can utilize this institution in the interests of their work. 
Advertising.-One of the chief advantages to be derived from the showing of swine is the advertising that is secured. If the breeder properly fits and shows his products, he will have no difficulty in placing his animals before the public in a way that will be a credit to himself and the herd. The great advantage of this method of advertising is that if we are breeding swine of sufficient merit to win they receive a stamp of approval from the judge. This is one of the cheapest ways we have to do

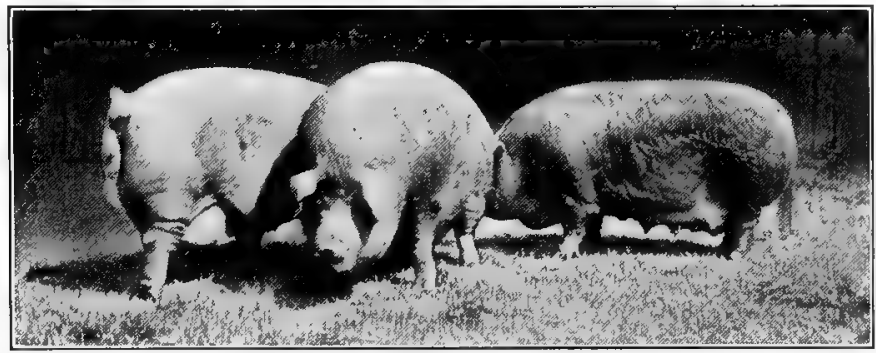

Mississippi State Fair Grand Champion sows of 1915, owned by $\mathrm{E}$. J. McCall of Louisiana.

our advertising, for when the animals really possess merit the winnings or prize money will more than offset the expenses attached to the showing. In the past the value of the live stock show as an advertising method has not been recognized as fully as it deserved. If animals really possess merit, they always sell for more if they have winnings back of them, and nothing adds to the value of an animal any quicker than to have won over hot competition at one of the better live stock shows.

Reputation.-One's reputation as a breeder depends to a large extent upon the show ring winnings he has made with animals of his own breeding. This is one of the 
chief advantages to be derived by the swine breeder from the show ring. Aside from the advertising which his herd and animals receive, his reputation as a breeder is at stake, as it were, and the show ring offers an opportunity which cannot well be ignored by one who wishes to make his reputation as a breeder of the most approved types. A reputation built on attainments in the show ring is a lasting one if attained honestly. It has an immense monetary value to the swine breeder if properly utilized.

Educational value of the show.-In addition to the reputation and advertising to be gained by showing the products of one's efforts at breeding, there are other advantages to be derived. One's general store of knowledge is added to along the line of swine breeding, because he cannot associate with other breeders without absorbing valuable information from them. He sees what others are doing, and he is thereby enabled to conduct his own operations more advantageously. This educational feature of the show ring is one of the most important; it lights the way, so to speak; standards are set; friendly rivalries stimulate one to greater accomplishments, and one becomes educated as to what is expected of a swine breeder and as to how best go about the production of an ideal.

Show ring standards.-The question sometimes arises in the show ring as to where we are to go to secure our standards in making awards. It is very obvious that since we are producing something to mect the discriminating demands of the market, we should go there to seek our standards. That has been one great difficulty 
we have had in the past. We have failed in a great many instances to secure judges who were familiar with the demands of the markets for which they were making awards. The judge should be absolutely familiar with what the market demands and is willing to pay the most for. The markets are constantly changing in what they demand, because the pork-producing industry is evoluting. The evoluting process is slow because our herds cannot be changed on short order. If we are to make progress in breeding, we must depend on the awards of judges to show what the market demands, and thus the responsibility resting on a judge in the show ring is much greater than we might consider on first thought.

The profitable type.-The hogs that are fitted for show are not necessarily the ideal farm type. They usually carry such an excess of fat as to preclude profits from their production. They do show, however, the type that is desired, for they could never attain the condition they carry were they not of the proper type. Therefore, we may with safety depend on the show ring to indicate the most desirable types for farm use. Especially does the show ring point out to us those types which fatten most readily and mature at an early age. In farm practice the hogs we grow for the market must be able to develop and grow rapidly from the start and be susceptible to fattening at almost any age.

Important shows.-There are numerous swine shows held over the South, and some of them rank well with the shows held farther north in what has been considered the swine belt proper. Of course, the better the show which one attends, or at which one shows, the greater are to be 
the rewards in case of winning. Some county and local fairs offer small premiums, and where the interest and competition are sufficient a great deal of good can be derived from showing at and attending these local fairs. The state fairs are, however, better in that they cover a broader field and give one more of a real insight into the use and value of the show ring. Every southern state has its state fairs, and some have more than one. In addition to these state fairs there are other fairs of a wider scope, such as the Feeders' and Breeders' Show, which is held at Fort Worth, Tex.; the Southeastern Fair that is held in Atlanta, Ga.; the Tri-State Fair, held at Memphis, Tenn.; the Alabama-Mississippi Fair, held at Birmingham; and similar fairs that offer exceptional opportunities for southern breeders to obtain the advantages to be derived from use of the show ring; and all breeders should attend one or more of the best of these shows, whether they show or not.

Making entries.-In order that one may show an animal in one of the better classes of shows it is generally necessary that entry blanks of the proper sort be filled out. These blanks are usually furnished free by the secretary of the fair association. On them is a place for the name of the animal, its date of birth, breed, registration number, the class in which it is desired to show it, and other spaces to supply whatever other information is needed. In the entering of animals it is generally possible to enter them in several competitions. When an animal really possesses merit and stands a chance of winning in more than one class, it is best to make the entry that way where permissible. Prize money sometimes comes easier than it looks, and with good indi- 
viduals and where the competition is not too great, one can reasonably expect the prize money to pay the expenses incidental to fitting and showing. Some breeders esteem the show ring so greatly that they will have out as many as three or four herds, that will remain out an entire season, going from one fair to another. In the making of entries one will be guided to a great extent by the particular show, for each makes its own rules governing exhibits. As a rule, the classification made to cover the different classes that will be shown is arbitrary, but a complete classification for the showing is given as follows. There are but few of the fairs that have all of these classes.

\section{SHOW CLASSES}

BOARS

Aged boars

Senior yearlings

Junior yearlings

Senior boar pigs

Junior boar pigs

Senior Grand

Champion

Junior Champion
Sows

Aged sows

Senior yearlings

Junior yearlings

Senior sow pigs

Junior sow pigs

Senior Grand

Champion

Junior Champion
Herds

Aged herds

Bred by exhibitor

Owned by exhibitor

Young herds

Produce of sow

Get of boar

Litters (4)

Fitting for the show.-In the fitting of swine for the show there is an opportunity for the exercise of great skill. It is well recognized that in order to properly fit swine both skill and experience are necessary. Above all, the feeding must be begun in time. The feeds must not only be of the right sort for the purposes desired, but the animal will require continual watching from start to finish. The feeding must be systematic and judgment must be used. In order to feed properly one must not only have the animals to feed, but he must be supplied with the right sort of feeds and have the right sort of 
equipment, in the way of lots, pens, troughs, sheds, etc. The whole thing resolves itself into the proper feeding and handling of the animal so that it will make use of feed up to the limit of its capacity. In the fitting for the show more is required than to merely attain a certain condition. The hair, skin, feet, disposition and form will have to be carefully watched. To fit swine properly for the show is no simple matter and is one at which great skill can be exercised.

Equipment for show fitting.-Not much equipment is required in fitting swine for show purposes above that which is ordinarily to be had on a hog farm. First, it is necessary to have pigs or hogs of breeding sufficient to make it possible for them to be developed into prize winners. Next, which is equally important, is the supply of the proper kind of feeds. The kind will depend on the kind of hogs to be fed and the length of time the feeding is to take place. After that, some shelter or shed space will have to be available, for show hogs cannot be run in the sunshine and weather to any great extent, as it injures the hair and skin. Also, proper exercising pens or paddocks must be available, these preferably to be sown to grazing crops. In addition to this, a place for washing the hogs, oils, brushes, soaps, straw, crates, troughs, and the like will have to be provided. As stated, most of these can be had on the average farm, and what little extra is required for proper fitting will more than repay for itself.

Feeding for the show.-It is necessary to feed liberally and judiciously when feeding for show purposes. The use of foodstuffs conducive to an excessive production of 


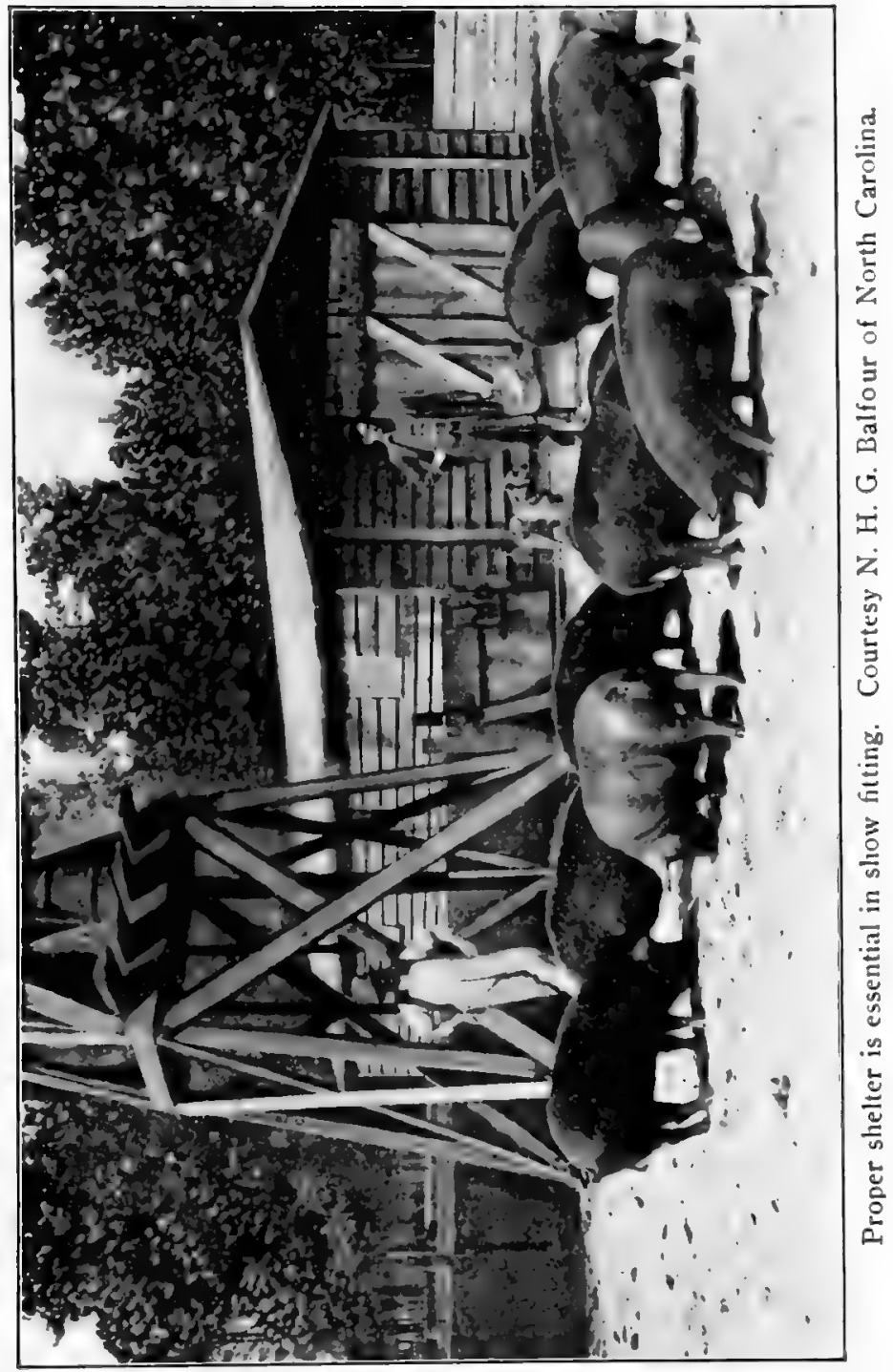


fat should be avoided, since such feeding is apt to result in an abnormal development of fat tissue in comparison with the lean. The distribution of fat and lean in the carcass can be influenced to a limited extent by the method of feeding. Proper covering and firmness of flesh are most desirable. Unnecessary expenses should be avoided. Vermifuges, tonics and appetizers may be used to advantage. The feeding of sugar, molasses, and starch is an expensive procedure that is seldom justifiable. The cooking of feeds is also of questionable value. The employment of some of these and similar methods is sometimes justifiable. Of course, in show fitting one is not justified in figuring too closely on costs of gains, and especially in the case of breeding swine when very high prices may obtain. Linseed meal is a food that we are justified in using in the South in show fitting only. It is very rich in protein and generally contains considerable oil, which is supposed to have a very beneficial influence on the skin and bristle.

Greater skill is required in the proper fitting of breeding swine than fat or market swine. In the fitting of breeding swine considerable exercise must be allowed. The all-important thing is to attain the proper condition for winning in the competition without injuring the breeding qualities. In the fitting of market hogs or fat hogs conformation and condition, combined with the right quality, are all essential. In the case of either class of swine, it must ever be borne in mind that after a hog is once fitted for the show he must not be allowed to decline in condition, for with a decline in condition a certain coarseness of fleshing and bone is brought about that can never be overcome by the most judicious feeding. 
Over-fitting for showing.-Swine that have been fitted ful the shows are nearly always too fat to have been produced at a profit. For this reason the show-yard standards and the commercial standards are not exactly in accord. The quantity and quality of fat usually demanded in the show ring are not only too great to have been produced at a profit, but the show hog is generally in too high a condition to suit the average consumer of pork. In this respect the show yards are inclined to set the wrong example for the grower. Of course, in fitting for the show the matter of cost is secondary, yet if our shows are to serve the purposes they should, more emphasis will have to be placed on whether or not an animal has been profitably produced by its owner, and we shall depend less on the old show standards that have had their origins in conditions different from what exist today in the southern states.

The proper finish.- The proper degree to which to fit show animals will depend on several factors. Different judges have different standards, there are different standards for the different classes, the amount of natural fleshing is a factor, the degree of hardness of the fat is another factor, and the competition that one has to meet is still another. Showmen make a practice of obtaining information in advance, where possible, of the fitness and merits of the animals against which they will have to show. This is not a bad practice. The proper condition to which to finish is difficult to describe. If a market hog, the animal must be finished, yet he must not be overly fat and soft. Breeding animals do not require the condition that is demanded of the fat classes. Under no circumstances must the animals be too soft, and never so fat 
as to be wrinkled. What is desired is a smooth finish in which there is a firmness, indicative of plenty of lean meat. To obtain the desired firmness such feeds as corn and cottonseed meal can be fed to harden the fat. In the breeding classes it is an easy matter to have the animals too fat. The exact condition and fleshing qualities required can only be learned by experience.

Different treatment for different ages.-It must be borne in mind that pigs of different ages will require different feed and attention to be properly fitted. Pigs will require greater attention and care than the older animals. The feeds of the pigs should be more of a nitrogenous nature, and especially should it have bulk. Pigs can be expected to make better use of certain leguminous pastures than the older hogs. They should be fed only a comparatively small amount of corn and such carbonaceous feeds, and greater quantities of skim milk, shorts, and nitrogenous feeds, especially legumes. More corn and other fattening feeds can be fed to older hogs. They are less apt to get out of condition than the pigs. The pigs will usually take sufficient exercise of their own accord, but older animals have to be encouraged to take exercise. All of these natural tendencies exhibited by swine of different ages should be studied and utilized in show fitting.

Securing width.-In the fitting of swine for competition in the fat or market classes some difficulty is generally cxperienced in securing the width that is desired to give the compact and blocky conformation. No two things make more for securing the desired width than breeding of the proper sort and ample food supply from birth. 
The use of bulky feeds during the early life of the pig is especially desirable, since it tends to produce and stimulate growth and general development without excess fattening. Bulky feeds enlarge the digestive organs and promote digestive activities in general. A full stomach and intestines in the show ring does a great deal toward giving the blocky appearance demanded.

Securing proper hair condition.-In order to show to the best advantage, swine intended for show purposes must have a smooth, lustrous coat of hair or bristles. In order to have a good hair coat the animal must be in the best of health, for when an animal gets off feed or in poor physical condition one of the first places that it shows up is in the hair coat and skin. Show fitters resort to several means to secure the condition of hair and skin required. On black hogs lamp black and oils are used to some extent. Rubbing and washing tend to give the coat a luster, and the use of oil dressings of several sorts is resorted to. Frequent washing with soap and water will keep the hogs cool and comfortable and tends to promote hair growth and condition. To obtain the proper condition of the hair and skin is no small matter, yet if one is to show and win in strong competition, we are compelled to resort to such impractical methods in self-defense.

General care previous to showing.-After the proper condition and weight has been secured to fit the hogs for the ring, care must be continually exercised to see that they maintain themselves, or even improve, until they come under the eyes of the judge. One of the main things to watch is to see that they take ample exercise. They should be encouraged to take this in the cool of the day. 
There are several ways in which they can be induced to take exercise, but in doing it care must be taken not to unduly disturb and excite them. In addition to the exercise, the feet must be properly looked after. They may

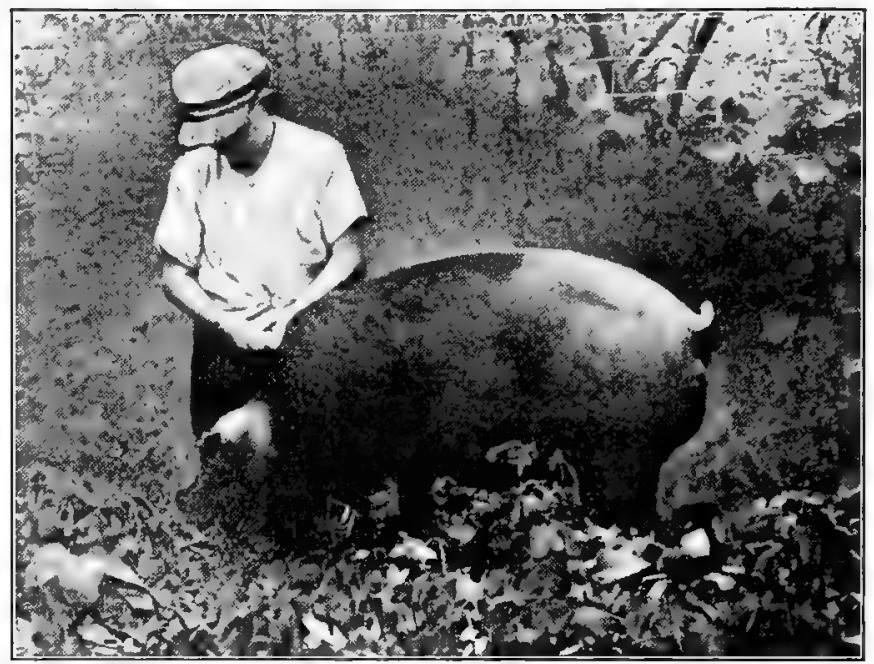

Personal attention is essential in show fitting. Courtesy S. H. Pedrick of Georgia.

need trimming. They should be trimmed if necessary, and sometimes they are sandpapered and polished with emery dust and oil. The hair coat and skin must not be permitted to become rough. Above all, the individuals should be trained so that they will not be wild and excitable, but so that they can be easily handled. Many animals of merit have failed in the show ring because they were not sufficiently docile to be judged properly. Frequent handling and rubbing will make them tame and fit 
them so that they can be shown to the best advantage when they enter the ring.

Equipment for showing.-After the animals have been fitted and the time arrives to take them to the place of showing, there is a certain amount of equipment required in order to carry out the program. First, one needs feeds for the hogs, unless these are supplied by the show association. If taken, the feeds are best taken already mixed in sacks. In addition, some buckets for watering and slopping and some feed troughs will be required. In addition to some crates, some small hurdles will be found useful in handling the hogs. Other accessories, such as bedding, brushes, oil, possibly lamp black or other pigments, hammer, nails, lantern, kerosene can, medicines, etc., will be required. In addition to these items, it is generally customary for the herdsman that attends the hogs to sleep in their vicinity, which calls for a cot and some bedding. A large trunk or two is usually provided, in which to keep the small items that are necessary. All of these things should be provided for. If one expects to attend the shows and show, it does not pay to go half prepared, and it takes preparation in other than properly finished hogs to show and win against the hot competition one finds at the better shows.

Transportation.-After the hogs are finished and all of the herdsman's outfit is prepared, the question of transportation is to be solved. It is generally necessary to make use of the railroads, for but few breeders live close enough to the shows to haul by wagon or truck. As to whether the hogs will be driven or hauled to the car will depend on local conditions. In some instances, where 
the switch is on the farm, or close to it, it may not be necessary to haul. Otherwise, if the distance is too great, the hogs will have to be hauled to the car. The ordinary box car is the most frequently used type of car in transporting the show herd. Other types are sometimes made use of, however. Usually pens have to be constructed in the car. These will have to be bedded. Arrangements must be made for feeding and watering en route. The attendant and his feeds and outfit are usually placed on a platform over the pens, especially if the car is crowded. If only a part of the car is occupied with the hogs, the other part may be utilized by the herdsman and to store feed, bedding and other equipment. Upon arrival at the show yards the hogs should be removed to the assigned pens as soon as possible. Preparations should then be made at once to prepare the animals for the show ring.

Proper showing.--Many animals of superior merit have lost in the show ring because of improper showing. The competition is such in our better shows today that every advantage counts for something. In many cases proper showing has won the blue ribbon, even though a better animal was competing. The herdsman or showman must know and appreciate the particular merits of his entry, and exhibit them to the judge to the best advantage possible. The herdsman should study the judge and learn his strong and weak points and play to them. In the present day of large entries and keen competition, showing is largely a game, and while individual merit counts, proper showing also frequently lands the blue or purple ribbon. 


\section{CHAPTER VI \\ FEEDING SWINE}

The South can grow pork.-The South can never compete with the Corn Belt sections of the North and West in the fattening of pork on corn. By the extensive use of grazing crops we can grow pork of a desirable quality, however, at figures which cannot be equaled under Corn Belt conditions. We should aim to make our hogs only so fat as to make the carcass juicy, palatable and tender. Any fat above this is produced at a loss, for so far as we know eight or ten times the weight of food required to produce a pound of lean is required in the production of a pound of fat. If we must have an extra quantity of lard or fat, we can best afford to import it from the Corn Belt, or, better still, make a more extensive use of our own vegetable fat, cottonseed oil.

The size of native swine.-The smallness of our native unimproved swine, especially of those farther South, is due to the animals not having had a constant and sufficient amount of nutritious food. They are not kept in a healthy and growing condition from the time they are weaned until ready for slaughter. Inbreeding and breeding at too young an age may have reduced the size more, but for the most part the inadequate food supply during winter and early spring has been the chief contributing factor. When ample food is supplied a much larger animal will be produced from this native stock, and the animal will be ready for slaughter at a much earlier age than when raised in the usual manner. 
Our carbohydrate supply.-For many years our investigators in feeding and nutrition have realized that the deficicncy of feeding nutrients in the South was not protein, but was in carbohydrates. This is the reverse of the condition in the Corn Belt, where corn supplies an abundance of carbohydrates and where proteins are naturally scarce. Fortunately, an adequate protein supply is more important than an adequate carbohydrate supply, so that while we have a problem, it cannot be considered with the same gravity as the protein supply of the Corn Belt. We must not feed too narrow a ration and must feed some carbohydrates. Corn will supply some. Sweet potatoes, chufas, molasses, saccharine and non-saccharine sorghums will supply some, and, in addition, legumes and all other feeds contain appreciable quantities of carbohydrates.

Too much corn not profitable.-In those sections of the South where corn can be grown to advantage, a mistake has becn often made of feeding a ration to hogs restricted almost entirely to corn. Corn has always been considered a valuable feed for swine, and so it is, but we too often fail to realize that to obtain the maximum value from it, it must be properly supplemented. As many as a dozen experiments have been tried at the several experiment stations in testing the value of corn alone and with corn supplemented. All have agreed that a ration of corn alone was not profitable and that production was obtained at a greatly reduced figure by properly supplementing the corn with a food rich in nitrogen and mineral matter. In several instances, notably at the Kansas Station, the pigs died on rations of corn alone. The supplements that were found most valuable were the legumes, and by their use, 
both of the seed and green pastures, a reduction of from ten to fifty per cent and more was obtained in the cost per 100 pounds of gain.

The use of grazing crops.-Pork production can be put on an absolutely permanent basis in the South by every farmer who will take up seriously the matter of growing forage crops so as to supply an abundance of roughage for his swine the year through. Every successful hog man knows that the greatest profits in pork production have come from the liberal and judicious use of forage

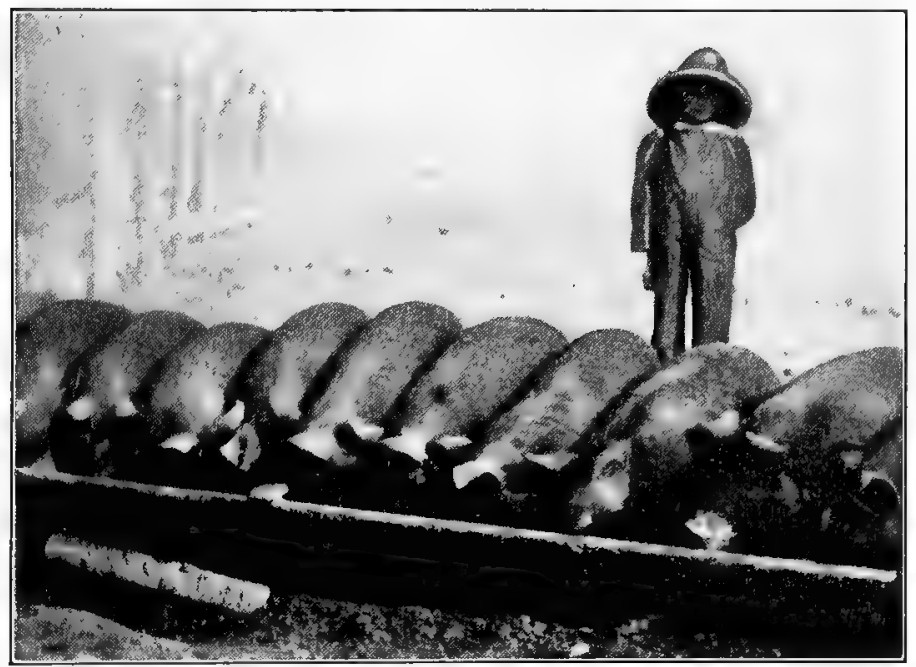

Most grazing crops should be supplemented. Courtesy D. T. Hardin of Tennessee.

crops. By the use of forage crops swine can be grown and maintained with but very little concentrates. For the proper finishing of pork for the market some concen- 
trates will have to be used, but it is also possible to grow these at low cost, and they can, for the most part, be harvested by the hogs themselves. We can have forage crops every day in the year for our hogs if we plan far enough ahead.

Rotations.-After one has decided upon the crops that can be grown under his conditions, the more important problem of arranging for a rotation or succession enters in. There are no rotations that are applicable all over the South, a specific one being required for each section and farm. In order to show how they are planned, some typical ones are presented. Of course, it will be necessary to have several fields in order to properly graze swine. As a general proposition, the more fields and the greater variety of crops grown the better. It is possible to provide grazing pretty well through the year and feed hogs in a limited way with three fields on a three-year rotation. Such a rotation might be planned about as follows:

Grazing from Jan. 1 to Jan. 1

Order planted

Field 1-Winter grains plus winter legume

Summer legume plus corn

Field 2-Winter grains plus winter legume

Sweet potatoes plus peanuts

Field 3-Rape plus oats Early corn plus legume
Approximate order grazed (months)
Mar., June Sept., Oct. May, July Nov., Dec. Jan., Feb., Apr, May Aug.

A four-field rotation could be made from the above by the addition of a field of alfalfa. A permanent grass pasture, such as Bermuda or blue grass, would also work in well with the above grazing plan, but it should not be rotated. An ideal five-field system would include the above three-field plan, with one field additional for al- 
falfa and one additional permanent pasture, which could be grazed off as needed.

In order to show about how the succession would run on a four-field rotation, the following is presented:

A Four-Field Rotation to Supply Grazing from July 1 to July 1 Order planted

Approximate Field 1-Early corn plus New Era peas_._-_-_-_-_-_-_-_July

Rape plus oats_._. Field 2-Sweet potatoes and peanuts Winter grain plus winter legumes_._-_-_-_-_-_Dec, May Field 3-Corn plus soy beans or cowpeas__._._. Winter grain plus winter legumes_._-_._-_-_Jan., June

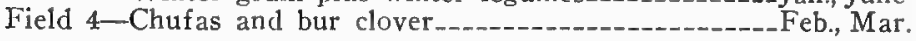

As pointed out in the case of the three-year rotation, this could be made a five or six-field plan by the addition of either alfalfa or a permanent grass pasture, or both.

In order to facilitate the planning of the right rotations and to assist in the selection of the most suitable crops, the following table is offered, which shows the most suitable crops for grazing for each month of the year under average southern conditions. The average planting date is also given. The number of hogs that an acre of the crops will carry is not given, for the reason that they will vary within such wide limits, varying in the length of time the grazing is to take place, upon the stage of growth, the fertility of the soil, the season, climate, and many other factors.

To supply Suitable crops Planting date grazing in January

Rape

Rye and vetch. Sept. 1

Bur clover Sept. 1

Oats July

Chufas Sept. May 


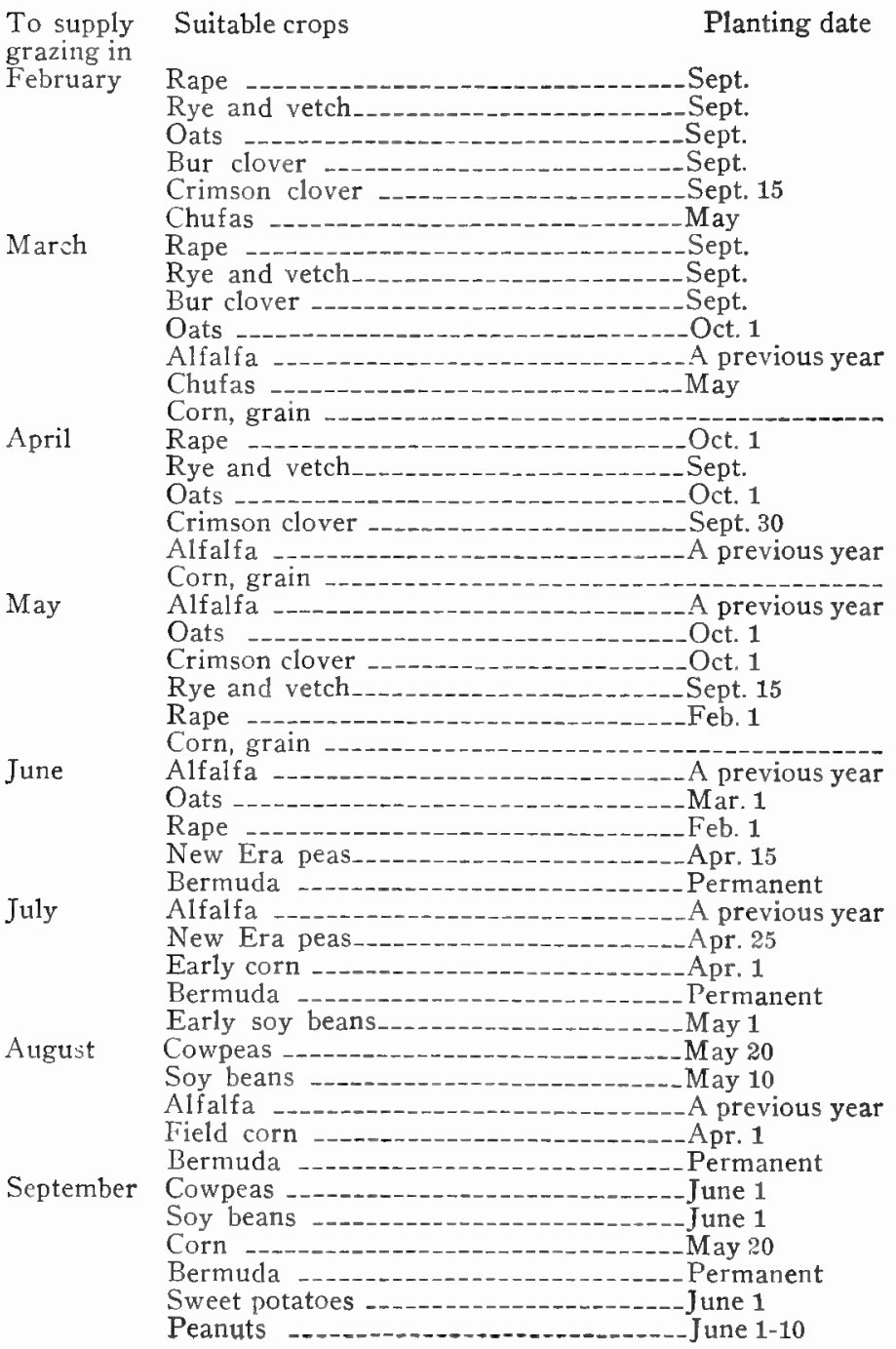


To supply Suitable crops

Planting date

grazing in

October

December Rape

Corn

June 1-15

Sweet potatoes

Cowpeas

Bermuda

June 1-15

Peanuts

July 1

Sweet potatoes

Permanent

November

Rye June 1-10

Rape June 1-10 Sept. 1-10

Peanuts

Sept. 1-10

Rye and vetch June 1-15

Chufas Sept. 1

Oats Sept. 1 May 1 Sept. 1

Perennial grazing crops.-By perennial grazing crops we refer to those crops that we plant once and then they reseed themselves. There are a number of true perennials that have value as grazing crops. Among these alfalfa is by far the most important. In addition to this there are several grasses that are perennial. Also, there are several plants that are not perennial, but they resemble perennial plants in that they reseed themselves. Among such plants is bur clover. The chief value in perennials is that they require less work in reseeding each year. A permanent pasture, such as Bermuda, is not difficult to obtain, and it is a sure crop. Usually perennials make a surer crop than the annuals, but will not yield quite so heavily.

Annual grazing crops.-Most of the swine-grazing crops in use are annuals. They have their chief value in that two crops can be planted and harvested in the same field in a season. Most hog-grazing crops are either planted in the early spring or early fall. It is almost impossible to arrange a system of crop rotation suitable for hog grazing without the annuals. Among them are 
such valuable crops as corn, sweet potatoes, peanuts, chufas, the small grains, and a number of clovers and grasses, without which we could not profitably graze swine.

Leguminous forage crops.-One of the greatest opportunities offered by a system of swine production is that means are provided whereby the fertility of the soil can be not only maintained, but very rapidly added to. This would result from the use of leguminous forage crops, which are both valuable as a feed and for the fixing of nitrogen in the soil. The South is extremely fortunate in that practically all legumes do well. Cowpeas, soy beans, vetches, velvet beans, peanuts, clovers and alfalfa all thrive in most places. Legumes, as a rule, not only possess greater feed value than non-legumes, but the residual effect on the soil is an added advantage which our farmers have failed to take proper advantage of as yet.

Available feeds.-Of necessity, forage crops must play a most important role in any extensive system of swine feeding that may be developed in the southern states. We can secure and properly manage swine with which to grow pork, but the greatest problem is and always will be that of adequate food supply. What the hog grower wants to know is, How can he economically provide the feed to grow and fatten swine and be assured of profits from his undertaking? It can be done and is being done in many places. It is never done without considerable effort and planning. A careful study of the characteristics of the different feeds and their values will assist the swine grower in providing the proper feeds for his swine. 
Space is given only to the more important swine feeds, and while there are many others, a few of which are enumerated, it will generally be found advisable for the feeder to restrict himself to those feeds described more in detail, for their value has been proven. In the making of these discussions and calculations, authoritative works have been freely consulted, and in most instances credit is given. In other instances, where several authors have concurred on a special point, the references have been omitted for obvious reasons.

Corn.-A description of the grain or seed of this standard American cereal is unnecessary. It is one of the most valuable carbohydrate feeds we have, containing about 68 pounds of digestible carbohydrates and 5 pounds of digestible fat per hundred pounds of grain. In the same amount there are only about 7 pounds of digestible protein, which shows that it is deficient in protein. It has a nutritive ratio of approximately $1: 11.3$. The weakness of corn thus lies in its small amount of protein. Also, research work has shown that the protein that is supplied by corn is not of the best quality. In addition, corn is deficient in mineral matter. These two deficiencies show the great necessity for properly supplementing a corn ration. Its composition suggests the value of corn in supplementing pastures rich in protein, such as peanut, rape, broom or rescue grass, alfalfa, vetch, velvet bean and bur clover. Practically every system of grazing crops for swine should contain corn. It is generally planted from March to May, or as soon as all dangers of frost are over. Yields vary greatly, although the average is low in the South. It is a feed that is available almost over the entire South and at all 
seasons of the year, which makes it a most valuable source of food supply.

Sweet potato pasture.-This is a summer-growing tuberous root of the utmost importance to the South so far as hog feeding is concerned. It is adapted to practically every section, but generally does best on light, sandy soils, where yields of 200 bushels to the acre are often obtained. It is a highly carbonaceous feed, having a nutritive ratio of about $1: 25$, containing per 100 pounds of potatoes about 25 pounds of digestible carbohydrate, .3 pounds of digestible fats and 1 pound of digestible protein. In feeding value it is equal to one-third the quantity of corn, which is remarkably high, considering its succulence. It is generally planted in May or June, and where intended for hog feed is never harvested except by the hogs. The grazing-off season generally runs from August to after frost in October. Owing to its highly carbonaceous character, it is admirably adapted for feeding in connection with legumes with ripe seeds, such as mature peanuts, velvet beans, soy beans, cowpeas, etc. This is a feed of proven worth that should be in every system of swine grazing that may be adopted, unless for certain reasons it will not grow well.

Peanut pasture.-This is a summer legume of proven worth, as indicated by the fact that already thousands upon thousands of hogs are annually fed upon this standard southern swine feed. There are two types that are commonly grown, the Spanish and common. The Spanish is smaller, but where it has been tried it has generally proven more valuable. Yields of two or three tons per acre have been secured, which indicates how 
cheaply the feed is produced. They do best on light, sandy soils. They go by the name of "pindars" in south Georgia and Florida, and in other sections they are referred to as goobers. While the usual practice is not to put the hogs into the fields until the nuts are mature, it is sometimes done. The stage at which they are pastured has much to do with their feeding value. One hundred pounds of the material eaten by the hogs will contain from 10 to 16 pounds of digestible protein, from 15 to 40 pounds of digestible carbohydrates and from 8 to 30 pounds of digestible fat, which indicates that as a food it is fairly well balanced, having a nutritive ratio of about $1: 5.5$. Being slightly of a nitrogenous nature, it should be balanced up with such feeds as sweet potatoes, corn, sacharrine and non-sacharrine sorghums. Peanuts tend to produce soft pork, and this condition is overcome by the feeding of a little corn, and especially at the end of the feeding of market hogs, for the corn hardens the fat sufficiently that it will not be discriminated against. It is generally planted in June and grazed off from August to January. The great pork-producing value of this crop is indicated by the fact that in one recorded instance a yield of over 1,000 pounds of pork was obtained from one acre.

Bermuda pasture.-This is by far the most important native grass in the South so far as swine production is concerned. It is a perfect grazing grass in that it seems to be uninjured by the most severe grazing and tramping. It can stand drouth when necessary. Swine make good use of it, but it must be properly supplemented. It has succulent underground roots of which swine are very fond. In rooting for these they do no other damage than 
to make the pasture rough. This is a highly carbonaceous feed, having only about one and a half pounds of digestible protein per 100 pounds of grass. The carbohydrates amount to about 16 pounds and the fat less than a half pound per 100 pounds. The nutritive ratio is $1: 11$ or 12, which suggests supplements of mature legume grazing crops, such as peanuts, velvet beans, soy beans or soy bean pasture, and when concentrates are used, linseed or cottonseed meal, meat meal, or wheat byproducts made into a slop are valuable.

This is a permanent grass, and it is generally not difficult to obtain a stand. It is propagated by means of roots, which will readily take hold if given half a chance. This is one of the most persistent grasses and is difficult to eradicate when it once gets a hold. In many parts of the South this grass grows in connection with lespedeza, which makes an excellent maintenance pasture for hogs of all kinds, available from one month after the last frost in spring to heavy frost in the fall.

Cowpeas pasture.-The great value of this legume to southern agriculture is attested by the fact that it has been grown here for over 150 years. It originally came from India or China. It is an annual summer legume. There are many varieties, and they vary from an upright plant to plants with runners 12 to 16 feet in length. The sceds are of all colors and mixed, and some varieties are early and some late. It is adapted to practically all parts of the South, and it is unequaled as a soil renovator and legume forage crop for swine. The pigs eat the pods and tender leaves and shoots. It is generally not grazed until the first peas begin to mature, the peas not all maturing at the same time, but coming on along for a month or 
more. The time at which the pigs are turned on has a great deal to do with the feeding value of the crop. One hundred pounds of the feed consumed by the pigs is of greater feeding value as the crop matures, the consump-

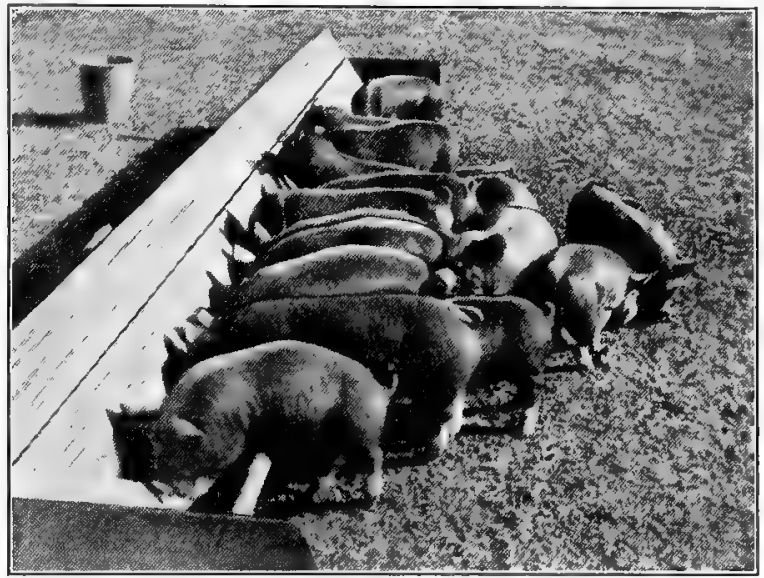

Feed wastes can be prevented by properly constructed troughs. Courtesy W. D. Troutman of North Carolina.

tion of this amount of feed containing all the way from 3 to 15 pounds of digestible protein, from 8 to 50 pounds of digestible carbohydrate and from .4 to 1 pound of digestible fat. It has an average nutritive ratio of about $1: 3$, which suggests its use in connection with such feeds as corn, sweet potatoes, sacharrine and non-sacharrine sorghums, Bermuda grass and by-products of the rice milling industry.

It is generally planted in April as soon as all danger of frost is past, and it is available from August to November. A common practice in most sections is to grow a crop of cowpeas either in corn or else after a 
small grain crop, such as oats, in which case it is generally September before it is available for pasture. It is not so valuable as soy beans for the production of seed for several reasons, not the least among which is the necessity for hand picking resulting from the uneven ripening, which must be classed as an advantage from the standpoint of a swine-grazing crop.

Oats pasture.-This is a small winter grain and is the most extensively grown of all sma!l grains in the South. It is planted in the fall in most southern states, but in the northern states it must be planted in the spring. It is most commonly raised for seed, but its value as a swinegrazing crop is rapidly becoming appreciated, especially when it is combined with vetch. It is one of the cereals that is grazed to quite an extent when young. After grazing during nearly all of the latter part of the winter, the hogs are generally removed about March 1st or a little later to give it a chance to make grain, after which it may be grazed off once or twice if properly handled. The pasturing of oats at different seasons makes its feeding value quite variable, 100 pounds of consumed feed containing from 2.5 to 7.5 pounds of digestible protein, from 12 to 48 pounds of digestible carbohydrate, from .8 to 3.2 pounds of digestible fat. It is a fairly wellbalanced ration, having a nutritive ratio of approximately $1: 6$, but in its immature state a concentrate such as middlings or soy beans should be added. It has also been found excellent when fed in rations containing vetch, rape and alfalfa pastures, although in such instances some concentrates should be fed. It is generally available from December to June, but the early pasturing does not amount to $s c$ much in the northern part of the 
South as nearer the Gulf. A common practice is to follow the crop of oats with cowpeas. September is the usual month of sowing.

Rape pasture.-This plant in many respects resembles the collard. In shape and color of leaf it resembles the rutabaga or Swedish turnip. The leaves grow very rank and succulent, and being sweet and tender they are quite palatable. It is primarily a winter grower and is of little value in summer. There are several varieties, but the Dwarf Essex is the best for swine-grazing purposes. The seed are usually broadcasted in September at the rate of five pounds per acre, and a common method is to grow the crop in connection with oats. Its value in yield of pork often exceeds $\$ 25$ per acre. The high feeding value of rape is largely due to its protein content and to its succulence. While the dry rape leaves have been reported to contain over 20 per cent of protein, the consumption of 100 pounds of rape on pasture yields only about 2 pounds of digestible protein, about 10 of digestible carbohydrates and less than one pound of digestible fat, with a nutritive ratio about 1:5.2. This is a fairly well-balanced feed and suggests the use of such carbohydrate concentrates as rice by-products, corn, or chufas, and the use of oats and rye pastures in conjunction with it.

Rape yields an immense quantity of forage, and the Iowa Station has reported the production of over 1,400 pounds of pork from an acre. Rape should never be grazed when wet or frozen. If it is not pastured too closely it will come back several times during the winter and spring. It should be allowed to attain a height of ten 
or twelve inches before the hogs are turned in. With this plant grazing can be had from November to June.

Chufa pasture.-This crop gives great promise for the reason that the food is available for pasture at a season when other feeds are scarce and the feed is of very high value. It is a summer sedge that makes its growth in summer, but provides tubers for winter grazing. It is admirably adapted to sandy soils and does not do so well on heavier soils, which in a way limits its use. Yields of from 75 to 150 bushels per acre have been reported. It is generally planted in May, 12 to 15 inches apart in 3 -foot rows. The tubers are generally grazed off at any time from October to April. Henry and Morrison ${ }^{1}$ report that as much as 600 pounds of pork can be made per acre from this crop. These same authors state that 100 pounds of chufas will yield .4 pounds of digestible protein, 10.2 pounds digestible carbohydrates and 3.3 of digestible fat, and will have a nutritive ratio of approximately $1: 44$. This suggests the use of this crop in connection with such nitrogenous feeds as buttermilk and skim milk, soy beans, bur clover and alfalfa pasture.

Alfalfa pasture.- In the South this is both a perennial winter and summer legume. It has been rather widely grown on a limited scale and requires no detailed description. Twenty to 30 pounds of seed are generally sown to the acre in September or October. As a pasture crop it is available at all seasons of the year, but to a much reduced extent in winter. Its feeding value is high for a succulent grazing crop, and the feeding value per 100 pounds will often run 3 pounds of digestible protein,

\footnotetext{
${ }^{1}$ Feeds and Feeding, p. 245.
} 
10 to 12 pounds of digestible carbohydrates, and approximately a half pound of digestible fat. Being a legume, it is of a nitrogenous nature, having a nutritive ratio of about 1:4, which suggests its use with such feeds as sweet potatoes, chufas, sacharrine and non-sacharrine sorghums, corn and rice by-products.

Soy bean pasture.-This legume is generally planted in May and provides pasture from July to November. It ought to be nearly mature before pasturing. It is highly digestible and is rich in oil and protein, containing from 3 to 25 per cent of the former and from .5 to 10 per cent of the latter. The digestible carbohydrates run rather low, ranking from 10 to 20 per cent, depending on the stage of growth and on the feed other than beans consumed. With a nutritive ratio averaging around $1: 3$, it naturally requires with it carbonaceous feeds, such as sweet potatoes, corn, rice by-products, and sacharrine and nonsacharrine sorghums to make a balanced ration.

Soy beans are sometimes grown in connection with corn, being planted between the rows, the rows having been left rather wide. It gives great promise of playing a very important role in our general system of swine feeding, as it is already doing in many sections.

Soy beans.-The seed of the soy bean promises to become one of the chief sources of our protein concentrates. The seed are heavy in oil, and this may cause the development of a considerable industry, which will leave the cake for feeding purposes. Either the meal is valuable, or the whole bean can be fed to advantage, as it is very digestible. The plant can be grown over practically the entire Ssuth, and an average yield per acre of around 
30 bushels can be secured. It is superior to cowpeas not only in yield, but the seeds ripen in such a way that the crop can be saved without hand picking, as is necessary in the case of cowpeas. The seeds are quite digestible, and it is not necessary to grind them. Their digestible protein content is quite high, being about 30 per cent, while the digestible carbohydrates run around 25 and the digestible fats from 12 to 15 per cent, with a nutritive ratio between $1: 1.5$ and $1: 2$. Their strong nitrogenous nature suggests their use in connection with such carbonaceous feeds as chufas, sweet potatoes, sacharrine and non-sacharrine sorghums, corn, and possibly molasses.

Bur clover pasture.-This valuable annual winter legume thrives on any soil where Bermuda does well, and is largely confined to that area. It is best to seed it broadcast in July. It can then be pastured from February to May. Its great value, too, comes in the fact that it can be grown in with Bermuda, as their growing or active dates do not interfere, and by the use of Bermuda and bur clover it is possible to have a valuable permanent pasture through the entire year. Even in cultivated ground it does not require reseeding when properly handled. Being a legume, it is naturally of a nitrogenous nature. Henry and Morrison ${ }^{1}$ give the per cent of digestible crude protein at 3.4 , that of digestible carbohydrate at 8.2 and that of digestible fat at 1.1, and with a nutritive ratio of $1: 3.1$. This suggests using with it such carbohydrate feeds as chufa pasture or corn, about the only highly carbohydrate concentrate feeds available at this season of the year. The value of this crop is three-

\footnotetext{
${ }^{1}$ Feeds and Feeding, p. 664.
} 
fold-it is not only a valuable swine-grazing crop, but on cultivated ground it serves as a winter cover crop, preventing washing, and in addition adds nitrogen to the soil.

Vetch pasture.-There are over 100 varieties of this valuable winter legume in America, but only a few attain any importance. So far as we are concerned, we are interested only in the hairy or sand vetch and the native Carolina and Louisiana vetches. These annuals have weak, slender stems, and for that reason generally do best with some support crop, such as oats or rye. They are generally seeded in August or September, and can be grazed from December to May 1 . They are of a nitrogenous character, having a nutritive ratio averaging around 1:3.5. Being grazed at all stages of growth, their feeding value is naturally variable, and the digestible protein will run from around 3.5 to 18 pounds per 100 pounds of feed eaten, and from 8 to 50 pounds of digestible carbohydrate and from 4 to 1 pound of digestible fat in the same amount of feed consumption. This suggests their use with such carbonaceous concentrates as chufas, corn, rice by-products, and possibly molasses, in order to make up a balanced ration.

Rye pasture.-This small winter grain offers a good winter pasture, because of all of the small grains it makes the most growth in the fall and winter months. It is often hogged down when mature. It can be pastured from December to March or April, when the pigs should be removed to give it a chance to make grain, putting the pigs back in again in May or June to finish up the crop. Being a cereal, it is naturally of a carbonaceous 
character, but it is not a badly balanced feed. The feeding value varies greatly on account of the different stages of growth at which it is fed. One hundred pounds of the feed that hogs will consume on rye pasture will contain from 2.5 to 8 pounds of digestible crude protein, from 13 to 60 pounds of digestible carbohydrate, and from a half to a pound of digestible fat, with a nutritive ratio of approximately $1: 6.5$. This suggests the combining with it of a winter legume like vetch, which is common practice, and of feeding with it such nitrogenous feeds as soy beans, garbage, rape, wheat by-products, and meat meal or tankage.

Wheat by-products (middlings, shorts, red dog flour). - These feeds should only be resorted to when other suitable protein concentrates cannot be grown on the farm, for protein feeds can generally be grown more cheaply than they can be bought. Of these feeds, the digestible protein per 100 pounds will run from 10 to 15 pounds, of digestible carbohydrates about 50 pounds, and the digestiblc fats from 3 to 5 pounds. The nutritive ratios will generally run about $1: 4.5$, which suggests the use of these feeds with such feeds as chufa pasture, swect potato pasture, saccharine and non-saccharine sorghums, corn, and rice by-products. These feeds are especially valuable in making slops and in enriching garbage.

Kentucky blue grass pasture.-This is a most valuable winter grass, but its usefulness is confined mostly to Kentucky, Tennessee, North Georgia, North Carolina, Mississippi and the northern southern states. The seed are ustially sown in September at the rate of about 25 
pounds to the acre, after which time it is permanent if allowed to seed. It furnishes grazing from July to October of a very superior sort, containing on the average above 3 per cent of digestible protein, about 20 per cent of digestible carbohydrates and a little less than a pound of digestible fat per 100 pounds of grass. The nutritive ratio shows the feed to be carbonaceous in nature, having a nutritive ratio of something over $1: 7$, which suggests its use with such nitrogenous feeds as soy beans, cottonseed meal, alfalfa hay, linseed meal, wheat by-products, and tankage and meat meal. This would be a most important feed if it were wider in its adaptability. Fortunately, where it leaves off, Bermuda is the grazing grass that supersedes it, and, as we have already seen, this is a valuable swine-grazing grass.

Velvet bean pasture.-For the extreme South this summer legume is a most valuable grazing crop. Its usefulness is limited farther north by the time required for the maturing of the plant, six months generally being required. The early speckled variety matures much sooner than the Chinese. By means of its beans it is valuable to supply a good protein foraging crop through winter. The yields on the better fields have amounted to as much as $1 \frac{1}{2}$ tons of beans in the pod per acre.

The plant is an annual and is generally seeded in April at the rate of six or eight quarts of seed per acre to supply fall and winter grazing from September to March. It is a very rank grower. As a general rule it cannot be satisfactorily grown north of $33^{\circ}$ latitude. It is a heavy yielder, making from 40 to 60 bushels of seed, and is generally grown with corn, for with it a fairly wellbalanced ration is made, and the two crops are ready for 
grazing at the same time. One hundred pounds of the feed :onsumed by hogs on velvet bean pasture will run from 3 to 15,7 to 45 and .4 to 5 pounds respectively of digestible protein, carbohydrates and fats. The nutritive ratio ranges between $1: 3$ and $1: 3.5$, which suggests the use of velvet bean pasture with such feeds as chufas, sweet potatoes, saccharine and non-saccharine sorghums.

Red clover pasture.-This is a rather important legume in all those sections where blue grass grows well, requiring for growth the same soil and lime conditions as this grass. It does not do so well on poor sandy or white pine soils. The seeds are generally sown in the fall farther south, and in the spring in the north, at the rate of 15 or 20 pounds per acre, yielding pasture from early in the spring until July. In those sections where it thrives it acts not only as a pasture crop, but as a cover and nitrogen-gathering crop as well. It is especially valuable as a feed for brood sows and pigs, for it tends to make good bone and develop a strong constitution. It is almost a balanced ration in itself, having a nutritive ratio of $1: 6$, and the remainder of the ration fed with it should, therefore, be pretty well balanced. Corn and wheat by-products with clover make an ideal ration.

Cottonseed meal.-This valuable by-product of the cottonseed industry is becoming of more and more value cach year as a feed for swine. In the past its consumption has been limited by the dangers accompanying its feeding, but as we better understand it we can safely feed continually larger quantities. It is not adapted for continuous long feeding, and heavy feeding should never exceed 60 days. It can, therefore, be used to advantage 
in the last feeding period prior to the marketing of fat hogs. Another factor that will conduce to greater consumption is that greater quantities of this feed can be fed when the hogs are on the pasture, and with a rapidly increasing tendency to the use of grazing crops the increased consumption of this feed will continue. In the feeding of cottonseed meal some precautions secm necessary. In no case should over one-fifth of the ration be made up of this feed, and in the case of young animals the amount should be still less. Cottonseed meal is one of the narrowest feeds we have, having a nutritive ratio of approximately $1: 1.2$, which suggests its use in connection with rations containing corn, chufas, molasses, sweet potatoes, saccharine and non-saccharine sorghums and other carbonaceous feeds. It is a very rich fecd, 100 pounds of the meal containing about 35,25 and 8 pounds respectively of digestible protein, carbohydrates and fat. It supplies a protein cheaply and is available at all times and at all places, and its judicious use is to be encouraged and recommended.

Other less important feeds.-There are many feeds that do remarkably well in a small locality, but the adaptability of the crop is not general. In this respect Florida is almost in a class by itself, for in addition to the fceds discussed, cassava, beggar weed, Japan cane, St. Augustine grass, Mexican clover, Para grass and Guinea grass all have some importance in swine grazing. In addition to these feeds mentioned, there are localities in the South where such legumes as white and alsike clover play a part in the feeding of swine, and where such grasses as Italian rye grass, teosinte, Sudan grass, large water grass, foxtail millets, red top, crab grass, carpet grass, 
Colorado grass, perennial ray grass, southern canary grass, big blue stem, tall fescue, Texas blue grass, barnyard grass, tall oat grass and Virginia rye grass attain importance. In addition to these, wheat bran, molasses,

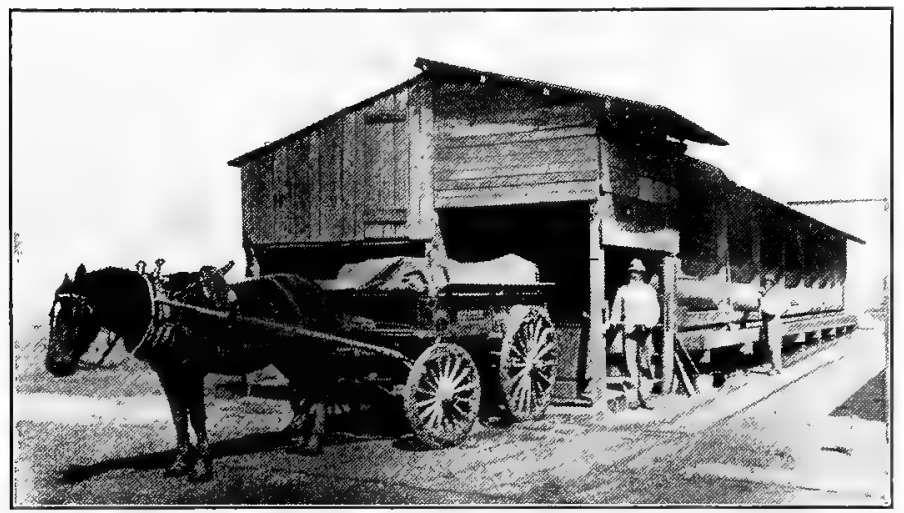

Feeding city garbage on the farm of F. W. Clew, near New Orleans, La.

barley, linseed meal, slaughterhouse and rice by-products, lespedeza, crimson clover and wheat pasture, brome and rescue grass, saccharine and non-saccharine sorghums, and the seeds of wheat, oats, barley, rye, swect corn, velvet beans, cowpeas, cottonseed and hog goobers play important roles in some localities. Root crops, as artichokes, carrots, mangel-wurzels, potatoes, sugar beets, rutabagas and turnips, are of some importance. Whole milk is rarely fed, whey is not available in any quantity, but some buttermilk and skim milk are fed. Pumpkins, watermelons and squash are made use of in some localities, and it is possible that legume hays, such as red clover, alfalfa and cowpea, may be used to a small extent. 
The droppings from fattening cattle is a feed of importance in some cattle-feeding sections. Frequently near large cities garbage is fed extensively to fattening swine.

Concentrated commercial feeding stuffs.-For several reasons commercial concentrated feedstuffs for swine have not come into very general use. They are subject to considerable adulteration with materials having low feeding value. Some common adulterants or fillers are chaff, oat hulls, peanut hulls, coffee hulls, screenings, corn cob, corn bran, oat dust, cottonseed hulls and mill sweepings. Most states provide statutes to protect the consumer from adulteration of feeds, and require the manufacturer to guarantee and keep the standard of their products up to certain specifications. Most of our commercial feedstuffs, such as bean culls, middlings, cottonseed meal, linseed meal, shorts, tankage, meat meal, etc., are the by-products of other industries. These kinds of feedstuffs have their places, but as a rule they should only be used in a supplemental way.

Condimental feeds.-For all practical purposes condimental feeds have but little value, and as a general proposition are not to be recommended. Careful experiments have shown that swine utilize no more, if as much, of their feed when condiments are added. Tonics and alteratives are generally present in these feeds, but aside from these the feed value is negligible. Well-known materials are used in the compounding of these proprietary articles, and where such medicines are called for the farmer can make for himself simple tonic mixtures. He can do this a great deal cheaper than he can purchase them. 
A simple mixture for preventing worms and conditioning swine that may be easily made up at home is that recommended by Dr. Carey of the Alabama Station. This mixture is made up of:

\begin{tabular}{|c|c|}
\hline 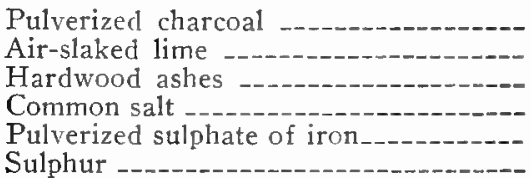 & $\begin{aligned} 10 & \text { pounds } \\
10 & \text { parts } \\
10 & \text { pounds } \\
5 & \text { pounds } \\
1 & \text { pound } \\
5 & \text { pounds }\end{aligned}$ \\
\hline
\end{tabular}

This should be mixed thoroughly and placed in a dry place, preferably in a self-feeder, so that the hogs can go to it at will. This mixture has met with considerable success in keeping down worm infestations and keeping the hogs in a healthy condition.

Hardening of fat.-In the making of pork on certain feeds, notably in the case of peanuts, we are apt to have a fat that is too soft and oily. Frequently such pork is discriminated against on the market, and it is up to the grower to either harden the fat in some way or to sell at a sacrifice. This hardening process is generally accomplished by feeding corn or corn and cottonseed meal in connection with the peanuts for a short time before placing on the market. Since corn cannot always be obtained as cheaply as some other feeds, we should look for other possible remedies for the condition. Above all, the degree to which the hog is fattened is an important factor. The greater the quantity of fat that is placed on the hog the softer it becomes. We should, therefore, be very careful not to fatten our pork too much, and especially the fattening should not be carried beyond that point where fattening no longer pays. According to some experimental work that has been done, we know 
that the first fat that is placed on the carcass contains more stearin than the later deposited fats, and is therefore harder. The later fats are composed of greater percentage of palmitin and olein and are softer. When we cannot feed to increase the proportion of stearin, we had best not fatten to too high a degree in order to secure the degree of hardness of fat that is most desirable.

Balancing rations.-We have for many years heard much of balanced rations. Theoretically, rations should be balanced so as to furnish the nutrients in the proper proportions and yet not be wasteful. The necessity for providing for the correct proportion of different nutrients results from the fact that the specific uses to which nutrients can be put are rather limited. To a limited extent carbohydrates and fats can take the place of one another, but proteins have a function that must be provided for with proteins. In some instances we have an excess of protein feeds, while in other sections we have a shortage of proteins as compared with the non-proteins. As a general proposition the South is pretty well supplied with proteins, and the greatest difficulty generally comes in securing an adequate quantity of carbohydrate feeds. So far as fats, proteins and carbohydrates are concerned, it is an easy matter to pay too much attention to the balancing rations. In certain instances, however, rations require special attention to see that a sufficient quantity of ash is supplied and to see that the quality of the proteins as well as the quantity is adequate.

Calculating of rations.-From published tables giving the feed requirements for swine, and from tables giving the nutrients contained in the several feeds, it is possible 
to calculate an accurately balanced ration for any given herd of swine. Thus, the mathematical calculation of a ration is an exact science, for it is possible to figure accurately the feed requirements of the animal.

Of course, under exceptional conditions it may be well to calculate the rations for swine where the feeding con-

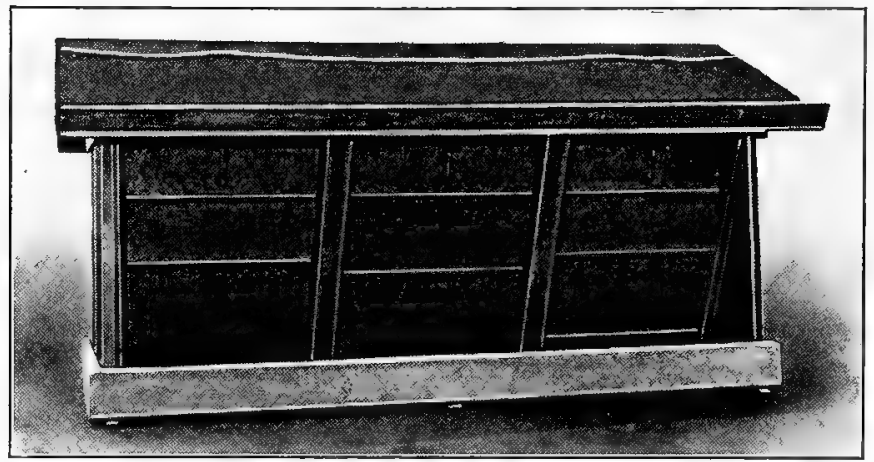

Self-feeders are becoming more common in the South. Photo by Earl Hostettler of North Carolina.

sists for the most part of lot feeding. However, investigations have shown that under average southern conditions quantity of food is more often deficient than quality. Hence, the best plan is to make sure of the quantity and provide for the quality as accurately as possible. To facilitate this, our swine feeds may be classified into carbohydrate, balanced and protein feeds. In feeding, it will suffice if sufficient quantities of feeds are given and if a carbohydrate feed is fed along with a protein feed, or vice versa, while the balanced foodstuffs may constitute a portion of the ration without necessity of balancing. If swine rations are calculated in this crude manner, it will be a step in the right direction and will 
be far superior to the blind way in which we have bcen conducting our feeding in the past.

The self-feeder.-This is a mechanical device that enables the pig or hog to secure feed at will. In principle the self-feeder consists of a bin to hold the feed, a feed trap through which the feed leaves the bin, and the trough. Self-feeders are made of various materials and in various shapes and styles. Wood and sheet metal are the two most commonly used materials in self-feeder construction. Self-feeders can be made at home or they can be purchased. Most agricultural colleges and experiment stations now furnish free plans or blue prints for their construction.

The use of the self-feeder.-While the use of the selffeeder in pork production is a new idea, it is one of the most economical, practical, labor-saving and efficient methods we can employ, especially where full feeding is desired. The importance of the self-feeder is largely the result of efforts made by Mr. John M. Evvard of the Iowa Station, who has secured some quite favorable results. It can be safely stated that the self-feeder has passed the experimental stage, and its use is to be generally recommended in pork production. Earlier maturity, with the resulting saving in feed and labor, is made possible. 


\section{CHAPTER VII \\ SWINE MANAGEMENT}

Shelter for swine.-The coat of hair on a hog is comparatively thin, and even a cold summer rain will cause considerable discomfort. The cold of winter, even in the mild climate of the South, is disagreeable to the hog, and

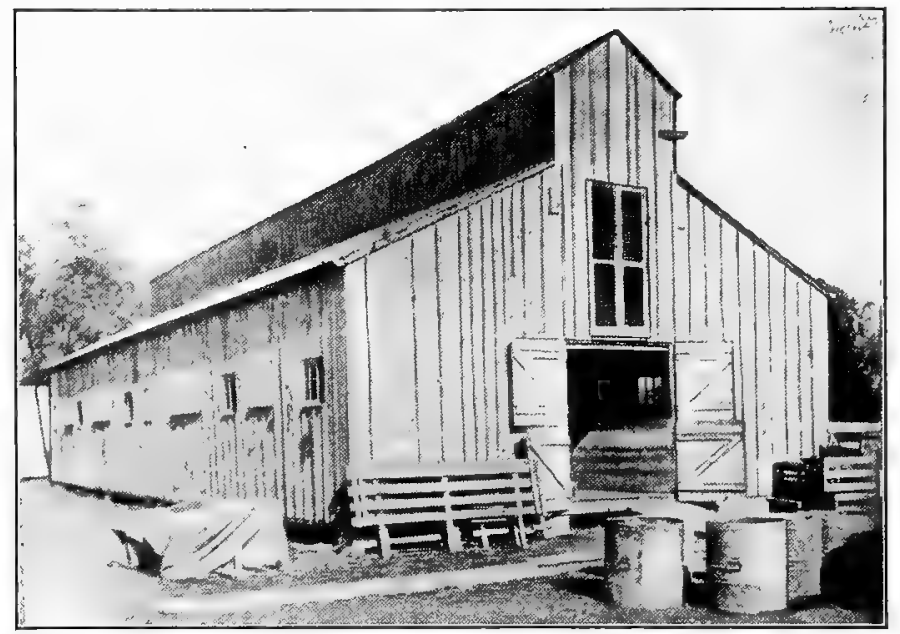

Monitor type winter farrowing house on farm of F. W. Clew, near New Orleans, La.

any suffering he must undergo will cost his owner something in the way of feed. Some sort of a roof and enough siding to keep out the wind are all that are necessary under most conditions. In the winter a good bed of leaves or straw not only adds to the hog's comfort and thrift, but a saving of feed will be effected. The hogs rarely need to 
be confined to shelter, but it should be so placed that they can make use of it at will. Shelter, shade and running water are the most desirable adjuncts to any swinegrowing plant and are essential to a proper foundation. All of these except the shelter may be natural. Under the most modern system of pork production a portable type of shelter is generally advisable, but there are conditions under which a permanent or stationary hog house is to be recommended. As a rule, the extent to which swine can be grown with grazing crops and the extent to which attention is paid to breeding rather than pork production determine the type of shelter that is best suited.

Houses and inclosures.-Serviceability is all important, and many have spent large sums in making shelters for swine that were not serviceable and that were not suited to the conditions. The matter of serviceability is largely a matter of design, and is dependent on soil, climatic and other conditions. Accessibility must be taken into consideration. This is especially applicable in the case of a permanent shelter or inclosure.

Materials used in construction.-Brick, cement and other heavy materials can be used only in the larger stationary houses, while practically all portable houses are made of wood. Most of the material that should be used for hog houses will be wood, on account of its lightness and cheapness. Over most of the South this is the proper building material to use, and in most cases rough lumber will be found quite good enough.

Sunlight.-Sunlight is one of the best germicides we have, and with ample sunlight the dangers from disease 
are reduced to a minimum. The houses need to be located where the sun can strike them at least a part of the day, and the houses, if of the closed type, should have

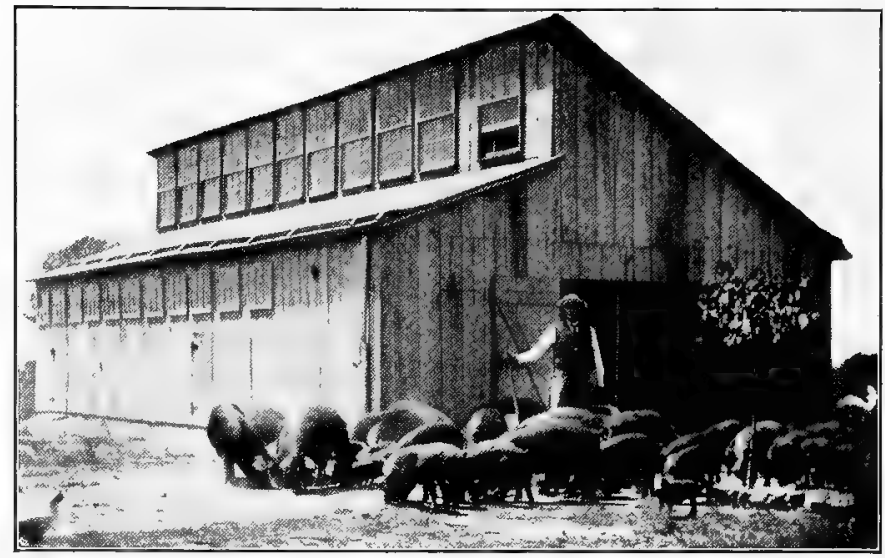

Half monitor type winter farrowing house on Maple Grove Farm, Walton, Ky.

as much window or glass in the tops as is possible and consistent. In the planning of a house of either the portable or stationary type provision should be made for ample sunlight inside the house, for it offers a cheap means of keeping disease bacteria and parasites in check.

Floors.-On many soils the earth makes as good a floor as is required. Cement is not advisable for covering the entire floor, but where used it has the advantage of being easily kept clean. Cinders and clay make an excellent floor for a permanent type of house. Boards will usually be found to give the best satisfaction where earth floors are not used. If the earth is dry, a dirt floor is good, and if properly constructed, with a binder of cinders, there 
will be but little dust. Regardless of what materials the floor is made of, ample bedding should be provided for the comfort of the hogs. This bedding should be changed often on account of vermin and disease

Drainage.-In the location of shelter and inclosures, whether portable or stationary, it is important to see that proper drainage is secured. This is of special importance in winter. Shelter for breeding swine should in particular be located so as to provide ample drainage. The house should never be located in a low place, but on a rather high place, with ample slope. With poor drainage there are apt to be worms and parasites through summer and pneumonia and other diseases during the colder months.

Ventilation.-It is just as important to the health of the hog that its house be provided with ample ventilation as it is to our health that the air in our homes be changed from time to time. Fortunately, it is rare that hog houses are made too close, but such is sometimes the case. Nearly all hog houses are so arranged that the hogs can go in and out at will, the opening providing ample ventilation for winter. In the summer, however, some houses are inclined to heat very greatly, and in such provision should be made at the top for ventilation. Windows in the top of the house should be arranged to provide a means of easy ventilation when necessary. When a wooden floor is used in hog house construction, provision should be made to have ventilation underneath the floor to keep it dry.

Large stationary hog house.-This type of house should be built to provide for ample sunlight. Plenty of 
windows at the right height are a most necessary thing. Hinged roofs or roof sections that can be turned back are also advantageous. If the floor is made of cement, a portion of it may be overlaid with boards for sleeping quarters. The separate pens in the building should open into separate pens outside, but where only a few hogs are kept and the building stands in a pasture field, the different groups of hogs may learn to come to the same pens to be fed. The styles of this type of house are numerous, but the fundamental requirements are the same.

Shed-roofed portable house.-This house is best made in detachable sections. The sections may interlock or be hinged or slightly nailed. The roof may slope in one direction or in two. The hinges may be at the highest part of the roof or may stand at right angles to the slope and connect sections. This facilitates raising portions of the roof to admit sunlight and air. If the houses are made without projections they may be placed close together in winter. Farmers' Bulletin 438 of the United States Department of Agriculture gives full directions for the construction of hog houses, and it may be secured without cost upon application to the Secretary.

The A-shaped portable house.-The A-shaped portable house may be made portable either by nailing all together and moving it on runners from one place to another, or it may be made in sections that interlock but which are easily detachable. The sections may be put on a wagon to be moved. The house made of sections is desirable from another standpoint, since it permits of greater ease in cleaning and can be used to admit a greater amount of sunshine. 
Movable shelter houses.-A very useful shelter, especially for summer use, can be made with a roof and one, two or three sides, as may be desired. Some of these have no sides at all, but have a low roof and are intended primarily for protection from the sun. These are more necessary on some farms than others, and if one has no

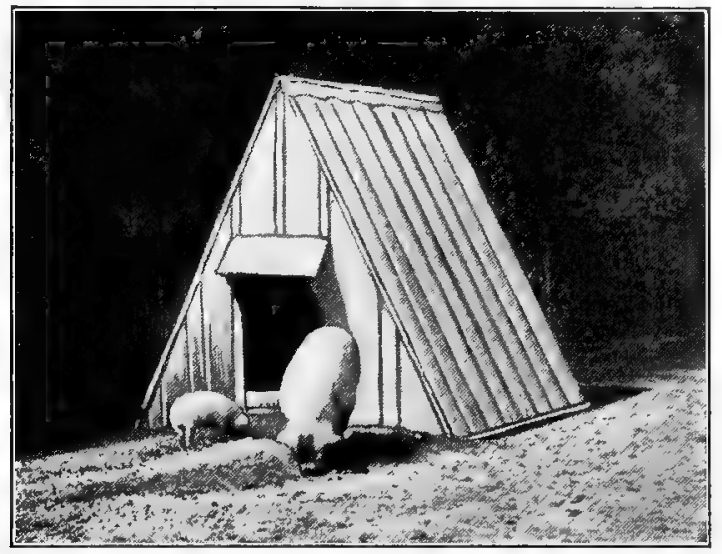

The common A-shaped portable hog house.

natural shelter in grazing patches or lots, something of this style will be very useful, for it is cheaply constructed, can be removed from a field as soon as the grazing is over, so that it will not be in the way of ground cultivation and preparation for the next crop.

Sleeping quarters.-The same shelter that protects the hogs from the sun can be used as well for sleeping quarters in the field, but when so used it becomes much more serviceable if one or two sides are put up. No flooring will be necessary in most cases, but if the soil is 
damp and muddy, a floor in a portion or under all of the roof may be advisable. It is only in the large stationary houses that one may need to consider the construction of separate sleeping and feeding quarters. Comfortable and healthy sleeping quarters are of sufficient importance to warrant some special attention.

Farrowing pens.-Where breeding swine are kept it often becomes advisable to have a few separate pens for the exclusive use of the sows at the time they drop their pigs and for a time thereafter. Such pens are called farrowing pens and are constructed in the usual manner, with the exception that a railing is placed around the

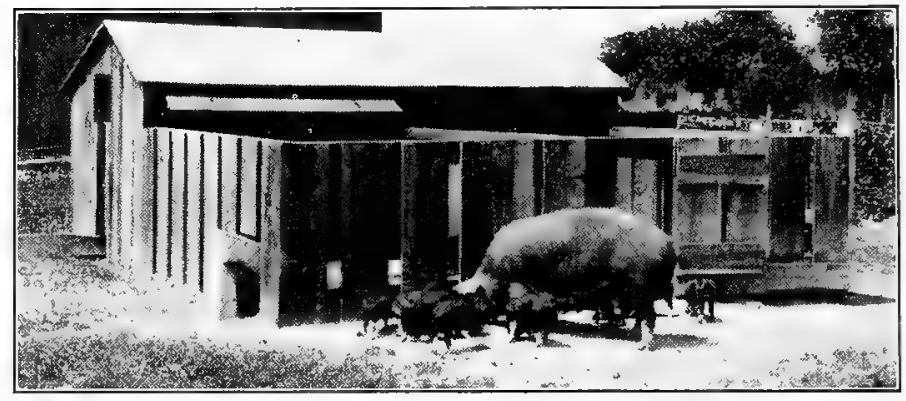

Cheap type small farrowing house and pen. Courtesy H.S. Lippincott of Maryland.

sides about eight or ten inches from the floor and allowed to extend out some six or eight inches, so that if the sow lies down against the side of the house any pigs that happen to be in the way will be given a chance to escape over-lying. A protective railing of this sort can be placed in almost any type of house, so that it can be readily converted into a farrowing pen without much cost or trouble. 
Pens and inclosures.-It is a lack of pens and inclosures on many farms that hinders many from raising hogs. What we want in the way of pens is something that is satisfactory yet cheap. In lot construction the materials to be used will depend on several factors and conditions. Board fences are sometimes advisable, but

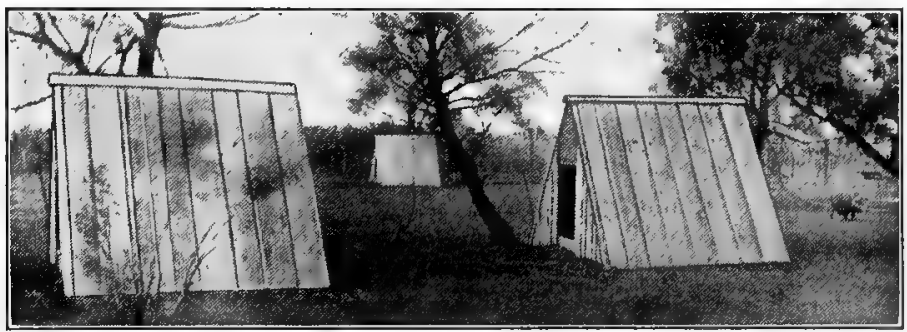

A-type of individual farrowing houses in use on farm of $F$. W. Clew, near New Orleans, La.

under most conditions a wire fence with wooden posts will be most economical. Around the hog houses, especially if the houses are permanent, a permanent system of lots should be constructed. If the houses are portable, a portable fence may also be used to advantage. The pens and inclosures should be arranged according to the hog house or houses, according to the water supply and according to the grazing patches. In the arrangement and location of lots each farm offers a special problem in itself.

Fencing materials.-In the permanent or stationary fences posts are used. These may be of several kinds of wood, of cement, steel or of rock. The material of the fence itself may be the same in the case of portable or drift fences as in the stationary fence. Boards are the 
most common materials used in drift fences, but wire can be used. In permanent fences wire is probably the most commonly used material. In portable fences the fence is supported by braces at the end of each panel, and with some a stake is driven down, to which the brace is lightly tacked. Drift fences are about as cheaply constructed as permanent fences, because the use of posts is done away with, and they have additional advantages in that they can be continually kept in use, thus requiring a small total length of fence, and they are readily taken out of the way to prepare land and cultivate the grazing crops.

Water supply.-There are but few farms that have a stream that is adapted to supply water to all fields. Where it is possible and feasible an artificial water supply system is best suited, for it is under control and clean water can always be provided. A small tank with a hydraulic ram is an ideal method of water supply where the ram can be used. If no stream is available for a ram a pump and well can be used to supply the water. In the arrangement of the lots the water supply should be taken into consideration. Not only is water needed for drinking purposes, but some is needed in the wallows, for mixing fecds and for cleaning up. A supply of ten gallons per day per hog should be available regardless of the source, and it should be placed so as to be of greatest value to the hog and still be economically supplied.

Bedding,-In the sleeping quarters, whether they be for brood sows or for fattening swine, attention should be given to the bedding. It should be changed often for sanitary reasons. It should not be so damp as to be soggy and unhealthy, and neither should it be so dry as 
to be dusty and cause lung troubles. If the place is inclined to be damp, such materials as sawdust, dry sand and straw should be used freely. If the place is already inclined to be too dry and dusty, fresh sawdust, cinders and straw may be used to advantage.

The herdsman.-Other things being equal, the owner himself makes the best herdsman. In addition to the experience, the herdsman must have a natural love for his pigs. A noticeable feature of a good herdsman is that he soon knows accurately each individual in the herd, not only knowing its physical conformation, but also its behavior and ability to respond to treatment. Painstaking care and constant attention are called for from the herdsman. He should be a willing worker, with intuition and judgment, especially at such times as farrowing, when the loss of a litter means the loss of at least six months' time with one sow, which, counting feeding and interest on the investment, soon amounts to an appreciable sum. Good herdsmen are scarce, but if one desires a good one and can secure one at a little additional cost, it is generally an economical investment.

One litter or two.-Something like half of the sows are only permitted to have but one litter a year, which comes generally in the spring. Since the period of gestation is only about 112 days, and since pigs can be weaned readily at two months of age, it is entirely possible and feasible to grow two litters a year, two months being allowed for the sow to rest and become rebred in. It is not economical for the sow to raise but one litter, and on any well-regulated farm two litters will be obtained. So far as the investment is concerned, two litters cost about the 
same as one, and since the sow must be maintained, the additional feed cost is not much greater. The great trouble has been that the food supply is always more abundant through the summer and fall, while it is generally scarce during the late winter and early spring. The aim should be to grow two litters a year, but to do this will require greater skill in the arranging for feed and in the caring for fall pigs, which are, as a rule, a little more difficult to raise than the spring pigs.

Little pigs need exercise.-Provision should always be made to see that the little pigs do not lack for exercise. Fortunately, under pasture systems of raising, provision is automatically made for exercise. The reason we desire the little pigs to have exercise is that the bone may be developed and that they may have ample constitutional capacity.

Runts.-In nearly every litter there is one runt, and frequently there are two or three. When the litters are quite large it may be economy to kill these runts. If the litter is small, it pays to worry along with them, and after a time all of the runts can be placed either in a lot or grazing patch to themselves, where they can be given special attention and feed. The occurrence of runts cannot be avoided, but it can be mitigated by ample and judicious feeding of the pregnant sow. In by far the majority of cases the lack of size has resulted from a lack of nutrition, and it is easily overcome if means can be made for special nourishment for a time for the runts.

Marking the litters.-It is desirable to mark the litters in the case of pure-bred swine in order that the ancestry may be definitely known. Perhaps the easiest system of 
marking is by means of notches in the ears. A single notch in the outer rim of the right ear indicates that the pig belongs to the first litter born that season. The second litter is marked by two notches in the outer rim of the right ear. Litter No. 3 is marked by a single notch in the outer rim of the left ear. A pig of the tenth litter is marked by a single notch in the inner rim of the right ear. A pig of the thirtieth litter has a single notch in the inner rim of the left ear. A notch, therefore, has a value of $1,3,10$ or 30 , according to its location in the outer rim of the right or left ear or the inner rim of the right or left ear. The number of the litter to which a pig belongs is indicated by the sum of the values of all of the notches present. A hundred litters in the same herd can be marked by this system. It is useless to try to give each pig an individual number, for all of the pigs in one litter should have the same ancestry.

Fall vs. spring pigs.-As has been pointed out in a previous paragraph, spring pigs have an advantage over fall pigs in that they come at a season of the year when they will have an abundance of feeds to grow on during the summer and an abundance to fatten on in the fall. Fall pigs come at a time when the feeds for growing come high and when the grazing feeds for fattening at an early age are almost not to be had. The result is that fall pigs must be kept longer than spring pigs before marketing, and the cost is thereby increased that much. A properly equipped breeder will arrange for nearly as many pigs to be dropped in the fall as in the spring and will arrange to get them off to market as early as possible in the summer or early fall, when prices are generally good. The advantages of spring pigs over fall 
pigs are thus largely offset by a slightly cheaper feed in the fall and early winter, and by being able to get them to market before the spring pigs at a time when hogs are generally a little higher. One should lay special emphasis on the supply of feeds for the late winter and

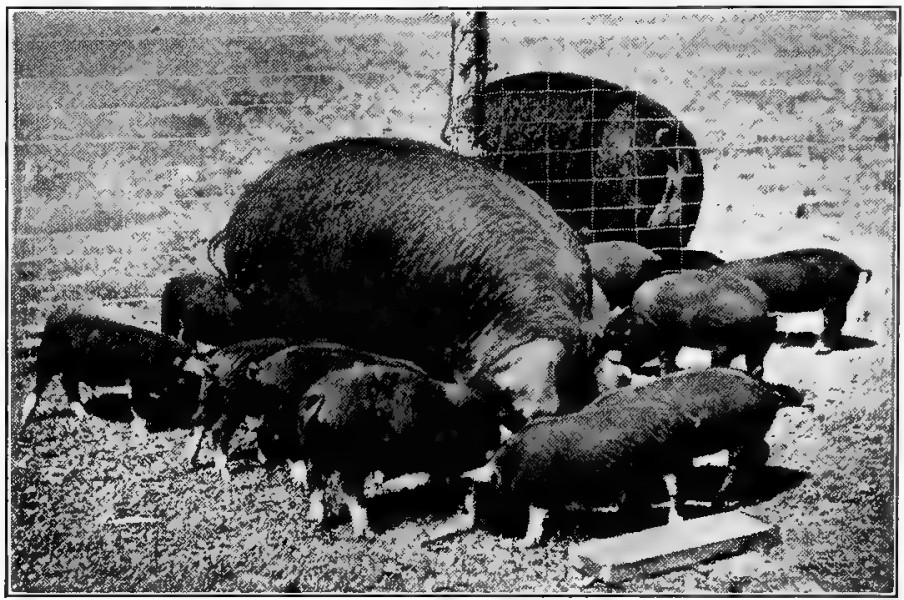

Grazing lots make fall litters as profitable as spring farrowings on the farm of Joe R. Martin in Georgia.

spring months, and by a proper system of feed supply the fall pigs can be made just as profitable as spring pigs.

Early castration best.-Many hog raisers let the pigs get too old before castrating. The castrating should be done at about five weeks of age, for the reason that the hog is then easier to hold, loses but little blood, and seems but little disturbed by the operation. This early castration also prevents miscellaneous breeding and breeding too young. The details of the operation are given in the next chapter. 
Young vs. old sows.-There is but little difference between the pigs of young and old sows. Owing to the fact that gilts with the first litter do not usually do as well as older sows, it seems advisable where possible to use sows, other things being equal. It is nearly always true that bred gilts can be obtained at lower figures than older tried sows, and this largely accounts for their more general use by those entering the swine business. It seems that the best sows for breeding purposes are therefore the young sows, but not gilts. With the old sows the period of usefulness is too limited, and after a certain age is reached they are apt to become barren. Other things being equal, a sow with the second litter is about as good as one can do, because she will take good care of her pigs and her period of usefulness will be greatest. A sow has generally lived the best part of her life during the first seven years. Some fail before that age and some exceed it. Some sows will breed regularly for ten years and more.

Pigs from old and young sows.-As pointed out in the previous paragraph, the age at which the sow is of greatest usefulness is between the time of her second litter and the time when her breeding powers begin to fail. Some are inclined to discriminate against the pigs of both the first and second litters, but there seems to be no just ground for such discrimination. Owing to the fact that pigs coming from sows that have had two litters have been more fully nourished than in the case of younger sows, they may have some slight advantage. With the sows of the first litter the pigs suffer some because during pregnancy the sow continues her growth and some extra nutrition is required, which is obtained at the expense of the nutrition of the pigs. 
Cost of a fifty-pound pig.-It is possible for a fiftypound pig to be produced at figures varying all the way from $\$ 5$ to $\$ 50$. To figure the cost of a pig at birth, one will have to figure the cost of the sow, interest and insurance on her for six months, and the cost of her upkeep for six months. Interest, taxes, insurance and other fixed charges would amount to $\$ 5$ for the six months. The feed cost for six months will range from $\$ 10$ to $\$ 18$. If the cost amounts to $\$ 18$, and there are six pigs, each will cost $\$ 3$ at birth. If the cost is $\$ 18$, and there are nine pigs in the litter, the cost at birth will be about $\$ 2$, which is a fair average cost figure. It costs all the way from less than 50 cents to over a dollar per weck to raise a pig. At eight weeks of age the pig should weigh close to 50 pounds, and at a maximum of $\$ 1$ per week for feed and care, and at $\$ 2$ each for cost at birth, the total cost would be about $\$ 10$ each. In many instances it will be possible to produce pigs at eight weeks of age for half the above, or for $\$ 5$ each.

Weaning the pig.-The time to wean a pig is when it is from six to eight weeks of age. The weaning process should consist in a gradual feeding of other feeds until the pig can get along without its mother's milk. After weaning the quantity of feed should be increased as rapidly as the pig's appetite indicates. The proportion of concentrates to be fed will depend on what other feeds accompany it.

Care of the sow and pigs at weaning time.-The weaning of pigs should not be sudden. By the time the pigs are eight weeks of age they will have become able to eat almost anything the older hogs can eat, and if they have 
been fed separately from the sows, they will have acquired more dependence on other feeds than the sow's milk. And, if they have become gradually accustomed to being absent from the sow, the weaning may be finally consummated by permitting them to return to the sow once a day for two or three days, meanwhile lessening the sow's feed so that less milk will be produced. The gradual weaning is as much for the sake of the mother as the pigs. The sow may be expected to come into heat a few days after the pigs are weaned and regularly thereafter until bred.

Care of the gilts.-After weaning the gilt will require but little special care and attention up to the breeding age. Ample grazing crops should be supplied, and she should be forced, especially with roughages and bulky feeds, as the middle will be developed in size, which will be a distinct advantage later. She should not, however, be fed so as to make her excessively fat. At eight or nine months she may be bred, after which some further attention will be required. She should not be placed with larger animals and the supply of proteins should be increased. The gilt usually grows but little during the later stages of pregnancy, which shows the importance of late breeding and liberal feeding.

Age at which to breed.-A mistake that is commonly made is to breed too young. The result is that the gilt is forced not only to nourish herself, but she must also nourish the developing embryos. She cannot do both of these perfectly. If pregnancy intervenes before the growth process has advanced beyond a certain point, not only will the final size of the sow be affected, but she 
will never make as good a mother as she would have had she been more nearly mature. It must be remembered that this extra drain on the gilt does not come only during pregnancy, but it exists all the time she is suckling the pigs. Under no circumstances should a gilt be bred so that she will farrow under one year of age

The time to breed.-Perhaps the most favorable time for a litter of pigs to come is in the early spring, when they can feed on the newly starting grass. A second litter, coming in September or October, should be provided for. Our southern climate will permit of this, and especially do they seem to do well where a good swamp pasture is accessible.

The breeding season.--Sows will usually come in heat a short time after the pigs are weaned and about every twenty-one days thereafter. The pigs should suckle for about eight weeks. When the sow comes in heat she should be taken to a boar, and after a single uninterrupted service she may just as well be taken back to her lot. The sow, when in heat, usually indicates it by swelling of the vulva and by a change in voice. Instead of a squeal there is a rather long-drawn-out roar. When a sow fails to come into heat there is something physiologically wrong. Of course, they will not come in heat if too old or if they have been bred. If the pigs are not yet weaned they need not be expected to come in heat, and if excessively fat they are not so apt to come in. The period may sometimes be hastened by placing the sow in the same lot with the boar. If a sow comes in heat but will not catch, the best thing that can generally be done is to fatten her for pork, unless she is an ex- 
ceptionally valuable sow, when other expedients may be resorted to.

Age and time to breed pure-bred sows.-A great many of our best breeders make a practice of having their gilts bred to drop pigs at one year of age, and, if they have been properly pushed along, this is not too young. Others seem to prefer to wait until later. In farrowing at from one year to fifteen months of age gilts from one spring may farrow the first litter the next spring. Fall pigs are usually a little slower growing than spring pigs and fall-farrowed gilts may frequently be bred to farrow in the winter or early spring after they are a year of age. While most breeders prefer spring litters on account of the food supply for the several months to come, fall litters or litters at any other season are all right and can be made successful. Throughout the southern states the market for pure-bred pigs is best in the late winter months and pigs farrowed in the early fall can often be sold early to good advantage.

Period of gestation.-After the ova or germ cells of the sow have been fertilized, gestation or pregnancy starts, which ends with the expulsion of the pigs from the uterus. The length of the period of gestation is fairly constant and will vary but little either way from 112 days. Heavy feeding tends to hasten and light feeding to retard the farrowing date. Early-maturing types also require slightly less time. A sudden cold spell, nervous excitement, the sight of another sow farrowing, the sight or taste of fresh meat or blood, and certain drugs, as ergot, cotton root extract and digitalis, may cause premature termination of gestation. 
Care of pregnant sows.-In the case of the gilt in particular, attention should be given to ample food supply, for she not only has to have additional feed for the developing pigs, but for the continuation of her growth. The quantity of concentrates or grain will have to be increased as pregnancy advances and the quantity of feed should be according to appetite. Pasture is especially valuable, for it gives ample exercise, which is necessary to the pregnant sow. After $2 \frac{1}{2}$ or three months has been reached, the pregnant sows should be placed in a lot together, away from other hogs, and especially away from large stock. The food supply should have variety, and it should be of such a nature as to encourage growth. The pregnant sow has a strong natural tendency to tatten, this being nature's way to provide for ample food for the coming pigs in case there comes a shortage in food supply. It is possible to make the sow too fat and clumsy. Thus the feeds must not be too fattening, but should contain a high percentage of protein. Cowpeas, alfalfa, peanuts, velvet beans, and other protein feeds have special value. A little tankage or meat meal is a good thing for brood sows at all times, and especially during pregnancy. Care should always be taken to see that too much corn is not fed for too long a time during pregnancy. The same may be said of other highly carbonaceous or fattening feeds.

Abortion.-We frequently have cases of abortion or slinking of pigs. This may be brought on by several things. It may be due to a contagion or disease. It is generally the result of some accident, such as a kick from a horse or mule, from over-heating, or from rough handling otherwise. It may also be due to something eaten, 
as many poisons occur in certain feeds that are capable of producing premature birth when sufficient quantities are consumed. When abortion takes place during the later stages of pregnancy, some difficulties may be experienced in handling the surplus of milk in the udder.

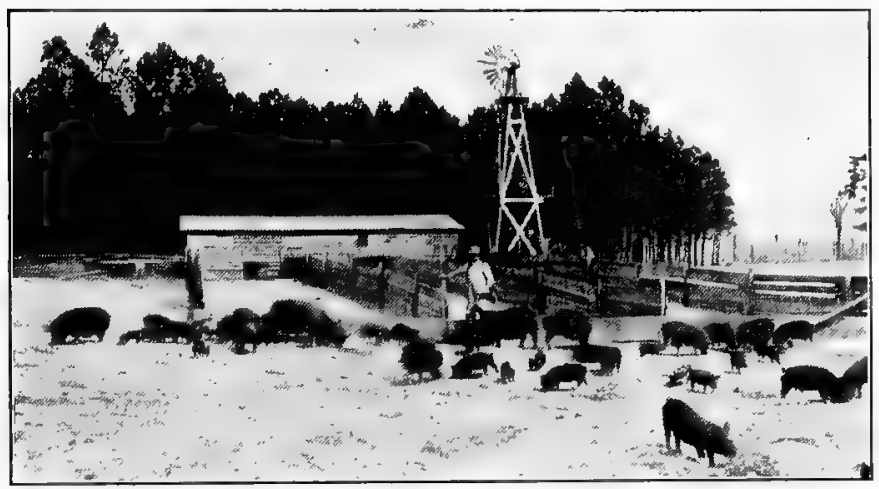

Winter farrowing house on farm of N. H. G. Balfour in North Carolina.

In most cases this milk will be absorbed without trouble, but in other cases some treatment will have to be given to check and dry up the secretion. In some instances abortion or premature farrowing becomes constitutional and chronic, when the best thing that can be done is to fatten the sow for pork.

Farrowing.-Prior to the delivery of the young certain changes take place with the mother, which indicate the approaching event. The causes of these changes are none too well understood, but they are purely physiological and normal, and are probably brought about through the agency of harmones or internal secretions. 
Among other changes the udder becomes congested and swollen. At first the secretion is waxy, but it later develops into colostrum and then to normal milk. Just prior to delivery the belly sinks and scemingly enlarges. The vulva becomes congested and swollen and quite elastic, capable of being widely distended. The cartilaginous connections between the bones, especially bones near the pelvic region, become very elastic. An uneasiness and restlessness are experienced. Seclusion is gencrally sought and an attempt is often made to make a rather elaborate bed. The gestation ceases with the expulsion of the embryos during labor, which normally results involuntarily from violent abdominal muscular cxertions and certain other physiological activities. In some instances it may be necessary to provide assistance to farrowing sows. This is because difficult farrowing is frequently encountered, which may result disastrously to both the sow and the pigs. High condition, disease, weakncss, wrong presentation, injury and abnormalities may cause these difficulties. Aid is imperative in cases where much difficulty is experienced, and it often becomes necessary to assist in removal of the pigs by means of pig forceps, which may be of various types and makes.

The sows should be watched carefully as the farrowing date approaches. About 112 days from service she may be expected to farrow. In the colder months the farrowing should take place under shelter, preferably in a well-lighted ventilated and roomy farrowing pen. The herdsman should watch all his sows carefully during farrowing time, but should not interfere in the least unless it becomes necessary. Soon after the pigs have 


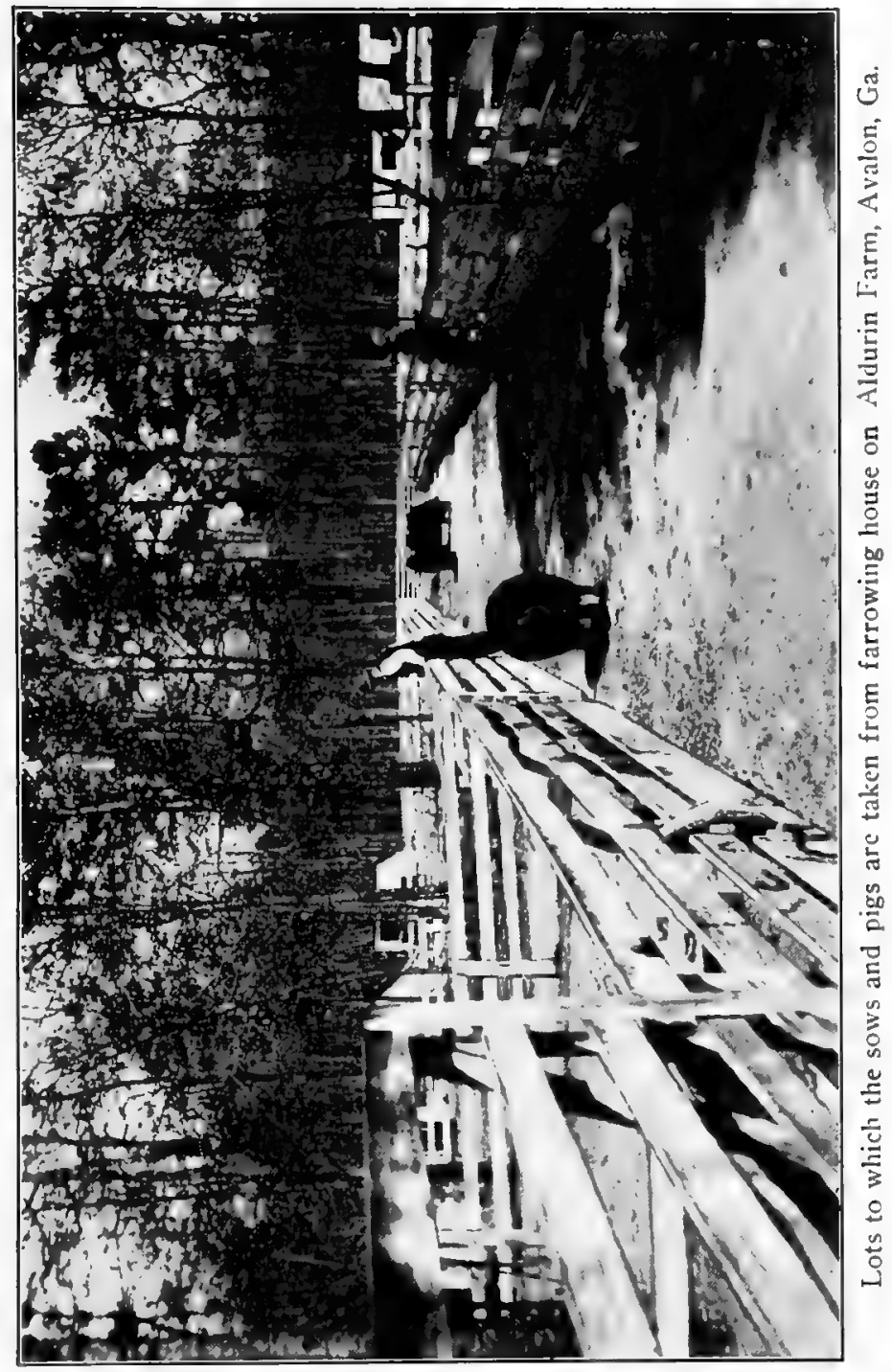


been dropped the pigs should be inspected to see that they are all right and to remove any dead ones. In the case of pure-bred swine the number, sex, and farrowing date must be recorded so that the pigs can be registered.

Management of brood sows.-Aside from the matter of adequate feed supply of the right sort, there is nothing of so great importance to the success of the swine business as proper brood sow management. So far as the sows are concerned, we must take into account such factors as age, breed, condition, conformation, quality and disposition in their relation to reproduction. In addition such external factors as feed supply, shelter, care and attention should be given due consideration. In all our efforts to secure maximum returns we must take every factor at what it is worth and constantly keep in mind in brood sow management that what is wanted is that animal that will mother the greatest number of thrifty pigs that will return a profit to their grower.

Caring for the boar.-While boars as a rule can stand more rough treatment and lack of care than any other class of hogs they respond readily to good treatment. They require a little different treatment from all other classes of hogs. It is an easy matter to make them too fat. They need pasture and only moderate amounts of concentrates. The boar should not be allowed to run with the sows, as he will worry both himself and them. Boars need some attention after they attain maturity to keep their tusks cut so that they will not injure people or stock. A very good way to do this is by means of a bolt cutter. When not on pasture and when lot fed, they may need their feet trimmed occasionally. If the 
skin becomes too harsh and rough it may be improved by applying crude oil, old lard or other greases. Above all, the boar should be kept gentle if such is possible. He should be handled often, firmly, but gently.

Bad habits.-Practically all bad habits to which swine are subject are either the direct or indirect result of poor feeding or faulty management. Hogs that are closely confined about the house or barn frequently develop such bad habits as chicken eating, rooting, fence breaking or climbing, ill temper, chasing other animals, eating pigs and cow sucking. Nine times out of ten these bad habits are the result of improper feeding and poor management. It is a difficult matter to break hogs of these habits, and a much better way of handling the situation is to remove the cause, which means proper feeding on grazing crops in the field. 


\section{CHAPTER VIII}

\section{SWINE DISEASES AND THEIR CONTROL}

Indications of disease.-One of the essentials to success in any system of swine industry must of necessity consist in the ability to detect and control swine diseases.

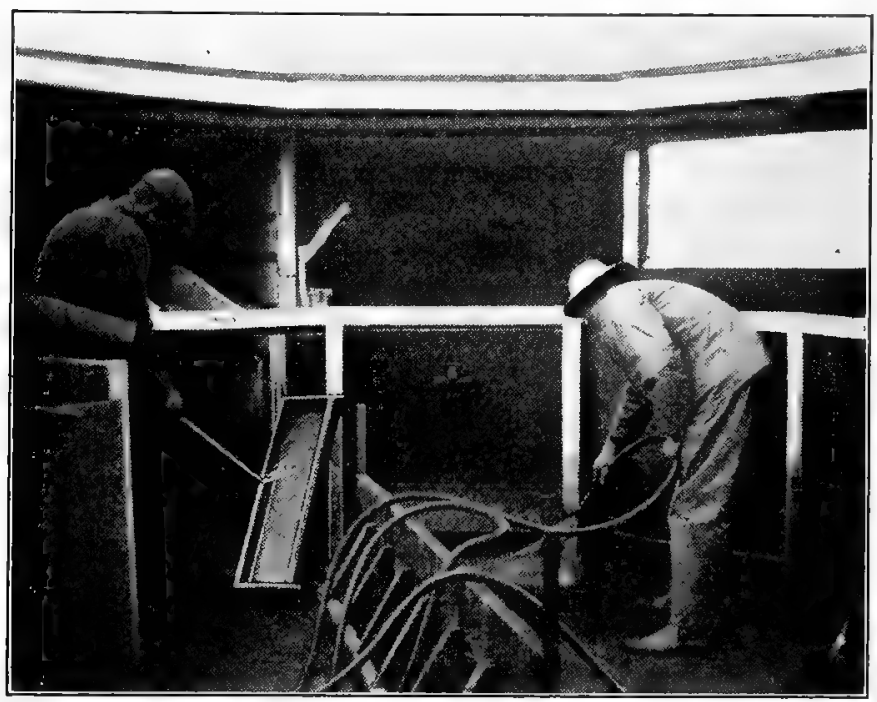

Sunlight and dip are used to prevent disease on the farm of W. W. Shay, Cruso, N. C.

There are so many ailments to which swine are subject and in which the mortality is high that it becomes important that we be able not only to recognize disease when it occurs, but we should know the causes of disease in order that we may more successfully prevent them. 
Likewise, we should know the recognized methods of treatment for the more common diseases. It is an art to be able to detect disease in its primary stage so that it can be properly handled to prevent spread and properly treated to effect a cure where possible. We must, therefore, know what the healthy condition of the hog is and know what conditions are indicative of lack of health.

In many diseases the first place where its effect will be noticed is in the temperament or disposition of the affected animals. They may be sluggish and dull, refuse to eat, and show other indications of lack of health. On the other hand, in some diseases the nervous system may be so affected that they become excitable to the extent of delirium. Staggering gait, convulsions, paralysis and twisting of the head to one side and walking in a circle are conditions of disposition and temperament suggestive of diseased condition.

Another valuable guide to the health condition of swine is the condition of the hair or bristles. While the hog has coarse bristles that are comparatively thinly distributed over his body, their general appearance is one of the best indications we have of a hog's general condition or thrift. When a hog is improperly nourished or is suffering from disease, one of the first places it shows up is in the hair coat. So long as the hair is bright and glossy, and lies down smoothly, giving the whole body a slick appearance, we look upon the hog as doing well and in a thrifty condition. If, on the other hand, the hair is dull and stands on end and is inclined to curl up we say he is not normal and is unthrifty or diseased in some way. This unthriftiness may be due to lack of sufficient food or feed of the right sort, or it may be due to parasites or to other 
pathological conditions. All of our hogs should be carefully watched, and when they show an unhealthy condition of hair coat the condition should be corrected as soon as possible.

In addition to the hair the condition of the hide is also an excellent indicator of the health condition of the hog. The hide or skin follows the hair coat in condition to a large extent. In health it is soft and mellow. An inelastic, hard, rigid, scaly skin is indicative of an unhealthy condition.

In diseased conditions we also find variations from the normal in the body temperature, pulse rate and respiration, or the rate of breathing. The normal temperature of a pig varies from 101 to 105 degrees with an average of about 103 degrees. The temperature is changed from the normal by several conditions, even in health. The normal pulse rate of the pig is from 70 to 80 , and the respiration rate is 10 to 20 normally, but with excitement or heat it may reach 50 or 60 . The pulse, respiration and temperature are all increased by excitement and heat, and lowered by cold and rest. Other indications of a diseased condition are to be found in the appearance of the exposed mucous membranes and in the condition and quantity of the excretions and secretions. The application of these to the detection of disease requires a little more skill than the previously mentioned indicators, and use can be made of them only by those that are more or less skilled.

Administering medicines.-The expert herdsman will become more or less experienced in the administration of medicines. Under the majority of circumstances the medicine will be administered in one of four ways. First 
of all is the administration by way of the mouth, next is by injection beneath the skin, the third is by direct application to the affected parts, and the fourth is by way of the rectum. There are other ways in whch medicines may be administered, but they are seldom resorted to. In administration by way of the mouth the medicine may be given in the food in most cases, or else it may be given as a drench, if proper care is taken. In drenching a pig the important consideration is not to pour the medicine in the pig's mouth while he is excited and squealing, but to wait until it becomes quiet. Injections under the skin are sometimes made use of where the drugs are not too irritant. The administration of medicine by way of the rectum is rarely made use of. Where the dosage is to be given to a number of hogs care must be exercised to get an even distribution to prevent overdosage and to get a sufficient dosage all the way round.

Veterinarians.-There are a few troubles that occur in the swine herd that can be treated by the herdsman without the aid of a veterinarian. There are many times, however, that the services of a veterinarian should be had when they are not. By all means when a condition occurs quite general over the herd a veterinarian should be called if there is the least doubt as to the disease and its condition. Even when the trouble is not general in the herd, but is not understood and the disease is doubtful, it will pay in most cases to consult a veterinarian. The fact should be impressed upon the grower of swine that practically all diseases of swine are amenable to treatment and control through the application of scientific knowledge, and above all a licensed or graduate veterinarian should be called in, and not a quack who 
can do little but harm in spite of his probably false reputation.

Swine diseases.-In a general way the diseases of swine may be divided into three main groups. The first of these is the result of an infection of some sort and may be either infectious or contagious, depending upon the method of transmission from one animal to another. In addition to diseases due to microscopic organisms there are certain other diseases due to macroscopical organisms. Such diseases as these are conveniently classified as parasitical diseases. There are also a number of diseases that can be classified as surgical, since surgery is involved in their treatment. As a good example of surgical diseases, we might refer to hernia or rupture. In addition to this classification, diseases are frequently classified into groups according to the organs, parts, or systems affected. Among these groups we find diseases of the circulatory system, digestive system, excretory system, locomotor system, nervous system, reproductive system, respiratory system and diseases of the skin.

Circulatory system.-The circulatory system involves the heart and the blood vessels carrying blood to the different parts of the body and returning it to the heart. Diseases affecting the circulatory system are generally the indirect result of unhealthful conditions in other parts of the body, and this becomes one of the first systems affected in general disease. Aside from the matter of pulse rate and strength and other minor diseases of the system, there are two diseases affecting this system that are not uncommon in the swine herd. The first of these is septicæmia or blood poisoning, and the other is fatty 
degeneration of the heart. Such diseases as pleurisy, hog cholera, pneumonia and rheumatism may give rise to inflammation of the tissues around the heart. General blood and heart diseases are indicated by high fever, weak, quick and irregular pulse, with indications of pain. Treatment of diseases of the circulatory system is usually unsatisfactory and should be preventive rather than curative.

Septicæmia (blood poisoning).-This trouble can be suspected where an operation has been performed, after a difficult farrowing, or following a bruise or injury. In the case of internal abscesses it occurs without apparent external symptoms: Fever, loss of appetite, muscular tremors, stupidity and weakness are the usual symptoms. The discase is due to absorption of the toxic substances produced by the bacteria. As a usual thing the infection comes from an external wound or bruise, but in the case of abscesses septiciemia may result from pyogenic bacteria or abscesses in different parts of the body, which abscesses may or may not become apparent on the surface. The treatment is preventive. Wounds should be kept in such condition as not to predispose to infection. Closed abscesses and wounds should be opened and cleansed and washed with a solution of boric acid, hydrogen peroxide or other disinfectants. Diseased individuals should be separated from the herd and given nutritious and easily digested feeds, and in some cases tonics may be advisable.

Fatty degeneration of the heart.-This disease occurs not infrequently under lot-feeding conditions where extensive use is made of corn. It is due to over-feeding with 
fat-making feeds without sufficient exercise. The disease is characterized by a fatty deposition around the heart and by a partial replacing of the muscular tissue of the heart with fatty tissue. The symptoms are a weak, irregular heart action, generally accompanied by difficult breathing. The prevention of the disease largely consists in proper feeding with ample exercise.

Digestive system.-There are many diseases affecting directly and indirectly the digestive system. This is because the system is so vitally connected with every other system on the body. When the digestive organs are diseased all other parts of the body will suffer. The proper fecding has more to do with the condition of the digestive system than any other factor, and under healthful feeding conditions organic diseases will be largely prevented and the animal will be better able to ward off infectious and contagious diseases. Diseased conditions of the digestive system are manifested in several ways. The appetite is invariably affected one way or the other. The pulse, temperature, and the respiration are also affected in most diseases. Among the more important diseases affecting the digestive system are indigestion or gastritis, which occurs in both the chronic and acute forms, gastro enteritis, scours, diarrhea, constipation, hog cholera and thumps.

Indigestion (gastritis).-Cases of indigestion are quite common in the average herd. Many of these cases are acute and others chronic. Where acute the cause is generally due to over-feeding or to irritating feeds, and indigestion is not infrequent from the administering of quack remedies for fancied ailments. Poor care in feed- 
ing or management, exposure and other debilitating influences may lead to forms of indigestion. Worms and insufficient supply of nutritious feeds and excess of cottonseed meal are common causes of chronic indigestion. The presence of indigestion is indicated by vomiting, fever, voluntary isolation, evidences of pain, constipation, which is generally followed by diarrhea, and in chronic forms it is generally accompanied by a general unthrifty condition and slow and stunted growth. Restlessness and evidences of abdominal pain are noticeable symptoms in acute forms of the disease. The trouble may or may not result in the death of the animal, depending on the cause of the indigestion, the severity and treatment. First the cause should be determined and that removed. Care must be taken not to give irritating drugs. In acute cases induced vomiting followed by a dose of oil is excellent treatment. Comfortable quarters, a light but nutritious diet and removal of the cause will generally effect a cure in a short time in acute cases. About the same treatment is recommended for chronic cases. A vermifuge, followed by a physic and repeated every 10 days, with possibly a tonic and with proper regulators should soon give relief.

Hog cholera.-There is no greater obstacle to a more extensive swine industry in the South than hog cholera, a very contagious disease, often sweeping away entire herds at a time. The serious nature of the disease makes it imperative that we more thoroughly understand the disease in order that we can more successfully cope with it when the necessity arises. It is caused by a specific organism so small that it cannot be seen under the most powerful microscope, and it can be filtered through the 
most dense filter. These facts make it difficult to study the organism and to trace its transmission from one place to another. Swine only are susceptible, and the susceptibility is very high, especially in the acute form, when frequently an entire herd will become infected very quickly. The disease is also characterized by a very high death rate. The period of incubation, or the time that elapses between the time the hog is exposed and the time it takes the disease, is variable. In some cases it may be two days, and again it may be two weeks, depending on the physical condition of the hog or on its susceptibility, the virulence of the strain and the method in infection. The period of incubation is much shorter in the acute than in the chronic form.

Among the symptoms are loss of appetite, rise in temperature, rapid intoxication and high death rate. Unfortunately, there are other diseases characterized by similar symptoms and it is only possible to definitely diagnose hog cholera by post-mortem examination. In addition to the ante-mortem symptoms we find a characteristic huddling together in pens or nests, stiffness of joints, a cough, especially in the chronic form, a mucous discharge from the eyes and nostrils and red blotches on the skin, especially on the abdomen. At first the animal is constipated, but that is later followed by a persistent diarrhea. In cholera, especially in the chronic form, we find a wide range of symptoms, which result largely from secondary infections with other organisms. These secondary infections frequently complicate diagnosis. In describing the diagnosis of hog cholera it is generally customary to differentiate between the acute and chronic forms, the differentiation being more or less arbitrary and 
based upon the rapidity of the course and mortality of the disease.

There are several diseases that are apt to become confused with hog cholera when only the external symptoms are considered. Among these parasitic infestation is commonly confused with cholera and is also associated indirectly with it. Acute and chronic gastritis or indigestion has somewhat similar symptoms. Pneumonia and swine plague are other diseases apt to be confused with it. Thus the post-mortem diagnosis is most reliable. On post-mortem the cholera hog will show in acute cases characteristic hemorrhagic lesions. These occur in the skin, in the serous mucous lining of the body cavity, intestines, kidneys and lungs. In chronic cases the lesions may take the form of ulcerations, accurring in about the same locations as in the acute form.

Knowing of the dangers of hog cholera, one of the most important things to know is how to prevent it. To do this we must first know how it is spread or introduced into herds. Above all, the infected hog is probably the most important factor. If the hog is alive, it should be subjected to the most rigid quarantine. It it dies the carcass should be burned or buried deeply. Before a new hog comes into a herd it should be placed in quarantine for at least four weeks. The disease can be controlled and prevented by proper sanitary precautions and the judicious use of preventive serum. The methods by which the disease can be carried from an infected to a healthy herd are numerous. Dogs, pigeons, other animals, men and farming equipment of all kinds can carry the disease from an infected to a healthy herd. The buzzard is reputed to play an important part in the dis- 
semination of the disease, but if we would destroy the carcasses of hogs that die from cholera this source of possible infection would cease to a large extent. Above all, a healthy herd is not nearly so apt to become infected with cholera as an unhealthy one. We should, thercfore, keep our hogs healthy and free from worms. If cholera is in the immediate community, or if the herd has had a good chance for infection, an experienced person should vaccinate the herd with serum. Good hog cholera serum properly used is a sure preventive of hog cholera. The use of serum as a preventive is to be recommended above all others. Losses from hog cholera can be eliminated by keeping the herd immuned, but under ordinary conditions this is not an advisable practice.

When a herd becomes infected quack remedies and medicines should be avoided. A competent veterinarian should be called in. If the disease is cholera, all healthy hogs ready for the market should be marketed at once where permissible by law. Sick animals should be isolated at once from the herd. Dead hogs should be burned and all rubbish cleaned up, houses and nests should be closed until disinfected, and wallows should be filled up or drained. Quicklime should be used on all places known to be infected. If cholera is present provision should be made at once to inoculate all animals in the herd, both sick and well. The serum is given to the weil to prevent them from having the disease and to the sick to effect a cure, which it will do in many cases where the disease is not too far advanced. Experience has shown that serum has some curative properties, and an experienced person can generally tell when it is advisable to give it to a sick hog. 
Many farmers and hog raisers administer the serum themselves. There is no reason why anyone cannot apply it successfully if he follows the few simple instructions. All hog raisers should know where the serum is obtainable. In most states the State Veterinarian has charge of the sale of serum and controls its use. It is sold at so much per c.c., which ranges in price generally from $3 / 4$ to $1 \frac{1}{2}$ cents per c.c. Full directions for the use

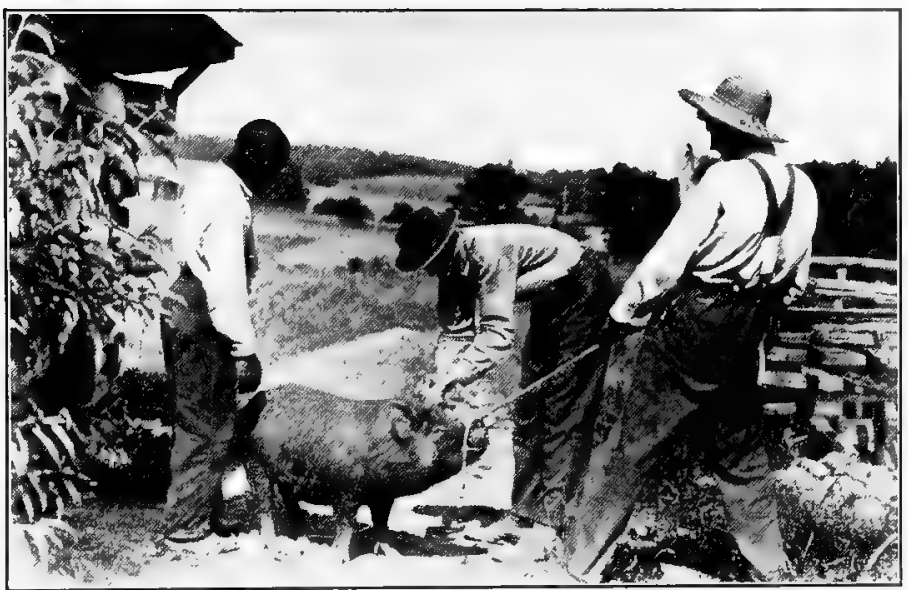

Administering serum to prevent hog cholera. Courtesy R. D. Goodman of North Carolina.

of the serum are also obtainable from the officer or institution in charge of the sale of the serum. The dosage of serum generally varies according to the gross weight of the hog. The following are the dosages generally recommended:

$$
\begin{aligned}
& \text { 25-50 pounds -...--_--_- 10-20 c. c. } \\
& 50-100 \text { pounds -..-_-_-_ 20-30 c. c. } \\
& \text { 100-200 pounds -........ 30-45 c. c. } \\
& \text { 200-400 pounds - }
\end{aligned}
$$

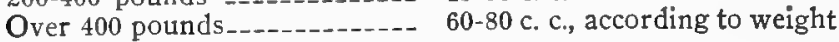


For some time use has been made of the double treatment by which the hog is given an infection of hog cholera and the serum at the same time, resulting in a more or less permanent immunity to the disease. This method of immunization has been given a most thorough trial, and in most states is either now prohibited or advised against on account of the resultant spreading of the disease and effects on the animal, many animals being more or less permanently stunted by the treatment. This brings up the question of the length of the immunity secured by the inoculation with serum alone. It has been found that this is quite variable, dependent to a large extent upon the natural susceptibility of the individual. In some cases the immunity will last but six weeks, while in others it will last as long as six months. Sows advanced in pregnancy can safely be inoculated with the scrum if proper precautions are taken. Many preventive measures and precautions are also a matter of actual experience. When a herd becomes infected one must know how long to keep the herd immuned until the danger of cholera is past. That will depend largely on the rigidity of the sanitary precautions taken.

Constipation.-Constipation is rather a common disease in swine herds, especially where the hogs are fed on dry feeds. It is characterized by a dry, hard feces containing but little moisture. It is indicative of disease rather than a disease itself. The treatment of the condition is simple. In mild cases dieting will soon bring about the proper condition. Dry feeds should be avoided and only sloppy and green feeds fed. The consumption of much water is desirable, and induced exercise assists in the recovery to normal condition. A small dose, from one 
to two ounces of castor oil, or two or three ounces of linseed oil, will often relieve the constipation, and in acute cases calomel at the rate of a grain per 25 pounds in weight should relieve the condition in a short while. Under the methods of swine growing which we should adopt in which grazing crops play an important role, trouble from this source becomes almost negligible.

Diarrhea.-Diarrhea is a common symptom of many diseases affecting the digestive tract. In most cases it is due directly to an irritation, which may be brought about by poisons, or, as is more often the case, it may be due to a bacterial infection. In the case of young pigs it may assume the form of scours, and the discharge may be a grayish liquid, with an offensive odor. This form of scours is generally fatal in quite young pigs, but diarrhea can generally be controlled in older pigs and hogs. The disease is characterized by a gradual loss of appetite, sometimes by fever, and indisposition to exercise, indications of pain and, above all, by the watery nature of the fecal discharge. Diarrhea may result from irritations due to intestinal worms. Indigestion, bacterial infection from putrid feeds, change from dry to green feeds and improper protection from the cold are other causes of diarrhea. The treatment consists in the removal of the cause. If the cause is another disease, the other disease should be treated. Light diet, purgatives of castor oil, nitrate of bismuth, opiates, formaldehyde and slaked lime may be indicated. Especially is the lime good where the cause is an acid irritation.

Thumps-spasm of the diaphragm.-This is quite a common occurrence in pigs, and is the result of an irrita- 
tion of the phrenic nerves. Indigestion, especially overloading of the stomach, intestinal parasites and lack of adequate exercise are some of the more common causes of the condition. The symptoms are marked. When standing the body will move forward with the shock of the contraction. When lying down the force of the spasm can plainly be seen on the side of the animal. The spasms occur with considerable regularity, but the contractions occur more often when the stomach is full. The treatment consists, first, in the removal of the cause. A vermifuge of turpentine, a half teaspoonful per 80pound pig, followed by a dose of calomel, should be given. Exercise on pasture is beneficial, and the bowels should be regulated with laxatives and tonics. Tincture of opium is generally recommended to stop the contractions of the diaphragm.

Excretory system.-The diseases of the kidneys and bladder are confined for the most part to inflammations. Congestions of the kidneys from an injury or from a poison are not uncommon in swine. Exposure is a cause of kidney and bladder trouble and the excretory organs are quite commonly affected by such diseases as swine plague and hog cholera. Germs may infect both the kidneys and bladder and give rise to irritations and inflammations. When the urine is retained for any length of time the fermentations release free ammonia, which irritates the mucous membranes with which it comes in contact. The symptoms of diseases of the excretory system are generally obscure. The appetite may be irregular, indications of pain may be manifested, the urine may be passed frequently in varying quantities, and it may be of high color. In some cases there is a retention 
of the urine. When the disease is advanced more general symptoms may become manifested, and death may result from uremic poisoning. The bowels must be kept open and frequent laxatives should be given. Home treatment in cases of diseases affecting the excretory system are generally not very satisfactory, and in most cases the treatment should be given under the direction of a competent veterinarian.

Diseases of the locomotor organs.-Diseases affecting the organs of locomotion may be either due to physiological or morphological conditions. Nearly all diseases of locomotion manifest themselves by lameness. Thus when lameness occurs we should at once ascertain the location of the trouble and proceed to remove the cause. The more common causes of lameness are rheumatism, sore feet, stiff joints and weak legs.

Rickets is a rather common disease, affecting the bones of the legs in particular. It is due to an insufficiency of mineral matter in the diet, and is generally easily corrected by the addition to the diet of such minerals as lime, phosphates and carbonates. Lack of exercise, crowded quarters, filth and poor fecding are common contributive causes. The disease may assume the form of a crumbling or fracturing of the bone without due cause, or it may assume the form of distortion in the extremities.

Lameness from rheumatism may result from articular and muscular rheumatism. Frequently we find muscular rheumatism resulting as secondary to another disease. Overfeeding and exposure are two causes to which rheumatism is generally attributed, but it may come from other sources, especially from diseases affecting the ex- 
cretory system. In the articular form there may be a swelling and stiffness of the joints. In the muscular form the muscles of the back are more commonly affected. The treatment is not very satisfactory. Comfortable quarters, a laxative diet and regular and judicious feeding are valuable.

Sore feet is due generally to an infection of the soft parts between the toes. If the disease is the result of confinement on hard pasture, the hogs should be placed on softer ground. In addition to removing the cause of the infection we should take means to destroy it. To do this the feet should be washed once a day in a 5 per cent solution of a coal tar dip. Another good remedy is to wash the feet daily in a saturated solution of copper sulphate. Above all, the animals affected should be kept out of the mud, mire and manure.

Diseases of the nervous system.-There are several causes that will give rise to an inflammation or congestion of the brain, with its resultant effects of paralysis, epilepsy, apoplexy, blindness and deafness. Among these are over-heating, tumors or parasites, injuries, improper feeding, filth and exposure and infectious diseases.

Apoplexy and paralysis are usually associated with inactivity. In the case of the former the condition is usually sudden and general, while in the case of paralysis the disease may be restricted to certain parts, and it may come on more slowly. A sunstroke is an apoplectic condition. In these diseases the cause should first be removed and the treatment applied according to the cause. In some instances recovery can be effected, but the best treatment is prevention, and the hog should not be placed under those conditions predisposing it to these diseases. 
Epilepsy is characterized by periodic convulsions, between which the animal may appear normal or only slightly stupid. The tendency may be congenital, or it may result from an injury. In young pigs it may result from an irritation due to parasitic infection or from the cutting of teeth. Here again treatment consists in removal of the cause where it is known. Cathartics should be given. Cold water applied to the head of the animal may give temporary relief.

Blind staggers is a symptom rather than a disease. Treatment is unsatisfactory, and unless the cause is known and can be removed it is generally better to kill the afflicted animal.

Diseases of the male reproductive organs.-While there are a few diseases of the reproductive organs or system of swine that occur frequently in the breeding herd, they are not nearly of the same importance as some other diseases. In the boar we find that there are several contributive causes to sterility, among the more important being too high condition with insufficient exercise, too much service and improper feeding. Sterility may result from an injury and may not be amenable to treatment, but many cases of sterility can be remedied by the removal of the cause. Medicines other than tonics are of little or no value.

Among boars orchitis is not uncommon. This consists in the inflammation of one or both testes. It is generally the result of an injury or an infection. If the infection results in an abscess, removal of the diseased testicle is the quickest remedy. Medicinal treatment is of some value. Potassium iodide administered in doses twice daily for a week or 10 days may bring relief. Laxa- 
tives and light feeding, with local applications of iodine tincture or mild blisters, will assist in rapid recovery. Another disease in boars is that of foul sheath, in which an inflammation is set up in the sheath as a result of an accumulation of dirt. The prepuce will swell and some discharge may be noticed. Some local fever, painful urination, retention of the urine and bad odor may be found. The remedy is to place the hog on his back, wash out the prepuce thoroughly with warm water, making an incision if necessary, and keeping it free from infection by washing daily with a disinfecting solution.

Diseases of the female reproductive system.-Barrenness in the sow is due largely to the same causes that bring about sterility in the male, and the treatment consists largely in removing the cause. High condition is perhaps the most common cause of barrenness in the sow. Closing of the os or entrance to the uterus, inflammation with an acid discharge, old age, and morphological conditions may result in barrenness. When a case shows up, the first thing to do is to provide for ample exercise, a reduction in condition if necessary, and if the periods do not occur the sow should be placed in the lot with the boar. If the sow comes into heat, but does not conceive, the trouble may be local. If an inflammation is present, it will have to be treated with disinfecting solutions until stopped and, if the uterus is closed, it may in most instances be opened. Most barrenness is due to improper feeding and management.

Abortions may occur in sows from injuries or from infections. Crowding, exposure, over-heating, excitement, spoiled feeds and disease in general must be avoided with pregnant sows. Nothing can be done to 
prevent an abortion after it once starts, so that the only cure is prevention. The after treatment will depend on circumstances.

Mammitis or garget results as an inflammation of the udder due to an over-supply of milk. Heavy milk supply, loss of all or a part of the litter, obstruction of a teat, injuries and infections may be causative factors. Equal parts of belladonna and gum camphor mixed with two parts of vaseline make an excellent ointment for such cases. Bathing with hot water is of value and withdrawal of the milk and massaging of the udder will assist in overcoming the inflammation.

Diseases of the respiratory system.-Nasal catarrh is a rather common disease of swine that corresponds with a cold in the head in people. The symptoms and treatment are similar. Over-heating, chilling and irritations are common causes. The inflammation and infection may extend to the pharynx and larynx, causing the disease technically known as pharyngo-laryngitis. The bowels should be kept open and health conditions carefully looked after. The same conditions that cause nasal catarrh and pharyngo-laryngitis may lead to bronchitis or inflammation of the bronchial tubes, which disease is nearly always accompanied by an infection. Here again prevention is the best and most satisfactory treatment. Comfortable quarters, light diet and general good care are usually a more effective treatment than medicines.

Neglected bronchitis frequently terminates in pneumonia. Fat hogs are more subject to this disease than thinner ones, and the chances of recovery are greater in thin ones. The general symptoms are fairly characteristic-fever, loss of appetite, depressed spirits, coughing, 
exhaustion and inflammation of the visible mucous membranes. Preventive measures are very important. Careful nursing, comfortable quarters and light diet are about as valuable as medicines. Counter irritants, stimulants and tonics may be used to advantage in the convalescent period. The bowels should be kept open at all times. Pneumonia is generally associated with pleurisy, an inflammation of the serous membrane lining the chest cavity. The causes, symptoms and treatment are similar to those for pneumonia.

Another disease of swine affecting primarily the respiratory organs, but often extending to other parts, such as the intestines, brain and lymph glands, is tuberculosis.

It is not very common in the South, but is probably becoming more prevalent. The common source of infection in swine is from cattle by way of the skim milk, manure, or through the eating of offal from slaughtered tubercular cattle. Pulmonary tuberculosis is accompanied by symptoms similar to those manifested in cases of chronic bronchitis. Methods of possible infection and predisposing causes should be removed, and all suspected animals and those known to have the disease should be isolated or destroyed.

Swine plague is another disease of swine affecting the respiratory system. It is often confused with both hog cholera and pneumonia. It occurs in both chronic and acute forms. The preventive treatment is about the same as that employed in hog cholera and pneumonia. This disease does not occur often in the southern states.

Canker or sore mouth (necrotic stomatitis).-This infectious disease is fairly common and frequently occurs in light form, when the animal may recover without 
the knowledge of the herdsman. It affects the mouth and adjacent parts and may extend to the nostrils, and even to the stomach and intestines in severe cases. It is caused by a specific micro-organism (bacillus nccrophorus). Congestion of the lips and gums, salivaton and the occurrence of necrotic patches in the later stages are primary symptoms. A foul odor is often present. Diarrhea, prostration and emaciation occur in advanced stages, followed by death in from two to six weeks. Where it occurs the infected animals should be isolated and their mouths or heads dipped daily in a 2 per cent solution of creolin or good coal tar dip.

Urticaria or nettle rash.-Concurrent with the abovedescribed disease there frequently occurs a general herd infection of urticaria or nettle rash. This disease arises from skin irritations resulting from various causes, and is characterized by skin eruptions on various parts of the body, especially on the inside of the thighs, the belly, between the forearms and back of the ears. Cleanliness, sanitation, disinfection and prevention of skin irritations are the best methods of prevention. Non-irritating dips, such as five gallons of water to which has been added six ounces of cresylic acid compound, U. S. P., or a two per cent solution of a good coal tar disinfectant should be used.

Eczema.-Conditions under which some hogs are kept render them susceptible to a chronic skin disease characterized by inflammation and tenderness, followed by watery vesicles or blisters, which change to pustules. The disease can easily be prevented by sanitation, disinfection and proper use of sanitary hog wallows containing a weak solution of coal tar dip. 
Sun scald.-A discase similar to the above occurs to some extent in the South known as sun scald. About the only difference between sun scald and pitch mange or eczema is in the cause. White hogs seem much predisposed to the disease. The symptoms are about the same as given for eczema except that parts exposed to the sun are more often affected. Shade and general good care in sanitation and disinfection are the main precautions necessary to successfully control the trouble.

Parasitic diseases of swine.-In addition to those diseases of swine caused by bacteria and morphological conditions, we have those caused by worms and lice. Fully 90 per cent of losses in swine are associated with parasitic infection. Roughly, the parasitic diseases of swine may be classified into those caused by worms and those caused by lice and mites.

Worms.-Among the diseases of swine caused by worms those affecting the alimentary tract are more numerous and important. The large thorn-head worms are found wherever the secondary host, May beetles, are found. The males are from 2 to 4 inches in length, and the females may attain a length of 12 inches. As a rule the worm is round, and the anterior end bears a number of recurved hooklets, to serve as an attachment to the wall of the intestines. The attachment may give rise to irritation and possible rupture, resulting in peritonitis and death.

Another very important worm affecting the alimentary tract is the large, round worm, known as Ascaris Suis. The females often attain a length of 12 inches. The worm is white, tapering off to a point at each end, segmented, 
and the eggs are laid and passed out to be reconsumed without an intermediate host. The distribution of this worm is most extensive, and but few herds are entirely free. They mostly inhabit the small intestines, but frequently penetrate the gall duct, and even enter the liver. A few worms do not cause serious results. When present in quantity, they cause indigestion, liver diseases, progressive emaciation and occasionally convulsions. This is one of the most troublesome worms affecting swine and must be provided against if serious damage is to be avoided.

The pin worm is a small white worm more commonly inhabiting the large intestines. It is shaped similar to the Ascaris, is white or grayish in color and about a half inch in length. These worms never do serious damage unless present in extremely large quantities, when intestinal indigestion may result.

Another less important intestinal worm is the whip worm. They attach themselves to the wall of the intestines and may give rise to irritations in this way.

Trichinosis.-This small round worm has the adult stage in the intestinal tract and the larval stages in the muscular tissues. It is supposed that the hogs become infected by eating rats and slaughter-house offal containing the cysts of the worm, growth to maturity taking place in the intestines. Copulation and reproduction take place to liberate numerous embryos which penetrate the intestines and migrate to the various tissues. This disease is communicable to man, and care must be taken not to eat infected pork. The medical measures are about the same as those recommended for other intestinal worms, but the preventive measures must be from a 
special angle owing to the methods necessary for infection.

Treatment for intestinal worms.-Preventive treatment is to be used in preference to medicinal, although the latter must be resorted to at times. It is very important to keep the hogs healthy and in a thrifty, growing condition. General sanitary and precautionary measures must be used in preventing infection and spread of these parasites. When an infection occurs medicines have to be resorted to. Many vermifuges and vermicides have been recommended. Turpentine, santonin, calomel and areca nut are all excellent for use with swine. Doses of a teaspoonful of turpentine, eight grains of santonin, five grains of calomel, or three drachms of areca nut are common doses. These should be followed by a physic of castor oil and repeated in two or three weeks if necessary. In addition to the above it is always well to keep before the hogs a worm preventive mixture such as recommended on page 146.

Lung worms.-The lung worms are present in most localities and are described by Craig as the most common parasite of swine. When conditions are favorable for its development, they may become present in such large numbers as to lead to bronchitis, pneumonia and other lung diseases. The lung worm is about the size of a thread and ranges up to nearly 2 inches in length. The chief source of infection seems to be by the breathing of dusty air bearing the eggs or encystments. The method of prevention and treatment is summed up in sanitation, proper feeding and proper management. 
Kidney worms.-This worm infests the kidneys and the fat surrounding them. Dr. Carey states that from 90 to 95 per cent of all hogs over one year of age in the South are affected with this worm. No satisfactory treatment is known, and preventive measures, such as recommended for other worms, should be used to keep the disease in check.

The hog louse.-This common external blood-sucking parasite is the largest louse known. It is the most common external parasite of swine. It affects unthrifty swine more often than the thrifty ones. The female cements the ova or nits to the bristles. These hatch in from 10 to 14 days. These lice suck the blood, irritate the skin in puncturing it, and it is possible that they may transmit infectious diseases.

Another parasite which burrows in the skin is the one that causes mange, of which there are two or more kinds. The most common is the sarcoptic mange. The adults are scarcely visible to the naked eye. The rapidity with which these parasites can multiply is almost beyond conception. The disease may become serious if not properly treated, resulting in loss of hair, thickening of the skin, cracking of the skin and soreness. The treatment of this disease consists in the application of oils and sulphur. Another form of mange known as the demodectic or red mange occurs rarely and is incurable.

Treatment for external parasites should be both preventive and curative. The dipping vat is the most valuable remedy. Dipping once every 10 days for three dippings, or longer if necessary, and each month thereafter, with a good coal tar or lime sulphur dip should soon control these parasites. In order to make the work effective 
it must be accompanied by adequate sanitary and disinfecting measures. Thorough rubbing with machine or other oils will often effect a cure.

Surgical diseases.-The expert herdsman should be able to perform the minor and simple surgical operations

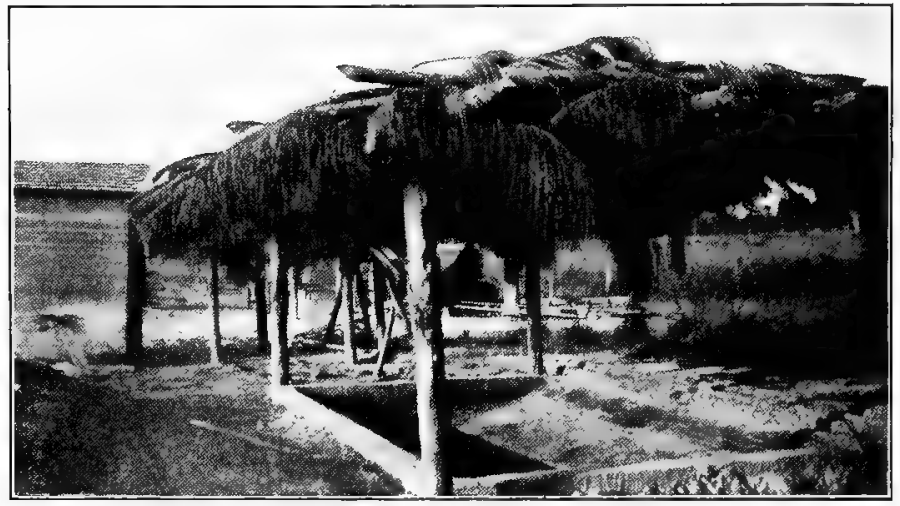

Cement wallowing hole used to control lice on Broadacre Farms, Bonifay, Fla.

necessary in the routine care of the herd and be able to understand and appreciate the procedure where more skill is required. He should understand the necessity for asepsis and the conditions favoring infection. Above all, the herdsman should be able to perform such simple operations as castration, treatment of some cases of hernia, abscesses, cuts and bruises.

Castration.-This is a very simple operation that is performed by many who do not take the pains and precautions with it they should. If properly done, there is practically no danger from complications, but as usually 
done abscesses, tumors, hernia, peritonitis and the like frequently result. The most favorable age for the operation is just before weaning time, when the setback caused by the operation will be reduced to a minimum. Castration can, however, be done successfully at any age. In the operation sanitary precautions are important. Hot and wet weather should be avoided. Filthy pens, wallows and other sources of infection should be eliminated. A good plan is to cut out feed for 12 hours before the operation. Confine the pigs to a small pen and catch one at a time without excitement or heating them up. The one that is to perform the operation should see to it that he is provided with a sharp knife or sharp knives. In addition he should have a $5 \%$ solution of a coal tar disinfectant, some cotton pledgets, some suturing thread and a needle or two if there be many to castrate. The scrotum should be thoroughly washed two or three times with the disinfectant, the knife should be disinfected, and with one stroke an incision should be made on either side of the median line parallel to it sufficiently large to permit the squeezing out of the testicle. In pigs the cord is generally severed by a jerk, in shotes by scraping into, and in boars by the use of the emasculator. When the pigs are of any size it may be well to ligature the cord before severing.

After the operation is performed care should be taken to see that the incision comes to the lowest part of the scrotal sac to prevent an accumulation of pus. In cool weather it will probably need no further treatment aside from washing with the disinfecting solution. In warm weather when the flies are bad some make a practice of applying pine tar to the wound. If a hemorrhage per- 
sists it may be treated by washing out with hot water, by crushing or ligating the blood vessel or by packing for twenty-four hours with absorbent cotton. Cases of rupture due to an enlarged inguinal canal require more skill than is ordinarily possessed by the herdsman, but some develop sufficient skill to handle such cases.

Tumors are rather common as a complication following castration. When present they must be dissected out. Abscesses are treated in a similar manner, and the main thing is to keep them open and washed out with a disinfectant. In some cases only one testicle comes down in the scrotal sac, or neither may come down. Such cases are called cryptorchids and require an abdominal operation, in which skill is required.

Spaying.-A few years ago spaying was practiced to some extent in swine herds, but now but few are spayed. This comes largely from the fact that a little more skill and care are required in the operation than in castration, and from the fact that we now market our sow pigs intended for slaughter at an early age. This operation is justified only in rare cases, and should be avoided as much as possible.

Hernia or rupture.-There are three kinds of hernia or rupture-umbilical, scrotal and ventral. All involve that condition in which a part of the intestines or omentum pass through the abdominal wall into a pocket in the skin. The umbilical hernias so common in pigs are generally congenital, although they may result from an injury. The scrotal hernias result from an overly large inguinal canal. Ventral hernias result from protrusion of the intestines as a result of a tear or injury in the abdominal wall. 
Ruptures are more or less dangerous and difficult to handle, and should only be treated by someone skilled in handling such cases.

Abscesses and tumors.-The location, nature and conditions will, to a large measure, determine the treatment indicated in the case of an abscess or tumor. Abscesses on the exterior should be opened if not already so. Prior to opening they should be brought to a head by fomentations or blisters. After opening they should be washed out daily with a 2 per cent solution of coal tar dip so long as is necessary. Provision should be made to prcvent reinfection. Tumors are more difficult to handle than abscesses as a rule. Their growth can generally be checked by two or three treatments of potassium iodide. After they become encapsulated they can be dissected out if exposed.

Prolapsus of the anus.-This condition is met with occasionally and may or may not recover of its own accord. It consists in a protrusion from the anus of a portion of the rectal intestines. The treatment will depend on the conditions. The protruding part can be cut off and the edges sutured together at the anus. Where practical the parts should be washed with astringent solutions and replaced. Hogs properly looked after and fed are seldom afflicted with this condition.

Cuts and bruises.-All wounds, cuts and exposed surfaces should be cleaned and disinfected, the jagged edges cut off and hydrogen peroxide applied followed by an application of turpentine, camphor or arnica ointment. In addition to this the healing can frequently be hastened 
by a dusting with powdered alum or iodoform. The wounds should be washed and treated daily and great care taken to prevent infection. Bruises are to be treated slightly different. In the treatment of bruises hot fomentations, ice packs, arnica, camphor, stimulating liniments and lead acetate are indicated according to conditions. All severe bruises should receive prompt and regular attention.

Sanitation and disease prevention.-Nothing is of greater importance in the control of disease than sanitation and disease prevention. Fully nine-tenths of the disease that occurs in our swine herds is preventable. Disease prevention consists in proper methods of breeding, feeding and management. Much of the disease we have is due to improper feeding. Pure foods are as important to the health of swine as they are to the health of men. The foods must be more than pure, the rations must be properly balanced, not necessarily so much as the relation of the nutrients is concerned, but so far as quality, quantity and suitability for the purpose are concerned. Not only must the food supply be looked after, but pure water must be present in abundance, and provision must be made to keep it cool, clean and free from contamination. The hogs must also be provided with suitable shelter in winter from the cold and wet and in summer from the heat and rains.

Disinfection.-In order to ward off disease it is necessary that precautions be taken to destroy disease germs. Especially when a disease of an infectious nature has existed on premises, efforts should be made to destroy the germs and their hiding places. The agents to be used 
in the disinfection of houses, sheds, lots, pens, etc., will depend on several factors, chief among which are the organism and the material or places in which it exists. A 1 per cent solution of corrosive sublimate is very effective, but its poisonous nature renders its use more or less undesirable. Chloride of lime is probably the most valuable, the least poisonous, and least expensive disinfecting agent we have, when used at the rate of five ounces per gallon of water. This is applied by spraying the infected parts or premises. All loose litter and rubbish likely to be infected should be burned.

In addition to the cleaning up and disinfection of premises proper disposition must be made of the bodies of hogs that have died of disease. These can be either buried or burned. In either case the work should be complete. In burying, the top of the carcass should not be nearer than four feet to the top of the ground. A good plan is to sprinkle some chloride of lime over the carcass after placing it in the ground. When the carcasses can be burned it is best. Fat hog carcasses burn fairly easy. A good plan is to place the carcass on a stump and pile brush about it to start the fire. Where brush piles are available hogs can frequently be burned by placing them on top of the pile and firing. Where wood is not plentiful a carcass can be burned at little expense and trouble by digging a trench and placing supporting iron bars across, and then by placing the carcass on the bars and burning wood beneath. As soon as the fat starts dripping the carcass will usually burn from then on of its own accord.

In disinfection work and prevention of infection care must always be taken to see that the hogs do not have 
an opportunity at infection. One of the most neglected sources of infection is the barnyard manure pile. Dirty and filthy lots with stagnant water, old mud wallows and outhouses are frequent sources of infection and disease germ breeding grounds.

Hog wallows.-A clean wallow is a source of comfort and health to the hog. The average farm hog wallow is, however, not kept clean, and instead of being a source of health they often become a breeding and distributing place for disease germs. A good concrete hog wallow can be kept clean and a little kerosene or coal tar dip added to the water occasionally will materially assist in killing the lice.

Dipping vats.-A very practical means contributing to the general health of the swine herd is the dipping vat. It consists essentially in a tank of special design into which a dipping solution is placed and through which the hogs are driven. Where feasible a dipping vat made of concrete is most satisfactory. The shape of the vat should be such that a hog falls into it at one end and walks out at the other. The arrangement of the pens, chutes, drain pipes and dripping boards are dependent on local conditions. The vat should be deep enough that the hog will be completely submerged when he first falls in. Experience in various instances has resulted in a general agreement as to the best size for a dipping vat. An inside top length of 8 feet, top width of 24 inches, and bottom width of 20 inches are very good dimensions. The end of the vat where the hog enters should be perpendicular, and the end where he walks out should be slanting, with corrugations to prevent slipping. 
In the construction of a concrete dipping vat the excavation should be dug 8 inches larger than the dimensions given above, which will allow for a 4 -inch wall. The grouting should be placed first on the bottom and on the incline. The inside forms should then be put up, using the dirt as the outside forms. Reinforcements of woven wire can be used to strengthen the vat, but it is unnecessary. A 1:2:4 mixture should be used for the grouting and a 1:2 mixture for the facing. Anyone contemplating the construction of a vat should secure some of the excellent bulletins and other publications devoted to the subject. Most all of the state veterinarians and State Agricultural Extension Departments are equipped to give instructions and information along this line and in many instances they can furnish a limited amount of immediate supervision.

Dipping solutions.-There are many effective solutions that can be used in dipping vats for treating lice and mange. Crude oil, lubricating or engine oil, or kerosene to which some sulphur bas been added, when placed on top of the water in the vat, makes a fairly good dip. A mixture of 8 pounds of fresh lime, 24 pounds of flowers of sulphur and 100 gallons of water makes a large quantity of good disinfectant when properly prepared. The lime should be slaked with enotigh water to form a thick paste, with which the sulphur should be well mixed. Twenty-five or 30 gallons of water are then added and the whole boiled for at least an hour. Water sufficient to make 100 gallons of dip is then added. This dip gives the best results when used warm, although it is nearly as effective used cold. In addition to the homemade dips there are several excellent commercial dips 
containing coal tar derivatives. Of course, the same solutions that are used in the dipping vats may be used in the wallows, but they should only be used in diluted form. The job is usually not so thorough in the case of the wallow as with the vat.

The hog oiler.-In recent years a number of new devices have been placed on the market designed to assist in killing lice on hogs by means of an application of oil to the skin. These have proven quite valuable. They do not take the place of the dipping vat on the hog farm, however. In principle these oilers have a reservoir for holding the crude oil, with a feeding arrangement so that the hog rubs on some part of the machine and the part of the hog rubbed receives a coating of the oil, which will kill all of the lice it comes in contact with. The same results can be secured by tying old grain sacks around rubbing posts and saturating with oil or by pouring the oil in the wallows, but these methods are a little more wasteful of the oil than are the patented devices. 


\section{CHAPTER IX}

\section{MARKETING}

Marketing.-Regardless of the phase of the pork industry in which one is primarily interested, it is quite essential that he carefully consider the marketing end if profits are to be expected. He is naturally a producer and must be prepared to sell his products. Growers of swine generally fall into one of two classes, depending on their source of profit. The hog grower or the pork producer is the man whose principal product is fat hogs for making pork. The swine breeder makes a business of breeding pure-bred swine, to be used either in the breeding of other pure-bred swine or to be used in porkproducing herds. Of course, in so far as the marketing end is concerned, the market producer of swine and the breeder of pure-bred swine bear a close relationship to each other. The market producer is dependent on the breeder to a large extent to keep up the perfection and standards of his herd. The breeder is largely dependent on the market producer for his sales of breeding stock. In many herds the owner is both breeder and market hog producer, which may be the ideal arrangement. In either case it is most important that every man engaged in the breeding or growing of swine closely follow the market and its demands in order to produce that type which sells to the best advantage. The marketing of pure-bred swine is distinct from the marketing of fat hogs and should receive separate consideration. 
Marketing of pure-bred swine.-There is a demand and market for pure-bred swine, but finding a purchaser is costly and a large advertising expense seems unavoidable. The two principal ways of advertising are by using the advertising space of farm papers and by going to the expense and trouble of showing. In many cases the breeder himself must attend the shows and sales in order to keep up his acquaintance with other breeders and swine growers and to keep posted on the types most highly prized and sought after. With the small breeder in particular does the cost of advertising come high. Combination and consignment sales will, of course, reduce the expense of selling and they are of special benefit to the small producer. The widely scattered small breeders are the ones that will really do the most good, and the ideal way will be, of course, when all farmers produce pure breds or nearly pure breds.

Shipping pure-bred swine.-One of the principal things in the marketing of pure-bred swine that does not concern the producer of pork hogs is that of proper shipping. In the case of pure-bred swine shipments are generally made by express with one or two pigs at a time, while in the case of swine intended for use as pork the shipments are usually made in quantity, generally in carload lots by freight.

The art of shipping pure-bred swine comes only from experience. Care must be taken to make the crates light but strong, provision must be made to see that the hogs are comfortable and do not have a chance to hurt themselves, and to see that ways and means are offered for feeding and watering if they are to go any distance. When a sow and pigs are to be shipped, the problem be- 
comes more complicated. If the distance is not over two or three hundred miles the sow can be shipped in one crate and the pigs in another. Where the shipment is farther the sow and pigs can be shipped in the same crate if it is of a special design. In the shipping of breeding swine there are other considerations not met with in the case of market hogs. The matter of registration papers has to be looked after, the inoculation against cholera and other health precautions are frequently different from those for hogs intended for slaughter.

Profits from pork production.-There are two factors controlling to a large extent the profits to be made from the production of pork. One of these is the cost of production and the other is the net sales. We are naturally interested in producing at least possible cost to give us a greater selling margin. So far as the selling end is concerned, we are especially interested in the gross sales and the costs incidental to making the sales. The difference between this net sale figure and the cost of production is the net profit from the operation. As a rule the market value can be approximated more closely than the cost of production, since the market value is influenced by fewer factors. The market value is almost entirely dependent on the supply and demand and upon the costs of marketing.

Factors influencing cost of production.-The cost of production is dependent on both economic and local conditions. Of the economic conditions influencing the cost of production we have the market value of the land and equipment, interest on the investment in other than land and equipment, and the natural adaptability of the 
farm for pork production. Among the local conditions influencing the cost of production we have as the most important the rate and cost of gains, the cost of maintaining a breeding herd, and the degree to which the hogs are grown or fattened before marketing. Under the first of these local conditions we might include the cost of feed, the cost of labor, the kinds of feed and the value of the manures produced. Under the last heading, the degree of condition and growth, we might include the breeding, which involves type and quality.

The lard type of hog.-The predominating type on the markets of the entire country is the American or lard type of hog, which has been developed largely as the type best suited to Corn Belt conditions. The type has been to a large extent adopted in its entirety by the South, although we are best equipped for the production of an intermediate type between the fat or lard hog and the bacon type, with the ideal approaching the lard type rather than the bacon hog. The hogs from the southern farms do not average as fat as the hogs from the Corn Belt, and the indications are that the hogs coming from southern farms will never average as fat as hogs coming from the Corn Belt farms. This will come about naturally from a more extensive use of grazing crops, the greater economy of production of lean over fat, and as a result of climatic conditions.

Bacon types for special markets.-In pork-packing establishments the carcasses are examined by experts, who determine which carcasses will make good breakfast bacon. Only a few are found that will make first-class bacon. It often happens that a hog of one of the lard 
brceds will make good bacon, owing to individual peculiarities, or to the influence of feeding, or both. But by raising the bacon type of hog and feeding properly, nearly every animal will make good bacon, and if there is a proper market accessible, or if the bacon is intended for family use, the raising of such hogs may become desirable and profitable. It is only in a very rare instance that the use of a strictly bacon breed of swine is to be recommended under southern conditions, for, as has been pointed out before, the ideal southern type will more nearly resemble the lard type rather than the bacon type.

Marketing finished pork.-The establishment of porkpacking plants in many towns and cities in the South is one of the most striking developments at present along the line of marketing swine products. Steady and constant markets will result as a natural sequence, and the marketing end of the swine business will not be so difficult in the future as in the past. It is the plan of these packing plants to take care of any excess production over immediate demands of the local butchers. A great many farmers do not raise enough pork for their own use, or else they raise it but sell it and buy fresh and cured pork for several times what they sell their own for. This failure to produce a supply of pork for home consumption is a loss to be regretted. We should first produce enough pork for home consumption and then have some to market, according to the emphasis we place on pork as a source of income.

Seasonal demands of the market.-One factor which the producer of pork must take into consideration, especially if he is supplying the demands of the local mar- 
ket, is the influence which the scason may have upon the demand for pork. This applies especially to fresh pork. As a rule the consumption of fresh pork is much greater in the colder than in the warmer months. The price will generally average over 10 per cent greater for the colder or winter months. In addition to this, the consumer in the winter months seeks pork with more fat than in the summer months. This influence of the seasonal demands of the markets is of special importance to the small producer, especially the one who markets locaily for home consumption. If a producer is supplying hogs to one of the central markets, it will generally be found that the demand is fair the year through. Fortunately, those seasons of the year in which pork is least in demand are the same months in which it is more difficult to fit hogs for the market. Later in the year, when the demands for fresh fat pork begin to improve, there is an abundance of forage crops admirably suited for fitting hogs for slaughter.

Pork producers should study the market.-Producers of pork should study the market in order that they may know what to produce that will bring the highest prices. It is very essential that they visit the market occasionally and familiarize themselves with the different market classes and grades. They could then interpret market quotations and know better what their hogs should bring if placed on the market at any particular time. Producers should keep posted on market conditions, either through a good market paper or through the letters of commission firms, who advise their clients as to market conditions daily or weekly as the case may be. By continually keeping up with the market one is frequently enabled to 
realize a greater profit than when the hogs are blindly thrown on the market, as they are in many cases.

Produce what the market demands.-All those interested in pork production are in the last analysis dependent upon the demands of the ultimate consumer. We must, therefore, learn what he desires, for if we have something that is wanted there will be no trouble to sell it. We must recognize that there are different kinds of pork. What the ultimate consumer wants is pork that is tender, juicy, palatable, and with as little waste as possible in cooking. It must also present an attractive appearance to sell well. The tenderness, juiciness and palatability depend largely upon cooking. Of course not all of our pork is sold over the block to be used as fresh pork, but a very large portion of it is made up into cured pork products, such as bacon, hams, shoulders, white or dry salt meat and various canned and smoked products. In general, these also must possess the qualities demanded in fresh pork to command the best prices.

Change in market demands.-An inspection of the kinds of hogs coming onto southern markets today as compared with ten years ago shows a marked difference. Ten years ago the percentage of swine with improved breeding predominating was much smaller than at present. They were generally a year or more of age, and the scrub and unimproved swine, of course, had no great size. Today, however, we find the majority of the hogs coming to the market show some evidence of breeding. The present types are the early-maturing types, and a large percentage are under one year of age. The hog in greatest demand seems to weigh in the neighborhood 
of 150 to 175 pounds, and pigs, when in good condition, are becoming much more popular than formerly.

Most desirable age for marketing.-The most desirable age at which to market is usually the earliest age at which the hog reaches that stage of maturity and fattening when it is suited for the making of pork. The most desirable age is dependent to a large extent upon the time of year the pigs are born and upon the crops grown for fattening. Early spring pigs are generally best marketed in the early fall at eight or nine months of age. Late spring pigs are generally marketed in late fall or during the fore part of the next year, at which time they will be ten months or a year of age. Fall pigs should be marketed in the summer or early fall. If they come early in the fall they may be marketed in summer, while if they come later they are generally at the proper age and condition for marketing very late the following summer or early fall at from nine to eleven months of age. It is rarely advisable to market before eight months or later than twelve months of age, and all else being equal, the earlier the better. One is controlled in marketing not alone by size and age of the pig and condition of the market, but primarily by the feed supply.

Most desirable size for marketing.-The most desirable size for marketing will depend on the time of year and the market. The market will usually take heavier hogs during colder months than during the warmer months. At a large packing center the size is not of such great consequence, for there is always a demand for every size of hog. It has been found, however, that the size that is in greatest demand on the central mar- 


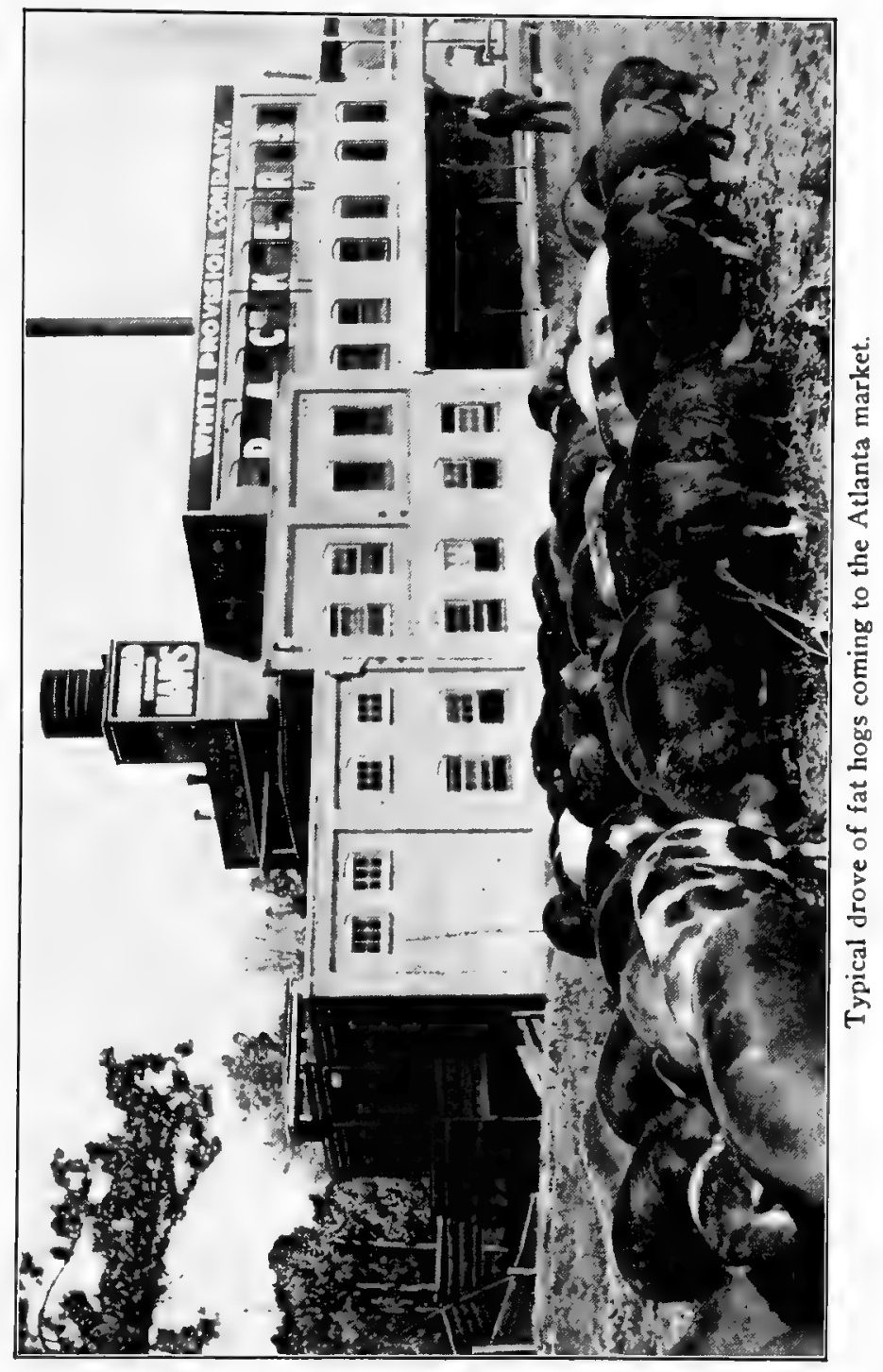


kets is that size averaging about 180 to 200 pounds. For home slaughtering purposes this is also a very satisfactory size. In the winter months a heavier weight may be used to advantage, and in summer a lighter weight is readily salable.

The economy of early marketing.-The producer of pork must continually bear in mind the advantages to be derived from early marketing. The gains are made at a greater expense as the hog grows older; the longer one keeps a hog the longer he has to maintain him or supply him with maintenance feed, that feed which makes no gain, but which is necessary for the continuation of the animal's life. Thus, in order to minimize this maintenance cost and to produce the gains at the lowest cost, we should aim to place on maximum gains at the earliest age possible, in order that the production may be the most economical.

Finishing for market.-While the growth process had best not be allowed to slacken from the time it is started until the hogs are marketed, it is often not advisable to try to make the maximum fat production from the start. It is easily possible to arrange for ample fattening feeds to come on in the summer and fall of the year. A few of these are of such a nature that they will keep over through early spring, but there is a decided dearth of fattening feeds from the time spring opens up until midsummer, or until the early cowpeas or corn come on. Of course one can feed corn or other concentrates during that season when fattening feeds are scarce, but so far as practical the fattening should be done in the fields with a minimum of lot feeding. Crops suitable to finish hogs 
for the market in the field must be provided for if the pork is to be produced in the most economical way.

When to ship.-With a continually fluctuating market a producer is at a loss to know when it is the most opportune time to make a shipment. What the producer desires is, of course, to sell at the best figure possible. In this connection, where a producer ships to market there is one general rule that most successful shippers follow, and that is to ship on a rising rather than a declining market. Too many shippers wait too long and ship about the time the market breaks, and they realize less on their shipments than they would have earlier. The object should be, therefore, to ship early on a rising market before the bulk of the shipments are received.

Preparing hogs for shipment.-Before loading a shipment of hogs they should be properly cared for so as to avoid excessive shrinkage in transit and insure arrival at the market in good order. Especially are hogs apt to shrink considerably if they go direct from a grazing patch containing succulent materials. Therefore, just before shipment, one should aim to feed them feeds that will stay with them, feeds not too heating or too concentrated in nature. Good feeds for this purpose are corn and cob meal, crushed oats and ripe grain pasture. This grain feeding is also desirable, since it will give the hogs the appearance of having been grain-fed when the grain shows up in the droppings, and they will be less apt to be discriminated against. If the haul is very long, provision must be made for feeding and watering in transit. According to the present law, the railroad has to unload and feed after 28 hours in transit, but the 
shippers generally sign a release allowing of a longer limit of time so that the hogs reach the market before it is necessary to feed again. However, in case it is necessary to feed in transit corn alone should not be fed, especially in summer, on account of its heating qualities and the possibilities of indigestion due to the riding. A good dry mash of bran, crushed oats and corn is cooling and refreshing and is apt to get the hogs through in the best condition. During the hot weather hogs should leave the shipping point, where possible, during the late afternoon, and in most cases they will arrive at the market in the night, or early the next morning.

Average carloads. - The number of hogs that can be shipped in a single car is dependent on several factors, among which are the size of the car, the size of the hogs, distance to be shipped, the kind of hogs, the kind of car, whether double or single deck, and the weather conditions. Extensive reports on railroad shipments and stockyard receipts show that in single-deck cars the number generally runs about 90 to 100 head for light hogs and from 150 to 175 for light hogs in double-decked cars. It is always better to have a car loaded too light than too heavy.

Marketing.-The two principal ways of marketing hogs are selling to local buyers and shipping direct to a central market. There are advantages to both methods and the most advisable one will depend on circumstances. Frequently one can do better selling to local buyers even in quantity. That will all depend, however, on the condition of the market and the kinds and quantity of hogs one is marketing. 
Marketing through local buyers.-Selling to the local buyer or shipper is one of the most feasible methods of marketing pork open to the farmer and small producer. The regular shipper is known on the market and can generally secure the best prices obtainable. Also, in selling to the local buyer the risks from loss are lessened and the trouble is far less. If there is a decline in the market during transit, it is the shipper and not the grower that suffers. The shipper's long experience is always worth something, and the seller gets the benefit of that. Thus the local buyer can frequently be used to advantage, as the difference between the price he is able to pay and the probable price one would obtain by shipping direct is not sufficient to cover shrinkage, freight terminal and commission charges, and the risks of one sort and another that must be assumed.

Shipping direct to the market.-This method of marketing has many distinct advantages, but it is accompanied by risks. By this method the producer always gets the profit which might fall to the local buyer. This method of marketing gives the grower a chance to learn what the demands of the markets are. By learning this he can more intelligently and profitably cater to the demands of the market. He meets men from other sections and profits from their experiences. He also comes to know the commission men, learns the markets and obtains information in general, which, when applied, will assist him in increasing profits.

Co-operative shipping of swine.-This method of shipping is to be recommended and should be more extensively practiced. By this method the profits of the ship- 


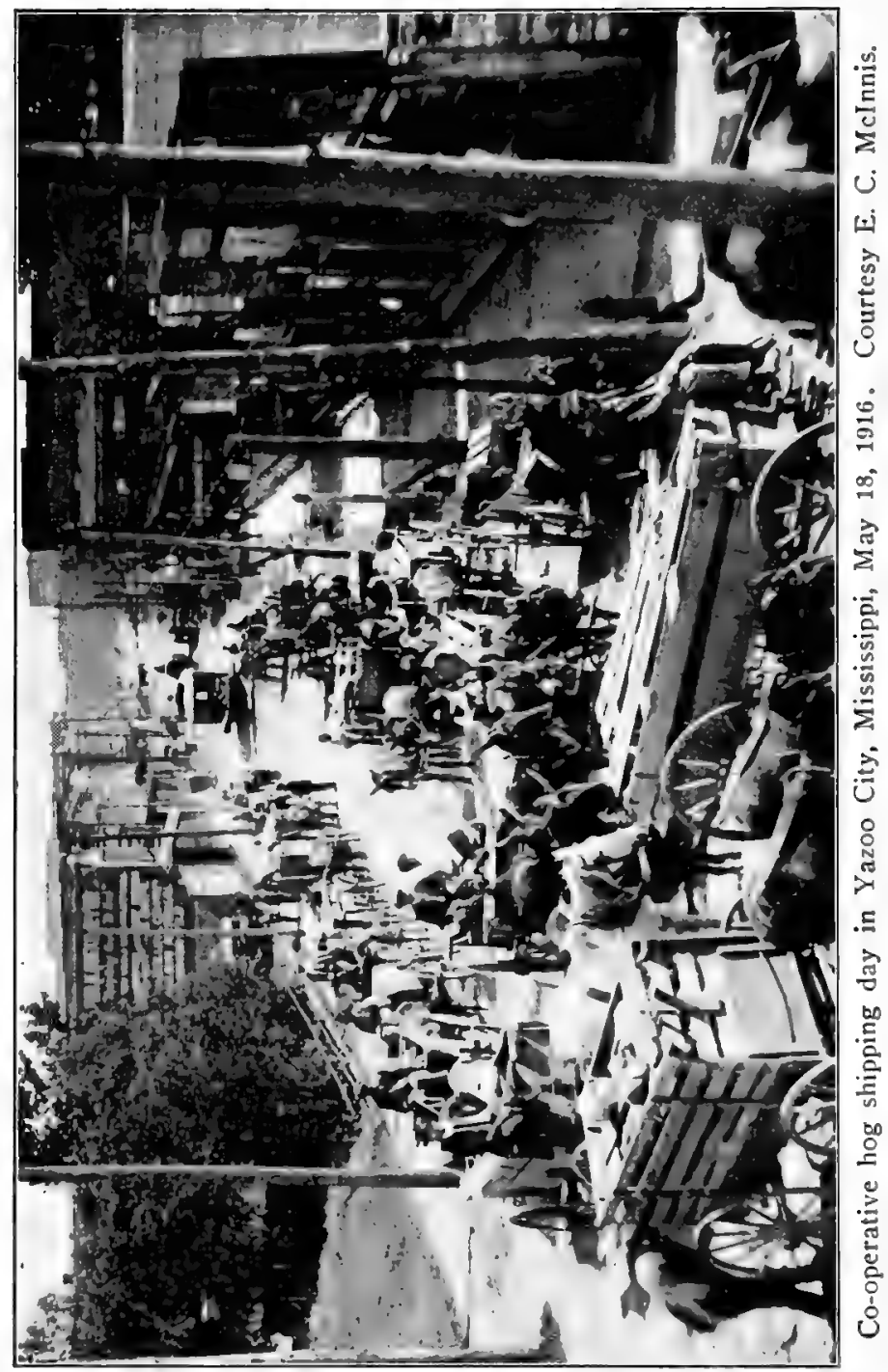


ping point buyer are eliminated. A co-operative shipping association in one state saves its shippers annually over $\$ 6,000$, according to figures given out by the United States Department of Agriculture. These co-operative shipping associations are organized for the most part in connection with other enterprises. Some handle in addition to swine and other live stock, lumber, coal, grain, feed and farm implements. A few handle live stock exclusively. The financial arrangement is generally for the shippers to share pro rata in costs and to pay the manager or shipper a flat rate per car of from $\$ 6$ to $\$ 10$ for the first car and $\$ 5$ each for additional cars on any one day. In some instances the fee may be put on the shipping-weight basis, the manager to receive from 5 to 10 cents per hundredweight. The advantages of such a co-operative shipping arrangement are obvious. The railroads give better service in this way, better prices are usually obtained, one can make a shipment when he is ready regardless of the number he may have, the member does not have to deal with the local buyers, and these, with the other advantages offered, are sufficient to justify the existence of such an organization whenever a sufficient number of hogs are produced in a community.

Lack of shipping facilities.-Under the present method of production the individual breeders and the different sections are not producing a sufficient number of swine to justify the most efficient methods of marketing. Even the railroads in the South do not handle shipments of swine with the same facility and satisfaction as in other sections where more are produced. They are rapidly overcoming this drawback, however, and as soon as swine 
are produced in greater quantities this will be one of the first of the serious handicaps to profitable marketing to be corrected.

Early methods of transportation.-The early method of transportation of live stock in the South was by driving. This method was extensively practiced up to the time of the war and for some time thereafter. In the earlier days this was the only feasible method of transportation. Even after the railroads traversed the country the necessary expense prohibited their use in the transporting of many droves of swine. Prior to 1850 the transportation of swine by any other method than driving was almost unheard of. Driving routes to market points were generally selected where ample feed could be secured en route. The practice was to drive largely at night during hot weather. Where the distance to market was far, several days would be required, and by this method they could be taken to market at a considerable profit with little or no shrinkage. The driving of hogs has largely been superseded by hauling with wagons and by railroads, and in the future railway transportation of swine will be of a considerably greater extent than in the past.

Stockyards.-At several central points in the South there are central markets at which there are stockyards to provide ample handling facilities for hogs. Markets of this kind are located at Augusta, Ga., Baltimore, Md., Oklahoma City, Okla., Ft. Worth, 'Tex., and at other points. Practically all of these stockyards are controlled by an incorporated company, with the stock held by various interests, generally railroads, packing companies 
and live stock dealers holding the greater part of the stock. These stockyards are usually located out some distance from the city on account of cheaper land and better location for the packing plants that are nearly always associated with the yards. The yards are usually laid out after the manner of a town site, with the various yards representing the blocks, and the driveways and alleys representing the streets. Packing plants and other buildings are generally near. Railway tracks usually run along the side of and through the yards. A central exchange building known as the live stock exchange is always present in the larger yards. The live stock exchange is really an organization of the buyers and sellers and dealers that do business in the yards. Their purpose is to control and regulate trading. Either the stock exchange or the stockyards company prescribes all the rules under which stock enter the yards. They have fixed charges on the use of the yards, commissions, costs of feeds, switching charges, insurance, etc. The stockyard companies handle the stock after it reaches the yards and they do all of the weighing which the buyer pays for at a fixed rate per head. The dealers in the yards are usually divided into two classes-the buyers and sellers. The sellers are generally commission men. Methods of settlement vary somewhat, but they are usually on a cash basis and are made through local banks.

Market costs.-When one has a car of hogs to be shipped, if he is the business man he should be, he will figure up all the attendant costs and figure the price his hogs should bring him. Fortunately, most of the costs incidental to marketing are fixed and are pretty well 
known, and the total costs may be figured quite closely. The freight charges are all well known and fixed. There may be some terminal charges, but these are also constant, then there may be yardage charges and commission charges, with possibly a few incidentals in the way of telegrams and telephone messages. These improved conditions make the business more profitable, and profits are almost guaranteed where certainties have displaced uncertainties to such a large extent.

Commission houses.-Commission firms on the larger markets are a very necessary adjunct. They are specialists in securing high prices. The stockyards company usually assigns pens or lots to each firm, and the firms then employ a force to see that their consignments receive prompt attention in the way of rest, feed and water. Frequently they may receive a large number of cars of mixed stuff. They may take these and grade and classify them and secure appreciably better prices. Then they pay each consignor just what his hogs totaled, although they may have been sold in three or four different lots in order to secure a larger sum for the consignment. The live stock commission business on the southern markets has not yet advanced to the same stage of development as on northern and western markets. When there are several commission firms, the particular one to be patronized will be largely a matter of taste. Some shippers occasionally split consignments and are thereby enabled to determine which firms secure the best prices. As soon as a good firm is found it is generally advisable to stick to them as long as they maintain their reputation, for they will be better able to advise and assist in making shipments at the most opportune time. 
Live stock exchange.-On most of the large markets, especially those of the West and North, we find live stock exchanges, which serve a most useful purpose. They handle all the larger matters for the better interests of the shipper, stockyards company, packing houses, commission men and all interested parties. They decide such questions as dockage, post-mortem examinations, freight rates, insurance, and yard regulations and charges. Before the development of the exchange the shipper was at the mercy of the larger buyers, who made prices and controlled the markets. The exchanges handle all disputes, guarantee security of property, and are beneficial in many ways. The live stock exchange is a necessary adjunct to any large market and its usefulness is only limited by the support given it.

Market classifications.-Owing to the great variations that exist among the hogs that are shipped to any market, it has been found necessary to standardize and classify those of certain qualifications into certain classes and grades. These classifications are based to a very large extent upon weight, condition, age, sex, quality and utility, and we find each class and grade better adapted to some particular commercial purpose than any other class or grade.

Market classes and grades of hogs.--Hogs that are sent to the market are classified into groups or classes according to the specific commercial purposes to which they are best adapted. These classes are numerous when the market receipts are large. When a small market is concerned the number of classes and grades is small. In order to give some idea of the extent of market clas- 
sifications, a complete classification, such as one might expect to find upon a large specialized market, is given:
1. Prime hogs
10. Heavy packing
2. Good butcher
11. Rough heavy packing
3. Good butcher pigs
12. Throwouts
4. Light pigs
13. Pigs
5. Heavy rough hogs
14. Boars
6. Mixed packing
15. Stags
7. Light pigs
16. Government
8. Light light
17. Cripples
9. Heavy shipping

These classes are in turn divided into grades, which indicate the degree of fitness of the animal for the specific commercial purpose which has determined its class. The several grades that may occur in a specialized market are from the best to the poorest, as follows: Fancy, prime, choice, good, medium, fair, common, and poor or inferior. Quality, condition, age, sex, conformation, breed, finish and soundness determine to a large extent the particular class and grade into which any hog or group of hogs will fall.

Market classes flexible.-It must not be considered that market classes and grades are inflexible, for no two markets have the same classification, and certainly all kinds, breeds and ages of hogs will be shipped to both. $\Lambda 1$ so, even on the same market, the various classes and grades will be made up of different kinds of hogs on different days, for if there is a demand for a certain class or grade of hogs and there are none or but few of these to be had, the deficiency will be supplied from other classes or grades. Therefore, we must not conclude that market classes and grades of swine are absolute and dis- 
tinctive, because they are subject to considerable flexibility to meet existing conditions.

Market type.-The term market type is distinctive from market classes or grades. Market type is a term employed by the breeder of pure-bred swine and by the pork producer to designate that class of hogs which the market desires. What the breeder and grower want to know is which type is most sought after that will at the same time yield the greatest profits, in order that they can make their business more profitable by directing their energies and efforts toward producing that particular type. The breeders will then select animals which seem to them to approach most nearly the most desirable market type. The grower will in turn be willing to pay the breeder better prices for breeding animals possessing this desirable market type to a marked degree. The market types are, therefore, much fewer than market classes, and the only type which the breeder and grower desire to eventually produce is the ideal market type.

Packing houses.-Of course wherever there are large stockyards there are also apt to be packing houses. It is to these that by far most of the hogs consigned to the stockyards find their way. These packing companies have buyers out with orders to buy so many hogs of one kind, so many suited for another purpose, and so on. The prices are generally rather steady, and these experienced buyers for the packing houses are generally careful not to pay more than the market price. On the whole, a healthy competition exists between the different packing firms, and the shipper gets from them the approximate market value of his shipment. The packing 
houses are the life of the central stockyards, for it is they that create the demand. They are most necessary and

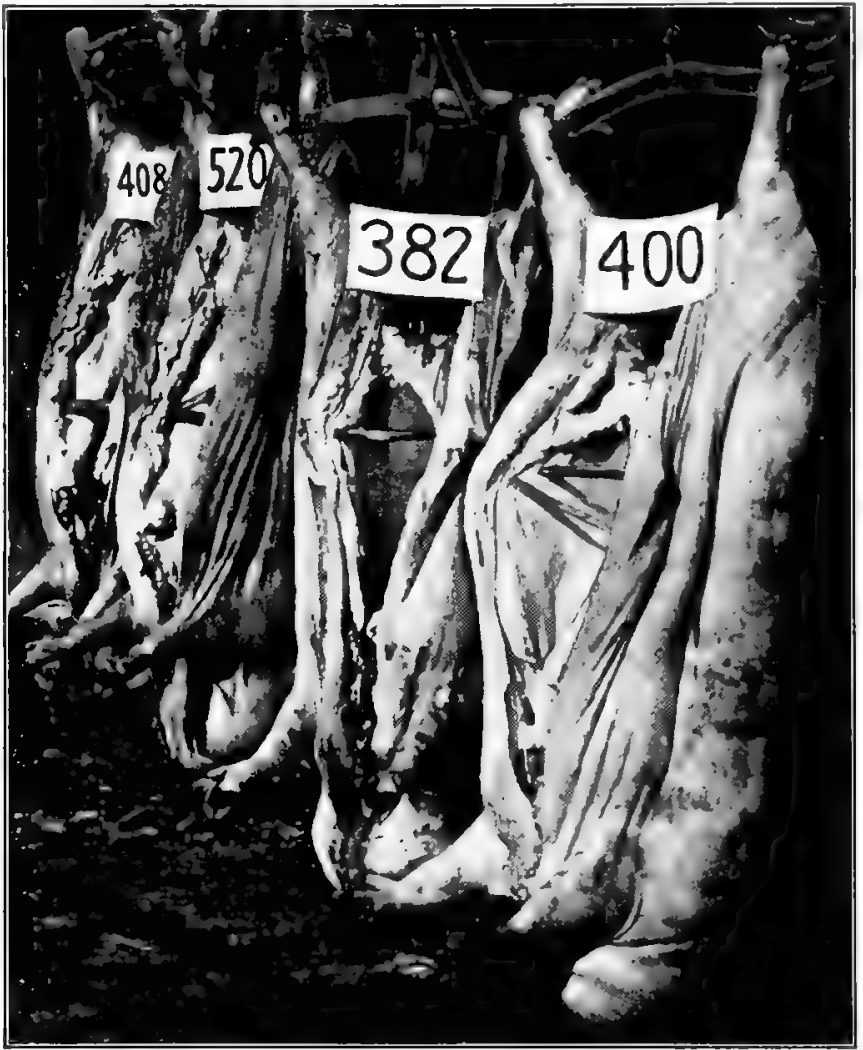

Too large for suitable pork production in the South. Courtesy S. H. Lippincott of Maryland.

developments of an extensive swine industry would be almost impossible without them. 
What the butcher wants.-Not only does the butcher desire a carcass with as large a percentage of edible meats as possible, but he also desires that as great a percentage as possible of the carcass be made up of the higher-priced cuts. These cuts are located in the hind part of the hog, and are made up mostly of the ham and loin. It is the hind half of the hog that makes money for the butcher and packer, for it is this part that sells materially above what he paid for it. Therefore, what the butcher really wants for the retail meat trade is a high dressing hog, not so fat that he has to be scaled, and with as large a proportion of the carcass weight in the hams and loins as is possible. A heavy ham, wide back and loin, with straightness of top and underline, and other characteristics indicative of capacity for the production of highpriced pork are sought.

The dressing percentage.-The dressing per cent of a hog is determined by dividing the dressed weight by the live weight and multiplying by 100 . Since it is the carcass of the hogs we are after, the dressing percentage becomes a very important factor. The expert buyer will accurately estimate the dressing percentage. The question of record and average dressing percentages is of interest. On southern markets average hogs will dress around 65 to 70 per cent. The better class range from 75 to 85 per cent. Hogs on southern markets will average nearly 5 per cent less than hogs from the Corn Belt. At one slaughter test held in Chicago in which seventy head of hogs were entered the highest dressing per cent was 90.2. This figure is exceptional, of course.

Factors affecting dressing per cent.-All kinds of hogs come to the market. They will be found to dress all the 
way from 50 up to 85 per cent, depending on several factors. Among these factors may be mentioned, first of all, condition. As a rule the higher the condition the higher the dressing percentage. Since the fat is deposited largely in and over the musculature, it is quite evident that the higher the condition the greater will be the proportion of carcass to offal and waste matter. Quility is also generally associated with a high dressing per cent. Especially is quality of importance in coarse hogs with large bones and paunchy middles. The butcher desires a minimum bone, just large enough to bear the weight of the hog's body from the time the hog is bought until it is on the killing floor. Next in importance is the paunchiness, or the relative size of belly compared with the rest of the body. The larger the paunch, regardless of the cause, the less will be the dressing percentage. Next, the seediness of old sows and the staginess of boars and stags will result in an appreciable lowering of the dressing percentage. Old sows that have raised a large number of pigs generally have considerable waste on their bellies that will have to be trimmed off.

Federal inspection.-At the present time in all of our larger packing plants federal inspectors are placed to see that no discased meats are slaughtered and that no spoiled meats are placed on the markets. This work was started several years ago, and the results of the constant care and watchfulness have greatly increased the quality of the packing plant output. At first the inspection was objected to, but the public and packers soon adjusted themselves to the new conditions, and although there is still ample room for improvement the work has proceeded most effectively. It is unfortunate that this in- 
spection and supervision cannot be carried on in even the smaller plants. The packers usually invite federal inspection on account of the prestige it gives and because the public demands federal inspected meats. For

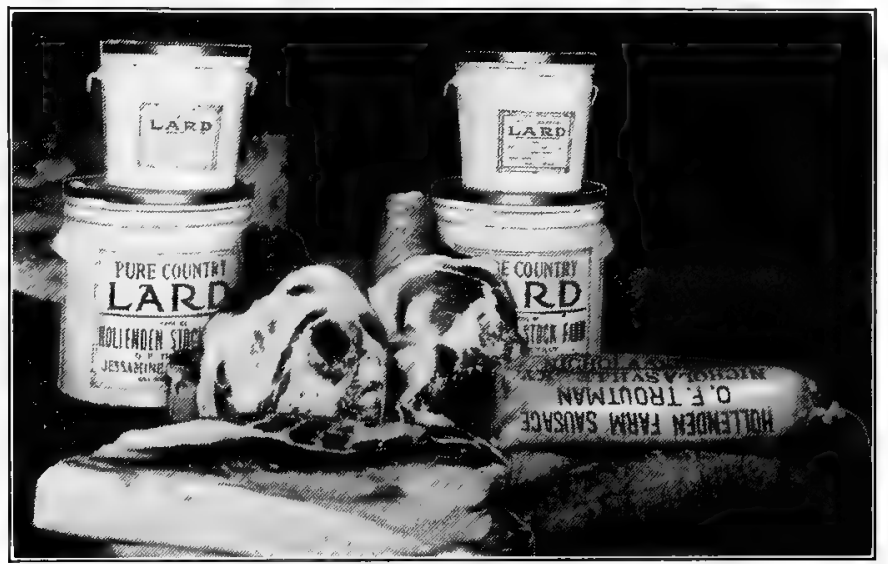

Home-packing products resulting from high specialization.

one plant to have inspection and another not to have it gives the latter an undue advantage, because in the latter case the condemnations will be very few, while the profits of the former will be greatly cut through the condemnations by the federal inspectors. A more extensive application of federal inspection is desirable.

Home retail marketing of pork.-The slaughtering of pork at home not only provides an ample supply for home consumption, but by home slaughtering a means is provided to secure greater returns from the hogs grown. The hogs may be slaughtered and sold as fresh pork to the butcher, or it may be retailed out and the 
greatest returns are realized. Many southern farmers are beginning to make a practice of curing a surplus of pork, to be sold later on in the season, generally to a select retail trade. The hams, shoulders and sides are especially adapted for selling as cured meats. It is very often the case that these parts of the carcass will bring as much or more than the entire hog would on foot, which would leave the head, ribs, backbone, sausage, lard and other parts as clear profit for the extra labor involved. The home retail marketing of pork is especially to be recommended for the small farmer, and a profitable method of marketing in this manner may be developed by the more extensive producer. 


\section{CHAPTER $\mathrm{X}$}

\section{PORK}

Pork as a food.-Pork has been in our dietary for many centuries. It is one of our standard meat foods. It has its advantages and disadvantages in comparison with other meats. It is fatter than most meats, which under some conditions would be considered a disadvantage. On the other hand, there is a larger proportion of meat to bone in pork than in either beef or mutton. Likewise, the percentage of water in pork is lower than in these other two meats and the energy content per pound is greater, which are advantages not easily overcome. The fact that in this country we annually produce and consume nearly $\$ 1,000,000,000$ worth of pork and pork products shows the extensiveness of its use as a food.

Composition of pork.-As a food pork may be considered as composed of two materials, the edible part and the non-edible or waste. The non-edible part consists of such refuse as skin, bone and gristle. The amount of waste in a piece of pork is dependent upon the cut from which it comes. The waste in pork chops will run from 12 to 24 per cent, while for ham it will run from 8 to 14 per cent. The edible portion is the portion in which we are primarily interested. This is made up of water, fat, protein and ash. All meats contain some water. Dry salt pork contains a minimum and may have as little as 4 per cent of water. On the other hand, fresh pork may contain as high as 60 per cent moisture. The fat is likewise variable, and pork may contain all the way 
from 10 to 95 per cent. From the standpoint of economy we desire pork with as much fat as possible. The proteins or nitrogenous compounds of pork are very important, as is the case with all meats. The amount of

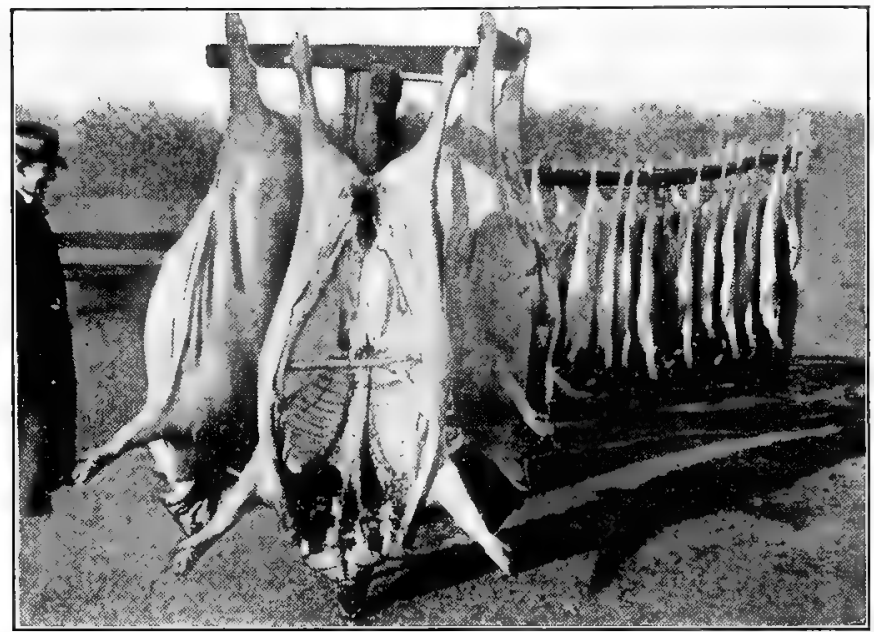

Making pure-bred Tamworth pork on Westview Stock Farm, Winston-Salem, N. C.

protein in pork will vary from 2 to 20 per cent. The ash of pork is of importance even though present in rather small quantities. On the whole, pork contains less waste matter than other foods, and the food value is greater than most other meats on account of its high fat content.

Pork-slaughtering industry. - The pork-slaughtering industry of the past on an extensive scale has for the most part been confined to northern markets. The southern markets are, however, coming to slaughter more and more pork annually. Practically all of the slaughtering 
centers pattern after Chicago in so far as is practical, since this is the largest pork-packing center in the world. It may be well, therefore, to refer to the industry as it is carried on there, where seven millions of hogs are slaughtered annually. It is here that the industry has been carried to its present high point of specialization.

Slaughtering.-The slaughtering of hogs takes place to a limited extent on the farm, to a much larger extent by the local butcher, and to a still greater extent by the pork packer. The volume of slaughtering by some of the larger packing plants is enormous. In order to accommodate the volume, methods are employed which insure rapidity of slaughter. In these larger plants the slaughtering takes place at the rate of several per minute. The usual plan is to have a hoisting wheel to which the hogs are shackled by a shackler with chains that are hung to the large wheel. This wheel revolves and elevates them and runs them off onto the sticking rail or bar automatically to the sticker. Expert stickers can stick as many as ten head per minute. From the sticker the hogs pass to the scalding vats and automatic scraping machines, the scraping being finished by hand. They are then beheaded, gutted, split, washed down and hung in the cooler.

Variations in carcasses.-Aside from differences in weight, the carcasses show marked differences in form as they hang in the cooler. Some are wide and compact showing high condition, while others are long and narrow. Great differences are manifested in particular in the region of the ham and loin. In the halved carcasses the various ratios between the amounts of fat and lean 
in similarly shaped carcasses are also quite noticeable. Even in those carcasses possessing the same degree of condition there is a marked tendency on the part of some to place it on the back, while others show more of a tendency to deposit it on the inside of the ribs and around the kidneys. In the cut carcasses there is also marked differences in the degree of marbling, even when the quantity of fat on the back is the same. The color of both the fat and the lean presents marked contrasts. The grain of the meat, the quality and size of the bone, and the degree of moisture presented on the cut surface are other respects in which the carcasses will be found to differ greatly. In some carcasses, especially where the hog is old and fat, the meat will separate from the bones if the cooling has not been begun soon enough after slaughter; or, if the carcass has not been cooled to a sufficiently low temperature, the same result may be seen.

Classification of hog carcasses.-This lack of un1formity necessitates a classification where the slaughtering is carried on on a sufficiently extensive scale to justify specialization. The butcher and packer are, of course, primarily interested in these variations, as they are used in determining the specific use for which the carcass is best suited. The different ways in which carcasses may differ are in age, size, condition, color of lean, shape, thickness of fleshing, thickness of external fat, distribution of fat, color of fat, grain and texture of meat, hardness and size of bone and in soundness and quality. In the large packing houses the carcasses are placed in various classes dependent upon the above qualitics. The most complete classification that has been made of hog carcasses is that by Hall reported in Bulletin 147 of the 
Illinois Station. In this, dressed hogs are divided into six classes--smooth, heavy hogs, butcher hogs, packing hogs, bacon hogs, shippers and pigs. Packing hogs are further graded into heavy, medium and light, and bacon hogs are further divided into choice, good and common. The classification is thus based upon the use to which the carcass is best adapted. It requires an expert to properly classify carcasses. This classification is, of course, more or less arbitrary and flexible, and if there is a shortage of a certain class the demand will be met from other classes having similar carcasses.

Qualifications of a good carcass.-The qualifications of a good carcass will largely depend upon the kind of a carcass or class and the use to which it is to be put. Above all, an extra development is sought in those parts that are of greatest value. The thickness and smoothness of outside fat are especially essential. The qualities of the lean meat are important. This should be abundant in quantity and of fine grain and proper color. The bones should be small and fine. Especially should there be a high development of ham and loin. These two parts command better prices than the rest of the hog because there is less waste in them, and they possess to a marked degree the required tenderness, marbling and palatability, and present an attractive appearance on the block. Experimental evidence has shown that there is but little difference in the nutritive value of meats from different parts of the carcass. There are differences in palatability and proportion of waste in preparing for the table. It is the proportion of higher-priced cuts or the form of the carcass that makes the greatest difference in value. Therefore, the aim of the producer of pork should be to 
grow those carcasses which will retail for the largest figures, for in the long run they will prove the most profitable.

Pork cuts.-When hogs are killed in the larger packing houses they may be sold either in the carcass or cut up. When cut up the regulation cuts and parts of the hog's carcass are the hams, sides, bellies, backs, shoulders. loins, butts and plates, miscellaneous and lard. These may be graded to some extent to meet the demands of the trade. The grading of pork cuts is more or less difficult owing to the fact that the grading is complicated by the style of cutting and methods of packing required for different classes of trade.

The offal.-With the high degree of specialization that comes with the development of a great industry we find that some use is made of everything and that nothing is wasted. This is especially true of the pork-packing industry. Everything that cannot be classed as pork to be eaten as food is used in some manner. The blood may go for the manufacture of dried blood to be used as a stock feed. From the small scraps of meat and other parts unfit for human food digester tankage is made as a feed for swine. A great many of the waste parts are used in the arts and trades. Soap stock is made from the fat rendered in the making of digester tankage and meat meal and from the making of fertilizers. Fertilizers are made from all of the contents of the alimentary tract and from the inedible organs. The stomachs and bladders may be used for packages for use in the various trades. The casings are sometimes used in the packing of sausages. It is largely on account of their ability to make 


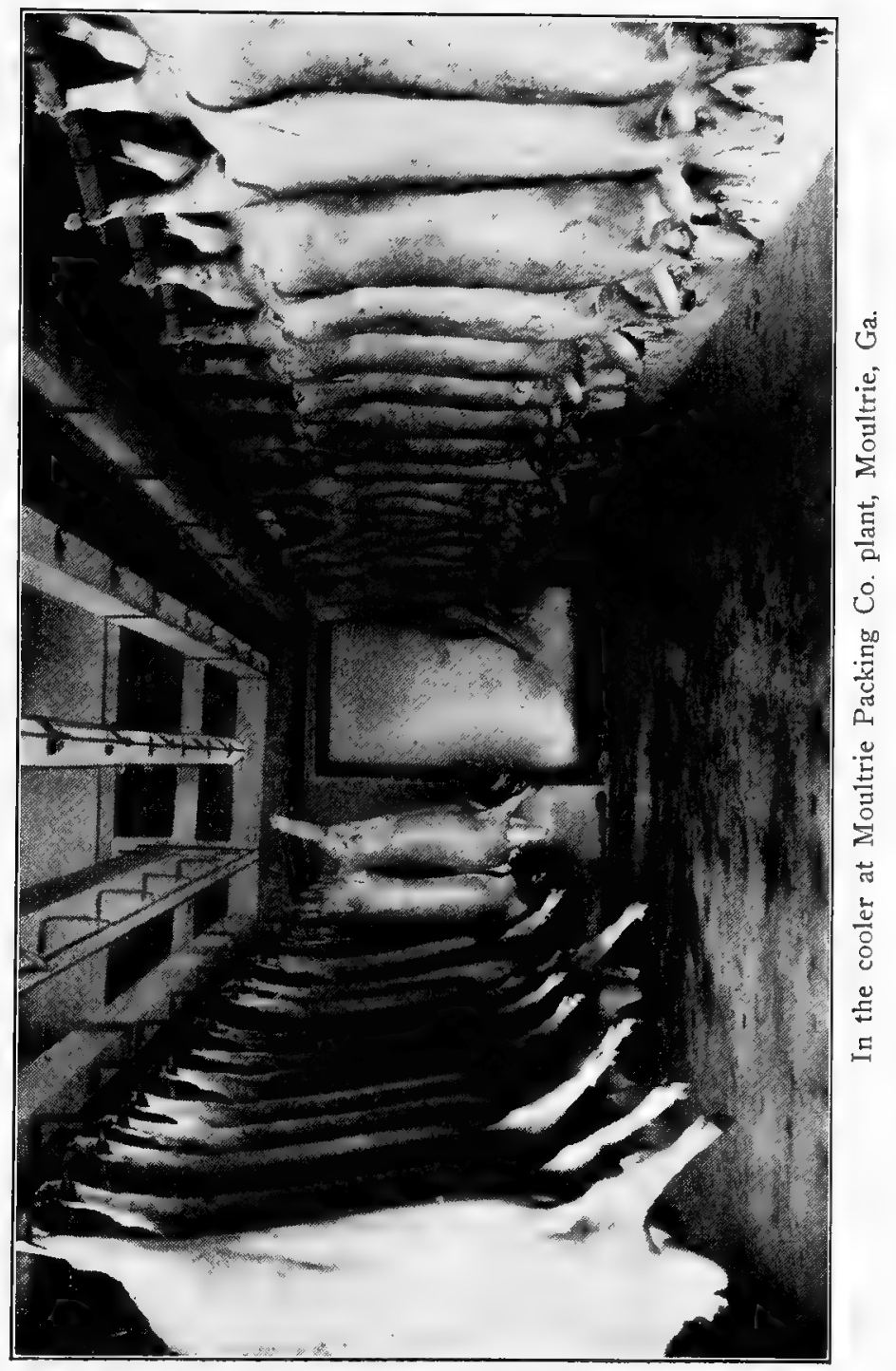


profitable use of all parts of the hog that the larger specialized packing interests are able to compete so successfully with the small butcher.

Pork for home use.-We are apt to consider that we can best sell our hogs on foot and then buy our required pork as we need it, but such is not economy. The slaughtering and curing of pork for home use has many advantages to commend it. One cannot only save money by it, but a better pork supply is to be had. Dry, hard and tasteless meats are not wanted. Juicy, sweet and tender meats can be had if some care is taken in the methods employed in slaughtering, dressing, curing and preserving. The aim of the farmer should be not only to supply enough pork for home consumption, but to supply a surplus to be sold in case it is not needed.

Co-operative slaughtering.-The extra force required to do slaughtering and butchering can best be overcome by co-operation among a few farmers in a community. By this method five or six farmers of a community will form a butchers' club and go from one farm to the other and do the slaughtering. Each one becomes more or less expert and adept at some particular phase of the work, which means added efficiency. One man may in this way become quite expert at scalding and scraping, another may become expert at dressing, and still another at cutting up, another at trimming, and another at sausage making and so on. An added advantage that comes from such an association is that fresh pork may thus be had at almost all seasons of the year. The plan would be to kill a hog turn about during the warmer weather and rotate the parts to the members of the association. 
This plan is already in operation and is working quite successfully in some sections.

Kind of hogs to butcher.-Under most circumstances one will not have an opportunity to exercise any great degree of selection in picking out animals for slaughter. He should know, however, those animals best suited for the making of home-cured pork and should strive to produce such animals. The hog, to be ideal, must have sufficient fat to make the meat palatable and juicy. He must not, however, have so much fat that it will make the meat unsavory. The exact amount to be desired will be largely a matter of taste. Also, it must be recognized that good pork cannot be made unless the animal is in perfect health. The hog must be of the right age and breeding. Hogs that have been bred for pork production for decades are more apt to make better pork than the scrub without improved breeding. Also, only young animals should be used. The best meats are not to be had from animals that are old. There are also other precautions to be taken prior to slaughter. Feed should be withheld for a period of twenty-four hours. The hogs should be killed with as little excitement as possible, for a little nervousness tends to bring on a rise in temperature, with its resultant bad effects on the keeping quality, taste and color of the meat.

Proper time to butcher.-In a great portion of the South where coolers are not to be had the most suitable time for butchering will depend to a considerable extent upon the weather conditions. Rainy and moist weather is to be avoided. Clear, crisp, cool weather around freezing is about the best. Most farmers prefer to kill in the 
forenoon, for the reason that it is generally a full day's work to do the butchering properly. Where one or two hogs are to be killed, the afternoon may be preferred, as the carcass will be allowed to cool overnight without passing through the heat of the day. Where the meat is not to be cured, but is to be disposed of as fresh pork, any weather is suitable.

Killing the hogs.--In some sections it is not customary to stun the hogs before sticking, but owing to the excitement resulting from holding while sticking, it is probably the best plan to stun in some way. Many prefer to strike in the forehead with an ax, but more satisfactory results may be secured by shooting with a small-calibered rifle, especially if the hogs are fat. Regardless of whether the hog is stunned or not, the essentials of sticking are the same. A narrow straight-bladed knife at least 8 inches long should be used. This is inserted in the hog's throat just in front of the breastbone, directed backwards toward the center of the body directly in line with the backbone. After penetrating to a depth of 6 or 8 inches, it is turned sideways, given a side thrust and withdrawn. To give the best results it should be sharp on both sides of the point. If the sticking is done properly the blood will come out in spurts. The sticking should pierce the heart or the aorta, the main artery leading from the heart. A novice must be careful not to deviate far from the median line in inserting the sticking knife, for the blade may run up between the shoulder and ribs, rendering the cut unfit for curing.

Scalding.-As soon as the hog is dead and the blood has stopped flowing the hog should be scalded without 
undue delay. This means that the water should be hot before the hog is killed. There is usually more danger of having the water too hot than too cold. If too hot, the hair will be set. More time is required with water not quite so hot, but the lessened dangers more than conpensate for the small loss in time. Unless one is expert a thermometer should be used to determine the temperature of the water. At the time the hog is being scalded the water should be between 150 and 175 degrees. Too much time is required below $\mathbf{1 5 0}$ degrees, and there is too much danger of setting the hair above 175 degrees. Between these temperatures from 40 to 80 seconds will be required to properly scald, the longer time being required with the lower temperature. While in the water the hog should be kept moving constantly to prevent cooking the skin. It is best to remove the hog and try the hair from time to time. Some use wood ashes in the water to make the scurf loosen, and others use soft soap and lye for the same purpose. By using these the skin is easier cleaned.

Scraping.-As soon as the hog is scalded he may be removed to a platform to be scraped. The head and feet are generally cleaned first. A knife is best for these parts. The feet and legs can be cleaned with the hands by twisting against the hair, if these parts are properly scalded. The longer hair of the body can be removed with the hands, and the shorter hair and scurf can best be scraped off with a corn knife, a hog scraper, or dull butcher knife. After scraping off all the hair the entire carcass should be shaved with a sharp butcher knife, after washing with hot water. The hog is now ready to be hoisted. The gambrel cords are raised and the gam- 
brel stick inserted and the hog hoisted, after which those parts not properly cleaned may be gone over again. The carcass is then washed off with cold water and is ready for dressing.

Dressing.-The carcasses should not be allowed to hang too long before they are gutted. To do this the hog is first split between the hind legs, separating the pubic bones with a knife. The cut is then continued down the median line of the abdomen and chest and through the breastbone to the sticking place in the neck. The cutting through of the breastbone may require an ax if the hog is of any size. The next operation is to return to the bung or rectum and cut around it and carry it on down, cutting supporting cords where necessary. This permits the stomach and intestines to fall out. The gall bladder can then be sliced off the liver. The artery should be cut that runs down the backbone, the diaphragm should be cut out around the wall of the body, and the heart, lungs, gullet and tongue removed with the rest of the offal. The mouth of the hog can be propped open with a block of wood and the whole carcass washed down several times. The leaf lard and kidney fat can then be removed if the weather is warm. If the carcass is large, it had best be split down the center by sawing after removing the head. The carcass should then be allowed to hang over until early the next day, when it is ready to be cut up and started curing, if not to be disposed of as fresh pork. If the weather is cold it may be allowed to hang longer, but usually the sooner the curing process starts the better.

Cutting up the carcass.-After the carcass has cooled overnight it should be taken down and cut up. To do 


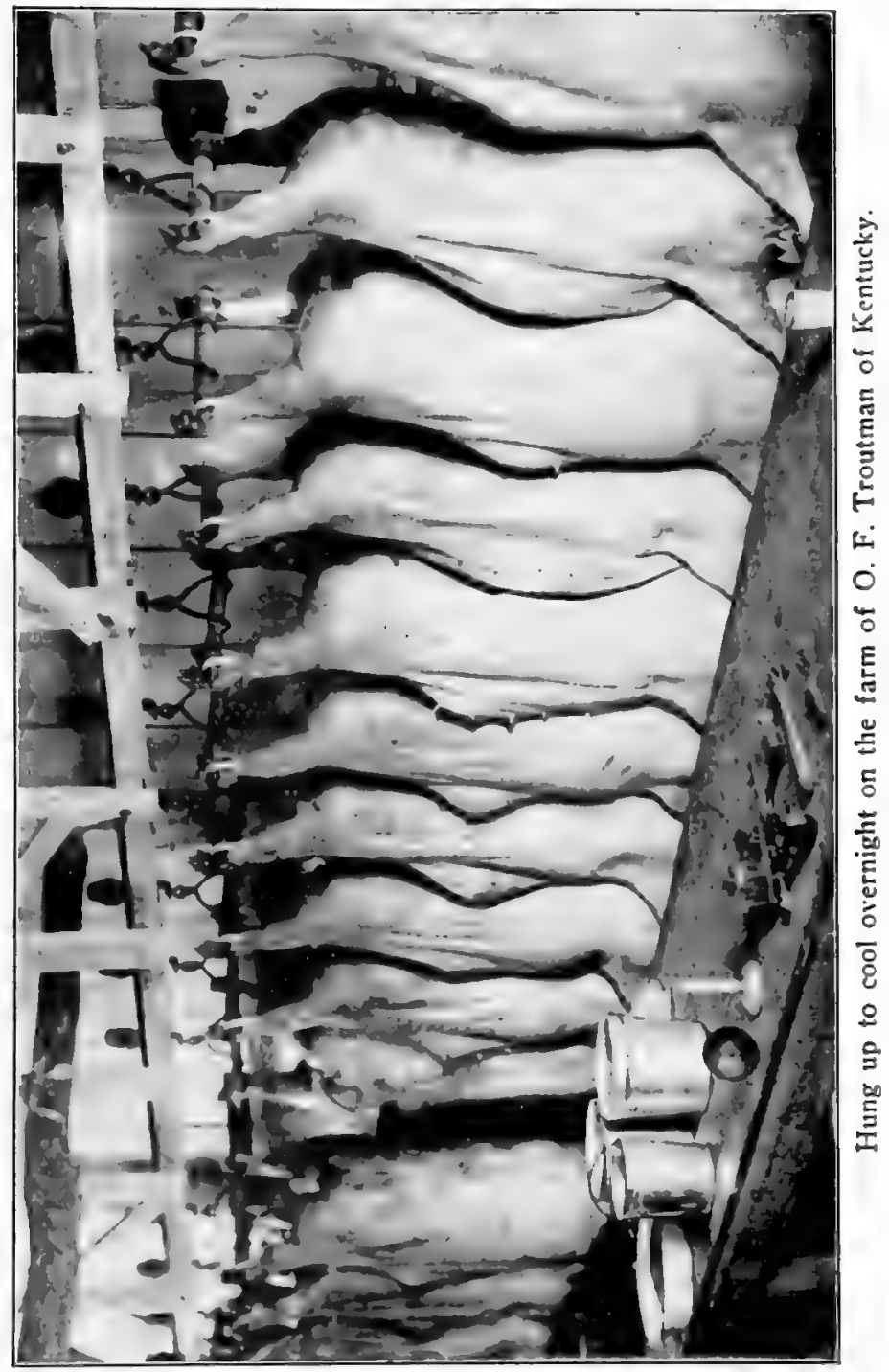


this properly requires a good sharp butcher knife, a long butcher knife, a saw, a sharp chop ax, and a solid table. If not already split the head may be removed and the

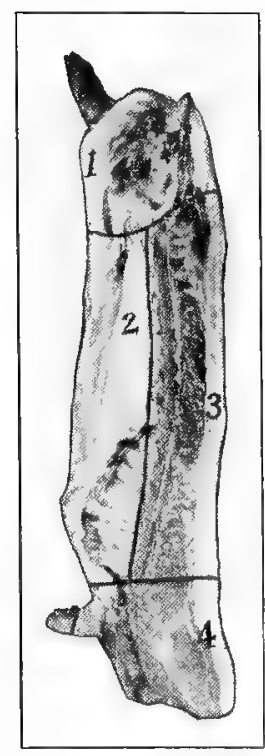

Showing the usual method of cutting the side into (1) ha m, (2) belly, (3) back, and (4) shoulder. carcass split while still hanging, if it is large. If not split and small, the best way is to place the carcass on the table and remove the head by cutting off an inch back of the ears. The shoulders are removed by cutting between the fourth and fifth ribs, and the hams are cut off about two inches in front of the pelvic bone. The hams and shoulders are then split apart, the feet removed and trimmed, the middle piece split and the leaf fat removed with the kidneys.

Cuts of pork. There are several common methods of cutting up pork, especially as regards the middle part of the body. Nearly everyone cuts off the head, the shoulders and the hams about the same. The middle part may be divided into backbone, ribs and sides, if to be cured, or, if to be sold fresh, it may be cut so as to secure a loin, from which pork chops are obtained, leaving the ribs and sirles; in either case the sides may be divided into the middle cut and belly. On the farm the most common method where the meat is to be cured is to have the following cuts: Head, shoulders, hams, side, ribs, backbone, leaf lard and trimmings. In addition to the above, one also has the feet, heart and liver. 
Trimming the cuts.-The method of trimming of the several cuts depends a great deal upon custom. The best way is to split the head in quarters, removing the jowl for salting. The shoulder is trimmed by cutting out the ribs and neck bone, trimming down to the top of the shoulder blade, trimming off all loose bloody meat and removing the foot above the knee joint. The middles may be trimmed in several ways. The backbone is gencrally used for fresh pork, the loin removed, the ribs cut out as close as possible, and the side stripped lengthwise into two or three pieces, depending on the size of the hog and the use to be made of it. The hams are trimmed by removing the feet about 2 inches above the hock joint and by rounding off the corners and edges. All lean trimmings are used for the making of sausage and the lat for lard. The feet, ears and snout may be pickled. The several cuts may be used for either fresh pork or for curing, as may be desired.

Value of the cuts.-The cuts coming from the several parts of the hog are of different values because some are in greater demand than others. These values are based upon convenience in cooking, tenderness, flavor and general appearance, and not so much upon their nutritive values. The comparative values fixed by the public for the different parts of the carcass are shown in the following figures and tables. A side of pork is shown with the cuts most commonly made and the location of these cuts on the live hog is shown by the diagram. The tables give the name, value per pound, average value in percentage of the whole carcass and average value in weight of the whole carcass. The value of the cuts depends to a large extent upon the method of cutting. The two 
recognized methods are the usual farm cut, and the other is the usual market or retail cut.

In 1 lis table the values given prevailed at several points when live fat hogs were selling at 8 cents per pound. On this basis a 200 -pound hog would bring $\$ 16$. From the table it is seen that a farmer can kill his hogs and hare as clear money on each hog the amounts brought by the parts other than the hams, shoulders and bacon or side meat, for these thrce parts will on the average bring cured as much as the entire hog on foot. These figures also show a slight advantage in method of cutting of the usual retail market cut as compared with the method used on the farm. In this table both methods of cutting are included. The basis for comparison is made on a 200 pound hog dressing 80 per cent, yielding a 160-pound carcass.

\begin{tabular}{|c|c|c|c|}
\hline Farm cuts & $\begin{array}{l}\text { Per cent } \\
\text { of carcass } \\
\text { weight }\end{array}$ & $\begin{array}{l}\text { Av. value } \\
\text { p. lb. in } \\
\text { cents }\end{array}$ & $\begin{array}{l}\text { Value of } \\
\text { cuts }\end{array}$ \\
\hline -_-_--- 16 & 10 & 6.5 & $\$ 1.04$ \\
\hline Shoulders _.....- 25 & 16 & 17.5 & 4.37 \\
\hline Hams _........ 30 & 19 & 21.0 & 6.30 \\
\hline Sides - & 27 & 15.0 & 6.60 \\
\hline Ribs --_-------- & 4 & 13,0 & 0.78 \\
\hline Backbone -.--- 20 & 12 & 13.0 & 2.60 \\
\hline Leaf lard & 6 & 15.0 & 1.50 \\
\hline Sausage ....-_... & 3 & 15.0 & 0.75 \\
\hline Feet & 3 & 5.0 & 0.20 \\
\hline $\begin{array}{l}\text { Total } \\
\text { Market cuts }\end{array}$ & 100 & --- & $\$ 24.14$ \\
\hline Head & 10 & 6.5 & $\$ 1.04$ \\
\hline Shoulders -...- 26 & 16 & 17.5 & 4.55 \\
\hline Loin _...... 36 & 23 & 16.0 & 576 \\
\hline Ham - & 20 & 21.0 & 6.72 \\
\hline Middle _........ 15 & 9 & 15.0 & 2.25 \\
\hline Belly _._._... 15 & 9 & 12.5 & 1.87 \\
\hline Ribs & 4 & 13.0 & 0.78 \\
\hline Leaf lard & 6 & 15.0 & 1.50 \\
\hline Feet _- & 3 & 5.0 & 0.20 \\
\hline Total _....... 10 & 100 & $\ldots$ & $\$ 24.67$ \\
\hline
\end{tabular}


Keeping fresh pork.-In the South we are unable to keep fresh pork as they do in colder climates, where carcasses and cuts are frequently hung in outbuildings to freeze, and from which fresh pork is taken as needed. This can be done only to a very limited extent in the South. We must therefore look to other means of keeping fresh pork. The most common method is artificial cold or cold storage. This preserves the pork in the most palatable and nutritious form. For keeping pork fresh, a temperature of 40 degrees or below should be main. tained. At this temperature, with good ventilation, fresh pork cuts can be safely kept for a week or ten days. Dampness is especially to be avoided in the refrigerator. Ice houses of proper construction may also be used to advantage in the keeping of fresh pork. Another method that is employed by sone is partial cooking. By this method the pork chops or lcin or sausages are partially cooked, packed down in jars and hot melted lard poured over the whole. The packed jars are then kept in a dark cool cellar. Pork preserved in this manner is not as good as freshly cooked fresh pork, but the method has several advantages to commend it. It is applicable to all parts of the South and may be employed where cold storage is not available. Another method used to a limited extent to preserve fresh pork for a short time is to pack it in salt.

Curing pork on the farm.-When a man raises hogs he should by all means cure sufficient pork to meet the needs of his family, and any additional, which he may cure, can always be disposed of at a good profit. There is and always will be a ready market for home-cured pork products, and but few farmers will meet with any 
difficulty in finding regular customers for their cured pork. To properly cure meats requires considerable work, and it is something at which considerable skill can be developed. The aim should be to produce only the best cured pork, whether it is to be used for home consumption or for sale. Juicy, savory, nicely put up cured pork will always command a good figure, and the common, dry, hard, tasteless, salty, roughly trimmed and poorly cured pork will never prove very profitable.

Vessels for curing.-A clean barrel or cask is good to pickle pork in. The only essentials for a suitable vessel are that it be clean, free from bad odors, tight and large enough to hold the meat.

Preservatives.-The more common preservatives used are sugar, salt and saltpeter. These are all that are necessary. Others, such as borax and salicylic acid, are used sometimes, but the use of such preservatives is probably dangerous for those who eat the meat. The common preservatives are not poisonous, but effect preservation by the withdrawal of moisture and by osmotic action, commonly termed astringent action. The sugar itself acts somewhat as a preservative, but its main function is the addition of a sweet flavor. In warm weather baking soda can be used in the brine to keep it sweet without danger of injurious effects.

Brine vs. dry curing.-There are two general methods employed in the curing of pork. One of these is the common dry curing and the other is brine curing. In most sections the dry-curing method is employed, while in other sections the brine method is used more extensively. The method to be recommended will depend to 
a large extent upon conditions. The brine curing usually gives the best results.

Dry curing.-When pork is dry cured more work is involved, although the actual expense is often much less. Each piece of meat must be rubbed over several times with the dry salt mixture. The most usual plan is to use 6 pounds of salt, 2 pounds of sugar, 2 ounces of saltpeter, thoroughly mixed, to every 100 pounds of pork. The meat is rubbed once every four days with a fourth of the mixture. After each rubbing it is repacked into a tight box or barrel. After it has stayed in the cure for a week after the last rubbing it may then be taken out, brushed off and hung up for smoking, if it is to be smoked. Pork will not dry cure well if the place is too hot and dry, a cool, moist place being much more desirable.

Brine curing.-The only thing necessary is to pack the cooled meat into a clean barrel and pour over it a properly prepared brine. This gives better protection to the meat from insects and rodents. Of course, the brine will have to be watched carefully, and if it shows signs of becoming ropy it should be either reboiled or new brine should be made. For proper brine curing of pork a cool, damp cellar is best. Any part of the carcass may be brine cured, but ordinarily fat backs and middlings cut into strips or 6 -inch squares are more commonly used.

The time the meat is to remain in the brine will depend on several factors, the principal one being the size of the pieces of meat. Smaller picces should stay not longer than six weeks, while larger pieces may stay eight weeks or longer without becoming too salty. If the brine is not too strong the cuts can be left in the brine 
until ready for using, but the best plan is to remove them after they have been properly cured, wash them off, hang and smoke, and wrap them for proper keeping. This method, if properly carried out, produces a juicy sweet meat with the desired flavor

The brine.-There are many formulas in use for making brine. The old standard recipe for sugar curing, of which there are many modifications, is made up for every 100 pounds of pork to be cured, of 8 pounds of salt, 2 pounds of sugar and 2 ounces of saltpeter dissolved in 4 gallons of boiling water. To this mixture some prefer to add a little seasoning, such as cayenne pepper or other spices. This brine should be made up the day before it is to be used, so that it will be cool when placed on the meat. After putting the brine on the meat it should be examined every few days, especially in warm weather, and it should be reheated if signs of ropiness or fermentations appear. Sometimes the fermentation can be checked by the addition of a small amount of common baking soda.

Recipes for curing pork.-Most recipes are modifications in some way of the sugar or plain salt method. Many of these variations consist essentially in the addition of flavors and spices, such as cayenne pepper, black pepper berries, allspice berries and molasses. Virginia has been noted many years for its hams of fine flavor. While there are many recipes used in the several parts of the State, one that has been used extensively and has met with much favor calls for a brine made up as follows: For every 100 pounds of pork, 8 pounds of salt, $2 \frac{1}{2}$ pounds of brown sugar, 1 quart of sugar cane mo- 
lasses, 2 ounces of baking soda and 1 ounce of saltpeter dissolved in 5 gallons of soft water. The meat is cut up and packed into the barrel in the usual manner with the skin side down. After the brine has cooled it is poured over the meat and allowed to stand for about six wecks, when it is taken out and smoked, if it is to be smoked, or it may be left in the brine and used as desired.

Another recipe that has been given some considerable attention and prominence is what is known as the Ashland cure, which gives the famous Ashland hams. In this $3 \mathrm{~T} / 2$ pounds of saltpeter are used for every ten hams of moderate size. This is rubbed into the meat thoroughly and the meat is packed down in a tight box or barrel for thrce weeks. The meat is then taken up and repacked in a tight barrel after brushing off most of the cure mixture, covered for two weeks with a brine strong enough to float an egg, after which it is taken out, dried, rubbed with fine salt and hung up to smoke, after which it is carefully wrapped and treated to hold the moisture. Both of these methods yield cured pork, especially hams, of a very superior sort. The two methods yicld a slightly different kind of ham. The first described recipe yields a more juicy ham paler in color, while the latter method gives a ham higher in color, but not quite so juicy.

Smoking.-The smoking process aids in the preservation of pork through the creosote absorbed, which also protects the meat from insects to some extent. The flavor is what is sought after in connection with smoking, hence more attention should be given to this point. The flavor is dependent to a large extent upon the wood or material burned in the smoking. Pines and resinous woods should never be used because of the bad flavor 


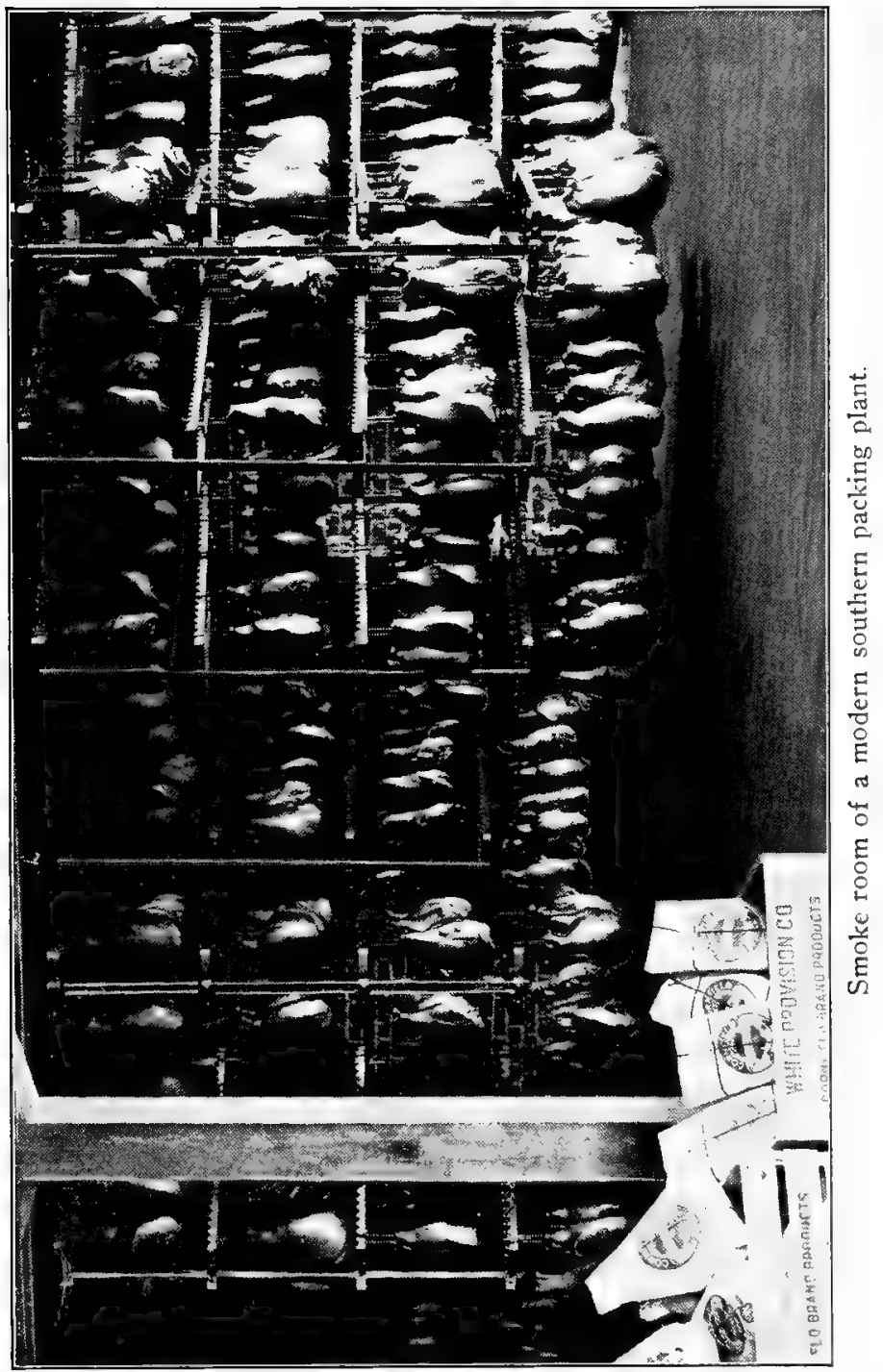


they impart. Green hickory or maple, corncobs and cottonseed are the more commonly used materials.

The pieces to be smoked are taken from the brine or dry cure and hung up to drip for a couple of days. Any loose salt on the surface should be brushed off with a stiff brush. The cuts should then be hung in the smokehouse so that no two pieces touch. The fire may then be started, using the materials as suggested above. A very small slow fire is started, and care should be taken to see that at no time the fire gets too hot, and to see that there is ventilation at the top to keep from cooking or overheating the pieces hung in the top. It is not necessary to do the smoking all at once. It is best to let the smoking cover a period of two or three wecks, starting the fire up every two or three days and continuing until the meat is of the desired color.

Smokehouses.-Any tight house with a ventilator in the top can be used to smoke meat in. Every farm should have a suitable smokehouse. These can be constructed very cheaply from rough lumber, and they will soon repay for themselves in better meat. In building smokehouses the most modern plans call for the fireplace outside with means of conducting the smoke in. This eliminates overheating and dangers from fires, and the work can be made a little lighter.

Sacking and keeping.-After meats are smoked they may be kept hanging in the smokehouse for a short time, if the house is kept dark and dry. If the meat is to be kept for any length of time it should be covered. In nearly every section skippers make it necessary for extra precautions to be taken. To properly prepare meat for 
keeping, take down after cooling, wipe it off thoroughly, and apply with a brush a coating composed of molasses and black pepper, nine parts of molasses and one part black pepper. After this is applied each piece should be wrapped carefully with wrapping paper and inclosed in either a heavy muslin sack or else in a paper sack, such is a meal or flour sack. After the sack is thoroughly and sccurely ticd with a string left for hanging, the whole should be dipped into a baking pan containing the yellow wash that is sometimes used for this purpose. This wash consists of 50 parts of powdered barytes, 1 part cach of glue and lead chromate, and 5 parts of flour. This is prepared by first making a thin paste of the flour, adding the glue and dissolved chromate, and finally by stirring slowly in the barytes. The entire package is covered with this wash and hung in a cool dark place to stay until used. Meat properly put up in this way will keep for several years and in some instances will improve with age. The pieces should be hung so that no two touch.

Sausage.-Sausage has a distinct advantage in that by converting certain parts of the poorer grades of pork into sausage it is rendered more palatable and can be kept for a longer time. Sausage is commonly made from scraps and trimmings. Sometimes on the farm meal or flour may be added to the sausage to give it more body and to make it more palatable. In the usual method of sausage making, however, only clean scraps from fresh pork are used. These should contain about one-fourth fat. To each 4 pounds of the finely ground meat scraps should be added 1 ounce of salt and a half ounce each of ground pepper and sage. The amount of scasoning will depend to a large extent upon the individual taste. The 
meat should be run through the cutter the second time after the seasoning has been added. Sausage will kecp fresh several days if the weather is cool or if a dry refrigerator is available. If it is intended to keep it any length of time, the sausage can be partly cooked and covered with hot lard, or it can be stuffed into sausage casings or muslin sacks, covered with or dipped into melted lard, and hung up and smoked, when it will keep for a considerably longer time.

Head cheese.-The hog's head and sometimes the feet are used in making this dish. The head is clcaned, the eyes removed, the skin cut off, the head split through lengthwise both ways, fat removed, brains taken out, and the whole put to soak in salt water overnight. The parts are then boiled until the meat easily falls from the bones. The meat is then finely chopped with a knife, the boiling liquor poured over the meat and cooked down until it begins to thicken. The whole is seasoned to suit with salt and pepper and poured into crocks, dishes and jars to be molded, when it can be sliced off and eaten cold as needed. Souse is made in about the same manner.

Liverwurst.-The liver, lights, hearts and other edible scraps are cut into chunks and stewed until tender, when they are removed from the fire, allowed to cool, when they are chopped finely, put back and reheated until the mixture begins to thicken, when they may be molded as in the case of head cheese. As needed it is sliced off and eaten either hot or cold.

Pickled pigs' feet.-The feet are scraped clean, toes remored, the clcan feet soaked in cold water overnight, cooked until soft and salted while cooking. They are 
then removed from the water, split, packed in earthen jars, and hot vinegar and spices are poured over the whole, in which case they will keep for several wceks, if placed in a cool place.

Scrapple.-Scrapple is made in the same manner as head cheese, except that when the meat is returned to the pot after chopping and when recooking begins, corn meal is stirred in until the whole attains the constituency of corn meal mush. This is cooked and stirred for 30 minutes, when it should be poured into shallow dishes or pans to be molded. When cool it can be sliced thin and fried or eaten cold.

Lard.-The best lard comes from the leaf fat on the inside of the abdominal wall. The fat from backs, sides and trimmings from the hams, shoulders and other cuts make a very good grade, while that lard from the intestinal fat, stomach and pluck is of an inferior grade and should be rendered separately. In rendering or trying out lard the chunks should be cut into cubes of about an inch square. The pieces of fat are then placed in a kettle, a small amount of water added to keep the bottom pieces from sticking, and the whole cooked until the cracklings brown and rise to the top. These cracklings should be skimmed off and the lard pressed out with a lard press. The remainder should then be strained through a cloth into cans or jars and stirred until cocl. The stirring and the addition of a small quantity of ba':ing soda will help to whiten the lard and make it more salable, if it is desired to sell it. The cracklings are frequently mixcd in with corn meal mush and with corn bread. In this way an otherwise waste product can be made into a palatable dish. 


\section{N D EX}

PAGE

Abscesses

Abortion,

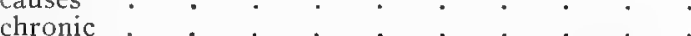

prevention . . . . . . . . . 193

Acre, pork-producing capacity of . . . . . . 34

Adulterants, feed . . . . . . . . . 145

Advertising . . . . . . . . . . . . . . . . . 108

Age, . . . . . . . . . . 28, 227

and weight . . . . . . . . . . . . 86

for breeding . . . . . . . . . . . . 16.5

of breeding swine . . . . . . . . . . . . 99

of maturity . . . . . . . . . . . 94,101

Agriculture, permanent . . . . . . . . . 7

Alabama

$14,15,16$

Alfalfa,

feeding, value of pasture

Animals, meat

Apoplexy

Appetite

Areca nut

Arkansas

Artichokes

Ascaris suis

Assimilation

Associations, record swine breeders'

Atavism

Back

Bacon, breeds

type

Barley

Barnyard manure

Barrenness

Beans

Bedding

Belly

Berkshire

adaptability

as feeders

association

$6,124,125,127,128$

136

136

10

190

163

198

$14,15,16$

6,144

196

25

22,77

32

27

$79,83,89,248$

$36,53,81,212$

144

2,3

44, 192

$.153,158,159$

$79,83,87,248$

$51,59,62,68,73,75,101$

66 
Berkshire, blood lines

PAGE color distribution $\cdot \cdot \cdot \cdot \cdot \cdot \cdot{ }^{\circ} \cdot{ }^{\circ} \cdot{ }^{\circ}$

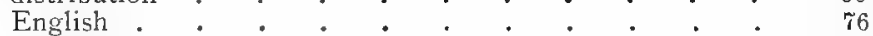
fecundity $. \quad . \quad . \quad . \quad . \quad . \quad . \quad .66$

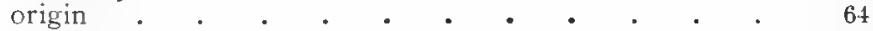
size . . . . . . . . . . . . 65 size of litters . . . . . . . . . . 66

Bermuda, . . . . . . . . 5, 1:24,127, 138 feeding value of . . . . . . . . . . 132 pasture supplementing

$\cdot \cdot \cdot \cdot 53,54$

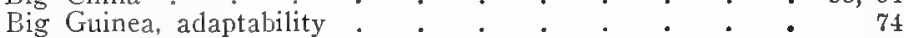

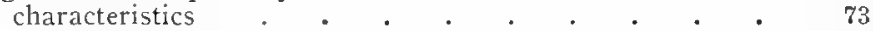
distribution . . . . . . . . . . . 74

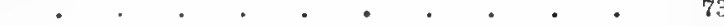

Biology . . . • • • • . . • • 25

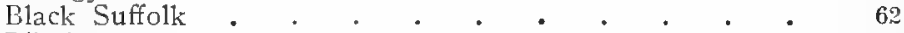

Blindness . . . . • • • . . . . 190

Blind staggers . • • • • • . • . . 191

Blood poisoning. . . . . • . . . . 179

Blue grass . • • . . • • . • . • 124 feeding value . . . . . . . . . 141 pasture . . . . . . . . . . . 140 supplements to . . . . . . . . . 141

Boar breeder . . . . . . . . . . 34

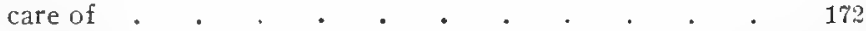
grade . . . . . . . . . . 30 pure-bred . . . . . . . . . . . . $16,34,96$ quality of . . . . . . . . . 104 scrub 30,31 Body selection of cells

Boll weevil

Bone, larger and stronger quality of size

Borax

Bran, wheat

Boys' pig clubs

Breed, best . .

associations characteristics selection of . time to type 
PAGE

Breeders, purchasing swine

Breeder's reputation

Breeding

Breeding animals, condition of selection of

Breeding, best to best

condition

conditions in South

cross

for pork

for type

for utility

improved, lack of

laws of

time

management

principles of

progress in

promotion of better

science of season

table

Breeding swine, age of

as a business

condition of

conformation of

constitution of

costs of maturity in

judging

quality of

principles of

selecting

Breeds, adaptability of

crossing of

new

number of

of swine

origin of

Bristle

white

Bronchitis .

Brood sow management

Bruises

Brine,

curing

fermentation in

formulas for. 
PAge

Brine, ropiness in

Bur clover, feeding value. pasture supplementing

Bureau animal industry

\section{Burning carcasses}

Butcher, demands of " time to

\section{Butchering} weather for

Butter milk.

Byfield

By-products of wheat Calomel

Canker

\section{Capital}

\section{Carbohydrates}

Carcasses, cooling classification of cutting up qualifications of quality of soundness of variations in

Carloads, average

Cassava

Castration age for

Catarrh, nasal

Cell,

$$
\text { division }
$$

functions

processes

structure

wall

Cells,

body

germinal

reproduction

somatic

Cervix, contraction of

Character,

in unsexed swine .

Characters, acquired

Mendelization of

segregation of

somatic 
Characters, transmission of acquired unit .

Cheese, head

Cheshire, association. blood lines

characteristics of distribution of

Chest origin of

Chester White, adaptability association characteristics distribution fecundity origin size of litters

Chicken eating

Chinese

Chloride of lime.

Chufas

feeding value

grazing

supplementing yield

Classes, market

of hogs show

Classification, market of hog carcasses of swine.

Climate

Clovers

alsike

bur

crimson

Japan

Mexican

red

white

Coal tar dips

Coastal plain

Cold storage

Coloration, protective Color of swine

Commercial fertilizer

Commission houses

Commission men

Condimental feeds 
PAge

Condition, $28,83,92,109,112,114,116,117,227$ degree of healthy

high

of breeding animals show

Confinement

Conformation, of breeding swine of swine

$28,43,1 \% 0$

$43,10:$

$10: 3$

$28,96,98,114,116$

186

Constipation

Constitution, indications of lack of

Consumer of pork

Cooking, of feeds fresh pork

Cooler

Co-operative, hog shipping $2 \times 1,222,203$ slaughtering swine breeding

clubs,

$5,6,116,122,124,128,129,146$

feeding alone

feeding value of

protein of

supplements for : 122

supplementing . . . . . . . . . . 129

Corn belt

129
54

205

Cost of fifty-pound pig

Costs of production, factors influencing . . . . . 211

Cotton,

farmers production, increasing

Cottonseed, .

meal

meal, feeding value of

meal, on pasture

Coughing

County swine breeders' association

Cowpeas, feed value of 
Page

Crops, cultivated

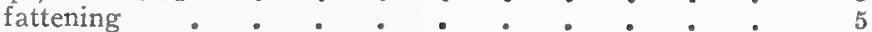

forage,

grazing

Cross-bred

Crossing breeds

Crude oil

Cryptorchids

Culls and waste

Cumberland

Curing, brine

dry

of meats

pork, recipes for

pork on farm

vessels for

Cutting up carcasses, tools for

Cuts, of pork

farm

market

trimming

value of .

wholesale

Cuts and bruises

Dairy products

Deafness

Delaware

Demands of butcher

Demonstration work

Determination of sex

Dew claws

Diarrhea, causes

Digestive system

Dipping solutions

Dipping vats

Dips

Diseases, swine.

control

detection of

indication of

of circulatory system

of digestive system

of excretory system

of locomotor system.

of nervous system

of reproductive system

of respiratory system

of skin.

4,123

5,123

38,41

$23,24,39,104$

207

202

11

59

252,253

.252, 253

13

254

251.

252

246

248

$.240,248$

250

250

249

249

87

$.200,203$

10

190

$14,15,16$

84

12

28

79

187

180

207

206

174

$5,28,174,178$

174

$.175,176$

$.174,176$

178

178

178

178

178

178

178

178 
Diseases, prevention of

PAGE

Disinfection

Disposition .

Distribution of surine

District of Columbia

Diversilied farms

Domestication of swine,

process of

Drainage

Drenching

Dressing,

carcasses

percentage

percentage, factors affecting

Driving hogs to market

Dry curing

Duroc-Jersey,

adaptalility of

association

as feeders

blood lines

characteristics of

distribution

fecundity

origin

size

Ditst

size of litters

Early maturity,

in breeding swine

Ears

indication of

Eating pigs

Eczema

Educational value of show

Embryo

English Berkshire

Entries, making

Environment

Epilepsy

Essex,

associations

blood lines

description of

distribution of

introduction to Anerica origin

Exchange, live stock

Excretory system, diseases of

13, 174,:204

. 204,20.5

11:

14,51

$14,15,16$

10

15.;

$1 \%$

24

240

85, 01, 2:31

2.31

2.4

$.252,253$

52,101

61

6.)

$2 \approx, 9: 98$ 
Exercise,

Eyes lack of

28,44 sufficient

Face

Fairs

79,83

79,83

110

Fall pigs

161

Fallopian tube

Farmers, pure-bred hogs for

Farming, live stock

Farms, diversified

Farrowing,

$$
\text { difficult }
$$

houses

houses, winter

Fat, pens

and lean .

and lean, distribution of

deposition

Fats

Fatten, tendency to

Fattening propensities

Fatty degeneration

Fecundity

Federal inspection

Feed, adulterants quality quantity . saving utilization

Feeding, for the show methods of stuffs, commercial Feeds, swine

$8,116,146$

85,86

147

100

44,179

27, 28

.232, 233

145

148

148

13,16

112

114

144

121

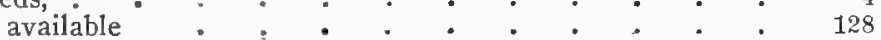

bulky

Feet, cooking

and legs

$$
\text { care of }
$$

Female germ cells

Fence breaking 
Fences, drift

PAGG

permanent

Fencing materials

Fertility,

of soil

of soil, increasing

Fertilization of ovum

Fertilizers, commercial

Finishing for market

Finish, proper

Fitting, and showing

Flanks, for show

Fleshing,

deep

heavy natural

Floors to houses

Florida

Food

supply and heaith

supply available

Foot

supply inadequate

Forage crops,

Form leguminous

Fresh pork, keeping

Front leg

Fruits, . fallen

Full blooded

Gains, cost of rate of

Garbage

Georgia

Germinal cells, male weakness of

Germ plasm

Gilts, care

Gestation, period of termination of 
Goober, hog

PAGE

Grade boars

Grading up

Grades,

$$
\text { high }
$$

$$
\text { market }
$$

Graffian follicle

Grains,

Grass winter

Grazing. summe

Ground peas

Growth

Guinea

Gulf Coast

Habits, bad . of swine

\section{Hair,} condition

Ham

\section{Hampshire,} adaptability o association characteristics origin

Hardening fat

Hay, alfalfa cowpea red clover

Head, cheese

Health

Heart, fatty degeneration of Heat, growth

$$
\text { periods of }
$$

Herd, foundation

Heredity, laws of Herdsman 
Hernia

PAGE

Hide

High grades

Hind leg

Hips,

points of

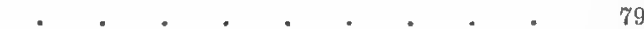

.,$\cdot 99$

Hog, breeding . . . . . . . . . 28

houses, stationary. $:$ : : : : : . 153

oilers

points of

Hog cholera, : $: \bullet^{\circ}: \bullet^{\circ}::^{*}: 181$

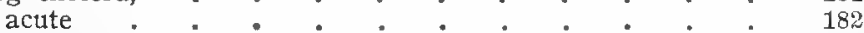

chronic : : : : : : : : 182

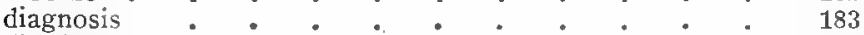

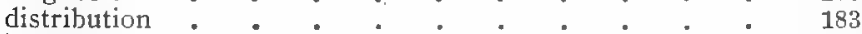

inoculation * . • . * . . . . . 186

prevention : : : : : : : : 183

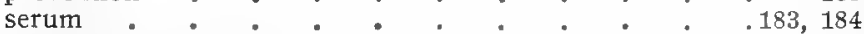

symptons 182

Hogs, number per acre : : : : : : : 125

number to grow . . . . . . . . 33

washing . $: \div \quad: \quad \div \quad 112$

weights . . : . . . . 84

Home, pork for . . . . . . . . . . 242

Houses, . . . . . . . . . . 151, 152

A-shaped, portable . . . . . . . . 154

movable shelter . . . . . . . 155

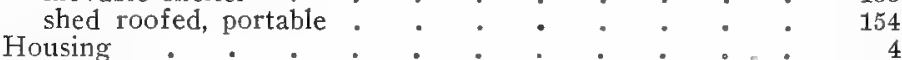

20

85

81

81

Impressions, maternal $: \vdots: 0^{\circ}: 0^{\circ}:{ }^{\circ} 18$

Improved swine . . . . . . . . . . 41, 42

Inbreeding - • • • • • • • • • • . 22, 23

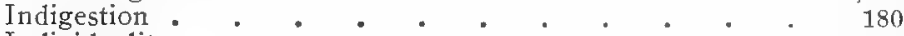

Individuality $\quad \cdot \quad \cdot \quad \cdot \quad \cdot \quad \cdot \quad \cdot \quad \cdot \quad \cdot \quad \cdot 17,22,37$

Infection, - • • • • • . . . . . 18

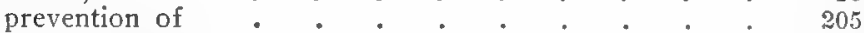

Infectious diseases . . . . . . . 178

Inheritance of acquired characters . . . . . . 19

Inspection, federal : . : : : : 232

Irish grazier . . . . . . . . . 53, 56,70

Japan clover . . . . . . . . . . . 6

Jowl • . . • • • • . . . . . 79,83

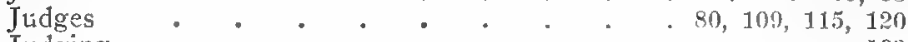

Judging, . . . . • . . . . . . 103 
Judging, bases for breeding swine method in of swine swine swine, standard

Kentucky, blue grass pasture

Kerosene

Labor,

Lard,

breeds

rendering

type

Large black,

association

characteristics origin

Large Yorkshire, adaptability association

characteristics

distribution importation origin

size

size of litters

Laws of breeding

Lean and fat

Lean meat

Legs

Legumes summer

winter

Leguminous forage crops Lespedeza

\section{Lice}

Limitations

Line lreeding

Linseed meal

Litters, age of sow on large

marking

per year

securing large

size of 
Liverwurst .

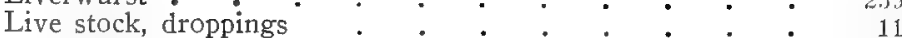

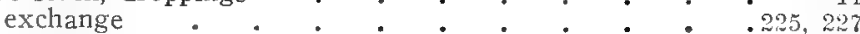
farming .

Local buyers

Locomotor organs, diseases of Loin

Louse, hog

Lots, hog

Louisiana

Male germ cells

Mammitis

Management, swine faulty

Mange

Manure, barnyard pile.

Marbling

Market classes flexibility of

Market, classification

conditions

costs

demands

demands, change in

finishing for

grades

hog, ideal

hogs

pork

standards

type

type, ideal

values

Marketing,

age for

age of

costs of

early

finished pork

home retail

size for

through local buyers

Markets,

central

seasonal demands of

Maryland

Maternal impressions

Mature swine, size of 
Maturity, age of

PAGE early quicker

Meat animals

Meat meal

Medicines, administering

Mendelian proportion.

Mendelism.

Mendel's Law

Methods of feeding

Middle Yorkshire

Millets, foxtail .

Middlings

Milk, butter. skim

Mineral matter

Mississippi

Mites

Molasses

Mule Foot, association characteristics distribution origin

Mutations

Native swine

Natural selection

Neapolitan

Neck

Nervous system, diseases of

Nettle rash .

New Jersey

Normandy swine

North Carolina

Number, of breeds of hogs to grow of pigs to litter

Nut grass

Oats, pasture pasture, feeding value of Offal pasture, supplementing .

O. I. C. association origin

Oiler, hog.

Ohio Improved Chesters

Oklahoma

$\dot{2} 2,5 \dot{2}, 94,102,109,149$

10

145

176

20

19,20

20

16

101

143

145

$14,15,16$

196

. 114, 122, 144

69

68

69

68

48,50

42

28

$49,62,64,70$

$79,83,88$

190

195 
Old Yorkshire

Olein

Orchitis

Organs, diseased

Origin, of breeds of strains

Original swine

Ova

Ovary

Oviduct

Ovum, fertilization of

Packing plants, .

Palmatín

Paralysis

Parasites

Parasitical discases of swine

Parturition

Pasterns

Pasture, Bermuda sweet potatoes

Pastures leguminous

Pasturing

Peanut pasture

Peanuts, feeding value of grazing yields

Pedigree

Pens and enclosures

Period of heat, appearance of

Peritonitis

Pickled pigs' feet

Piedmont area

Pig club agent

Pig clubs,

Pigs, boys'

eating

exercise for.

fall

from old sows

from young sows

spring

to litter.

to litter, controlling

$$
\begin{aligned}
& \div \quad \cdot \quad \cdot \quad \cdot \quad 147 \\
& \cdot \quad \cdot \quad \cdot \quad 191 \\
& \text {. } \quad . \quad \text {. } \quad . \quad 50 \\
& \text {. } . \quad . \quad .50 \\
& \text {. } . \quad . \quad . \quad 49 \\
& \text { • } \quad \text { • } \quad . \quad 99 \\
& \text { - } . \quad \text {. } 26 \\
& \begin{array}{lllll}
\bullet & \bullet & \bullet & \bullet & 26 \\
\cdot & \bullet & \cdot & . & 26
\end{array} \\
& \text { - } . \quad \text {. } 26 \\
& \text { - . } \quad .12,225,229 \\
& \text {. . . } 147 \\
& \text {. } . \quad . \quad . \quad 190 \\
& \text { • . . . } 175 \\
& .178,196 \\
& 26 \\
& .125,165 \\
& 131 \\
& 130 \\
& 116 \\
& \text { 5, } 10 \\
& \text {. } 6,8,10,124,128,131,146 \\
& \text {. 18, :2: 31,:38, } 97 \\
& 15 \% \\
& 26,46
\end{aligned}
$$


PAGE

Pigs' feet, pickled

Pindars

Pharyngo-laryngitis

Pneumonia

Plasm, germ

Pleurisy

Points of hog

194

Poland-China, adaptability

associations

blood lines

description

distribution

fecundity

origin of

Pork size of litters

as a food

breeding for

composition of

cuts of

finished

for home use.

fresh, consumption of

palatable

producers

protein in

production, breeding for limitations of profits from slaughtering soft tender type, ideal

Portuguese. types, early

Potato, sweet

Pregnancy, double

Pregnant sows, care of Prepotency, of pure-bred boars

Preservatives Process, reproductive Producers, ideal . Production, cost of Profits . Prolapsus of anus Prolificacy 
Protein

PAGe

Protoplasm

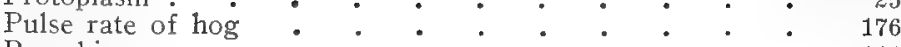

Pumpkins . . . . . . . . . . . . 144

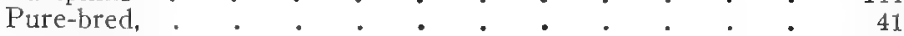

advantage of . . . . . . . . . . 41

boars,

prepotency of

hogs for farmers

pigs, market for

sire

sows

swine

swine business, future of tempting

swine, expensive

swine, marketing

proportion of .

shipping .

type of .

type, characteristics of

Quality,

$16,31,43,96$

167

35,41

96,167

33,38

Rape,

in breeding swine.

$83,85,90,92,96,105,114,212,227$

Razorback

Recipes for curing pork

Record associations, purpose of work of.

Red clover.

adaptability

feeding value of

pasture

supplements to

Registration of swine

Reproduction

Reproductive, cells

functions, limiting

organs, diseases of

process

system, diseases of

Respiration of swine

Respiratory system, diseases of 


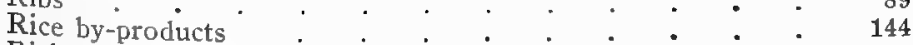

Rickets.

Rooting" ${ }^{\circ} \cdot{ }^{\circ} \cdot{ }^{\circ} \cdot{ }^{\circ} \cdot{ }^{\circ} 173$

Rubbing post ${ }^{\circ} \cdot{ }^{\circ} \cdot{ }^{\circ} \cdot{ }^{\circ},{ }^{\circ} 208$

Rump

70,83

Runts

Ruptures

202, 203

Russian

Rye,

pasture

pasture, feeding value pasture, supplementing

Sacking and keeping pork

Salicylic acid . . . . . . . . . $\quad 252$

Salt

Saltpeter

252

Sanitation

Santonin

Saturation

Sausage, making

Scalding

Science of breeding

Score card

Scraping

Scrapple

Scrubs.

Scrub boars.

Scrub sire

Scrub swine

Season

Selecting breeding swine

Selection, artificial

basis of .

breeding swine

natural

of boar

Selections, how to make

Self-feeders, use of

13, 195, 204 
Serum, hog cholera

Sex,

hog cholera, dlosage

character

control of

determination of

Sexuality

Shade

Sheath, foul

Shelter,

and health

192

22, 151

204

for swine

Shipping, co-operative

direct to market

facilities, lack of

of swine, co-operative

pure-bred swine

Shipment, preparing hogs for

Ship, when to

Shorts

Shoulder

Show, feeding for fitting equipment for

Showing, equipment for

Show ring,

\section{classification}

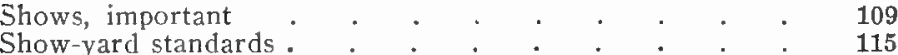

9, 64

Siamese

Sides

Size

Skim nilk

Skin

Slaughter, animals for

Slaughtering, co-operative

Sleeping quarters

Small Yorkshire adaptability association description 
Smokehouses

Smoking meats

Smoke room

Snout

Soda, baking

Soft pork

hardening

Soil fertility, increasing

Soil conservation

Solway .

Somatic cells

Somatic characters

79,83

8,131

131

$1,2,10$

9,10

1, 2

59,69

25

Sore mouth

Sorghums,

non-saccharine

Southern type

South Carolina

Sow and pigs, care of

Sow, quality in. 105

Sows, old pure-bred size of

Soy beans

Soy bean meal

Soy bean pasture, feeding value of supplementing

Soy beans, feed value of supplementing yield

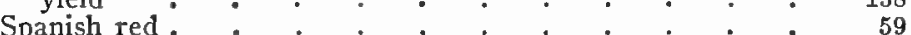

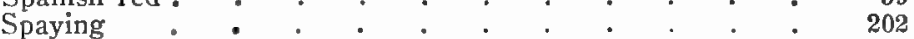

Spermatozoa . . . . . . . . . . . . . 25,26

Spring pigs . . . . . . . . . . . 161

Standards, show ring . . . . . . . . . . . 108

Starch . . . . . . . . . . . . 114

Stearin . . . . . . . . . . . 147

Sterility . . . . . . . . . . . 44, 191

Sticking hogs. . . . . . . . . . 244

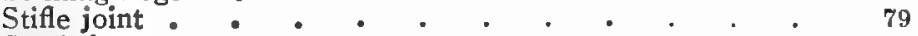

Stock hogs • : . • • . • . . . • 95

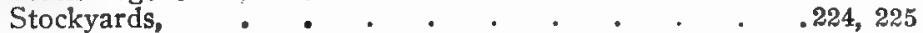
central . . . . . . . . . . . 230

Strains, of swine. 
Strains, origin of

Style

Sudan grass

Suffolk

Sugar

Suidae

Sulphur

Sunlight

Sun scald

Sunshine

Sunstroke

Superfœtation

Superfecundation

Surgery

Surgical diseases

Sus Cristatus

Sus Indicus .

Sus Scrofa.

Sweet potatoes, pasture

$5,6,112,124,128$

Swine, bacon type

breeders

breeders' association, county

breeds of

breeding as a business

48,51

breeding, co-operative

breeding principles

breeding terms

color of

cross-bred

diseases

distribution of

grazing

high-grade

improved

influence of domestication on

lard type.

native

original

plague

plasticity of 
PAGg

Tamworth, as feeders

association characteristics

distribution importation origin

Tankage

Temperament

Temperature of hog

Tenancy

Tenderness of pork

Tennessee

Teosinte

Terms, swine-breeding

Testicle

Texas

Thin rind, origin :

Thoroughbred

Thrift

Thumps, causes treatment

Tonics

Trichinosis

Trimming cuts of pork

Transportation, early methods of

Truck crops .

Tuberculosis

Tumors

Turpentine

Tusks of boars

Type,

bacon

breed

breeding for

for South

grazing

ideal

ideal market

instability of

lard.

market

pork

profitable
Types,
of swine

early maturing

Udder, congestion of . 
Uniformity of pigs

PAGE

Unit characters

Urticaria

Uterus

20,50

Utility,

breed for

Utilization of feed

Vagina

Value, per head. of swine

Variation

Variations, acquired congenital in carcasses inherent in weights

Vats, dipping

Velvet beans, feed value of . for pasture supplements to yield

Ventilation

Vermifuges

Vermicides

Vessels for curing

Vetch, pasture tame wild

Vetches, feeding value supplementing

Veterinarians

Victoria, adaptability association characteristics origin

17, 37, 38,22

Vigor.

Virginia

Vitality

Wallows, hog concrete

IVarren county pig

IVaste and culls

Water, supply supply and health 
Washing

PAGE

Weaning the pig

Weight

Weights,

average

standard .

variations in

West Virginia

Wheat bran .

Wheat by-products feeding value of supplementing

White Leicester.

White Suffolk

Wholesale cuts

Windsor

Wire grass .

Worms, kidney

lung

pin

round

thorn-head

treatment for. whip

Yellow wash

Yorkshire 




